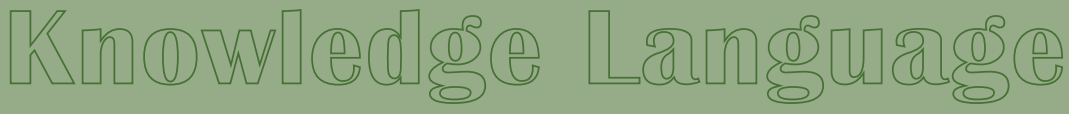 conntunntarication 3
}

\section{La gramática del sentido: Léxico y Sintaxis en la encrucijada}

José Francisco Val Álvaro María del Carmen Horno Chéliz (eds.)

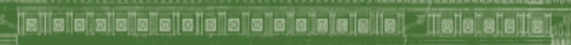

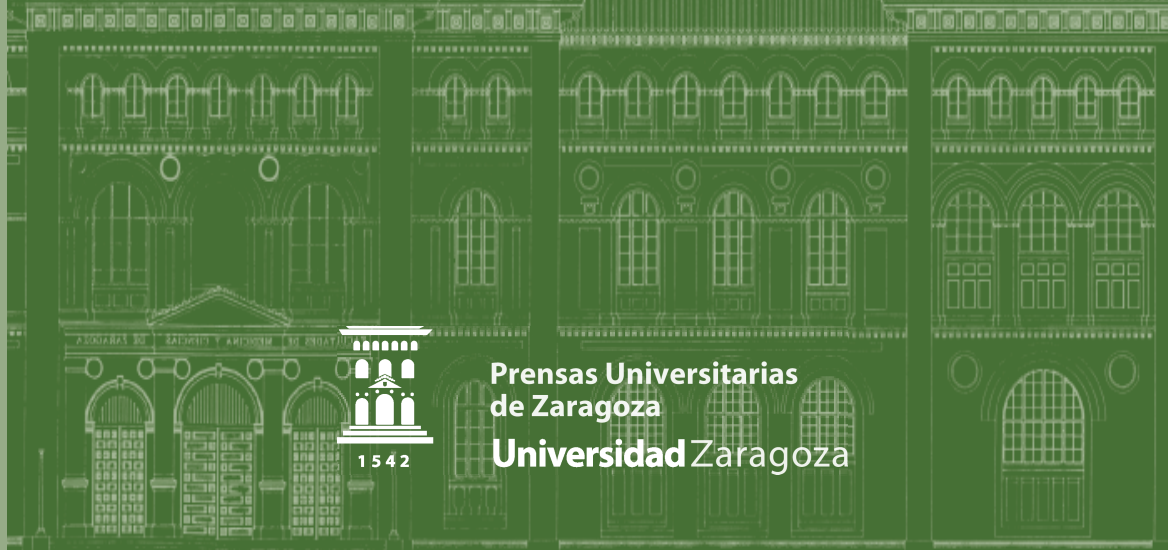



LA GRAMÁTICA DEL SENTIDO:

LÉXICO Y SINTAXIS EN LA ENCRUCIJADA 


\section{Knowledge Language Communication Conocimiento Lenguaje Comunicación}

\section{Editores}

José Francisco Val Álvaro (Universidad de Zaragoza)

María del Carmen Horno Chéliz (Universidad de Zaragoza)

\section{Comité editorial}

Ignacio Bosque (Universidad Complutense de Madrid), José M.a Brucart (Universidad Autónoma de Barcelona), João Costa (Universidad de Lisboa, Portugal), Violeta Demonte (Universidad Autónoma de Madrid), Victoria Escandell (Universidad de Alcalá), Salvador Gutiérrez (Universidad de León), Ángel López García (Universidad de Valencia), Juan Uriagereka (Universidad de Maryland, EE. UU.), Jacqueline Guéron (Universidad París III, Francia)

Secretario editorial

José Luis Mendívil

Departamento de Lingüística General e Hispánica

Facultad de Filosofía y Letras

Universidad de Zaragoza

Pedro Cerbuna, 12

E-50009 Zaragoza

jlmendi@unizar.es 


\title{
LA GRAMÁTICA DEL SENTIDO: LÉXICO Y SINTAXIS EN LA ENCRUCIJADA
}

\author{
José Francisco Val Álvaro \\ María del Carmen Horno Chéliz \\ (eds.)
}

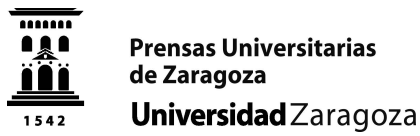


La GRAMÁTICA del sentido : léxico y sintaxis en la encrucijada / José Francisco Val Álvaro, María del Carmen Horno Chéliz (eds.). — Zaragoza : Prensas Universitarias de Zaragoza, 2010

270 p. ; $22 \mathrm{~cm}$. - (Knowledge Language Communication $=$ Conocimiento Lenguaje Comunicación ; 3)

ISBN 978-84-15031-50-5

\section{Sintaxis. 2. Léxico}

VAL ÁLVARO, José Francisco

\section{$81^{\prime} 367$}

$81^{\prime} 373$

Cualquier forma de reproducción, distribución, comunicación pública o transformación de esta obra solo puede ser realizada con la autorización de sus titulares, salvo excepción prevista por la ley. Diríjase a CEDRO (Centro Español de Derechos Reprográficos, www.cedro.org) si necesita fotocopiar o escanear algún fragmento de esta obra.

(C) Los autores

(C) De la presente edición, Prensas Universitarias de Zaragoza 1. ${ }^{\mathrm{a}}$ edición, 2010

Prensas Universitarias de Zaragoza. Edificio de Ciencias Geológicas, c/ Pedro Cerbuna, 12 50009 Zaragoza, España. Tel.: 976761 330. Fax: 976761063

puz@unizar.es http://puz.unizar.es

Prensas Universitarias de Zaragoza es la editorial de la Universidad de Zaragoza, que edita e imprime libros desde su fundación en 1542.

Impreso en España

Imprime: Octavio y Félez, S.A.

D.L.: Z-3280-2010 
A D. Félix, el maestro 



\section{ÍNDICE}

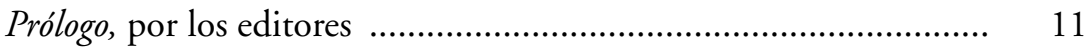

La encrucijada del léxico y la sintaxis

José Francisco Val Álvaro

Neurolingüistica de la interfaz léxico-sintaxis

Ángel López García

Un modelo lexicalista de la estatividad verbal

María del Carmen Horno Chéliz y Juan Miguel Cuartero Otal .....

Cuestiones pendientes de la tipología semántica para el análisis de los eventos de movimiento

Iraide Ibarretxe-Antuñano

Verbos y construcciones en el espacio cognitivo-funcional del siglo XXI

Ricardo Mairal-Usón y Francisco Gonzálvez-García

Observaciones sobre la proyección argumental Juan Romero

Por debajo de la palabra, silencio. La sintaxis como interfaz y la naturaleza del léxico José Luis Mendívil Giró 
Hacia un análisis sintáctico del género en español Antonio Fábregas Alfaro e Isabel Pérez Jiménez

El género en los sustantivos: ¿flexión y/o derivación? David Serrano-Dolader 


\section{PRÓLOGO}

La facultad del lenguaje que los seres humanos poseemos como principal característica propia, es, como todo el mundo admite, uno de los objetos de estudio más complejos que un científico puede analizar. Y esto por diversos motivos. Desde un punto de vista externo, la complejidad del lenguaje reside en que es una facultad que soporta prácticamente todas las actividades que nos caracterizan como especie. El ser humano es, ante todo, un ser racional, que piensa y soluciona problemas. Y es obvio que el lenguaje nos sirve como herramienta y soporte de, al menos, gran parte de este pensamiento racional. Pero además, el ser humano es un ser social, que ha basado su adaptación como especie en su habilidad para establecer sistemas de cooperación, donde el lenguaje es y ha sido siempre un elemento clave. En este sentido es en el que cabe admitir que el lenguaje es, a un tiempo, un sistema de pensamiento y un sistema de comunicación social. Por otra parte, la complejidad de este objeto de estudio se debe también a motivos internos. Y es que la facultad del lenguaje se pone en relación con dos limitaciones básicas del ser humano: por una parte, ha de relacionarse con nuestro sistema cognoscitivo, con el modo en que los seres humanos percibimos el mundo (sistema perceptivo), lo entendemos o imaginamos (pensamiento racional), lo recordamos (memoria) y lo sentimos (emoción y motivación). Por otra parte, se debe circunscribir a las limitaciones fónicas de nuestro aparato fonador (o motriz, en lenguas de signos), de tal modo que todo aquello que hemos pensado podamos expresarlo de forma perceptible a los demás.

Esta complejidad de nuestro objeto de estudio es la responsable de las muy diversas formas que existen de entender y llevar a cabo el análisis lingüístico. Por un lado, justifica las muy diversas áreas y disciplinas que lo ana- 
lizan: la psicolingüística, la sociolingüística, la semántica, la fonética, etc. Por otro lado, también explica muy bien la existencia de diversos modelos de análisis, pues lo que les diferencia (entre otros aspectos) es fundamentalmente el peso relativo que conceden a una u otra influencia externa o interna.

En este libro que ahora presentamos hemos tomado dos decisiones importantes: en primer lugar, hemos decidido centrar esta obra en la esencia básica del lenguaje humano, una vez despojada de todas esas influencias. Pues la facultad del lenguaje, con independencia de que se vea influenciada por todos los aspectos hasta ahora mencionados, es fundamentalmente una capacidad que se puede caracterizar por dos elementos básicos: una lista de elementos que adquirimos en un momento determinado de nuestra adquisición lingüística y que almacenamos de uno u otro modo en nuestra memoria a largo plazo y una serie de reglas de combinatoria, que se aplican sobre estos elementos. En esta obra colectiva nuestro empeño es profundizar sobre de qué modo estos dos componentes básicos (que podemos llamar, por simplificar, léxico y sintaxis) se relacionan en las lenguas humanas: cuál es el peso relativo de cada uno de ellos y de qué modo se combinan para permitir la expresión perceptible de nuestro pensamiento.

Ahora bien, si hemos sido específicos en el objeto de estudio elegido, desechando la mayor parte de los temas que uno puede abordar cuando se encarga de estudiar el lenguaje, no se puede decir lo mismo con respecto al modelo teórico o la perspectiva adoptada. Nuestra segunda decisión al plantear este estudio monográfico sobre las relaciones entre léxico y sintaxis fue que fuera una obra polifónica. Y esto no solo por el hecho de ser una obra colectiva, sino sobre todo porque, como se verá, se ha tratado de recoger diversos estudios que, desde muy distintos marcos teóricos (o distintos modos de entender los pesos relativos a los que antes nos referíamos), se plantean cuestiones sobre la relación entre las unidades léxicas y la combinatoria de las mismas. A continuación, vamos a presentar de forma sintética lo que el lector va a encontrar en cada una de las aportaciones de este libro, especificando cuál es el problema concreto que se aborda (dentro del análisis de la relación léxico-sintaxis) y cuál es la perspectiva desde la que se trabaja en cada caso.

José Francisco Val Álvaro (páginas 17-47): «La encrucijada del léxico y la sintaxis». La primera aportación de este volumen tiene como objetivo dar cuenta, de un modo sencillo y resumido, de las principales 
propuestas teóricas que a propósito de la interfaz léxico-sintaxis se han propuesto en los últimos cincuenta años. Comienza el autor planteando una breve reseña histórica sobre lo que ha supuesto este medio siglo en el análisis de este problema para, acto seguido, distinguir dos grandes apartados. En el primero de ellos (del léxico a la sintaxis), se presentan los conceptos básicos que fundamentan la postura lexicista: en primer lugar, parte de las propuestas de descomposición en niveles del lexicón (ELC, EA), presentando la hipótesis clásica de las jerarquías temáticas y llegando hasta la noción de protopapel (Dowty); en segundo lugar, se aborda la naturaleza aspectual del léxico, comenzando por la clasificación vendleriana de los tipos de eventos, pasando por la descomposición de predicados en primitivos y las cadenas causales de Croft y llegando al modelo de lexicón generativo de Pustejovsky, que plantea un nuevo modelo de relaciones eventivas y entronca muy bien con la propuesta de las redes semánticas. En tercer y último lugar, se presentan las propuestas más sintactistas de la configuración del lexicón, con la propuesta ya clásica de Hale y Keyser. En el segundo de estos apartados (de la sintaxis al léxico) atiende a la perspectiva sintactista de la relación léxico-sintaxis, presentando las bases de la denominada morfología distribuida, la gramática de construcciones y las propuestas neoconstructivistas más actuales. En definitiva, este primer capítulo del libro se ha concebido como una breve introducción histórica que sirva como soporte teórico en el que adscribir, posteriormente, el resto de contribuciones de esta obra.

ÁngEL López GARCía (páginas 49-75): "Neurolingüística de la interfaz léxico-sintaxis». El Dr. López García afronta en este capítulo la relación entre el léxico y la sintaxis desde un punto de vista neuronal, con una sugerente propuesta al respecto. Partiendo de la diferencia, bien comprobada experimentalmente, entre memoria explícita (esto es, consciente) y memoria implícita (de uso inconsciente), trata de relacionar el conocimiento del léxico con aquella y el conocimiento de las reglas de la combinatoria con esta. Tras presentar una síntesis de lo que se sabe desde la neurología tanto de la memoria implícita (incluidos procesos perceptivos) como de la explícita, el autor da cuenta de los diversos procedimientos experimentales que se llevan a cabo en esta área del conocimiento y afronta, desde este punto de vista, los procesos de categorización, en los que confluyen mecanismos conscientes e inconscientes. 
María del Carmen Horno Chéliz y Juan Miguel Cuartero OTAL (páginas 77-104): «Un modelo lexicalista de la estatividad verbal». En este capítulo, se trata de presentar una propuesta sobre la naturaleza de la estatividad verbal, partiendo de una premisa clara: determinados verbos se almacenan en la memoria como verbos estativos, con independencia de su uso en los enunciados concretos, mientras que el resto se almacenan como verbos no estativos, aunque a veces participen de enunciados estativos. Tras justificar este doble nivel de análisis (léxico frente a enunciado), se presenta un resumen general de los principales estudios sobre la estatividad y se resume su propuesta sobre la naturaleza de los verbos estativos. A partir de ella, se analizan los distintos enunciados estativos.

IRAIDE IBARRETXE-ANTUÑANO (páginas 105-122): «Cuestiones pendientes de la tipología semántica para el análisis de los eventos de movimiento». Tal y como se desprende del título, el objetivo de este capítulo es presentar una serie de "cuestiones abiertas» de la teoría de los patrones de lexicalización de Talmy. Tras un repaso general de los fundamentos de esta propuesta teórica, se plantean los principales problemas al respecto, no solo en el ámbito estricto de los verbos de movimiento, sino también en otros ámbitos, en los que la solución parece exceder, según la autora, los límites de la gramática.

Ricardo MAIRAL-UsÓn y FranCISCO GONZÁlveZ-GarCÍA (páginas 123-152): «Verbos y construcciones en el espacio cognitivo-funcional del siglo XXI». El objetivo de este capítulo es presentar un modelo teórico (Modelo Léxico Construccional: MLC) como alternativa tanto a las propuestas lexicistas como a las construccionistas. Tras una breve introducción, se muestra la evolución que ha experimentado el concepto mismo de construcción y se justifica la necesidad de dar cuenta de una serie de contenidos (como por ejemplo los pragmáticos) a los que tradicionalmente no se les ha dado importancia. De forma análoga, se realiza un panorama general de los estudios léxicos, para terminar presentando una propuesta alternativa y quizá más ambiciosa (pues asume otros niveles de análisis no afrontados en los otros modelos).

JUAN ROMERO (páginas 153-179): «Observaciones sobre la proyección argumental». Este capítulo también trata de presentar una alternativa a los modelos proyeccionistas y neoconstructivistas, ya que, según palabras del propio Dr. Romero, «unos y otros fracasan a la hora de explicar la proyección argumental. Este fracaso se debe bien a problemas de 
sub o sobregeneración o bien a su incapacidad para predecir el comportamiento intercategorial de la proyección argumental»; problemas que la propuesta del Dr. Romero trata de solventar.

José Luis Mendívil Giró (páginas 181-224): «Por debajo de la palabra, silencio: la sintaxis como interfaz y la naturaleza del léxico». Este capítulo presenta una propuesta sobre la naturaleza del léxico, que es, a un tiempo, "antilexicista" (en el sentido de que no distingue entre dos niveles de análisis) y "neo-lexicista» (en el sentido de que reivindica el valor de la morfología paradigmática basada en el signo lingüístico y renuncia así a los principios de la morfología distribuida).

Antonio Fábregas Alfaro e Isabel Pérez Jiménez (páginas 225248): «Hacia un análisis sintáctico del género en español». Este capítulo coincide con el anterior en plantearse los límites entre la morfología y la sintaxis, aunque la propuesta que van a plantear y el modo de encararla sean sustancialmente diferentes. De hecho, el problema que van a tratar de solucionar en estas páginas se circunscribe al género nominal. La propuesta que presentan pasa por considerar la existencia de dos funciones distintas del género nominal y explicar determinados comportamientos del adjetivo (en concordancia o discordancia) en este marco teórico.

DaVID SERRANO-Dolader (páginas 249-270): «El género en los sustantivos: ¿‘flexión y/o derivación?». Este último capítulo que cierra el volumen considera el mismo objeto de estudio, el género, pero para plantearse una pregunta diferente: asumiendo que este se circunscribe al ámbito de la morfología, queda ahora por decidir si se trata de una unidad propia de los procesos flexivos, derivativos, o de ambos. Tras un análisis pormenorizado de los distintos procesos en los que se involucra el género de los sustantivos, el Dr. Serrano abogará por una solución teórica no discreta para dar cuenta de los asuntos más problemáticos.

El objetivo de esta obra colectiva ha sido, por tanto, demostrar cómo diferentes posturas teóricas y metodológicas, que no pocos presuponen incompatibles, pueden converger, aportando diferentes perspectivas complementarias con un objetivo común: entender cómo es el lenguaje y cómo funciona. Este es, de hecho, el espíritu del grupo de investigación Sylex (Grupo consolidado DGA, H32), desde el que parte este trabajo. El lector juzgará si lo hemos conseguido. Por nuestra parte, nos comprometemos a seguir trabajando en esta dirección. 



\title{
LA ENCRUCIJADA DEL LÉXICO Y LA SINTAXIS*
}

\author{
José Francisco Val Álvaro \\ (Universidad de Zaragoza. Grupo Sylex)
}

\section{Introducción}

Desde que Chomsky introduce en Aspects of the Theory of Syntax (1965) el componente del lexicón, este desempeña un papel crucial en la teoría gramatical. A partir de los años setenta, con el desarrollo del lexicismo, se consolida la idea de que el lexicón no es una mera lista de morfemas, sino un componente productivo de la gramática. Es responsable de operaciones morfológicas (creación de compuestos y derivados así como de formas flexivas —en la hipótesis fuerte-); pero también de operaciones léxicas que cambian la estructura argumental (o valencia) de un verbo y que, por tanto, son la base de las alternancias sintácticas. Con distintas variantes, la idea de que la estructura de las oraciones refleja en buena medida las propiedades de los elementos léxicos que la constituyen se diversifica en perspectivas teóricas diferentes. Un problema común a todas ellas es regular cómo se proyecta la información léxica en la estruc-

* La investigación subyacente a esta aportación forma parte del proyecto HUM2007-64200/FILO subvencionado por el Gobierno de España. 
tura sintáctica. Esto supone determinar cuáles son las propiedades sintácticamente relevantes del léxico y las propiedades que interactúan con el léxico para configurar la estructura de la oración.

El debate, no obstante, se plantea cuando se comprueba que algunos procesos están sujetos a restricciones sintácticas y, por consiguiente, se explican mejor mediante operaciones en la sintaxis. Es, por ejemplo, lo que sucede en el influyente trabajo de Baker (1988) sobre la incorporación. Se produce así una ruptura con el lexicismo que culminará en las hipótesis construccionistas de la sintaxis. El lexicón es degradado a uno o más repertorios de unidades elementales que la sintaxis computa para construir unidades mayores (tanto palabras, como oraciones). De este modo, todos los procesos derivativos se trasladan a la sintaxis. En esta línea se enmarcan trabajos como los de Marantz 1997, 2001; Borer 1998, 2003; y Arad 2003, entre otros.

\section{Del léxico a la sintaxis}

\subsection{Argumentos y papeles temáticos (o semánticos)}

Las primeras formulaciones sobre cómo se regula la aparición de argumentos en la estructura de la oración — dejando aparte los trabajos sobre la gramática de casos (Fillmore 1968) — se basa en la llamada «red temática» (Stowell 1981) en el marco de la Teoría de Rección y Ligamiento (Chomsky 1981). Esta idea, concomitante con la hipótesis lexicista, supone que la estructura de argumentos de un predicado está determinada por las propiedades léxicas del predicado. La perspectiva clásica acepta que una entrada léxica entraña tres tipos de información:

(i) información fonológica

(ii) información semántica

(iii) información sintáctica

- categoría

- propiedades de subcategorización (red temática...)

Así, poner comprendería en el lexicón:

$$
\begin{aligned}
& \text { poner: /po'neR/ } \\
& {[+\mathrm{V},-\mathrm{N}]}
\end{aligned}
$$


$\left.+\mathrm{x}_{\text {Agente, }}^{+} \mathrm{y}_{\text {Tema }}, \mathrm{z}_{\text {Locativo }}\right\}^{1}$

El Principio de Proyección chomskiano (Chomsky 1981) permite que estos argumentos sean proyectados a la estructura sintáctica de la oración. El mecanismo que asegura que cada argumento vaya a su posición específica en la configuración oracional es una jerarquía temática del tipo de Agente $>$ Tema $>$ Fin $>$ Oblicuos (Modo, Locación, Tiempo) (Larson 1988). De este modo se extiende una línea de trabajo que concibe que los papeles temáticos están ordenados en una jerarquía, de tal forma que la realización sintáctica de un argumento depende de su posición en dicha jerarquía. Así, en distintos marcos teóricos se proponen jerarquías como las siguientes:

(3)

Agente $>$ Dativo/Benefactivo $>$ Paciente $>$ Locación $>$ Instrumental/Asociativo $>$ Manera (Givón 1984: 139)

Agente $>$ Beneficiario > Recipiente/Experimentador > Instrumento > Tema/Paciente > Locación (Bresnan y Kanerva 1989: 23)

Actor $>$ Paciente/Beneficiario $>$ Tema $>$ Locación/Fuente/Término (Jackendoff 1990: 258)

Agente > «Effector» $>$ Experimentador $>$ Locativo/Recipiente $>$ Tema $>$ Paciente (Van Valin 1993: 75)

El rasgo común a todas las propuestas es que un número reducido de papeles temáticos (o semánticos) es suficiente para dar cuenta de la dimensión gramaticalmente relevante de los argumentos. El modo en que se vincula la información léxica argumental y la estructura sintáctica varía según la propuesta que se tome en consideración. ${ }^{2}$

1 Por supuesto, el tipo de información que se ofrece en las entradas es también objeto de controversia. Por ejemplo, Pesetsky (1982) muestra que las propiedades de selección categorial (selección-c) son en gran parte predecibles de la selección semántica (selección-s): si un verbo denota un proceso que se aplica a un objeto, esto es, selecciona semánticamente un objeto en su predicado, seleccionará categorialmente una construcción nominal como complemento.

2 Más refinada que la jerarquía temática es la idea de que la estructura argumental está en sí misma estructurada en cada entrada léxica y que la estructura profunda de una oración simplemente resulta de la proyección directa de esa estructura del elemento léxico. Es la hipótesis que subyace en la "Universal Alignment Hypothesis» (UAH) de Perlmutter y Postal (1984: 97) o la más extendida "Uniformity of Theta Assignment Hypothesis» (UTAH: «Identical thematic relationships between items are represented by identical structural relationships between those items at the level of D-Structure» (Baker 1988: 46); véase también Baker (1997). 
Los problemas para este tipo de propuestas surgen a partir del estudio de los verbos psicológicos (agradar, molestar) —Belletti y Rizzi (1988) - y se extienden con verbos en los que varias construcciones nominales parecen desempeñar el mismo papel (semejar, parecerse) o con predicados en los que resulta controvertido o difícil identificar el papel del argumento interno (imaginar). Pero más allá del análisis de tipos de predicados particulares, permanecen sin resolver asuntos como el inventario de papeles (con definiciones precisas y pruebas de identificación no ambiguas), relaciones de prominencia entre los distintos papeles (salvedad hecha del acuerdo de que el Agente es el más alto en la jerarquía) y, sobre todo, la naturaleza atómica y de primitivo teórico de esta noción.

Si se quiere mantener como básica esta noción, una opción a las jerarquías temáticas es la propuesta de Dowty (1991) de protopapeles. Concibe solo dos papeles semánticos como relevantes para la realización sintáctica de los argumentos, Agente y Paciente. Ahora bien, son concebidos como prototipos que resultan de un conjunto de propiedades; de ahí la denominación de proto-agente y proto-paciente. Ya no se trata de que un predicado asigne una propiedad a un argumento, sino de que imponga entrañamientos léxicos como los que va a delimitar su carácter agentivo o de paciente, sin que ninguno de esos entrañamientos tenga preeminencia sobre los demás:

(4)

Proto-Agente:

a. volitivo

b. capacidad de experiencia perceptiva («sentience»)

c. causador de un evento o de un cambio de estado en otro participante

d. movimiento (respecto a la posición de otro participante)

e. existencia de referente independiente del proceso denotado por el verbo

Proto-Paciente:

a. subyace cambio de estado

b. tema incremental

c. causalmente afectado

d. estacionario respecto al movimiento de otro participante

e. no existe independiente del evento

Para regular la forma en que se realizan los argumentos, Dowty propone el «Verbal Argument Selection Principle» («In predicates with grammatical subject and object, the argument for which the predicate entails the greatest number of Proto-Agent properties will be lexicalized as the subject of the predicate; the argument having the greatest number of 
Proto-Patient entailments will be lexicalized as the direct object», Dowty 1991: 576).

\subsection{Tipos de eventos y representación semántica del léxico}

Los problemas de delimitación y definición de los papeles temáticos llevan a algunos lingüistas a considerarlos no como primitivos teóricos, sino derivados de otras nociones elementales. Esto converge con la idea de que los significados de las unidades léxicas están estructurados. Una forma de presentar esta idea es suponer que el contenido puede ser descompuesto en unidades menores. En el caso de los verbos: estas unidades serían predicados semánticos básicos, de forma que una clase verbal comparte esos predicados básicos y cada verbo añade, además, otros rasgos idiosincrásicos que lo diferencian de otro. Estos componentes semánticos básicos estarían no solo estructurados, sino también restringidos. En el caso central de los predicados verbales, esta hipótesis va a ir paralela a la investigación sobre los tipos de eventos denotados por los verbos.

La tradición moderna de distinguir diversos tipos de eventos con objeto de explicar el comportamiento de los predicados tiene su precedente más notorio en Vendler $(1957,1967)$. Este, basándose en las propiedades aspectuales (en el sentido de aspecto léxico, "aktionsart») de los predicados, diferencia cuatro tipos: estados, actividades, realizaciones y logros («states», «activities», "accomplishments», «achievements»): saber, creer, desear / correr, caminar, nadar / pintar un cuadro, hacer una silla / encontrar, perder, morir. Los estados y las actividades se refieren a situaciones que son inherentemente no delimitadas desde la perspectiva temporal, esto es, son predicados no télicos. La diferencia entre ambos es que los estados remiten a situaciones estáticas y las actividades a situaciones dinámicas. Realizaciones y logros tienen en común el incorporar un cambio de estado y, por tanto, denotar situaciones temporalmente delimitadas, esto es, télicas. Los logros son puntuales, mientras que las realizaciones suponen un desarrollo a lo largo del tiempo. ${ }^{3}$

3 En términos de telicidad, pues, actividades y estados, de una parte, y realizaciones y logros, de otra, forman dos clases. Sin embargo, el comportamiento de los diversos tipos con la forma progresiva de los verbos muestra que actividades y realizaciones admiten el 
La tipología de Vendler es la base sobre la que se construyen representaciones semánticas de las predicaciones y teorías sobre la estructura argumental basadas en la descomposición semántica de los predicados. Un trabajo pionero en este sentido es la propuesta de Dowty (1979) de descomponer esos tipos eventivos en términos de predicados semánticos elementales (DO, CAUSE, BECOME):
a. estado: $\pi n(\alpha 1, \ldots, \alpha n)$
b. actividad: $\mathrm{DO}(\alpha 1,[\pi n(\alpha 1, \ldots, \alpha n)])$
c. realización: $\operatorname{BECOME}[\pi n(\alpha 1, \ldots, \alpha n)]$
d. logro: [[ DO $(\alpha 1,[\pi n(\alpha 1, \ldots, \alpha n)])]$ CAUSE [ $\operatorname{BECOME}[\pi n(\alpha 1, \ldots, \alpha n)]]]$
(Dowty 1979: 123-124)

De este modo, la estructura eventiva que propone para las oraciones del inglés John walks y He sweeps the floor clean es la siguiente:
a. John walks.
[ DO (John, walk) ]
b. He sweeps the floor clean.
[ [ DO (he, sweeps(the floor)) ] CAUSE [ BECOME [ clean(the floor) ]]]

El segundo ejemplo presenta lo que va a constituir una hipótesis general en el análisis de los causativos: dos subeventos, uno causador y otro resultativo vinculados al predicado CAUSE. ${ }^{4}$

Un desarrollo notable de los tipos de Vendler es la descomposición léxica defendida por Rappaport Hovav y Levin (1998). ${ }^{5}$ Definen cinco clases básicas de «plantillas» eventivas:

tiempo progresivo, mientras que estados y logros, no. Asimismo, la naturaleza de los logros como clase independiente no es compartida por todos los autores. Este tipo es caracterizado por ser télico y puntual. No está claro, sin embargo, si la duración es una propiedad codificada por el verbo o es resultado del conocimiento enciclopédico del hablante, del conocimiento de la realidad extralingüística (Verkuyl 1993). Pustejovsky (1991), por ejemplo, une realizaciones y logros en el tipo de eventos que denomina "transiciones».

4 La interpretación de la descomposición de predicados tal como es presentada en el capítulo 2 de Dowty (1979) es adoptada por otros autores y corrientes, como, por ejemplo, en la Gramática del Papel y la Referencia de Foley y Van Valin (1984) o en el modelo de Bierwisch $(1988,1990)$.

5 Si se deja aparte el temprano trabajo de Carter (1976) como intento de descomponer los verbos en primitivos semánticos (darken: $x$ CAUSE ( $y$ BE DARK) CHANGE)), la raíz de algunos de estos planteamientos se halla en el concepto de estructura conceptual 
a. actividad: [ $x$ ACT $<M A N N E R>$ ]

b. estado: $[x<S T A T E>$ ]

c. realización: [ BECOME [ $x<S T A T E>$ ] ]

d. logro: [ $x$ CAUSE [ BECOME $[y<S T A T E>$ ] ] ]

e. logro: [ $x$ ACT $<M A N N E R>$ ] CAUSE [ BECOME $[y<S T A T E>$ ] ] ]

(Rappaport Hovav y Levin 1998: 108)

El fundamento de esta hipótesis es que los verbos codifican estructuras eventivas complejas, de tal modo que el significado de un verbo puede interpretarse por la relación entre una constante y una "plantilla» en la que aparece. Las constantes, representadas entre ángulos y en cursiva, se expresan mediante cadenas fonológicas de la lengua (por ejemplo, de nombres en verbos denominales). La asociación de estas constantes con la correspondiente "plantilla» está determinada por un conjunto de «reglas de realización canónica» que fija la compatibilidad entre unas y otras:

\author{
a. «manner» $\rightarrow[x \mathrm{ACT}<M A N N E R>]$ \\ (jog, run, creak, whistle, etc.) \\ b. «instrument» $\rightarrow[x$ ACT $<$ INSTRUMENT> ] \\ (brush, hammer, saw, shovel, etc.)
}

propuesto y desarrollado por Jackendoff (1983). Una de las hipótesis en que se fundamenta esta noción es que hay correlación entre categorías sintácticas de las lenguas y categorías conceptuales. La hipótesis central de la semántica conceptual es que el lenguaje puede ser explicado en este nivel mediante representaciones internas de información conceptual. De ahí que Jackendoff (1983) considere las representaciones semánticas como un subconjunto de la estructura de los conceptos. Para ello asume que lo apropiado es emplear representaciones independientes de las lenguas y definir un conjunto de primitivos semánticos que reflejen interlingüísticamente los fenómenos examinados. La aproximación de Jackendoff a los componentes semánticos distingue "tipos» (Event, State, Position, Path, Thing, Property, Location, Time, Mannner) que son especificados en diversos "primitivos" (por ejemplo, Event se especializa en CAUSE, LET, GO y STAY; State, en BE, GO-EXT, ORIENT; Position, en AT, IN, ON; Path, en TO, FROM, TOWARD, AWAY-FROM, VIA; etc.). El verbo, núcleo del sintagma verbal, desempeña un papel esencial en la conformación de la estructura semántica de la oración. De una parte, delimita su categoría ontológica; de otra, define las posiciones argumentales mediante las funciones establecidas en su estructura conceptual, posiciones argumentales susceptibles de ser saturadas por elementos sintácticos para construir la oración. Un aspecto diferencial de la propuesta de Jackendoff (1990) es que distingue dos estratos en la representación léxica conceptual: el estrato temático, que comprende las relaciones temáticas que intervienen en el movimiento o la localización (incluida ahí la atribución de estados), y el estrato de acción, en el que se representan las relaciones de afectación, esto es, de Agente y Paciente. Las relaciones temáticas se expresan mediante funciones semántico-conceptuales como GO, BE, CAUSE, etc. Las relaciones de afectación se reflejan en la función AFF (véase también Jackendoff, 1996). 
c. «placeable object» [ $\mathrm{x}$ CAUSE [ BECOME [ $\mathrm{x}$ WITH $<$ THING $>$ ]]]

(butter, oil, paper, tile, wax, etc.)

d. "place» $\rightarrow[x$ CAUSE [ BECOME $[x<P L A C E>]]]$

(bag, box, cage, crate, garage, pocket, etc.)

e. «internally caused state» $\rightarrow[x<$ STATE $>]$

(bloom, blossom, decay, flower, rot, rust, sprout, etc.)

f. «externally caused state» $\rightarrow[$ [ $x$ ACT $]$ CAUSE [ BECOME $[y<$ STATE $>]]]$

(break, dry, harden, melt, open, etc.)

(Rappaport Hovav y Levin 1998: 109)

En el caso particular de las predicaciones secundarias, Rappaport Hovav y Levin consideran necesario permitir el incremento de los «templetes» básicos, de forma que a estos se les pueda añadir otro (para un desarrollo específico de los resultativos, véase Rappaport Hovav y Levin 2001). Así, para un ejemplo semejante al analizado como tipo causativo por Dowty, proponen la siguiente solución:
a. Phil swept the floor.
[ Phil ACT $<S W E E P>$ floor ]
b. Phil swept the floor clean.
[ [ Phil ACT $<S W E E P>$ floor ] CAUSE [ BECOME [ floor $<C L E A N>$ ]]]

Esta propuesta acepta que estas representaciones forman parte del saber léxico de los hablantes y, por tanto, son independientes de la estructura sintáctica. Ello exige hacer explícito el mecanismo por el que los argumentos de la representación léxica semántica se proyectan en las posiciones argumentales de la configuración sintáctica oracional. Inicialmente, la realización sintáctica de las estructuras eventivas propuestas ha de cumplir dos condiciones (Rappaport Hovav y Levin 1998: 112-113): (i) condición de "Identificación de subeventos»: cada subevento de la estructura eventiva debe ser identificado con un núcleo léxico (por ejemplo V, A o P) en la sintaxis; (ii) condición de la «Realización de argumentos»: (a) debe haber un argumento SX en la sintaxis para cada participante en la estructura eventiva; (b) todo argumento SX de la estructura sintáctica debe ser asociado con un subevento identificado en la estructura eventiva. Además, frente a las jerarquías temáticas, adoptadas por ejemplo por Jackendoff, Rappaport Hovav y Levin definen restricciones de buena formación (como la de "Argument-Per-Subevent Condition») y reglas de enlace que vinculen la estructura eventiva de los elementos léxicos y la estructura sintáctica. Así, proponen reglas como las siguientes: 
(i) «Immediate Cause Linking Rule»: El argumento de un verbo que denota la causa inmediata del evento descrito por ese verbo es su argumento externo (Levin y Rappaport Hovav 1995: 135).

(ii) "Directed Change Linking Rule»: El argumento de un verbo que corresponde a la entidad que es objeto directo del cambio descrito por ese verbo es su argumento interno (Levin y Rappaport Hovav 1995: 146).

(iii) «Existence Linking Rule»: El argumento de un verbo cuya existencia es afirmada o negada es su argumento directo interno (Levin y Rappaport Hovav 1995: 153).

(iv) "Default Linking Rule»: Un argumento de un verbo que no cae bajo el alcance de cualquiera de las otras reglas de enlace es su argumento directo interno (Levin y Rappaport Hovav 1995: 154).

Las representaciones léxico semánticas de esta naturaleza no carecen de problemas. Los hay de carácter general que afectan a la perspectiva adoptada: una representación semántica independiente de la sintaxis y con capacidad para realizar operaciones que parecen violar el principio de que la sintaxis es el único componente generativo de la gramática o un tipo de lexicón que puede derivar en estipulaciones con objeto de llegar a la configuración sintáctica adecuada. Pero las hay, también, de carácter particular. Identificar las actividades mediante un predicado semántico básico ACT no explica por sí mismo por qué leer o nadar admiten una construcción del tipo de Tu primo leerá durante dos horas, El atleta nadó durante una hora, y en cambio no permiten la interpretación de que el evento se ha completado en un tiempo determinado en construcciones como \# Tu primo leerá en dos horas, \# El atleta nadó en una hora. Por otro lado, no parece que la selección de argumentos determinada por el tipo de evento (STATE, ACT, etc.) esté necesariamente en correspondencia con la selección que se da en verbos con un aspecto léxico dado. Por ejemplo, en el planteamiento de Rappaport Hovav y Levin (1998) los estados están formulados de tal modo que solo presentan una variable (x); sin embargo, oraciones de estado se dan no solo con estructuras atributivas de una propiedad expresada "adjetivalmente» (El alero del equipo es bajo, El explorador tiene sed) o inacusativas (Los almendros florecen), sino que también aparecen construcciones transitivas, con dos argumentos ( $E l$ gato teme la oscuridad). 


\subsubsection{El lexicón generativo}

Una de las conclusiones de las propuestas anteriores es que el tipo de evento emerge como el marco donde se establecen las condiciones suficientes para deducir la estructura argumental de los elementos léxicos predicativos. Esto supone que la representación léxica habilita posibilidades que se realizan en la estructura sintáctica, pero también que establece los límites de esas posibilidades. En lo que atañe al aspecto, el aspecto de una construcción predicativa puede tomar como base el aspecto léxico verbal, pero tiene naturaleza composicional. Por ello, las posibilidades abiertas en el léxico se fijan en el momento de la construcción oracional, según los constituyentes que intervienen. En este sentido, pruebas habituales, como la compatibilidad o incompatibilidad con expresiones adverbiales de distinto tipo (casi, poco a poco, gradualmente, lentamente, mucho), con perífrasis verbales (estar + gerundio) y flexiones verbales (perfecto e imperfecto), con construcciones temporales (en 'x tiempo', durante 'x tiempo', hace 'x tiempo') delimitan lo que en cada clase aspectual y en cada predicado se focaliza respecto del momento de desarrollo de la acción. Desarrollar estas ideas en el ámbito de la semántica léxica requiere contar con instrumentos teóricos que permitan establecer la estructura interna de los eventos. Una de las propuestas más interesantes en esta línea se debe a Pustejovsky. La idea de un lexicón con capacidad de procesamiento de unidades y, por tanto, con capacidad generativa, adquiere una de sus formulaciones más exhaustivas en la propuesta del «lexicón generativo» de Pustejovsky (1991, 1995). Los cimientos sobre los que se erige el lexicón generativo son la información distribuida en varios estratos y la infraespecificación de las unidades léxicas. Nombres, adjetivos y verbos son definidos mediante entradas infraespecificadas con información repartida en varios estratos o niveles de representación, de modo que se puedan deducir las interpretaciones diversas de la unidad léxica según el contexto en que aparezca. En este sentido, objetivo central de la propuesta es resolver el problema de la polisemia.

Este tipo de lexicón comprende unidades para las que se proponen representaciones en distintos niveles, fundamentalmente: la estructura argumental, la estructura eventiva y la estructura de «qualia». ${ }^{6}$ La estruc-

6 La estructura de herencia léxica, o de tipos léxicos, da cuenta de cómo se relacionan las palabras entre sí en el diccionario. Esta información, no obstante, podría considerarse que está comprendida, en general, dentro del rol formal de la estructura de «qualia». 
tura argumental da cuenta del tipo y número de argumentos de un predicado. La estructura eventiva presenta la composición interna de un evento complejo en términos de subeventos o fases más simples, de forma que alguna de ellas puede ser focalizada y proyectarse en la configuración sintáctica e interpretarse semánticamente. La estructura de "qualia» comprende informaciones prototípicas vinculadas a entidades, propiedades y eventos denotados por las unidades léxicas.

La estructura argumental que propone Pustejovsky (1995) no se ciñe a los argumentos obligatorios de un predicado, sino que comprende también participantes opcionales del tipo de «argumentos defectivos» $\mathrm{y}$ "argumentos sobreentendidos». Los primeros intervienen en las expresiones lógicas de la "qualia», pero no materializan necesariamente en la estructura oracional (Ya han aliñado el pescado con albahaca). Los segundos corresponden a elementos semánticamente incorporados en los elementos léxicos y que pueden aparecer como especificaciones en la oración (Embotellaron el vino en botellas de diseño; Salaron la truch a con sal marina).

Una de las aportaciones más relevantes es la estrutura de los eventos. Los fundamentos para la formulación de los eventos son, según Pustejovsky (1991), los siguientes (Val Álvaro 2000):

- diversos fenómenos gramaticales requieren una estructura de subeventos para fijar su dominio de aplicación (por ejemplo, la modificación con casi);

- las propiedades semánticas de las palabras no pueden presentarse como un repertorio de rasgos, sino como una estructura;

- la información de tipo conceptual (ELC') se construye partiendo de las propiedades aspectuales del predicado, reflejadas en la estructura eventiva (EE); estas dos estructuras representan paralelamente el contenido general del predicado;

- la estructura léxico-conceptual (ELC) se forma a partir de las dos estructuras, EE y ELC';

- de la estructura léxico-conceptual se extrae la estructura argumental.

Pustejovsky (1991, 1995) distingue tres tipos de eventos: estados, «procesos» y transiciones. En términos aspectuales, esta distinción de eventos está en correspondencia débil con la oposición de eventos dinámicos («procesos» y transiciones) y no dinámicos (estados), y con la opo- 
sición de eventos télicos (transiciones) y no télicos («procesos»). Los estados son eventos simples, sin contraposición con otro evento. De ahí que se representen como:

$$
\stackrel{\mathrm{e}}{\mathrm{e}}_{\mathrm{e}}^{\mathrm{E}}
$$

Los «procesos» comportan una secuencia de eventos idénticos $\left(e_{1} \ldots e_{n}\right)$; de ahí que en Pustejovsky (1991) se representen del modo siguiente:

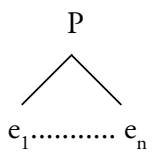

Las transiciones, que incluyen las clases aspectuales de realizaciones y logros, implican un cambio producido por una actividad; de ahí que se definan por la idea de cambio reflejada en la oposición de subeventos $\left(\neg e_{1}, e_{2}\right)$, que implica un subevento inicial de proceso y un subevento final de resultado:

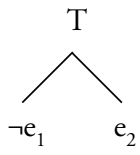

La estructura eventiva no solo presenta la composición de subeventos, sino que también establece entre ellos orden de relación temporal: $\mathrm{e}_{1}$ precede a $\mathrm{e}_{2}\left(\mathrm{e}_{1}<\mathrm{e}_{2}\right)$, $\mathrm{e}_{1}$ es simultáneo a $\mathrm{e}_{2}\left(\mathrm{e}_{1} \mathrm{o} \mathrm{e}_{2}\right)$ y el desarrollo de $\mathrm{e}_{1}$ comienza antes pero se solapa con el de $e_{2}\left(e_{1}<0 e_{2}\right)$. Por último, la representación de eventos permite definir un núcleo, entendido como el evento que recibe el foco de la interpretación $\left(\mathrm{e}^{*}\right)$.

En la estructura de "qualia» convergen las dos estructuras anteriores. En este nivel de representación se aplicarán operaciones dotadas de capacidad generativa (algo análogo a transformaciones semánticas) que cambiarán las denotaciones de las unidades léxicas en relación con el contexto. Esta estructura comprende cuatro tipos de información distribuidos en lo que Pustejovsky (1995) denomina «roles»: rol constitutivo, rol agentivo, rol formal y rol télico. El rol constitutivo ofrece información sobre la relación 
entre una entidad y las partes que la componen o entre la entidad y el todo del que forma parte. El rol agentivo da cuenta de los factores que intervienen en la creación de una entidad o de un evento (para un sustantivo como libro tendría en valor de 'escribir', por ejemplo, y para un evento como hundir estaría vinculado al primer subevento - el proceso-). El rol formal, que tiene especial aplicación en unidades que denotan entidades, presenta las propiedades características lexicalizadas en las unidades léxicas conforme a parámetros como orientación, magnitud, forma, dimensionalidad, color, etc., de modo que la entidad pueda quedar diferenciada en un dominio más amplio (por ejemplo, un coche debe ser especificado con rasgos que muestren que es un tipo de vehículo). El rol télico concierne al propósito de una entidad o de un evento; en este sentido, por ejemplo, delimita la finalidad inherente de un agente al realizar una actividad (así, 'leer' mostraría una relación télica con libro).

Las informaciones atribuidas a una unidad en los diversos roles se relacionan mediante mecanismos de composición. De este modo, la aplicación de las operaciones de composición apropiadas a las representaciones infraespecificadas de una entrada léxica permite la interpretación correspondiente en una oración determinada. Por ejemplo, para un verbo como romper, entendido como una transición, es decir, como resultado de la combinación de un subevento de proceso y otro de resultado, habría una entrada que contendría la información siguiente:

(13) romper

\begin{tabular}{|c|c|}
\hline ESTR_EVENT: & $\begin{array}{l}{\left[\mathrm{E}_{1}: \mathrm{e}_{1}=\text { proceso }\right.} \\
\mathrm{E}: \mathrm{e}_{1}=\text { resultado }\end{array}$ \\
\hline ORDEN: & $\mathrm{E}_{2}: \mathrm{e}_{2}=\underset{<}{<}$ \\
\hline NÚCLEO: & : ] \\
\hline ESTR_ARG: & $\begin{array}{l}{\left[\mathrm{ARG}_{1}: \mathrm{x}\right.} \\
\left.\mathrm{ARG}_{2}: \mathrm{y}\right]\end{array}$ \\
\hline UALIA: & $\begin{array}{l}\text { [Formal: hundir_resultado }\left(\mathrm{e}_{2}, \mathrm{y}\right) \\
\text { Agentivo: hundir_acción }\left(\mathrm{e}_{1}, \mathrm{x}, \mathrm{y}\right) \text { ] }\end{array}$ \\
\hline
\end{tabular}

Puede apreciarse en (13) que las dos fases denotadas por el evento de romper quedan expresas en la asignación en la "qualia» de rasgos comunes a las estructuras argumental y eventiva. Además, la ambigüedad entre las interpretaciones causativa (El niño rompió el cristal) e incoativa (El cristal se rompió) requiere que el rasgo de núcleo no esté especificado en la estructura eventiva. En El niño rompió el cristal, la asignación del papel de 
núcleo al subevento $\mathrm{e}_{1}\left(\mathrm{e}=\mathrm{e}_{1}{ }^{*}<\mathrm{e}_{2}\right)$ hace que la interpretación relevante sea el rol Agentivo de la "qualia» (la que presenta como argumento la variable $\mathrm{e}_{1}$ ), de modo que queda «inactivo» el parámetro Formal. En el caso de El cristal se rompió, el núcleo es atribuido al segundo subevento $\mathrm{e}_{2}\left(\mathrm{e}=\mathrm{e}_{1}<\mathrm{e}_{2}{ }^{*}\right)$, lo que hace que sea prominente el rol Formal y se «desactive» la interpretación agentiva.

Aparte de la selección pura (cuando el tipo exigido por el predicado queda satisfecho por el argumento), Pustejovsky $(1995,2006)$ distingue otros dos mecanismos generativos que conciernen a las restricciones de un predicado sobre sus argumentos y explican casos en los que un argumento cambia la interpretación semántica del predicado: ligamiento selectivo («selective binding») y coerción de tipos («type coertion»). El ligamiento selectivo actúa seleccionando un componente determinado en una subestructura de la entrada léxica sin alterar los tipos; es lo que explica la alternancia de las interpretaciones causativa e incoativa en (13). La coerción de tipos se produce típicamente cuando un predicado obliga a la unidad seleccionada a cambiar su tipo semántico; es lo que explica que Han empezado el hospital sea interpretado como, por ejemplo, 'Han empezado a construir el hospital', ya que empezar selecciona como objeto un tipo semántico de 'evento' y hospital pertenece al tipo semántico de 'objeto': la coerción obliga a que hospital cambie de tipo y la interpretación mencionada sea posible porque el rol Agentivo del sustantivo especifica que —como 'edificio'- es predicado de 'construir'. El mecanismo semántico puede cambiar también la interpretación semántica del predicado. Es lo que sucede en la co-composición («co-composition»), operación que requiere que haya coincidencia parcial de rasgos en uno de los roles de la "qualia» de los elementos que se componen, por ejemplo, predicado y argumento. Este mecanismo permite explicar, por ejemplo, alternancias verbales entre el sentido de cambio de estado y de proceso de creación de objeto, como la del inglés bake o del español pintar (pintar una fachada / pintar un paisaje).

Un planteamiento de este tipo, al igual que en la descomposición léxica anterior, implica reconocer la naturaleza independiente de una representación semántica composicional paralela a las representaciones sintácticas. En el marco generativista, esto contradice el principio de que 
la sintaxis es el único mecanismo generativo del lenguaje humano. De ahí que, incluso en el nivel léxico, se llegue a plantear una computación estrictamente sintáctica.

\subsection{Codificación sintáctica del léxico}

En el umbral entre las hipótesis llamadas proyeccionistas y las neoconstruccionistas se hallan los planteamientos que desde los años noventa realizan en diversos trabajos Hale y Keyser (1993, 1998, 1999, 2000 y 2002). No obstante, su propuesta es plenamente proyeccionista, pues conciben un repertorio de unidades léxicas (lexicón) cuya información relevante se proyecta en la sintaxis oracional. Lo peculiar de la hipótesis de estos lingüistas es el tipo de información léxica sintácticamente relevante en la oración: una estructura léxico-relacional planteada en términos de configuración sintáctica.

Hale y Keyser dudan del planteamiento habitual de que las propiedades sintácticas de los elementos sean predecibles en buena parte tomando como base su significado. Su perspectiva consiste en asumir que la Gramática Universal no especifica los significados en sí mismos (sean papeles temáticos o constituyentes de otro tipo empleados en la tradición lexicista). Lo que hacen es más bien establecer principios que restringen la construcción de esos significados. Esos principios coinciden básicamente con los que regulan la derivación sintáctica. De ahí que planteen que las categorías léxicas se definen a partir de dos relaciones estructurales primitivas, la de complemento (relación de hermandad) y la de especificador (relación de adjunción). Asimismo, la estructura argumental de una unidad predicativa no es un primitivo de la gramática, sino que se deduce de la teoría de la X-barra; por tanto, los papeles temáticos se pueden derivar, en todo caso, de las relaciones entre elementos y configuraciones sintácticas en que aparecen esos elementos. Estas representaciones sintácticas del léxico se incluyen en la Estructura léxico-relacional, que delimita la sintaxis léxica (opuesta a la sintaxis oracional).

Hale y Keyser (1998: 82) definen las configuraciones básicas siguientes para la proyección de un núcleo $n$ : 
(14)
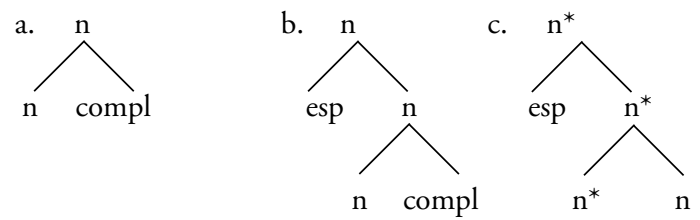

d. $\mathrm{n}$

Ellos mismos advierten de que sería precipitado prejuzgar la correspondencia entre los núcleos (n) de los esquemas de (14) y las categorías léxicas básicas. No obstante, es fácil deducir que la tendencia general es que, por defecto, en (14a) el núcleo ( $\mathrm{n}$ ) sea $\mathrm{V}$ inergativo, que en (14b) sea $\mathrm{P}$, que en (14c) sea A y que en (14d) sea N. Como indican Hale y Keyser, esta correspondencia general no se mantiene ni interlingüísticamente ni intralingüísticamente. Claro que, asimismo, aseguran que es obvio que hay interesantes generalizaciones que hacer al respecto.

El dominio empírico preferente para Hale y Keyser es la formación de verbos. El esquema más simple, el de (14 a), es propio de verbos denominales inergativos, como laugh ('reir') construido a partir de laugh ('risa'):

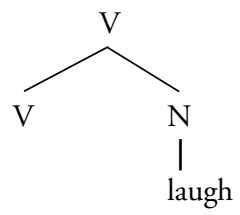

La formación del verbo se produce mediante una especie de incorporación léxica («conflation» es el término empleado por los autores) que copia la representación fonológica del sustantivo en el nudo $\mathrm{V} y$, por tanto, la verbaliza:

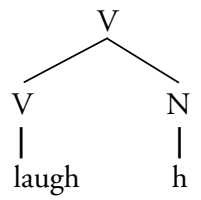


En esta hipótesis configuracional, el argumento externo es solo el argumento que se ensambla en la sintaxis oracional como resultado de proyectar esta configuración léxico-relacional (de la sintaxis léxica) en una construcción oracional (de la sintaxis oracional).

Un campo especialmente transparente -más en inglés que en otras lenguas, por ejemplo, las lenguas romances - es el de los verbos deadjetivales. ${ }^{7}$ La estructura de $(14 \mathrm{c})$ es la base de estos verbos en la modalidad inacusativa (verbos con el significado de cambio de estado):

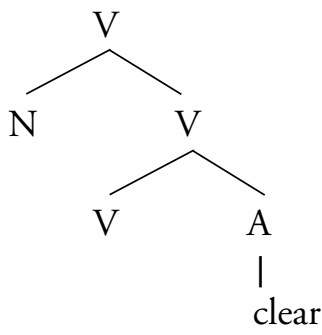

Esta representación permite establecer la relación entre un predicado estativo (el A clear que aparece como complemento), y un nudo verbal vacío (o con un afijo expreso, como en redden) intermedio. Este V intermedio sería el responsable de la denotación del cambio de estado que afecta al especificador $\mathrm{N}$. La incorporación léxica del adjetivo a $\mathrm{V}$ formaría el verbo clear y se proyectaría en la sintaxis oracional para derivar construcciones como The sky cleared. La alternancia causativa relajada en las oraciones transitivas (They cleared the screen) se explica como resultado de combinar la estructura léxico-relacional de (17) con la variante de (14 a) insertándolo como complemento:

7 Los verbos denominales locativos (enjaular, embotellar) y locatum (ensillar, empapelar) comparten la misma estructura léxico relacional. Es una combinación de las configuraciones de (14 b) — proyectada sobre la preposición como núcleo-y de (14 a). 

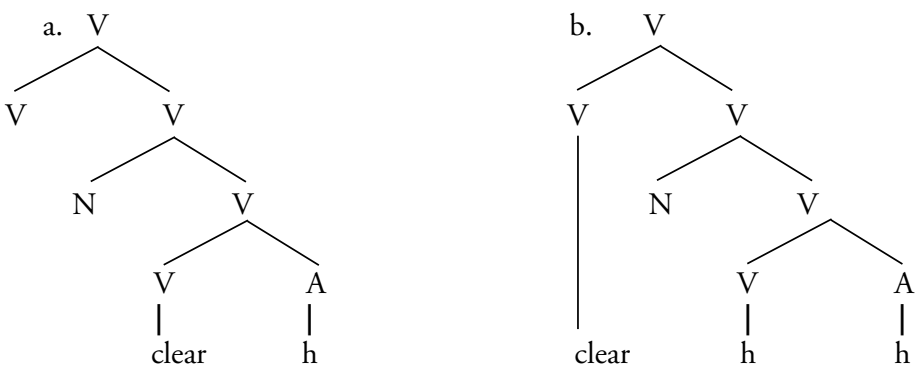

Como bien indica Mendikoetxea (2007), esta aproximación aventaja a los modelos basados en propiedades semánticas del léxico en dos aspectos. La estructura léxico-relacional se basa en «principios sintácticos restringidos, fundamentados y bien establecidos»: proyección, movimiento de núcleos y huellas propiamente regidas. De ahí el interés de esta hipótesis para delimitar la estructura argumental. The sky es interpretado como Tema en The sky cleared porque corresponde al Especificador $(\mathrm{N})$ de la configuración de (17), no lo es porque así se estipule en la red argumental del verbo en virtud del significado de clear. Además la otra ventaja de este modelo «es que la relación entre el léxico y la sintaxis es homomórfica (trivial): cada categoría se identifica con un tipo 'nocional' ( $\mathrm{V}=$ evento; $\mathrm{P}$ = interrelación; $\mathrm{A}$ = estado y $\mathrm{N}$ = entidad) y su proyección define un sistema asociado de relaciones semánticas (el significado elemental)». ${ }^{8}$

Con todo, hay también aspectos controvertidos. El último caso (clear), por ejemplo, muestra que, en las alternancias de construcciones inacusativas y transitivas, la forma básica es la configuración inacusativa, de modo que la transitiva deriva de ella y es más compleja. La morfología de las lenguas romances parece indicar un sentido contrario, ya que la variante inacusativa suele ser más compleja. Este es un indicio de un problema de más calado. Como indican Levin y Rappaport Hovav (1995), las construcciones transitivas tienen menos restricciones que las inacusativas. La consecuencia es que hay verbos transitivos que no aparecen en la variante inacusativa. Esto puede llevar a construir predicados imposibles en las lenguas.

8 Ramchand $(2003,2008)$ argumenta que si hay solo una estructura en la que se derivan las configuraciones oracionales, los procesos que Hale y Keyser incluyen en la sintaxis léxica pueden ser los que se producen en la primera fase derivativa (Chomsky 2001). De ahí su expresión "first-phase syntax». Esta es léxica solo en el sentido de que comprende combinaciones de categorías léxicas, no funcionales. 


\section{De la sintaxis al léxico}

Frente a la perspectiva lexicista, emerge un punto de vista basado en la idea de que la estructura eventiva va vinculada a la oración y se construye sintácticamente mediante categorías funcionales que tienen esa misión. Se mantiene así el principio de que la sintaxis es el único mecanismo generativo de la gramática y tiene por objeto derivar estructuras jerárquicas a partir de un número finito de elementos. Convergen en este planteamiento, de una parte, reflexiones sobre el lexicón y la interfaz léxico-sintaxis y, de otra, investigaciones sobre el papel del aspecto y de las categorías funcionales en la configuración de la oración. Las primeras van a profundizar en la idea de que las unidades léxicas (raíces o «listemas») no contienen información sintácticamente relevante y, en todo caso, son pares de expresión y contenido sin ni siquiera asignación categorial. Las segundas van a consolidar la hipótesis de que la estructura del evento es de naturaleza sintáctica y han de ser categorías funcionales las que la hagan explícita. ${ }^{9}$

\subsection{Morfología distribuida}

La morfología distribuida (Halle y Marantz 1993, 1994; Marantz 1997) es una hipótesis sobre la naturaleza del léxicón y, por tanto, de la morfología, y sobre la relación entre léxico y sintaxis. Rechaza la distinción entre derivación sintáctica y morfológica. No cabe, por tanto, hablar de procesos morfológicos o morfoléxicos y procesos sintácticos como

9 La trascendencia de la categoría Aspecto no es desconocida en la teoría sintáctica (v. especialmente Verkuyl 1972). La telicidad, fundamentalmente, forma parte de las pruebas en construcciones inacusativas o medias, por ejemplo, y en un modelo proyeccionista puede desempeñar un papel explícito en la realización de argumentos, como lo demuestra la hipótesis de la interfaz aspectual de Tenny (1994: 2) ("The universal principles of mapping between thematic structure and syntactic argument structure are governed by aspectual properties. Constraints on the aspectual properties associated with direct internal arguments, indirect internal arguments, and external arguments in syntactic structure constrain the kinds of event participants that can occupy these positions. Only the aspectual part of thematic structure is visible to the universal linking principles»). En términos generales, no son pocos los trabajos que vinculan la posición de objeto de un predicado a nociones aspectuales como telicidad (Ritter y Rosen 1998), tema incremental (Rothstein 2000), medida del evento (Tenny 1992, 1994), resultado (Borer 1998) o cantidad (Borer 2005). La consecuencia que se deduce es que los diversos tipos de eventos están determinados por su extensión y delimitación temporal. 
mecanismos distintos. En consecuencia, parte de la idea de que en la facultad humana del lenguaje solo la sintaxis tiene capacidad generativa. La sintaxis, además, no opera con elementos léxicos como tales, con su información fonológica, sintáctica y semántica. El principio de «inserción tardía» propone que los segmentos fonológicos sean insertados en nudos terminales en la interfaz perceptiva-articulatoria (Forma Fonética) mediante reglas que emparejan representaciones fonológicas y contextos de inserción especificados en términos de rasgos. No hay, por tanto, lexicón en el sentido que habitualmente tiene esta noción en la teoría gramatical. Las funciones atribuidas a este lexicón se distribuyen en varios componentes: Lexicón en sentido estricto (comprende las unidades básicas de la gramática, esto es, raíces, haces de rasgos funcionales - $\mathrm{T}, \mathrm{A}, \mathrm{V}-$ ); Vocabulario (repertorio que proporciona representaciones fonológicas para los nudos terminales de la sintaxis) y Enciclopedia (repertorio de unidades con sus representaciones semánticas). Por consiguiente, el lexicón —en sentido estricto- no contiene unidades con información sintáctica (por ejemplo, la categoría) ni semántica. Tampoco es un componente que permita generar palabras complejas. Toda la computación reside en la sintaxis. Y esta se inicia construyendo las categorías: los rasgos funcionales se combinan con raíces para formar una categoría (en el contexto de $v$, una raíz se convierte en una categoría $\mathrm{V}$, etc.).

La gramática, que quiere encuadrarse en un marco chomskiano minimista (Chomsky 1995), tiene la forma siguiente:

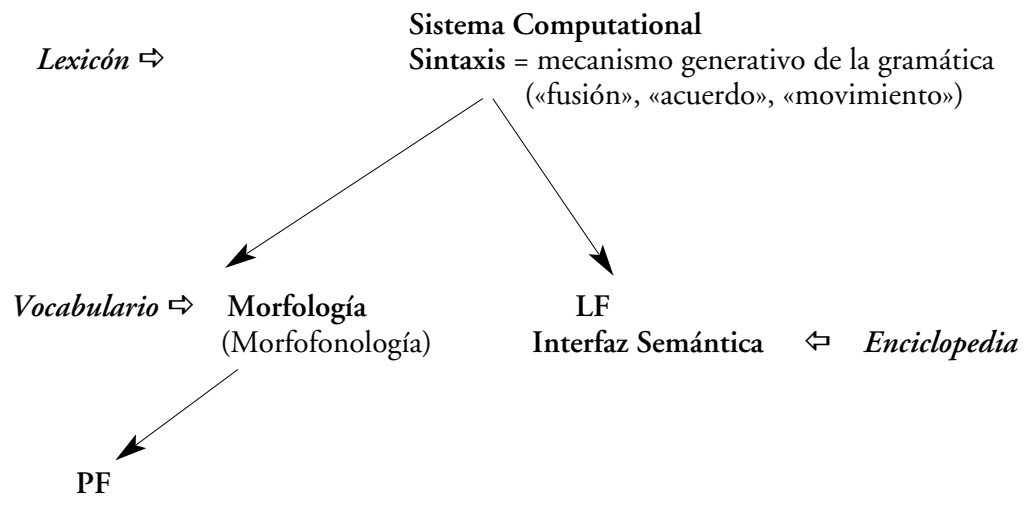

Interfaz Fonética 


\subsection{Teorías sintácticas neo-construccionistas}

La degradación del lexicón que caracteriza a los modelos neo-construccionistas tiene su origen en la hipótesis de que gran parte del significado de las unidades léxicas (el gramaticalmente relevante) es construido en la computación sintáctica de la oración. Es la solución sintacticista a dos tipos de observación: las categorías resultan de añadir a las raíces propiedades funcionales (niño es un nombre porque niñ-se combina con rasgos como NÚMERO, por ejemplo) y, con ciertos límites, las unidades léxicas pueden recategorizarse según el contexto sintáctico (Borer 2003), no la información gramatical:
a. Es leche
b. Analizaron tres leches
$N$ incontable
c. Laura ha llegado
$N$ contable
d. Es mucha Laura para ti
Npropio
N común
e. Diego pulió diamantes durante un año
$V$ actividad
f. Diego pulió el diamante en un día
$\checkmark$ realización

Por ello, Borer (2005) argumenta que las interpretaciones que el sistema conceptual-intencional atribuye a las piezas léxicas no están determinadas completamente por los rasgos que almacenan en el lexicón, sino que más bien vienen configuradas por las estructuras jerárquicas de las oraciones en las que se insertan. En los predicados, por tanto, la información eventiva no reside en el contenido de las piezas léxicas, sino en la configuración oracional en que aparecen. La proyección argumental y el comportamiento sintáctico dependen de las categorías funcionales responsables de la información eventiva que están presentes en la derivación. $\mathrm{Al}$ aceptar que la estructura del evento es la estructura sintáctica se simplifica radicalmente la teoría argumental, que ya no requiere redes de argumentos en el léxico, descomposiciones léxico-semánticas de los verbos o teorías de enlace entre argumentos y posiciones en la estructura de la oración.

Esta nueva perspectiva, en cambio, exige hacer propuestas sobre qué estructura funcional insertada encima de cada raíz asigna de modo inequívoco su categorización en la derivación, así como qué proyecciones funcionales son responsables de hacer explícito el contenido sintácticamente manipulable de una oración, por ejemplo el concerniente al tipo 
de evento y a las alternancias. Y ello teniendo en cuenta que puede variar la información que se permita a las unidades léxicas y la que se atribuya a las categorías funcionales. Tomando como objeto de examen la estructura del evento se defienden varios modelos que, en general, se apoyan en consideraciones aspectuales. ${ }^{10}$ Uno de los más desarrollados y que menos permite a la información léxica es el llamado modelo exoesquelético de Borer (1998, 2003, 2005).

Desde la perspectiva adoptada por Borer (2005) categorías funcionales como el tiempo y el aspecto (en la oración) o el número y la definitud (en el sintagma nominal) son interpretadas como variables a las que se debe atribuir rango en la derivación. ${ }^{11}$ Una categoría funcional, Evento, permite la proyección de un Sintagma Eventivo (SE) sobre la proyección del nudo Tiempo (ST) —asociado a la proyección e interpretación del argumento externo- - tiene la misión de hacer explícitas las propiedades referenciales del evento. Respecto a la delimitación del evento, hay ya tradición (Verkuyl 1972, Dowty 1979, Verkuyl 1993) en relacionar la oposición de cantidad y heterogeneidad con la de telicidad y atelicidad de los predicados y vincularla a los argumentos internos del verbo. Cuando el argumento interno carece de cantidad, se produce un predicado atélico (actividad); cuando el argumento interno posee cantidad, se da un predicado télico (realización).

10 Ya Ritter y Rosen (1998), partiendo de Borer (1994), proponen explicar el evento mediante un «originador» (que lo causa o lo promueve) y un «delimitador» (que señala el punto final) asignados mediante proyecciones funcionales dependientes de ST y SV. En Travis (2001) se opera con un sintagma eventivo (SE) por encima del SV y un sintagma aspectual (SAsp) interpolado entre las capas larsonianas (Larson 1988) del SV.

11 En la derivación siguiente

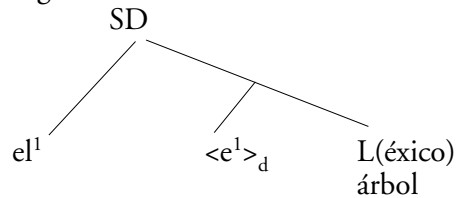

el asignador de rango a la variable $<e>$ es $e l$, un morfema libre en este caso. El índice $\left(\left\langle e^{l}\right\rangle\right)$ conecta a la variable con $e l^{l}$ y el rasgo $<e{ }^{\cdots}{ }_{d}$ determina el conjunto de sus potenciales asignadores. El valor atribuido por el asignador asigna propiedades gramaticales al listema (elemento léxico) con el que se encuentra en relación de hermandad, es decir, a árbol. De este modo $\left\langle e^{1}\right\rangle_{d}$ hace que árbol sea N. Borer (2005, vol. I, cap. 2) plantea que estas variables son necesarias para categorizar los listemas. 
En las construcciones nominales, la estructura básica es la siguiente por encima del sintagma raíz $(\sqrt{ } S \mathrm{R} \ldots):^{12}$

$\left[\mathrm{SD}\left[\# \mathrm{P}\left[\mathrm{SCl}\left[\sqrt{ } \mathrm{SR} \ldots{ }^{13}\right.\right.\right.\right.$

Aceptando que la configuración da cuenta de las distinciones de cantidad, Borer (2005) sugiere que la proyección de \#P permite hacer explícita la cantidad en las construcciones nominales. Los plurales desnudos y los nombres de masa (22) son ejemplos de formadores de nominales homogéneos, al contrario que en otros casos (23):
a. agua, plomo, tierra
b. casas, manzanas, perros
a. la casa, un agua
b. las manzanas, los perros
c. más de tres casas

En las oraciones, la estructura básica es la siguiente:

$\left[\mathrm{SE}\left[\mathrm{ST}\left[\mathrm{SAsp} / \mathrm{ScF}\left[\sqrt{ } \mathrm{SR} \ldots{ }^{14}\right.\right.\right.\right.$

El movimiento de un argumento interno con propiedades de cantidad a una proyección por encima del SV (en (24) por encima de $\sqrt{S R}$ ),

12 En diversos momentos, tanto a propósito de las construcciones nominales como de las oraciones, Borer $(2005$, vol. I, $\$ 2.1 .4$ y vol. II, $\$ 1.2 .4)$ aplica una teoría de la estructura del sintagma de proyecciones desnudas ("the theory of bare phrase structure») $y$, en consecuencia, no diferencia, por ejemplo, un estrato SV de otro V. Para facilitar la legibilidad e interpretación se emplea aquí el desarrollo habitual de la teoría de X-barra.

13 A lo largo del capítulo 6 del primer volumen de Borer (2005) se introducen dos nudos funcionales en la configuración de las construcciones nominales, \#P y SCl. Mientras que el segundo es conocido del estudio de los clasificadores (Sintagma Clase), el primero es equiparable en algunos aspectos al sintagma de número.

14 En ella, SE = Sintagma Evento, ST = Sintagma Tiempo, SAsp = Sintagma Aspecto, $\mathrm{ScF}=$ Sintagma capa Funcional, $\sqrt{ } \mathrm{SR}=$ Sintagma Raíz. El SAsp es la contrapartida en el ámbito predicativo del nudo funcional \#P y su proyección en las construcciones nominales. Por otra parte, la proyección $\mathrm{ScF}$, que domina inmediatamente el sintagma raíz (la proyección de $\mathrm{V}$, por defecto) aparece como el lugar natural para albergar el objeto del verbo (Borer 2005, vol. II: 109). El análisis de la marcación de caso en finés justifica, según Borer, la distinción de dos proyecciones funcionales por encima de $\mathrm{V}$ (la de $\operatorname{Asp}_{\mathrm{Q}} \mathrm{y}$ el $\mathrm{ScF}$ ): los objetos en construcciones télicas se realizan en caso acusativo, pero en estructuras atélicas reciben caso partitivo. Por ello, $\mathrm{Asp}_{\mathrm{Q}}$ es el nudo en cuya proyección se dará el caso acusativo y $\mathrm{ScF}$ es el sintagma que comprende el caso partitivo. 
en particular a SAsp, legitima al evento para tener divisiones cuantificables. Este nudo funcional comprende rasgos de dos clases: fonológicos (información sobre la expresión de rasgos fonológicos de Caso) y semánticos (información sobre cuantificación del evento y, en consecuencia, sobre su telicidad). ${ }^{15} \mathrm{El}$ núcleo $\mathrm{ASP}_{\mathrm{Q}}$ debe estar habilitado por algún elemento $\mathrm{Q}$ (cantidad), como cuantificadores fuertes, definidos, etc. La interpretación de Q se deduce de lo siguiente (Borer 2005: vol. II, cap. 9):

a. Cantidad: P tiene cantidad ssi P es no homogéneo

b. Homogéneo: $\mathrm{P}$ es homogéneo ssi $\mathrm{P}$ es acumulativo y divisivo

i. Acumulativo: P es acumulativo ssi $\forall x, y[P(x) \& P(y) \rightarrow P(x \cup y)]$

ii. Divisivo: $\mathrm{P}$ es divisivo ssi $\forall x[P(x) \rightarrow \exists y[P(y) \& y<x]] \& \forall x, y[P(x) \& P(y) \& y<x$ $\rightarrow P(x-y)]$

Esto es, $\mathrm{P}$ es homogéneo si y solo si para todo $x$ e $y$ la unión de $x$ e $y$ tiene también la propiedad $\mathrm{P}$ y, además, si y solo si hay un subconjunto de $\mathrm{P}$ que no es $\mathrm{P}$. Así, en agua toda partición que se haga dará como resultado agua; en cambio en más de tres casas, un subconjunto que podamos extraer ya no será más de tres casas. Estas propiedades, interpretadas en el argumento interno, dan resultados que afectan a la telicidad del evento: «atelicity is the absence of quantity structure» (Borer 2005, vol. II: 160).

La felicidad — dando por supuesto la asignación de caso acusativorequiere la proyección de un argumento interno en $\mathrm{Asp}_{\mathrm{Q}}$ por encima de V:

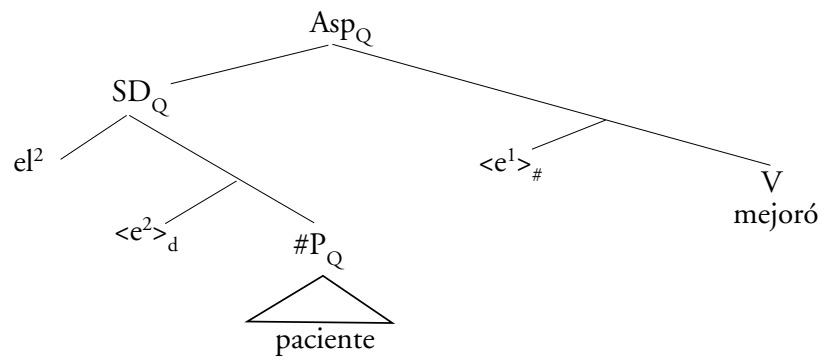

15 Sobre el papel de la telicidad en la interfaz de léxico y sintaxis en el dominio empírico del español aplicando el modelo de Borer, véase el trabajo de Pérez y Moreno (2005). 
Según cómo se construya la oración a partir de aquí puede resultar una oración inacusativa o una transitiva. El SD puede copiarse en ST y en SE, de modo que se derivará la configuración inacusativa:

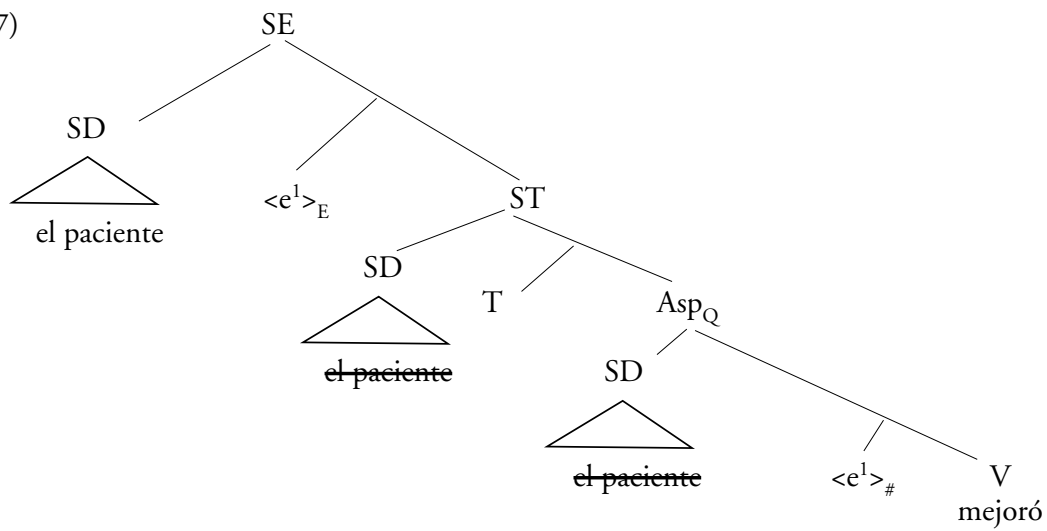

En cambio, si otro SD distinto se fusiona en ST y asciende a SE, el resultado es una estructura transitiva:

(28)

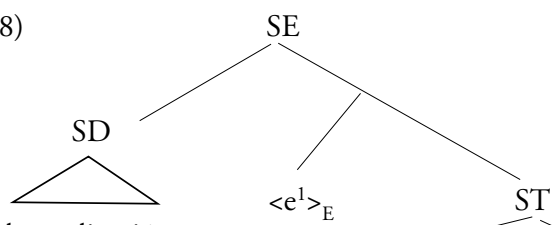

la medicación

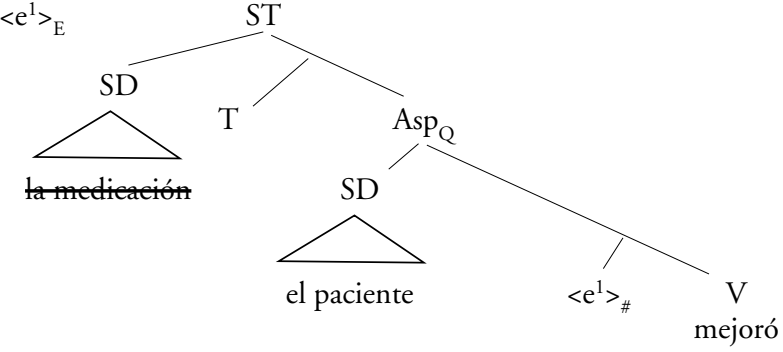

La diferencia con oraciones transitivas que denotan eventos atélicos del tipo de El gato bebió leche es que el objeto no tiene las propiedades necesarias para delimitar el evento. Pese a recibir caso, este puede interpretarse que es, como en finés, un partitivo y, además, la construcción nominal es homogénea. De ahí que se proyecte bajo un $\mathrm{ScF}$ y no bajo la 
proyección de Aspecto. En el caso de las construcciones inergativas, como El gato corrió, no hay objeto verbal (por tanto, ni asignación de caso, ni necesidad de proyección aspectual), de modo que el SV es dominado inmediatamente por ST, que es quien habilita el argumento externo. ${ }^{16}$

Los modelos neo-construccionistas, y en particular el modelo exo-esquelético de Borer, pretenden resolver problemas teóricos y empíricos. Como se ha indicado ya, desde la perspectiva teórica, las propuestas lexicistas deben incorporar varios estratos de representación y recursos de enlace con la sintaxis que los hacen complejos. En este aspecto, los modelos neo-construccionistas simplifican la teoría. Además, y referido al modelo de Borer, se defiende el punto de vista de que las variaciones estructurales entre las lenguas no provienen de los denominados parámetros, sino que dependen del modo en que las categorías funcionales se expresan en cada construcción en cada lengua o tipo de lenguas. En un dominio empírico, los retos de estos modelos, como indica Mendikoetxea (2007: 100), son los mismos que ha de abordar un modelo proyeccionista: "(i) las alternancias verbales; (ii) la 'elasticidad' o 'flexibilidad' del significado verbal y (iii) el comportamiento inestable de algunos verbos». De hecho, la flexibilidad y la polisemia verbales están en el origen de estas propuestas. Y es cierto que muestran notable capacidad explicativa de esos fenómenos. Pero también lo es que los modelos neo-construccionistas, y el modelo de Borer, por tanto, también, se muestran sobregeneradores (Demonte 2002, 2003). No toda estructura télica de Asp $\mathrm{Q}_{\mathrm{Q}}$, por ejemplo, puede insertarse indistintamente en una configuración transitiva o inacusativa (languidecer, palidecer, etc.).

\section{A modo de síntesis}

La teoría gramatical viene debatiéndose, desde hace años, entre dos opciones que giran en torno al papel del léxico en la construcción sintáctica. La idea de un léxico activo, generativo, se fundamenta en la hipótesis de que los hablantes, al aprender las piezas léxicas, aprenden más que la simple

16 Una representación de la arquitectura de distintos tipos de eventos en español puede verse en Pérez y Moreno (2005). 
asignación de etiquetas significantes a significados. Son capaces de aprender y manipular información relevante para la configuración oracional. La mayoría de los modelos que operan con un léxico de este tipo que se proyecta en la sintaxis están centrados en nociones de raíz semántica (papeles, descomposición semántica), aunque Hale y Keyser se apartan de esta línea y se centran en nociones sintácticas. La perspectiva semántico-céntrica tiene una gran capacidad descriptiva, pero ha de afrontar una notable complejidad técnica: la justificación y delimitación de sus primitivos teóricos y el problema del enlace entre información léxica y sintaxis. En el extremo opuesto, concebir el léxico como un simple repertorio de «listemas» (o distribuirlo en diversos repertorios, como hace la morfología distribuida) simplifica drásticamente la teoría gramatical. Se sustenta en la hipótesis de que lo único relevante para la capacidad de lenguaje del ser humano es el procesamiento de estructuras, la computación sintáctica. Y esta se inicia en la asignación de categorías a las raíces léxicas. Los modelos que se ajustan a esta hipótesis apuntalan su desarrollo enfatizando su capacidad explicativa. Dan cuenta de modo simple de la polisemia que caracteriza a numerosos verbos, de cómo la configuración de un objeto directo cambia la denotación de un evento (según delimite o no el predicado), de fenómenos del contexto sintáctico, en fin, que definen el comportamiento variable de los verbos. Pero esta opción supone también diluir la morfología léxica en la sintaxis y aceptar el coste de la sobregeneración de estructuras.

\section{Bibliografía}

ARAD, M. (2003): «Locality constraints on the interpretation of roots: the case of Hebrew denominal verbs", Natural Language and Linguistic Theory, 21: 737-778.

BAKER, M. C. (1988): Incorporation: A theory of grammatical function changing, Chicago, Illinois, University of Chicago Press.

- (1997): "Thematic roles and syntactic structure», en L. Haegeman (ed.), Elements of grammar, Dordrecht, Kluwer Academic Publishers: 73-137.

Belletti, A., y L. RizZi (1988): «Psych-verbs and theta-theory», Natural Language and Linguistic Theory, 6: 291-352.

BIERWISCH, M. (1988): "On the grammar of local prepositions», en M. Bierwisch, W. Motsch e I. Zimmermann (eds.), Syntax, Semantik und Lexikon, Berlín, Akademie: 1-65. 
BIERWISCH, M. (1990): «Verb cluster formation as a morphological process», en G. Booij y J. van Marle (eds.), Yearbook of Morphology, 3, Dordrecht: 173-199. Borer, H. (1994): "The projection of arguments», en E. Benedicto y J. Runner (eds.), Functional projections, vol. 17 de University of Massachusetts Occasional Papers, Amherst, Massachusetts, GSLA: 19-48.

- (1998): «Passive without Theta Grids», en S. G. Lapointe, D. K. Brentari y P. M. Farrell (eds.), Morphological Interfaces, Stanford, CA, CSLI Publications: 60-99.

- (2003): «Exo-Skeletal vs. Endo-Skeletal Explanations: Syntactic Projection and the Lexicon», en M. Polinsky y J. Moore (eds.), Explanation in Linguistic Theory, Stanford, CA, CSLI Publications: 31-67.

- (2005): Structuring Sense, Oxford, Oxford University Press, 2 vols.

BRESNAN, J. (1980): «Control and complementation», Linguistic Inquiry, 13: 343-434.

- y J. M. Kanerva (1989): «Locative inversion in Chichewa: A case study of factorization in grammar», Linguistic Inquiry, 20: 1-50.

Carter, R. J. (1976): «Some constraints on possible words», Semantikos, 1: 2766.

CHOMSKy, N. (1981): Lectures on government and binding, Dordrecht, Foris.

- (1995): The Minimalist Program, Cambridge, Massachusetts, MIT Press.

- (2001): «Derivation by Phase», en M. Kenstowicz (ed.), Ken Hale: A life in language, Cambridge MA, MIT Press: 1-52.

Demonte, V. (2002): «Preliminares de una clasificación léxico-sintáctica de los predicados verbales en español», en S. Grosse (ed.), Ex Oriente Lux: Festschrift für Eberhard Gärtner zu seinem 60 Geburstag, Valentia, Fráncfort del Main: 121-144.

- (2003): "Qué es sintáctico y qué es léxico en la interfaz entre sintaxis y léxico-semántica. Hipótesis y Conjeturas», VI Coloquio Internacional de Lingüistica Hispánica, Leipzig, 2003 [publicado en 2006: Signo y Seña, 15: 1742].

DowTy, D. (1979): Word meaning and Montague Grammar, Dordrecht, D. Reidel Publishing Company.

- (1991): «Thematic proto-roles and argument selection», Language, 67: 547619.

Fillmore, C. J. (1968): «The case for case», en E. Bach y R. Harms (eds.), Universals in linguistic theory, Nueva York, Holt, Rinehart \& Winston: 1-88.

Foley, W. A., y R. D. VAN Valin, JR. (1984): Functional Syntax and Universal Grammar, Cambridge, UK, Cambridge University Press.

GIVÓN, T. (1984): Syntax: A functional-typological introduction, vol. 1, Ámsterdam, John Benjamins. 
HALE, K., y S. J. KeYSER (1993): «On argument structure and the lexical expression of syntactic relations», en K. Hale y S. J. Keyser (eds.), The view from building 20: Essays in linguistics in honor of Sylvain Bromberger, Cambridge, Massachusetts, MIT Press: 53-109.

- y S. J. Keyser (1998): "The basic elements of argument structure», en H. Harley (ed.), Papers from the UPenn/MIT roundtable on argument structure and aspect: MIT working papers in linguistics, 32, Cambridge, Massachusetts, MITWPL: 73-118.

- y S. J. KeYSER (1999): "Bound features, merge, and transitivity alternations», en Liina Pylkkänen (ed.), Papers from the UPenn/MIT roundtable on the lexicon: MIT working papers in linguistics, 35, Cambridge, Massachusetts, MITWPL: 73-118.

- y S. J. Keyser (2000): «Conflation», en Ana Bravo, Carlos Luján e Isabel Pérez (eds.), Cuadernos de lingüistica, VII, Madrid, Instituto Universitario Ortega y Gasset: 39-76.

- y S. J. KeYSER (2002): Prolegomenon to a theory of argument structure, Cambridge, Massachusetts, MIT Press.

Halle, M., y A. Marantz (1993): «Distributed morphology and the pieces of inflection», en K. Hale y S. J. Keyser (eds.), In the view from building, 20, Cambridge, Massachusetts, MIT Press: 111-176.

- y A. Marantz (1994): «Some key features of distributed morphology», en Andrew Carnie y Heidi Harley (eds.), MITWPL 21: Papers on phonology and morphology, Cambridge, Massachusetts, MITWPL: 275-288.

JaCKendoff, R. (1983): Semantics and cognition, Cambridge, Massachusetts, MIT Press.

- (1990): Semantic structures, Cambridge, Massachusetts, MIT Press.

- (1996): «The proper treatment of measuring out, telicity, and perhaps even quantification in English", Natural Language and Linguistic Theory, 14: 305-354.

LARSON, R. K. (1988): «On the double object construction», Linguistic Inquiry, 19: 335-391.

Levin, B., y M. RAPPAPORT HOVAV (1995): Unaccusativity: At the syntax-lexical semantics interface, Cambridge, Massachusetts, MIT Press.

MarantZ, A. (1997): «No escape from syntax: Don't try morphological analysis in the privacy of your own lexicon», en Proceedings of the 21st Annual Penn Linguistics Colloquium: 201-225.

- (2001): «Words», Manuscrito, MIT.

MendikoetXeA, A. (2007): «En busca de los primitivos léxicos y su realización sintáctica: del léxico a la sintaxis y viceversa», en Teresa Cabré (ed.), Lingüistica teòrica: anàlisi i perspectivas, II, Barcelona, Universitat Autònoma de Barcelona: 55-102. 
Pérez Jiménez, I., y N. Moreno Quibén (2005): «Argumentos a favor de la centralidad de las nociones aspectuales en la interficie léxico-sintaxis: la correlación telicidad-inacusatividad en español», en J. Cuartero Otal y G. Wotjak (eds.), Algunos problemas especificos de la descripción sintácticosemántica, Berlín, Frank und Timme: 197-212.

Pesetsky, D. (1982): Paths and Categories, Tesis doctoral, MIT.

Perlmutter, D., y P. Postal (1984): «The 1-Advancement Exclusiveness Law», en D. Perlmutter y Carol S. Rosen (eds.), Studies in Relational Grammar, II, Chicago, Chicago University Press: 81-125.

Pustejovsky, J. (1991): «The syntax of event structure», Cognition, 41: 47-81.

- (1995): The Generative Lexicon, Cambridge, Massachusetts, MIT Press.

- (2006): «Type Theory and Lexical Decompostion», Journal of Cognitive Science, 6: 39-76.

Ramchand, G. (2003): First phase syntax, Manuscrito inédito, University of Oxford.

- (2008): Verb Meaning and the Lexicon: A First Phase Syntax, Cambridge, Cambridge University Press.

Rappaport Hovav, M., y B. Levin (1998): "Building verb meanings», en M. Butt y W. Geuder (eds.), The projection of arguments: Lexical and compositional factors, Stanford, California, CSLI Publications: 97-134.

- y B. LEvin (2001): «An event structure account of English resultatives», Language, 77: 766-797.

RitTer, E., y S. Thomas Rosen (1998): «Delimiting events in syntax», en M. Butt y W. Geuder (eds.), The projection of arguments: Lexical and compositional factors, Stanford, California, CSLI Publications: 135-164.

Rothstein, S. (2000): «Secondary Predication and Aspectual Structure», en Approaching the Grammar of Adjuncts, ZAS Papers in Linguistics, 17: 241264.

STOWELl, T. (1981): Origins of Phrase Structure, Tesis doctoral, MIT.

TenNy, C. (1992): «The Aspectual Interface Hypothesis», en I. A. Sag y A. Szabolcsi (eds.), Lexical matters, Stanford, California, CSLI Publications: 1-27.

- (1994): Aspectual roles and the syntax-semantics interface, Dordrecht, Kluwer Academic Publishers.

TRAVIS, L. (2001): «The L-Syntax/S-Syntax Boundary: Evidence from Austronesian», en I. Paul, V. Phillips y L. Travis (eds.), Formal Issues in Austronesian Syntax, Dordrecht, Kluwer Academic Publishers: 167-194.

Val Álvaro, J. F. (2000): «Sobre la naturaleza del conocimiento léxico», en V Jornadas de Lingüistica, Cádiz, Universidad de Cádiz: 129-171.

VAn Valin, R. D. (1993): «A synopsis of Role and Reference Grammar», en R. D. Van Valin (ed.), Advances in Role and Reference Grammar, Ámsterdam, John Benjamins: 1-164. 
Vendler, Z. (1957): «Verbs and times», Philosophical Review, 56: 143-160.

- (1967): Linguistics in philosophy, Ithaca, Nueva York, Cornell University Press.

VerkUYL, H. J. (1972): On the compositional nature of the aspects, Dordrecht, D. Reidel Publishing Company.

- (1993): A theory of aspectuality: The interaction between temporal and atemporal structure, Cambridge, Cambridge University Press.

- (1995): «Aspectual classes and aspectual composition», Linguistics and Philosophy, 2: 39-94. 



\section{NEUROLINGÜIISTICA DE LA INTERFAZ LÉXICO-SINTAXIS}

ÁNGEL LÓPEZ GARCÍA

(Universidad de Valencia)

El tema de la interfaz léxico-sintaxis constituye uno de los asuntos más controvertidos de la gramática. Es evidente que cualquier palabra no puede combinarse con cualquier otra, de manera que unos lexemas determinan a otros. Por ejemplo, un verbo como comer parece que solo puede llevar prototípicamente como complemento directo algo susceptible de ser comido, por ejemplo pan, y como sujeto un ser humano o un animal, por ejemplo, el canario, lo que conduce a la oración el canario come pan y excluye a *el sol come pan o *el canario come libertad. Como el canario y pan tienen entidad referencial independiente y comer carece de ella, se conviene en que es comer quien rige el entorno /sujeto animado ... objeto comestible/ en el que se insertan los mencionados términos el canario y pan y no a la inversa, aunque también podríamos hacer un listado de los verbos que pueden seguir a el canario como sujeto en español. Sin embargo, "prototípicamente» significa que también son posibles desviaciones que van desde lo que se suele llamar colocación hasta el modismo puro y duro. La expresión el sol se ha comido el color de la pared sería una extensión del empleo prototípico de comer y la consideramos una colocación porque la variación del sujeto es bastante limitada (el sol, la humedad, la nieve, la lluvia...) y la del objeto (el color, el barniz, el brillo, el 
tono...) también; por el contrario, la expresión no te comas el coco, en la que las posibilidades de alternancia léxica se reducen aún más, se considera un modismo.

Por lo que respecta a las relaciones de la sintaxis con el léxico las propuestas que se han hecho se ajustan a dicho patrón. La sintaxis es una combinatoria de términos y, naturalmente, para formar la oración el canario come pan hay que elegir los lexemas canario, comer y pan en algún almacén de la memoria, comprobar su compatibilidad mutua, e insertarlos en una secuencia abstracta adecuada a los mismos que sea compatible a su vez con las circunstancias de la enunciación que permiten convertir esta oración formal en enunciado:

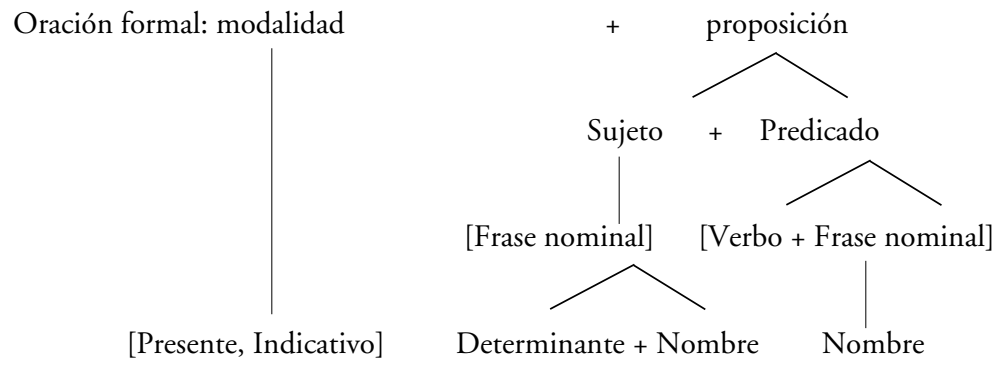

\section{Neurología del lenguaje y de otros procesos perceptivos}

No me interesa discutir aquí la corrección del análisis de arriba y si algún colega propone uno mejor lo aceptaría sin problemas. Lo que sí me interesa destacar es que los procesos descritos hasta ahora son altamente redundantes. Elegimos canario y pan porque son compatibles con comer, pero también elegimos comer porque es compatible con ellos. Además el sentido comer (el canario, pan) es compatible con el esquema formal propio de las oraciones transitivas. Los distintos modelos propuestos por los lingüistas han debatido acaloradamente estas cuestiones buscando una descripción «elegante y tan simple como sea posible». Nunca he tenido muy claro qué se debe entender por "elegancia» en este contexto, sobre todo porque el uso normal de la palabra alude a una noción básicamente social y, por lo tanto, opinable. Pero «simple» está claro lo que quiere 
decir y excluye cualquier redundancia. Sin embargo, es dudoso que este ideal de los lenguajes formales deba ser adoptado por la Lingüística. Se dice que como se trata de una ciencia natural, su modelo debe ser el de la Física, la cual se sirve de algoritmos matemáticos simples y elegantes. Pero siendo discutible que la Lingüística es una ciencia natural como la Física, no creo que nadie pueda poner en duda que su objeto de estudio, el lenguaje, es un producto de la mente adecuado a los intercambios comunicativos y, por lo tanto, que es natural en un sentido mucho más obvio e indiscutible: el biológico.

¿Cómo procede el cerebro al codificar una oración en la que se plantea la cuestión de la interfaz entre el léxico y la sintaxis, con redundancias o sin ellas? Hoy por hoy la Neurolingüística no está en condiciones de ofrecer una respuesta. Mas la Neurología como tal sí puede suministrar algunas pistas basándose en comportamientos nerviosos que no son sustancialmente diferentes del lenguaje pues también reproducen el mundo (aunque no lo comunican). Entre ellos el más sofisticado es la percepción visual, la cual constituye probablemente un antecedente evolutivo del propio lenguaje (López García 2003 y 2004).

Hace un siglo que sabemos que el córtex visual lo integran las áreas 17 y 18 de Brodmann situadas en el lóbulo occipital. Sin embargo, la percepción visual no es un proceso unitario. En la realidad las cosas son más complicadas. Brodmann se había basado en la forma de las células neuronales, básicamente piramidal o estrellada, pero solo había podido acceder a ellas post mórtem. Dichas células desarrollan una intensa actividad metabólica que la autopsia no puede revelar, con lo que se hace imposible la confirmación del axioma principal de la neurología, a saber, que a las diferencias de forma corresponden diferencias correlativas de función. El empleo de otras tinturas más modernas, en particular las que afectan a la enzima citocromo oxidasa de las mitocondrias (Horton y Hedley-Whyte 1984), ha puesto de manifiesto, primero en los monos y luego en los seres humanos, que existen hasta seis áreas visuales diferentes —V1, V2, V3, V4, V5 y V6-, de distribución menos agrupada de lo que sugieren las áreas 17 y 18 de Brodmann, pues se alarga ampliamente hasta la llamada área de asociación visual (la 19). Dos de estas áreas, V1 y V2, son generales, mientras que las otras cuatro, V3, V4, V5 y V6, están especializadas respecto al movimiento, la orientación, la longitud de onda 
y la profundidad. El área V1 envía una señal de salida a las áreas V2, V3, V4 y V5; a su vez el área V2 envía señales a V3, V4, V5 y V6: por lo tanto las áreas generales V1 y V2 deben dividir su señal antes de enviarla a sus destinos.

En cualquier caso los descubrimientos más recientes, aunque no han roto con la hipótesis de la jerarquización, la han matizado rebajando su importancia epistemológica. Hubel y Wiesel (1962) habían distinguido tres tipos de células en V1, las simples, las complejas y las hipercomplejas, tales que: las simples tienen campos receptores pequeños y sus salidas se unen en las complejas; estas tienen campos receptores más grandes; pero no tanto como los campos receptores de las hipercomplejas (situadas en el córtex de asociación visual), en las cuales convergen a su vez las salidas de las células complejas. Así se llegaba a una estructura jerárquica tanto por lo que respecta a las células como en lo relativo al campo visual al que son sensibles:

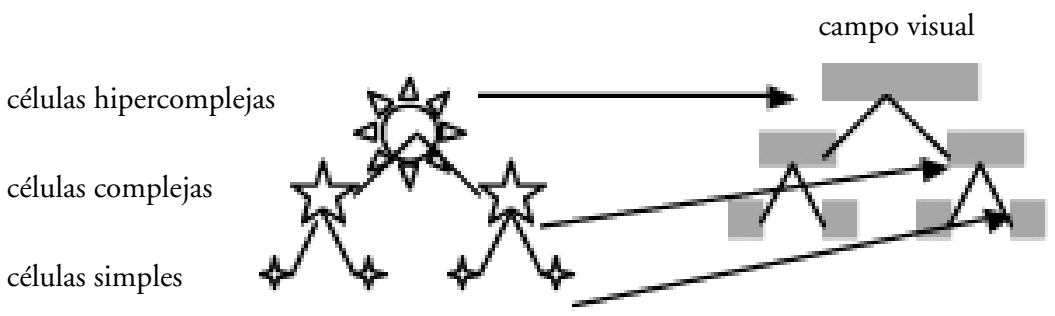

Es difícil resistir la tentación de trasladar esta estructura tan jerárquica a la organización de las cadenas lingüísticas, tal y como se expresa en nuestro árbol de dependencias sintácticas de arriba. También allí las unidades formales se agrupan según niveles y sus agrupaciones determinan unidades más grandes llamadas a agruparse a su vez. Sin embargo, las semejanzas son engañosas. Porque en el caso de la visión, junto a los aspectos composicionales señalados, hay también importantes características que revelan un aspecto distribuido de las conexiones. Lo de menos es que en la realidad los campos visuales correspondientes a cada neurona no se sitúen los unos al lado de los otros, como en el esquema, sino que más bien se superpongan parcialmente: 


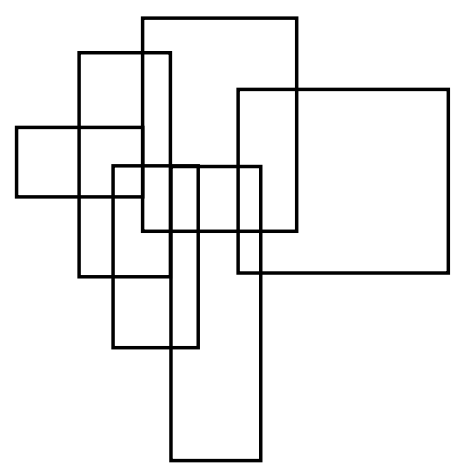

Mucho más importante es una corrección introducida por Livingstone y Hubel (1984). Hubel y Wiesel habían observado que la arquitectura metabólica del área V1 consiste en una serie de columnas - los blobsque la cruzan perpendicularmente, desde la superficie de la corteza hasta la sustancia blanca, y a las que la citocromo oxidasa tiñe de oscuro, las cuales están separadas unas de otras por regiones que tiñe mucho menos - los interblobs-. Al analizar esta estructura más detalladamente, Livingstone y Hubel advirtieron que las células de los blobs tienen propiedades funcionales diferentes de las de los interblobs: mientras que estas son selectivas respecto a la orientación e indiferentes al color, aquellas o son selectivas respecto a la longitud de onda (y por tanto al color) o son de banda ancha (luz blanca), pero, en cualquier caso, resultan indiferentes a la orientación. El resultado era revolucionario: no es que cada área visual se aplique a una modalidad categorizadora (orientación, color, profundidad, movimiento, etc.) y que luego la corteza asociativa las reúna todas, es que ya V1 explora el campo visual para todas las submodalidades proyectando varios mapas visuales a la vez. Este esquema se repite en V2 (compuesto de bandas delgadas y gruesas entreveradas con interbandas), de manera que los blobs de las capas celulares 2 y 3 de V1 conectan con las bandas delgadas de $\mathrm{V} 2$ y los interblobs de V1 con las interbandas de V2, mientras que la capa 4B de V1 lo hace con las bandas gruesas de $\mathrm{V} 2$, y desde aquí con V3 y V4. En esquema tendríamos algo parecido a esto: 

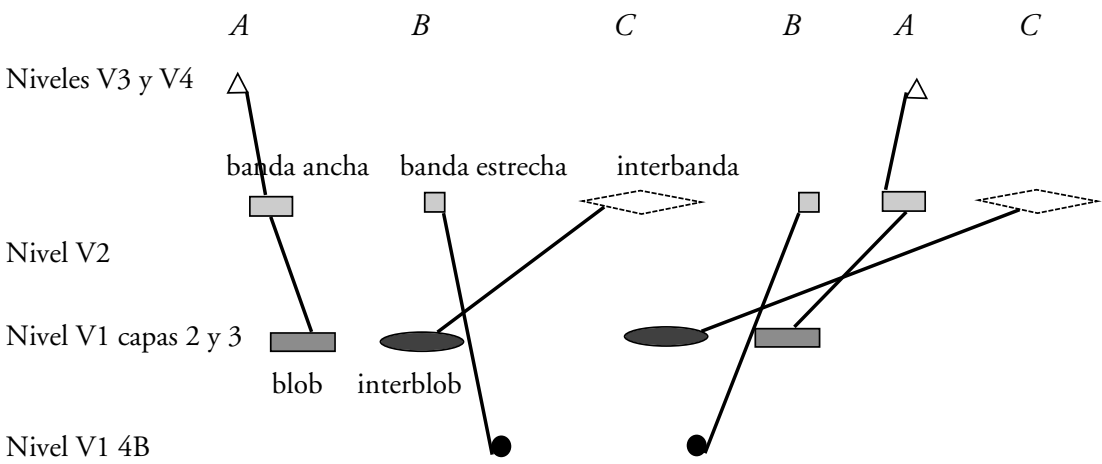

con secuencias paralelas A-A, B-B, C-C.

Desde luego, este esquema no es jerárquico, sino que implica más bien un procesamiento en paralelo, el cual se superpone al patrón composicional de las proyecciones de campo. La percepción visual participa así de la estructura composicional y de la estructura distribuida, con claro predominio de la segunda, pero sin que se pueda decir que la primera le es por completo ajena. De la misma manera, la interfaz léxico-sintaxis del lenguaje presenta también aspectos distribuidos (y por lo tanto redundancias) y aspectos composicionales, aunque en este caso la proporción relativa de los mismos es la contraria, siendo mucho más importantes las relaciones verticales de composicionalidad que las redundancias horizontales. Cuestión diferente es la de si el léxico y la sintaxis están ubicados neurológicamente en la misma área o en áreas contiguas — según sucede con las columnas de la percepción visual - o si ocupan emplazamientos distintos en el cerebro. El paralelismo que acabamos de establecer entre lenguaje y visión sugiere que el modelo de aquel siga siendo el de esta. Sin embargo, la extensión de la analogía resultaría en este caso errónea porque mientras la visión es un proceso enteramente automático, el lenguaje combina los automatismos de la sintaxis con la elección consciente del léxico.

Para entender cómo pueden funcionar neurológicamente los procesos de interfaz es preciso considerar la estructura de la memoria. Básicamente se distinguen dos tipos de memoria (Baddeley 1982), con ulteriores subdivisiones en cada uno: la memoria a corto plazo (STM: short-term 
memory) y la memoria a largo plazo (LTM: long-term memory). La primera tiene una retención de algunos segundos, la segunda retiene el material durante largos periodos que pueden durar toda la vida; sin embargo, mientras que la STM reproduce fielmente el original (permitiéndonos captar en el cerebro la imagen de un paisaje en la retina o la melodía de una canción que estamos oyendo), la LTM supone un proceso de elaboración mental que llega a modificar en ocasiones seriamente la percepción originaria. Evidentemente tanto el léxico como la sintaxis pertenecen a la memoria a largo plazo, pues el hablante acude a almacenes mnemotécnicos para elegir un determinado esquema sintáctico-semántico y unos determinados lexemas adecuados al mismo. El oyente funciona igual, descompone el mensaje en sus partes componentes, esquema y lexemas, y los recuerda en su LTM. Ello no es óbice para que la emisión concreta tenga una vigencia de segundos en las STM de ambos interlocutores cuando la oración es enunciada, como es natural.

La STM (llamada también working memory) y la LTM fueron diferenciadas mediante numerosas pruebas experimentales realizadas en laboratorios de psicología. Una determinación empírica de otro tipo permitió diferenciar dentro de la LTM la llamada memoria implícita (o no declarativa) de la llamada memoria explícita (o declarativa). Se comprobó que los pacientes, casi siempre epilépticos, a los que se les había realizado una lobotomía del lóbulo temporal, sobre todo si afectaba al hipocampo, eran incapaces de recordar hechos y conocimientos del pasado, pero sí lograban aprender habilidades nuevas, aunque no consiguiesen recordar cuándo lo hicieron. Algo similar ocurría con pacientes amnésicos o enfermos de Alzheimer, los cuales eran capaces de recordar una lista de palabras si se les facilitaba previamente la primera sílaba de cada una (priming), pero no de recordarlas con un esfuerzo consciente de memoria. Todo ello condujo a oponer dos subtipos dentro de la memoria a largo plazo, la memoria explícita y la implícita (Squire y Kandel 1999).

Por lo que respecta a la memoria explícita, sus circuitos nerviosos se conocen bastante bien (Suzuki y Amaral 1994). El hipocampo y el parahipocampo constituyen el sistema mnémico del lóbulo temporal medio, el cual pertenece al sistema límbico y, como tal, no forma parte del neocórtex. El parahipocampo o córtex rinal integra impulsos multifuncionales (visuales, acústicos y somáticos) llevando una señal única 
hasta el hipocampo donde es reelaborada por tres estratos sucesivos (el gyrus dentatus, CA3 y CA1) hasta llegar al subiculum, que reexpide la señal otra vez hacia la zona del parahipocampo y de aquí al neocórtex (LeDoux 2002):

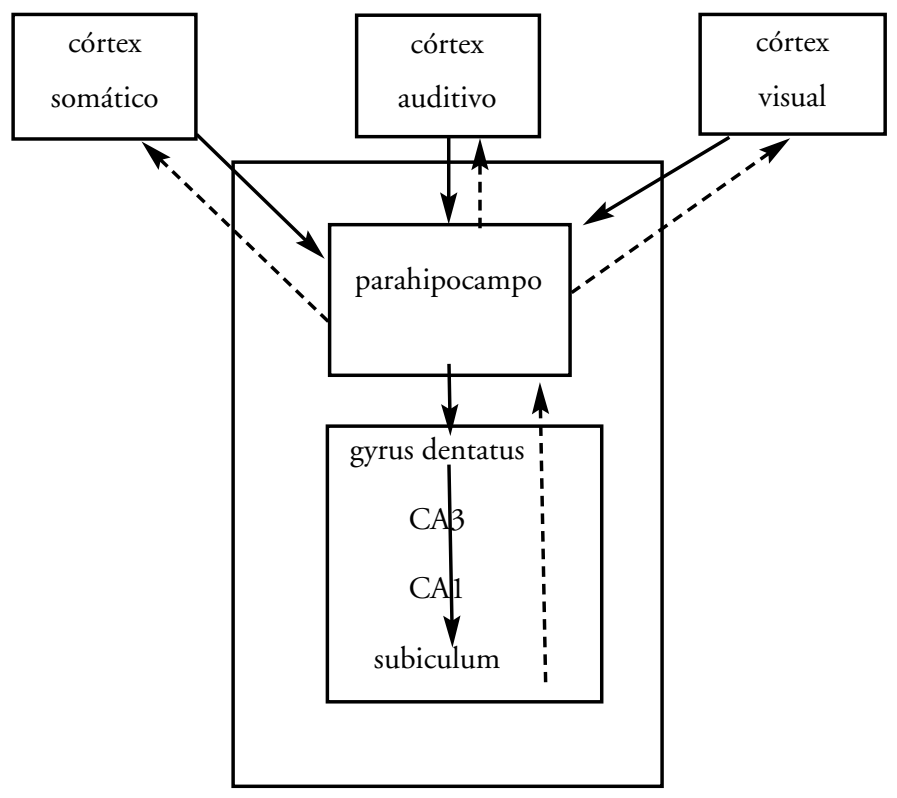

Todos estos datos proceden de investigaciones llevadas a cabo con monos para comprobar el procesamiento de estímulos visuales o sonoros y el almacenamiento memorístico de imágenes visuales o de melodías. Dicha información se ha extrapolado a seres humanos, ya que la experimentación (que suele dejar impedido al animal) está éticamente vedada como es natural. El problema es cómo proceder en el caso de los esquemas sintácticos y de los lexemas que los rellenan. Cuando adquirimos nuestra lengua materna incorporamos mentalmente los esquemas y los lexemas al mismo tiempo. Por ejemplo, la oración el cartero metió la carta en el buzón nos suministra un esquema actancial del tipo "AgenteObjeto-Lugar», un verbo meter subcategorizado precisamente como meter $_{\mathrm{Ag}, \mathrm{Obj}, \mathrm{Lug}} \mathrm{y}$ tres nombres, cartero $_{\text {Animado }}$, que es un buen candidato 
para ser Agente, carta $_{\text {inanimado }}$, que es un buen candidato para ser Objeto, y buzón lugar para guardar cosas, que constituye un buen candidato para ser Lugar. Estas subcategorizaciones tienen inicialmente una base contextual referencial, esto es, remiten al córtex visual, al auditivo y al somático, si bien con el tiempo también se establecen de manera cotextual. Toda esta información es procesada por el hipocampo siguiendo etapas similares a las del esquema de arriba y queda almacenada un tiempo en dicho sistema límbico:

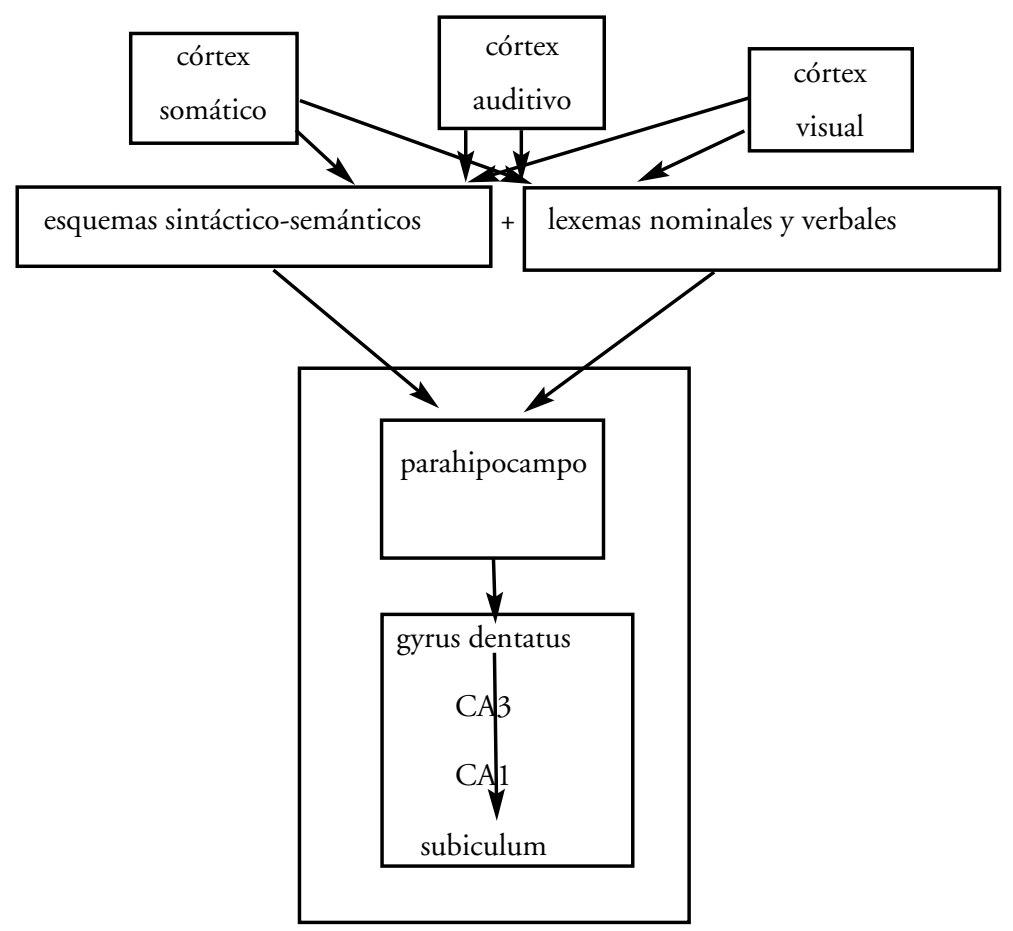

Sin embargo, los esquemas y los lexemas no siguen los mismos derroteros en la fase retroactiva. Los lexemas son conocimientos conscientes que requieren un esfuerzo cognitivo para ser recuperados, algo que no siempre se logra o que se logra en distintos grados, según la habilidad del sujeto (compárese la recuperación de un escritor con la de un hablante cualquie- 
ra) o la inspiración de cada momento. Por el contrario, los esquemas son automáticos, los vamos extrayendo del almacén de la memoria conforme los vamos necesitando y además todos los hablantes nativos de una lengua lo hacen de la misma manera. Todos los hispanohablantes poseen el mismo conjunto de esquemas sintáctico-semánticos, el cual ha podido ser inventariado en forma de paradigma (Báez San José 2002), pero no tienen la misma disponibilidad léxica por lo que respecta a los lexemas. De ahí se infiere que el subiculum retorna la información léxica hasta el neocórtex, donde queda almacenada, pero no la información relativa a los esquemas sintáctico-semánticos. Estos últimos corren la misma suerte que otras habilidades cognitivas o motoras de tipo automático, como ir en bici o reconocer el rostro de los amigos, las cuales son sustentadas por la memoria implícita y se aprenden por condicionamiento de la conducta.

Los sistemas de la memoria implícita tienen una larga historia evolutiva, mientras que el hipocampo parece ser una exaptación del procesamiento espacial (O'Keefe y Nadel 1978) exclusiva de la especie humana. Ello explicaría que el diccionario mental y su explicitación verbal en forma de palabras son privativos del hombre, en tanto que los esquemas actanciales pertenecen también a la cognición de los animales superiores, y por ello hay autores (Calvin y Bickerton 2000) que cifran el origen del lenguaje en una simbolización de dichos esquemas, si bien con ello solo explican una parte del proceso evolutivo. Los sistemas de la memoria implícita han sido estudiados en numerosos experimentos realizados con animales, algunos de los cuales carecen de hipocampo, y afectan a diversas partes del tronco cerebral y del sistema límbico. Por ejemplo, las reacciones de miedo implican el tálamo y la amígdala, el parpadeo ante los destellos luminosos se asienta en el cerebelo, etc. Las personas que padecen la enfermedad de Alzheimer experimentan tempranamente la destrucción de las neuronas del hipocampo y pierden la memoria explícita, pero conservan la implícita. Todo ello nos permite suponer que los esquemas sintáctico-semánticos o bien son procesados por el hipocampo junto con los lexemas, pero luego se almacenan en partes del sistema límbico no conectadas con la corteza cerebral, o bien se depositan directamente en estas últimas. Sin embargo, aunque los esquemas son automáticos, el hablante posee cierto control sobre ellos, pues a lo largo de su vida puede cambiar algunos o incrementar sus posibilidades variacionales. De ahí que la primera opción parezca la más razonable: 


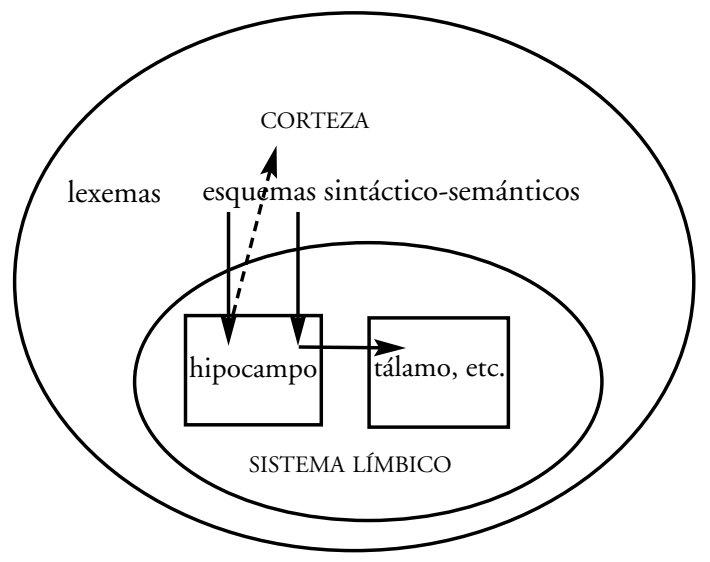

Las unidades intermedias, del tipo de las colocaciones o de los modismos, plantean una dificultad. Evidentemente se trata de esquemas oracionales, pero son de variación reducida o nula: por lo primero deberían almacenarse en la memoria explícita, por lo segundo, en la implícita. Desde luego los modismos se aprenden tal cual, como si se tratase de un lexema extenso: se trata de lexemas con forma oracional (López García 1984), por lo que parece razonable asimilarlos a las unidades léxicas y suponer que una vez procesados por el hipocampo vuelven a la corteza en calidad de esquemas de la memoria explícita:

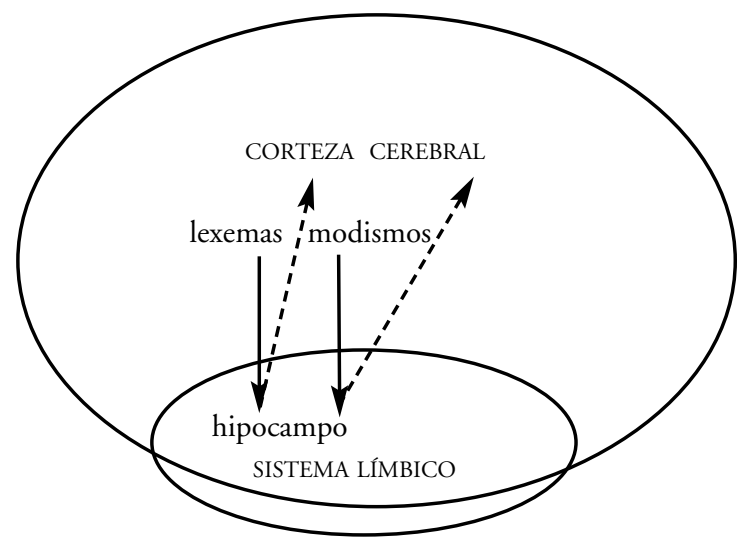


En cambio, las colocaciones se comportan más bien como los esquemas sintáctico-semánticos, solo que con restricciones en la inserción de lexemas dentro de sus huecos funcionales. Todo parece presentarse como si, en el momento del aprendizaje, los esquemas que subyacen a las colocaciones fueran almacenados en la memoria implícita, pero arrastrando consigo a unos pocos lexemas al mismo tiempo:

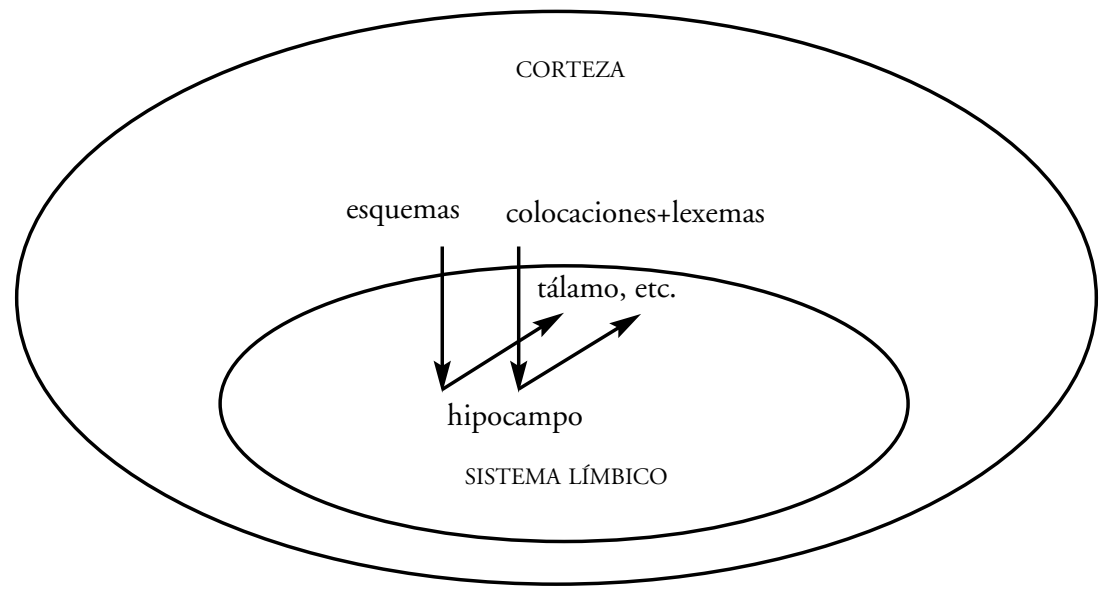

\section{Verificación experimental}

¿Qué evidencias empíricas se pueden aportar de todo lo anterior? La neurolingüística actual se sirve de varios tipos de procedimiento experimental, unos caracterizados por su resolución espacial y otros, por su resolución temporal: tomografías de emisión de positrones (PET), resonancias magnéticas funcionales (fRMI), electroencefalogramas (EEG), etc. Los dos primeros proporcionan medidas indirectas de la actividad neuronal, aunque permiten representar zonas muy amplias y se ajustan a las redes distribuidas del cerebro: el PET utiliza iones radioactivos inyectados en la corriente sanguínea, los cuales dejan trazas en una pantalla; la fRMI se basa en la reconstrucción del campo electromagnético producido por una zona del cerebro tras su interrupción. Frente a ellos, el electroencefalograma (EEG) y el magnetoencefalograma (MEG) tienen la ventaja 
de que representan medidas directas de la actividad de las neuronas con excelente resolución temporal, aunque no permitan registrar zonas amplias del cerebro y por lo general aporten localizaciones espaciales poco fiables, ya que los datos proceden de electrodos situados en el cuero cabelludo y se espera que informen sobre lo que sucede en el interior del cerebro. De ahí que modernamente se tienda a combinar ambos procedimientos.

Se han realizado experimentos recientes (Stowe et alii 2002) con las técnicas de alta resolución espacial, los cuales demuestran que en la comprensión de las oraciones entran en juego tres zonas del cerebro: la circunvolución frontal inferior izquierda (LIFG, left inferior frontal gyrus), el lóbulo temporal anterior (ATL) y la circunvolución temporal superior izquierda (LSTG). Mientras LSTG parece estar implicada en el procesamiento oracional, puesto que la actividad de dicha zona se incrementa con la complejidad sintáctica, LIFG interviene en el almacenamiento de material léxico y frástico durante la comprensión de oraciones. Por su parte ATL parece ocuparse de codificar los lexemas de cara a su integración en estructuras sintácticas. Todos estos datos se refieren a la memoria corta o memoria de trabajo, de manera que solo pueden ofrecer indicaciones indirectas sobre la memoria larga. Los experimentos demuestran la disociación del procesamiento respecto del almacenamiento. Se comprobaron cuatro hipótesis relativas al grado de complejidad creciente de ciertos procesos mentales midiendo los respectivos flujos sanguíneos. Se consideraron los siguientes parámetros: oraciones simples (OS), lista de palabras $(\mathrm{P})$, oraciones complejas (OC), oraciones muy complejas (OMC).

Hipótesis 1: La memoria léxica verbal no está estructurada, lo que supone $\mathrm{P}=\mathrm{OS}=\mathrm{OC}=\mathrm{OMC}$;

Hipótesis 2: La memoria léxica verbal está estructurada y requiere máximo gasto de almacenamiento, lo que supone $\mathrm{OS}<\mathrm{OC}<\mathrm{OMC}<\mathrm{P}$;

Hipótesis 3: Se almacena el procesamiento de estructuras oracionales: $\mathrm{P}<\mathrm{OS}<\mathrm{OC}<\mathrm{OMC}$;

Hipótesis 4: Como las oraciones simples, en las que las palabras se asocian fácilmente unas a otras, requieren poco coste de almacenamiento, el coste de las listas de palabras será mayor que el de aquellas, pero menor que el de las oraciones muy complejas, esto es: $\mathrm{OS}<\mathrm{P}=\mathrm{OC}<\mathrm{OMC}$. 
Se sometió a PET a una veintena de sujetos a los que se estimulaba con listas de palabras, oraciones simples, oraciones complejas (subordinadas sustantivas o de relativo) y oraciones muy complejas (oraciones compuestas con ambigüedades estructurales). Se usaron programas estadísticos para compatibilizar datos de diferentes personas y de respuestas a diferentes estímulos (el SPM95 del Wellcome Institute of Cognitive Neurology de Londres). Se obtuvieron los siguientes resultados: a) la hipótesis 1 y la hipótesis 2 carecen de soporte empírico, es decir, siempre aparecen diferencias en la actividad sanguínea cuando se cambian los estímulos, mas en ningún caso la simple lista de palabras produce la máxima actividad, lo cual quiere decir que el léxico no está desestructurado, pero tampoco se halla máximamente estructurado según pretende el análisis componencial clásico; b) la hipótesis 4, que muestra un incremento de actividad para los pesos combinados del almacenamiento léxico y frástico, se cumple en la zona LIFG; c) la hipótesis 3, que supone un incremento de la actividad conforme se complica la estructura sintáctica, se cumple en la zona LSTG. En resumen, anatómicamente es posible diferenciar dos zonas de la memoria verbal de trabajo, la de complejidad sintáctica, correspondiente a LSTG (áreas 21 y 22 de Brodmann) y la de memoria léxico-frástica (áreas 44 y 45 de Brodmann):

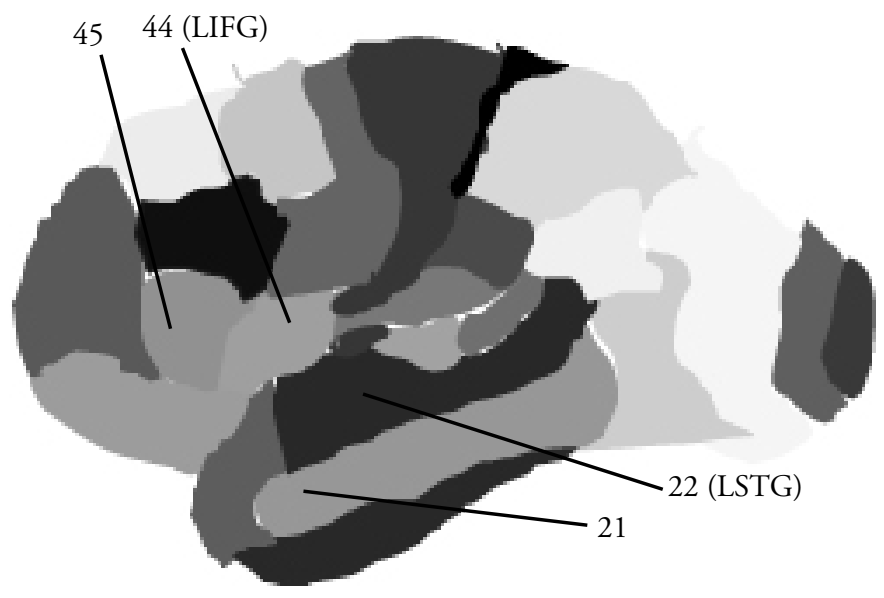


Esto se corrobora mediante las técnicas basadas en la detección de mínimas oscilaciones temporales en la actividad eléctrica. Cualquier acontecimiento, ya sea sensorial (un olor, un ruido, una luz) o puramente mental (un deseo, un pensamiento), provoca la acción concertada de miles de neuronas. Como normalmente coexisten muchas respuestas simultáneas ante los datos del mundo, es imposible aislar una en concreto (la red eléctrica neuronal que aparece al ver un objeto, ¿es debida a su forma, a su brillo, a su color, a lo que nos recuerda, a que nos da miedo...?). Pero cuando el estímulo se repite, la señal emerge del ruido de fondo como una variación de voltaje a lo largo del tiempo entre electrodos aplicados al cráneo, la cual es simultánea a la emisión del estímulo. El EEG (Kutas y Van Petten 1994) consiste en una curva continua, que se manifiesta como una serie de máximos y mínimos por debajo - positivos - o por encima - negativos - de la línea de base y que resulta de corrientes post-sinápticas en las dendritas apicales de las células piramidales del neocórtex. Cuando dos registros EEG ligados a dos condiciones experimentales específicas difieren notablemente entre sí, se entiende que las actividades mentales subyacentes a dichas condiciones lo hacen igualmente. Un ejemplo de lo anterior sería el componente N400 utilizado para medir violaciones semánticas en varias lenguas (inglés, español, francés, alemán, holandés y japonés). Cuando los sujetos del experimento oyen una secuencia en la que se ha violado alguna restricción semántica (tomo café con leche ${ }^{*}$ perro, p. ej.), la curva punteada del ERP muestra, a los 400 milisegundos, una singularidad (un mínimo negativo, en este caso) que la aleja de la curva continua característica de las secuencias sin violaciones. La amplitud de $\mathrm{N} 400$ es inversamente proporcional a la expectativa semántica (close probability):

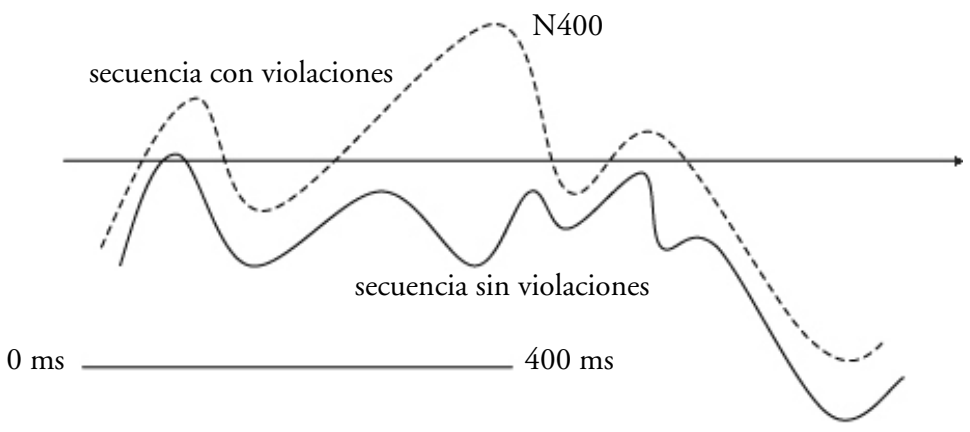


También las violaciones sintácticas pueden detectarse con ERP. Aparecen típicamente en el componente P600, es decir, las revela una singularidad positiva a los 600 milisegundos del comienzo del enunciado (Münte y Heinze 1994):

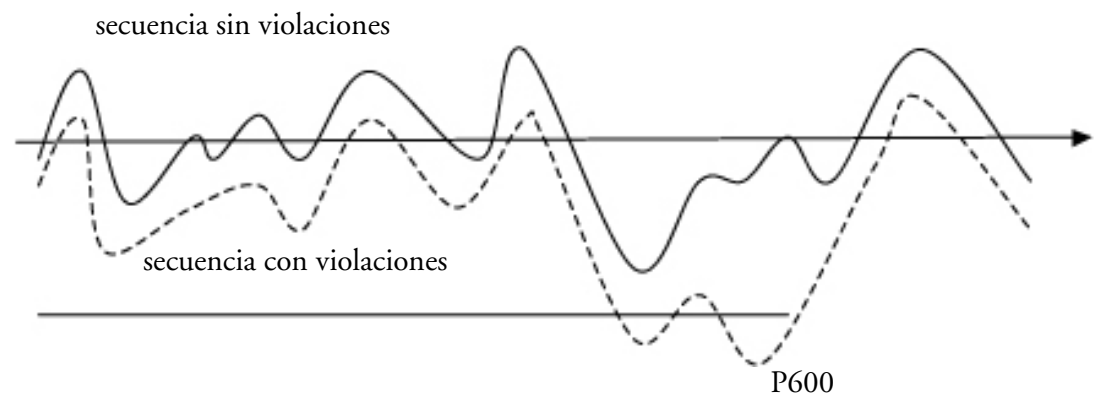

$0 \mathrm{~ms}$

$600 \mathrm{~ms}$

Sin embargo, no debe creerse que la ERP avala necesariamente una visión modularista. Lo único que refleja el contraste de N400 con P600 es que el procesamiento léxico-semántico (N400) implica (Osterhout y Holcomb 1992) redes neuronales diferentes de las que se ponen en juego en el procesamiento sintáctico (P600), pero no que cualquiera de ellas sea específica del lenguaje. En cuanto al procesamiento léxico-semántico, se produce normalmente en situación contextual o cotextual, movilizando redes distribuidas que también aparecen en presencia de los referentes de la secuencia: en realidad, la red sináptica que subyace a la palabra manzana no difiere demasiado de la que se activa al ver, oler, etc., una manzana. En cuanto al procesamiento sintáctico, el componente P600 aparece igualmente cada vez que algo inesperado reclama nuestra atención.

Más difícil de probar experimentalmente es el almacenamiento diferenciado del léxico en la corteza y de los esquemas sintáctico-semánticos en la memoria implícita larga del sistema límbico, pues este último no puede ser detectado por los ERP. Para obviar este inconveniente se acude a filtros digitales que permiten obtener potenciales lentos, los cuales se desarrollan a todo lo largo de la secuencia. Entre estos potenciales destaca una lenta positividad frontal que podría representar una especie de mode- 
lo mental de la oración (es decir, un esquema sintáctico-semántico) susceptible de integrar la huella de los lexemas en memoria corta (King y Kutas 1995):

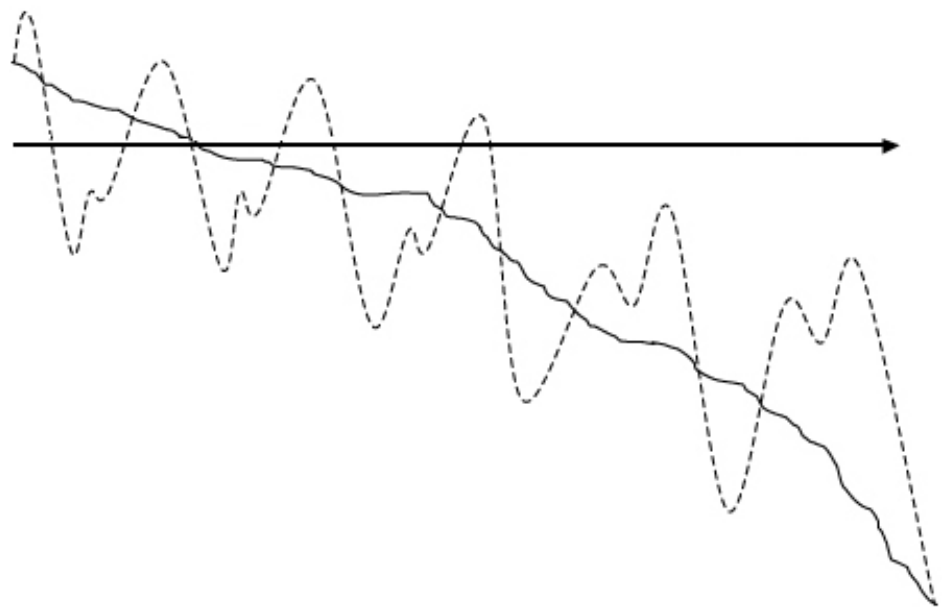

¿Se trata de un mero efecto formal, derivado de la utilización del filtro, o la línea continua descendente representa una actividad eléctrica real relativa a las conexiones que enlazan con la memoria implícita? Una confirmación de este último supuesto parece hallarse en el lenguaje de los afásicos. Sabemos que buena parte de sus déficits sintácticos son debidos a un deterioro genérico de la memoria de trabajo (Miyake, Carpenter y Just 1994). Sin embargo, como ha notado Carlos Hernández (2006: 140), dicho déficit no afecta al léxico y a las construcciones sintácticas por igual. Lo normal es que se reduzca la longitud de los esquemas configuracionales y también su número, esto es, que se utilicen menos esquemas sintáctico-semánticos de la memoria implícita. Ello parece sugerir que más que la memoria de trabajo — que no es específica del lenguaje y debería verse afectada igualmente en otros tipos de percepción- lo que resulta afectado en la afasia es el sistema neuronal de conexión entre la memoria de trabajo y la memoria implícita. Por eso, una característica del discurso afásico la constituyen las estereotipias, que son fragmentos de lenguaje que surgen cuando el paciente intenta hablar. Veyrat y Serra (2002) han mostrado su similaridad con el discurso repetido, al que per- 
tenecen las colocaciones: ello torna bastante plausible la hipótesis de arriba en el sentido de que tanto las colocaciones como los esquemas se almacenan en la memoria implícita.

\section{La categorización desde el punto de vista neurolingüístico}

Un aspecto que no suelen tratar los estudios de neurolingüística es la forma en que se produce la categorización de los contenidos lingüísticos de la memoria. No obstante, este asunto ha reclamado reiteradamente la atención de los psicolingüistas y, por supuesto, la de los semantistas, si bien sus propuestas carecen de contrapartidas neurológicas. Estos modelos suelen ser de tipo lógico, siguiendo la estela de Aristóteles (Collins y Quillian 1969), y han sido muy criticados desde la escuela de prototipos (Kintsch 1980), aunque tampoco aquí se llegue a adoptar una postura neurológica. En realidad el problema de la categorización de los contenidos de la memoria es el primer asunto del que se ocupó la antigüedad. Como es sabido, los retóricos diferenciaban una serie de loci o lugares de la memoria a los que el orador debía acudir a la hora de construir un argumento y que Quintiliano (Institutio Oratoria, V, 10) resume en el célebre hexámetro: quis, quid, ubi, quibus auxiliis, cur, quomodo, quando ("quién, qué, dónde, con qué, por qué, cómo, cuándo»). El inventario oscila ligeramente en otros tratadistas (algunos incluyen cuál, cuánto y excluyen por qué, con qué, por considerarlos variantes de qué) y reaparece modernamente en las famosas $w$ - (who, whom, what, where, when, etc.) del periodismo. Básicamente se distinguen tres tipos de noción: escalares, que son valores relativos estáticos situados en un eje, cuantores, que son valores absolutos, y vectores, que son valores relativos orientados hacia el yo a lo largo de un eje de animación creciente que va desde las cualidades abstractas hasta las personas pasando por las cosas. La importancia de los escalares Tiempo y Espacio, de los cuantores Pluralidad y Discriminación y de los vectores es capital, pues cualquier expresión lingüística se sitúa respecto a ellos. Estos factores se dan, por supuesto, en la oración simple concebida como una escena del mundo:

alguien hace algo de alguna manera alguna vez en algún lugar

y es a través de esquemas actanciales pragmáticos como la especie humana los incorporó al lenguaje, seguramente como una exaptación de hábi- 
tos pragmáticos de naturaleza social. Pero desde allí han irradiado a todos los dominios de la gramática. Para que el lector pueda hacerse una idea de la fecundidad de estos valores cognitivos (Temporal, Local, Pluralidad, Discriminación y el vector Introspectivo de cercanía al hablante) en el lenguaje, reproduzco el esquema general de subcategorización de las partes de la oración, así como los subesquemas del nombre propio, del verbo y de los determinantes en la lengua española (López García 1998):

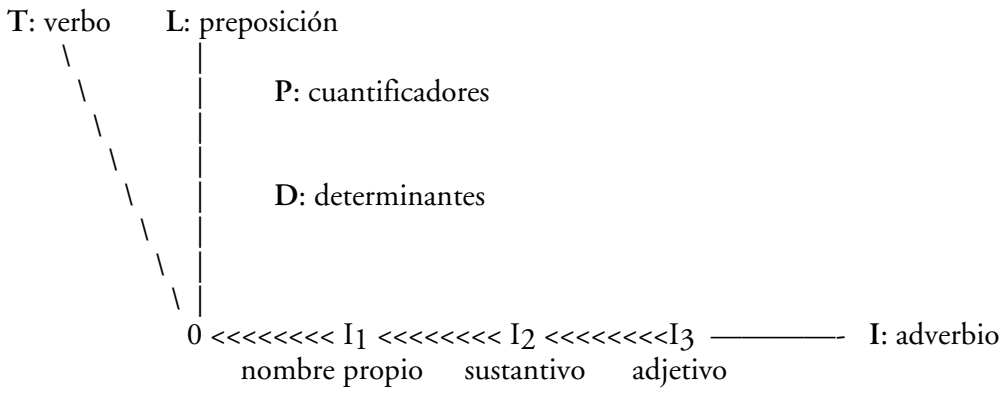

$\mathrm{T}$ : fechas L: topónimos
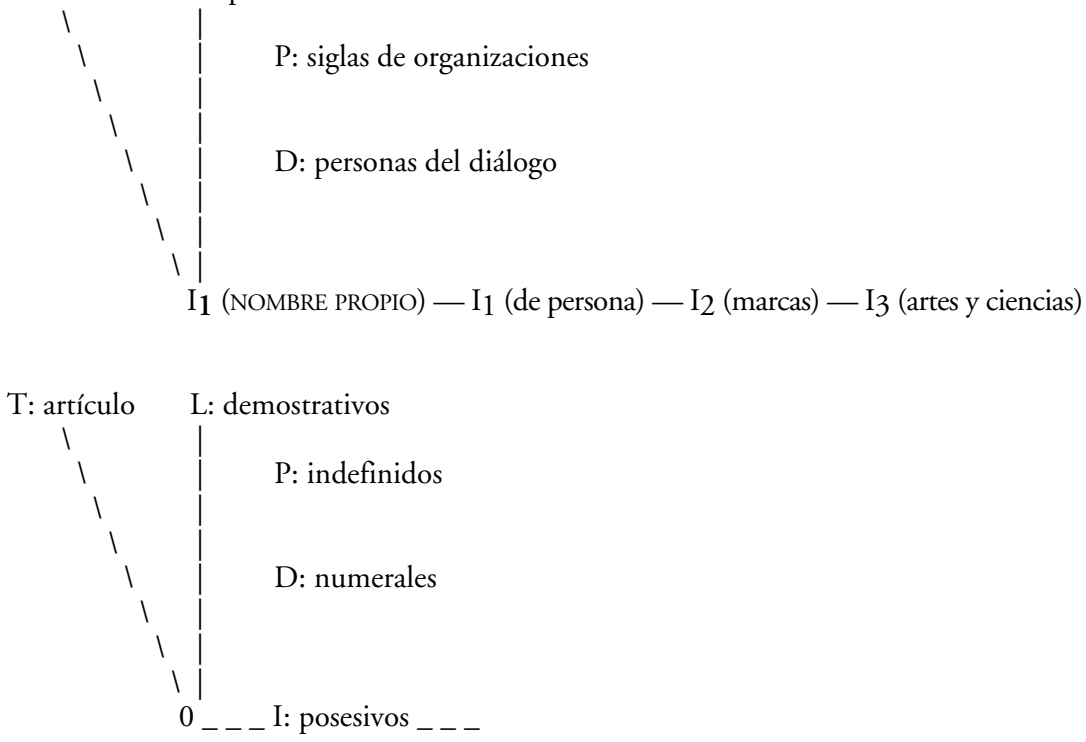


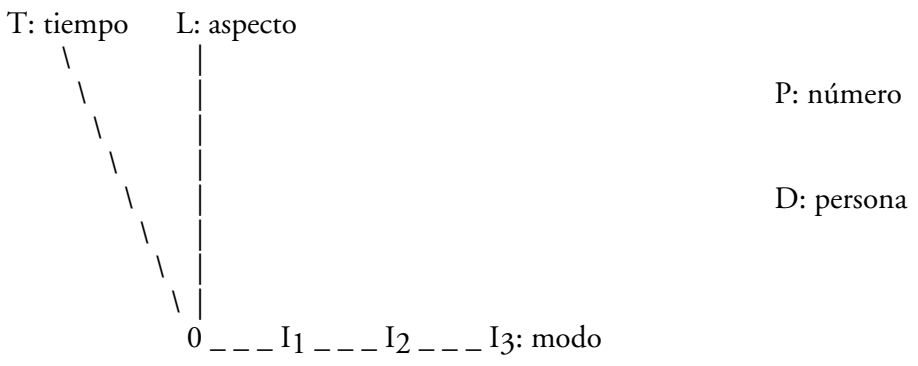

La notable recurrencia de este sistema de categorización demuestra que la información gramatical almacenada en la memoria implícita del sistema límbico realmente se estructura conforme a dicho patrón. Pero no solo la memoria implícita automatizada. La memoria explícita de la corteza, que es un sistema abierto del que nos servimos para manipular el léxico, también se estructura de la misma manera. Esto se advierte claramente cuando se considera el inventario de sufijos derivativos del español, por ejemplo los de formación nominal, que se subclasifican como (López García 2002):

- Afijos locativos, entre los que destacan los sufijos - dero (lavadero) y -ería (frutería) y los prefijos entre-(entreacto) y ante- (antebrazo).

- Afijos temporales, como los prefijos pos- (posguerra) y pre- (prelavado).

- Afijos de agente, tan frecuentes como -ero (carpintero), -ista (chantajista), -ante (representante), -dor (consumidor).

- Afijos de instrumento, como -dor (aspirador).

- Afijos de acción y efecto, como -ado (lavado), -aje (aterrizaje), -ción (consolidación), -dura (rozadura), -ido (silbido), -miento (enriquecimiento), -sión (extorsión), postverbales en -a (tala), -e (toque), -eo (mareo), -o (costo).

- Afijos de objeto, como -aje (forraje), -dura (armadura), -mento (armamento).

- Afijos de cualidad abstracta, como -ancia (vagancia), -dad (parquedad), -ería (brujería), -ez (solidez), -ismo (socialismo), -ura (compostura).

- Afijos colectivos en -al (barrizal), -eda (rosaleda).

- Afijos negativos, como anti- (anticiclón), contra- (contraespionaje), los cuales reparten el universo semántico del que se ocupan en una noción y su contraria. 
Lo cual conduce a nuestro conocido sistema de ejes de abajo:

T: temporales $\quad \mathrm{L}:$ locales

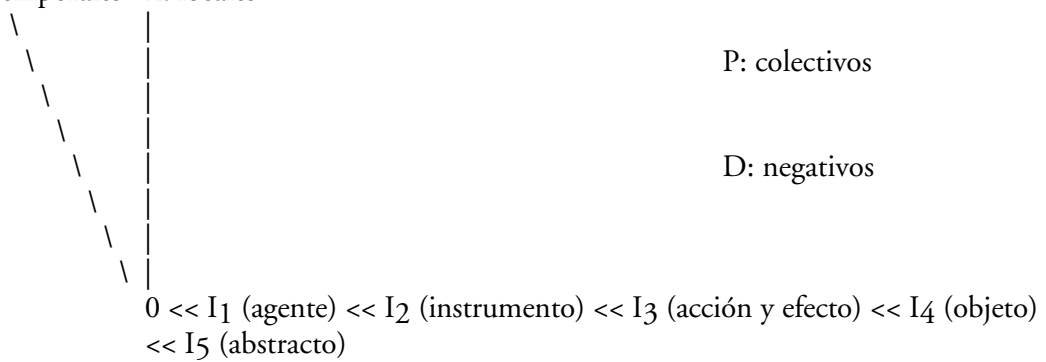

Una situación parecida se registra en el dominio categorial de la adjetivación. Así tenemos:

- Afijos gentilicios, que señalan la procedencia local del elemento al que modifica el adjetivo: -aco (egipciaco), -ano (zaragozano), -eño (caraqueño), -és (muniqués), -i (ceutí), -ino (alicantino), -ita (vietnamita), -ol (español), etc.

- Afijos procesuales como -ble, el cual señala la capacidad activa o pasiva de desarrollo de un proceso: responsable («capaz de responder»), temible («susceptible de ser temido»). Al mismo grupo pertenecen los activos -ante (amenazante: "que amenaza») y -dor (abrumador: "que abruma»), y el mediopasivo -izo (enamoradizo: "que se enamora con facilidad»).

- Afijos personales, con los que se señalan preferentemente cualidades propias de personas o afiliación a sus ideas, como -esco (quijotesco), -il (varonil), -ista (felipista).

- Afijos objetuales, los cuales se aplican más bien al señalar las cualidades de las cosas: -al (estival), -istico (futbolístico), y los numerosos adjetivos de color (grisáceo, rojizo, amarillento).

- Afijos abstractivos, los cuales se aplican a nociones abstractas, como -istico (novelístico), -orio (sucesorio).

- Afijos abundanciales como -oso (mucilaginoso).

- Afijos negativos, como a-(anaerobio), in- (inútil).

Se llega así para la formación de adjetivos a un espacio cognitivo similar al de las nominalizaciones: 
$\mathrm{T}$ : procesuales L: gentilicios

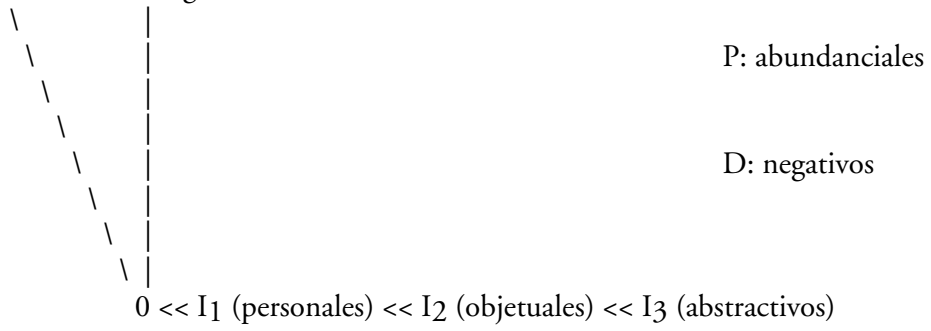

Las estructuras de subcategorización en que se basan los loci aparecen, pues, indistintamente por referencia a la oración en su conjunto, en relación con la frase (como clases o subclases de palabras) o aplicadas a la formación léxica. Las dos primeras situaciones pertenecen a la memoria implícita, la última a la memoria explícita. También se incluye en este mecanismo mnemotécnico creativo la propia estructuración semántica del léxico. Se comprueba (López García 2007) que las equivalencias sinonímicas dentro de una misma lengua y las equivalencias traductológicas entre dos lenguas distintas están organizadas precisamente así; por ejemplo, el español traduce los siguientes términos de otras lenguas con dos posibilidades que son seleccionadas por los contextos entre paréntesis:

\begin{tabular}{|c|c|c|c|c|c|c|c|}
\hline \multicolumn{2}{|c|}{ (al.) Faul } & \multicolumn{2}{|c|}{ (it.) quartiere } & \multicolumn{2}{|c|}{ (fr.) salué } & \multicolumn{2}{|c|}{ (fr.) ecrasé } \\
\hline $\begin{array}{c}\text { vago } \\
\text { (genérico) }\end{array}$ & $\begin{array}{c}\text { perezoso } \\
\text { (específico) }\end{array}$ & $\begin{array}{l}\text { barrio } \\
\text { (mayor) }\end{array}$ & $\begin{array}{c}\text { piso } \\
\text { (menor) }\end{array}$ & $\begin{array}{c}\text { saludado } \\
\text { (meta) }\end{array}$ & $\begin{array}{c}\text { proclamado } \\
\text { (inicio) }\end{array}$ & $\begin{array}{c}\text { despachurrado } \\
\text { (físico) }\end{array}$ & $\begin{array}{c}\text { abatido } \\
\text { (psíquico) }\end{array}$ \\
\hline \multicolumn{2}{|c|}{ (al.) schlicht } & \multicolumn{2}{|c|}{ (ing.) $m o p$} & \multicolumn{2}{|c|}{ (ing.) involvement } & \multicolumn{2}{|c|}{ (fr.) lucarne } \\
\hline $\begin{array}{l}\text { escueto } \\
\text { (habla) }\end{array}$ & $\begin{array}{c}\text { modesto } \\
\text { (no habla) }\end{array}$ & $\begin{array}{l}\text { fregona } \\
\text { (objeto) }\end{array}$ & $\begin{array}{c}\text { melena } \\
\text { (animado) }\end{array}$ & $\begin{array}{c}\text { enredo } \\
\text { (negativo) }\end{array}$ & $\begin{array}{c}\text { compromiso } \\
\text { (positivo) }\end{array}$ & $\begin{array}{l}\text { tragaluz } \\
\text { (exterior) }\end{array}$ & $\begin{array}{c}\text { buhardilla } \\
\text { (interior) }\end{array}$ \\
\hline \multicolumn{2}{|c|}{ (finés) tarkkuus } & \multicolumn{2}{|c|}{ (ing.) purge } & \multicolumn{2}{|c|}{ (port.) virar } & \multicolumn{2}{|c|}{ (vasco) guti } \\
\hline $\begin{array}{l}\text { puntualidad } \\
\text { (temporal) }\end{array}$ & $\begin{array}{c}\text { exactitud } \\
\text { (local) }\end{array}$ & $\begin{array}{l}\text { purgante } \\
\text { (concreto) }\end{array}$ & $\begin{array}{l}\text { ourga política } \\
\text { (abstracto) }\end{array}$ & $\begin{array}{c}\text { voltear } \\
\text { (eventual) }\end{array}$ & $\begin{array}{c}\text { volver } \\
\text { (estable) }\end{array}$ & $\begin{array}{c}\text { poco } \\
\text { (cantidad) }\end{array}$ & $\begin{array}{l}\text { precario } \\
\text { (cualidad) }\end{array}$ \\
\hline
\end{tabular}

Como se puede ver, [concreto/abstracto] y [animado/objeto] se combinan en un vector que significa alejamiento progresivo del centro de coordenadas YO (el que habla). A su vez, [local] y [temporal] dan lugar a sendos ejes situacionales en el interior de los cuales se establecen oposiciones dinámicas, como [inicio/meta], estáticas, como [interior/exterior], o aspectuales, como [eventual/estable]. Además, hay dos cuantores, el de 
discriminación y el de pluralidad, los cuales están organizados primariamente por [cualidad] y [cantidad] y de manera subsidiaria por [positivo/negativo] en el primer caso y por [no reforzado/reforzado] en el segundo. Es decir, que la propia estructuración del léxico reproduce internamente el sistema de ejes que estamos considerando.

La pregunta que ahora nos formulamos es si existe alguna evidencia empírica que permita justificar la omnipresencia de este sistema de ejes desde el punto de vista neurológico. Las teorías neurológicas que pretenden dar cuenta de la organización del conocimiento son básicamente de tres tipos:

a) Hipótesis basadas en el canal, las cuales suponen que el principio de organización fundamental es el canal o modalidad sensomotora a través del cual se adquirió la información. Por ejemplo, la forma alargada y puntiaguda de un destornillador se almacenaría siguiendo los principios del módulo visual, pero su utilidad, la de atornillar, correspondería almacenarla a un módulo funcional motor. Hay autores que practican un reduccionismo biológico consistente en identificar la red sensomotora con el significado (Pulvermuller 2001) y otros que los diferencian (Crutch y Warrington 2003) porque este último no se ve afectado por las lesiones de aquella.

b) Hipótesis basadas en el dominio conceptual, las cuales suponen que el principio de organización fundamental es la categoría semántica (Kanwisher 2000). Por ejemplo, los seres humanos y los animales se representarían y procesarían mediante redes neurales diferentes, las cosas igualmente, etc. Estas hipótesis son similares al modelo de los loci, si bien este es retórico y lingüístico y aquellas son neurológicas.

c) Hipótesis basadas en rasgos, las cuales suponen que el conocimiento almacenado en la memoria se estructura en forma de rasgos porque la exposición diferenciada de los conceptos a las lesiones cerebrales está en función de las propiedades estadísticas (frecuencia, dispersión, etc.) de los rasgos que integran dichos conceptos (Tyler y Moss 2001).

Los estudiosos no se ponen de acuerdo a la hora de dirimir entre estas tres hipótesis. Las pruebas empíricas disponibles han registrado unos cien pacientes con DSCE (déficits semánticos de categoría específica) para los seres vivos y unos veinticinco pacientes con DSCE para objetos 
inanimados: en principio esta diferencia se puede justificar desde cualquiera de las tres hipótesis, pero la que mejor se acomoda a ella es la segunda (Caramazza y Shelton 1998), porque la divergencia categorial (entre el recuerdo de seres vivos y el de seres inanimados, por ejemplo) no está correlacionada con deficiencias de un determinado canal frente a otro ni es atribuible a un solo rasgo dado que los rasgos son compartidos por varios conceptos (/+animado/ sería común a seres humanos y a animales, /+viviente/, a animales y a plantas, etc). Sin embargo, ello no excluye las otras dos hipótesis: lo más plausible es suponer que, en efecto, el conocimiento está organizado en el cerebro por dominios específicos - es decir, conforme a los loci-, aunque bien puede cada concepto tener diferenciados sus componentes de acuerdo con el canal a través del cual le llegaron o participando de rasgos redundantes distribuidos en redes neuronales (Caramazza y Mahon 2003).

Ello traslada el problema a la memoria de trabajo, es decir, al momento de la adquisición. Se han realizado experimentos con simios (Fuster 1999) para comprobar cómo se producen los procesos de reconocimiento visual. El córtex visual comprende el lóbulo occipital y la parte inferior del lóbulo temporal; las lesiones de este último provocan varios tipos de agnosia visual. Durante el reconocimiento visual se activan las células del lóbulo temporal inferior a instancias de una combinación de estímulos externos (sensoriales) e internos (mnémicos e intencionales). Fuster realizó un experimento consistente en enseñar cuatro botones de distintos colores a un simio al que se había enseñado 15 segundos antes uno de estos colores: el resultado fue que reconocía dicho color con más facilidad. Mediante electrodos instalados en el lóbulo temporal inferior se pudo comprobar que esto era debido a que ciertas neuronas - las llamadas células de la memoria - permanecían activas durante un cierto periodo después de dispararse. Lo notable es que la activación de dichas células solo se mantiene cuando el estímulo debe guardarse en la memoria de trabajo para realizar la prueba, esto es, cuando la memoria larga indica que es necesario. Ello sugiere que existe un almacén permanente de la memoria corta en el lóbulo temporal inferior, el cual es compartido por la memoria larga y permite estar preparado para las tareas requeridas. Esto no sucede solo en el córtex visual, pues Fuster ha descubierto células de la memoria parecidas en el córtex prefrontal y que se destinan a prevenir los comportamientos motores. 
¿Cuáles son los caminos de acceso de la información a la memoria de trabajo? Los dos más obvios son el visual y el auditivo, que ya reconocía Baddeley en su clásico estudio sobre el tema (Baddeley 1986): ${ }^{1}$ parece razonable imaginar que el canal visoespacial, que opera en el ámbito de la simultaneidad, es responsable de la acuñación del locus mnemotécnico correspondiente al eje escalar Local y que el canal auditivo, basado en la sucesividad, sustenta el locus mnemotécnico correspondiente al eje escalar Temporal. A ellos habría que añadir el canal motor encargado de la coordinación de las acciones intencionales como agarrar un objeto con la mano, lanzarlo lejos, etc.: la acción motora (Wilson 1998) supone siempre una diferenciación entre el agente y los objetos, por lo que resulta un candidato razonable para fundamentar el locus mnemotécnico del vector de Intencionalidad.

La ubicación cortical de estos tres canales se aprecia en la figura siguiente donde la neuroimagen recoge diferenciadamente la actividad cerebral cuando una palabra se lee (visual), se oye (auditivo) o se pronuncia (motor):

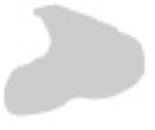

oír

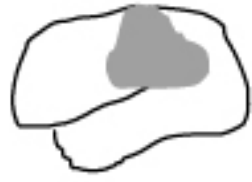

pronunciar

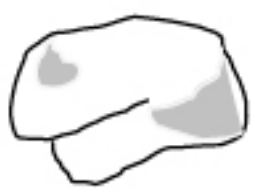

leer

\section{Bibliografía}

BADdeley, A. (1982): Your Memory, Nueva York, MacMillan.

- (1986): Working memory, Oxford, Oxford University Press.

BÁez SAn José, V. (2002): Desde el hablar a la lengua. Prolegómenos a una teoría de la sintaxis y la semántica textual y oracional, Málaga, Âgora.

CAlvin, W., y D. BiCKerTON (2000): Reconciling Darwin and Chomsky with the human brain, Cambridge, MIT Press.

1 Modernamente la memoria corta se interpreta más bien como un mecanismo de mantenimiento de la atención, pero a los efectos de la presente exposición ello es indiferente. 
Caramazza, A., y B. Z. MaHON (2003): "The organization of conceptual knowledge: the evidence from category-specific semantic deficits», Trends in Cognitive Sciences, 7: 325-374.

- y J. Shelton (1998): «Domain-Specific Knowledge Systems in the Brain: animate-inanimate distinction", Journal of Cognitive Neuroscience, 10-1: 1-34.

Collins, A. M., y M. R. Quillian (1969): «Retrieval time from semantic memory", Journal of Verbal Learning and Verbal Behavior, 8: 240-247.

CRUTCH, S. J., y E. K. WARRINGTON (2003): «The selective impairment of fruit and vegetable knowledge: a multiple processing channels account of finegrain category specificity", Cognitive Neuropsychology, 20: 355-373.

Fuster, J. M. (1999): Memory in the Cerebral Cortex: an Empirical Approach to Neural Nets in the Human and Nonhuman Primate, Cambridge, MIT.

Hernández SaCristán, C. (2006): Inhibición y lenguaje. A propósito de la afasia $y$ la experiencia del decir, Madrid, Biblioteca Nueva.

Horton, J. C., y E. T. Hedley-Whyte (1984): «Mapping of cytochrome oxidase patches and ocular dominance columns in human visual cortex", Philosophical Transactions of the Royal Society of London, B, 304: 255-272.

Hubel, D., y T. WiESEL (1962): «Receptive fields, binocular interaction and functional architecture in the cat's visual cortex», Journal of Physiology, 160: 106-154.

Kanwisher, N. (2000): «Domain specificity in face perception», Nature, 3: 759-763.

KING, J., y M. KUTAS (1995): "Who did what and when? Using word and clausal-level ERPs to monitor working memory usage in reading», Journal of Cognitive Neuroscience, 7, 3: 376-395.

KINTSCH, W. (1980): «Semantic memory: a tutorial», in R. S. Nickerson (ed.), Attention and perfomance, VIII, Hillsdale, Lawrence Erlbaum: 595-620.

Kutas, M., y C. VAn PetTen (1994): «Psycholinguistics electrified: Event-related potencial investigations", in M. A. Gernsbacher (ed.), Handbook of Psycholinguistics, Nueva York, Academic Press: 83-143.

LeDoux, J. (2002): Synaptic Self. How Our Brains Become Who We Are, Nueva York, Penguin, 104.

Livingstone, M. S., y D. H. Hubel (1984): «Anatomy and physiology of a color system in the primate visual cortex», Journal of Neuroscience, 4: 309356.

LÓPEZ GARCÍA, Á. (1984): «Ein formales Modell für einige spanische Redewendungen», Umgangssprache in der Iberoromania, Tübíngen, Gunter Narr: 344-350.

- (1998): Gramática del español. III. Las partes de la oración, Madrid, Arco. 
LÓPEZ GARCÍA, Á. (2002): «La formación de palabras como proceso cognitivo», en J. García-Medall (ed.), Aspectos de morfología derivativa del español, Lugo, Tristram: 79-93.

- (2003): «De nuevo sobre el origen del (proto)lenguaje», Estudios ofrecidos al profesor José Jesús de Bustos Tovar, Madrid, UCM: 875-889.

- (2004): «El lenguaje como organismo?», Homenaje al profesor Estanislao Ramón Trives, Murcia, Universidad de Murcia, tomo II: 433-450.

- (2007): «Sinonimia y circuitos neuronales», en Luis Luque (ed.), Léxico español actual, Venecia, Università Ca'Foscari: 71-91.

Miyake, A., P. Carpenter y M. Just (1994): «A capacity approach to syntactic comprehension disorders: Making normal adults performing like aphasic patients», Cognitive Neuropsychology, 11: 671-717.

MÜNTE, T., y H. HeInZE (1994): «Event-related negativities during syntactic processing of written words», en H. Heinze et alii (eds.), Cognitive electrophysiology, Boston, Birkhauser.

O'KeEFe, J., y L. NADEL (1978): The Hippocampus as a Cognitive Map, Nueva York, Oxford University Press.

Osterhout, L., y P. Holcomb (1992): «Event-Related brain potentials elicited by syntactic anomaly», Journal of Memory and Language, 31: 785-806.

Pulvermuller, F. (2001): «Brain reflections of words and their meaning», Trends in Cognitive Science, 5: 517-524.

SQUiRe, L., y L. KANDEL (1999): Memory: From Mind to Molecules, Nueva York, Scientific American Library.

STOWE, L., et alii (2002): «Encoding and storage in working memory during sentence comprehension», en P. Merlo y S. Stevenson (eds.), The Lexical Basis of Sentence Processing. Formal, computational and experimental issues, Ámsterdam, John Benjamins: 181-205.

SUZUKI, W., y D. AMARAL (1994): «Topographic organization of the reciprocal connections between the monkey entorhinal cortex and the perirhinal and hippocampal cortices", Journal of Neuroscience, 14-3: 1856-1877.

Tyler, K., y H. E. Moss (2001): «Towards a distributed account of conceptual knowledge», Trends in Cognitive Science, 5: 244-252.

VeYrat, M., y E. SERRA (2002): «Una perspectiva lingüística para el estudio de las estereotipias en el discurso afásico», en C. Hernández y E. Serra (eds.), Estudios de Lingüistica Clínica, Universitat de València: 71-85.

Wilson, F. R. (1998): The Hand. How Its Use Shapes the Brain, Language and Human Culture, Londres, Random House. 



\title{
UN MODELO LEXICALISTA DE LA ESTATIVIDAD VERBAL*
}

\author{
María del Carmen Horno ChÉliz \\ (Universidad de Zaragoza. Grupo Sylex) \\ JuAn Miguel Cuartero Otal \\ (Universidad Pablo de Olavide)
}

Se pueden apreciar enormes diferencias teóricas y metodológicas en los diferentes modelos de descripción de los fenómenos relacionados con la aspectualidad y en las distintas clasificaciones de aktionsarten al uso, y, sin embargo, se produce acuerdo casi general al distinguir la clase de los estados frente a las demás clases de situaciones, a las que se suele llamar eventos. Igualmente es cierto que tras este acuerdo general se hallan hipótesis y concepciones en las que a menudo pesan concepciones de la naturaleza de los estados elaboradas a partir de planteamientos todavía excesivamente intuitivos, así como la aceptación no siempre bien contrastada de afirmaciones previas acerca de las propiedades lingüísticas que esa naturaleza específica podría implicar.

* Este trabajo contó en parte con el apoyo del proyecto de investigación «Las relaciones entre semántica y sintaxis: el modo de acción. FFI2008-0081» parcialmente financiado por el Ministerio de Ciencia e Innovación con fondos FEDER. También forma parte del proyecto HUM2007-64200/FILO subvencionado por el Gobierno de España. 
Con el objetivo en mente de clarificar la naturaleza de los predicados estativos, ya hemos propuesto en un trabajo anterior cuáles son los rasgos específicos que los distinguen de las demás clases de predicados. En esta ocasión, nuestro objetivo es doble: en primer lugar, contextualizar nuestra propuesta en el marco de los planteamientos más clásicos sobre la estatividad (apartados 1 y 2), para, en segundo lugar (apartado 3), pasar a analizar el comportamiento de los enunciados de carácter estativo (contengan o no un estado léxico) y comprobar si tal comportamiento es compatible con la hipótesis planteada sobre la naturaleza de los estados. El trabajo concluye (apartado 4) con la formulación explícita de nuestras conclusiones.

\section{El modelo de trabajo: estados léxicos y enunciados estativos}

Creemos que en el ámbito de la aspectualidad resulta más adecuado partir de una distinción entre dos niveles de análisis y descripción, establecidos de manera paralela a la dicotomía denotación/referencia (Lyons 1977) que separa la faceta virtual del signo de sus realizaciones concretas. ${ }^{1}$ Así, en Cuartero Otal (2006) se diferencian:

a) La información sobre desarrollo temporal que un predicado puede proporcionar potencialmente en sus diferentes realizaciones. Esa información se formula mediante un esquema temporal, ${ }^{2}$ entidad abstracta que se hace corresponder a cada predicado y representa las informaciones aspectuales que le corresponden mediante estructuras compuestas de fases subeventivas ordenadas cronológicamente: estas entidades son las que nos permiten dar cuenta de las diferentes posibilidades de uso de los predicados para dar lugar a enunciados con distintos tipos aspectuales. Corresponde básicamente a los tipos de aktionsarten aplicados estrictamente al léxico, entendidos como información inherente.

1 Encontramos planteamientos que también distinguen explícitamente dos niveles en los trabajos de Lys y Mommer (1986: 218), Klein (1994: 2-3) o Vetters (1996: 79).

2 Las reglas sobre los temporal tier, los esquemas temporales inherentes de Jackendoff (1987: 398-402), pueden servir de modelo, a pesar de que él los emplea solamente para describir el nivel del enunciado. 
b) La información sobre desarrollo temporal que un predicado está proporcionando de hecho cuando se encuentra realizado en un enunciado concreto. Esa información se formula mediante distintas clases llamadas tipos de situación, que son el resultado de la focalización de alguna o algunas de las diferentes subfases eventivas que se encuentran previstas en el esquema temporal correspondiente, focalización a la que da lugar necesariamente el aspecto gramatical de la forma verbal y en la que pueden influir eventualmente otros fenómenos combinatorios. Corresponde por lo tanto a los tipos de aktionsarten pero aplicados esta vez en el nivel del enunciado, entendidos como información composicional.

Comenzando por el primero de los dos niveles, aceptamos un modelo de lexicón generativo (cf. Pustejovsky 1995), según el cual las entradas léxicas suelen presentar diversas subfases. De entre ellas, una es la que aparece por defecto (en presente o infinitivo) y, por tanto, se puede escoger como fase principal y responsable de la caracterización de ese predicado en términos de los aktionsarten más tradicionales.

En general, desde ese modelo de análisis, el desarrollo temporal de los verbos estativos se puede representar del siguiente modo:

(i)

En esta representación se refleja que todo estado incluye una fase subeventiva previa (i) en la que dicho estado no se daba. Así, hemos renunciado implícitamente a considerar pertinente en el nivel de información léxica la dicotomía establecida (Carlson 1977 o Dowty 1979) entre estados que se comportan como propiedades permanentes y estados que se comportan como propiedades transitorias (cf. Cuartero Otal y Horno Chéliz, en prensa).

Existen asimismo algunos predicados que evidencian una estructura subeventiva distinta, ${ }^{3}$ como por ejemplo los formados a partir de verbos

3 Renunciamos aquí, por exceder los objetivos del presente estudio, a hacer un análisis detallado sobre los distintos tipos de estados léxicos. Consideramos, no obstante, que es imprescindible realizar este estudio para explicar de forma adecuada el modo en el que, 
como conocer o saber. Estos predicados se deben representar como una sección de la línea temporal con varios subestadios: un subestadio previo (i) de «desconocimiento" y «adquisición de informaciones», seguido de una transición (ii) que da paso al subestadio final (iii), que implica la atribución de unos conocimientos al sujeto. Gráficamente se puede representar así:

(2)
(i)
(ii)
(iii)

Pasando ahora al segundo de los niveles, tenemos que resaltar la importancia de la categoría gramatical aspecto en el proceso de focalización de subfases eventivas. En el caso de conocer, las formas progresivas focalizan el subestadio inicial (i), los tiempos de pasado perfectivos, la transición (ii); y las formas imperfectivas, el estado (iii). ${ }^{4}$ Para ejemplificar esto, considérense los ejemplos de (3):

Adán está conociendo a Eva

Adán conoció a Eva

Adán conoce a Eva

Como vemos, los tipos de situaciones que presentan las construcciones con conocer o saber varían notablemente, pero, a pesar de ello, no creemos que en el lexicón se deban considerar entradas distintas de cada verbo, ni siquiera entradas relacionadas por la variación de algún rasgo semántico inherente. Como decíamos, en la información contenida en el lexicón acerca de un verbo incluimos en su esquema temporal toda una «historia prevista», que consta de diversas subfases. Así, en el ejemplo de (3a) se presenta a Adán en un proceso paulatino aún no culminado de adquisición de conocimientos sobre Eva; esto es, se muestra el desarrollo

por ejemplo, los verbos estativos participan de los enunciados no estativos y remitimos al lector interesado al trabajo de Cuartero Otal (2007) para los detalles sobre los esquemas temporales que se han atribuido a las distintas clases de estados.

4 Se puede observar que estas sencillas reglas sirven igualmente para construcciones con verbos como saber, entender, etc., y que no diferirán mucho para las construcciones con otros verbos de naturaleza distinta, como ocupar, coger, etc. 
del proceso que en (2) marcamos como fase (i) y que se prevé que desemboque en la transición (ii) a la que aquí no se hace referencia. En el ejemplo de (3b) se presenta una situación de cambio: de no saber quién era Eva, Adán pasó a saberlo; focaliza así la transición que en (2) marcamos como fase (ii). Por último, (3c) refiere la conciencia de Adán con respecto a Eva, esto es, se muestra la subfase estática que en (2) marcamos como (iii). Estos ejemplos ilustran como el aspecto nos «deja ver» partes de ese esquema temporal, abstracto e ideal, que le adscribimos a un predicado verbal.

Defendemos por tanto que el verbo conocer debe aparecer en el lexicón como verbo estativo (en virtud, como veremos, de que esta es la fase que focaliza por defecto), si bien solo uno de los tres enunciados de (3) -el último - se puede considerar estativo. Nótese que, por más que deban estar en relación, no es lo mismo la estatividad de un predicado abstracto que en su esquema temporal contiene una subfase con determinadas características semánticas y tempo-aspectuales que la de un enunciado que atribuye una característica o una situación a un sujeto. Con el modelo que estamos aplicando, además, las clases de los esquemas temporales y las de los tipos de situación no son ni pueden ser las mismas. La gran mayoría de los modelos de análisis no se han planteado claramente tal posibilidad y emplean las mismas categorías en ambos niveles. $^{5}$

Una de las consecuencias negativas que ha tenido esa falta de distinción entre estos dos niveles y entre las clases de los predicados y las de los enunciados se observa en las evidentes dificultades que suele haber para describir las estructuras correspondientes a estados. El propósito de los siguientes apartados es, precisamente, establecer las claves que distinguen estos dos niveles de estatividad: estados léxicos (en concreto, verbos estativos) y enunciados estativos (de predicación verbal).

5 Hasta ahora, la diferenciación de las clases de los dos niveles solo se ha planteado abiertamente en el trabajo de Croft (2000: 5): «Aspectual classes of predicates cannot be identified with aspectual types». 


\section{La estatividad y verbos estativos}

\subsection{Algunos planteamientos clásicos}

Repasando la bibliografía acerca de los estados hay una cuestión básica sobre la que debe llamarse la atención: la inmensa mayoría de los autores que se han ocupado de cuestiones de aspectualidad han pasado en lo posible de puntillas sobre el asunto. Apenas existen definiciones claras que digan qué se puede considerar un estado y, todo lo más, algunos autores han solido acentuar un rasgo ontológico-semántico que han escogido (conscientemente o no) como necesario y suficiente y que han aplicado como criterio diferenciador frente a todos los demás tipos de aktionsarten. Como comprobación objetiva de ese rasgo se escogen algunas pruebas combinatorias sobresalientes, lo que ha dado lugar a caracterizaciones fuertemente circulares y difícilmente aprovechables que con frecuencia se han seguido citando y aun justificando mediante algunos (pocos) ejemplos. Por lo demás, no existen listados amplios ni exhaustivos de verbos de estado y solo algunas pocas propuestas que presentan tipos léxico-semánticos de verbos de estado.

Inicialmente, Vendler (1957) presentó los estados como un grupo muy bien caracterizado por su incompatibilidad con la perífrasis progresiva (que compartía con los logros) y por su duratividad (que a su vez los diferenciaba frente a estos últimos, que son eventos puntuales). La aplicación de los contrastes en los resultados de sus tres pruebas es la siguiente:

\begin{tabular}{|l|c|c|c|}
\hline & $\begin{array}{c}\text { Compatibles con } \\
\text { progresivo }\end{array}$ & $\begin{array}{c}\text { Compatibles con } \\
\text { For how long...? }\end{array}$ & Con carácter durativo \\
\hline States & - & + & + \\
Activities & + & - & - \\
Accomplishments & + & & + \\
Achievements & - & + & \\
\hline
\end{tabular}

El éxito de la propuesta de Vendler y su influencia en todos los trabajos posteriores se puede justificar fácilmente ya que proponía un modelo sistemático para clasificar situaciones que definía características temporales de distintos tipos de situaciones basándose en pruebas más o menos 
objetivas. Un asunto aparte es que los logros sean compatibles con la perífrasis progresiva y los estados muy frecuentemente. Vendler no definió los estados: sugirió que no son compatibles con adverbios del tipo deliberately o carefully ni sustituibles por to do y afirmó que son internamente homogéneos (1957: 106).

Kenny (1963: 176) había destacado la incompatibilidad de los adverbios de temporalidad interna como slowly o quickly con los estados, lo que parecía ayudar a decidir sobre su falta de dinamicidad y de desarrollo a lo largo del tiempo. Lo mismo sería aplicable a la incompatibilidad con indicaciones de gradualidad como poco a poco o gradualmente (Bertinetto 1997: 78 o De Miguel 1999: 3017). Ello, sin embargo, no es válido para enunciados caracterizadores que adscriben propiedades graduables (cf. Cuartero Otal y Horno Chéliz, en prensa) como:

(5)

a. Poco a poco se va pareciendo más a su padre

b. El experimento conlleva gradualmente muchas dificultades

c. Este mozo cada vez nos inspira menos confianza.

Hay dos trabajos clásicos que contribuyeron decisivamente a dar gran popularidad al modelo vendleriano: Comrie (1976) y Dowty (1979). Comrie (1976) fue el primero en establecer la distinción entre las tres propiedades semánticas inherentes [Punctual/durative], [Telic/atelic] y [State/dynamic situation] (citadas a menudo como [ \pm dynamicity], $[ \pm$ telicity] y $[ \pm$ durativity]), de modo que aportaba un matiz más claramente lingüístico a la propuesta ontológica del filósofo Vendler y justificaba su procedimiento de análisis: «these [inherent aspectual properties] interact with other aspectual oppositions, either prohibiting certain combinations, or severely restricting their meaning» (Comrie 1976: 41). Compárese el modelo siguiente con el de la propuesta inicial de Vendler:

(6)

\begin{tabular}{|l|c|c|c|}
\hline & {$[ \pm$ dynamicity $]$} & {$[ \pm$ telicity $]$} & {$[ \pm$ durativity $]$} \\
\hline States & - & - & + \\
Activities & + & - & + \\
Accomplishments & + & + & + \\
Achievements & + & + & - \\
\hline
\end{tabular}


Comrie se atrevió con una primera definición, intuitiva y tal vez más cerca de la Física que de la Lingüística, pero que marcó rotundamente las concepciones posteriores acerca de los estados frente a los denominados eventos y por ende su caracterización: «[S] tates are static, i. e. continue as before unless changed, whereas events and processes are dynamic, i. e. require a continual input of energy if they are not to come to an end [...]» «To remain in a state requires no effort, whereas to remain in a dynamic situation does require effort, whether from inside [...] or from outside [...]» (1976: 13 y 49).

En su trabajo, Comrie sugiere unas pocas pruebas que permiten adscribir a los verbos esas tres propiedades: en el caso de la estatividad, puede comprobarse la homogeneidad de las fases que constituyen un estado: "In the case of know, all phases of the situation John knows where I live are identical; whichever point of time we choose to cut in on the situation of John's knowledge, we shall find exactly the same situation" (1976: 49). Esa homogeneidad de la estructura temporal (denominada a menudo subinterval property) ya se atribuye a los estados y a las actividades desde Vendler (1957: 106): «For states: A loved somebody between $t_{1}$ and $t_{2}$ means that at any instant between $t_{1}$ and $t_{2} A$ loved that person». La presencia de la subinterval property se puede objetivar comprobando con un test si las construcciones con aspecto gramatical imperfectivo implican a las perfectivas al estilo de Garey (1957: 105): «There might be two categories (or constructions) according to the answer you get for the following question: if one was verbing, but was interrupted while verbing, has one verbed? [...] Substitute the test verb where the formula was verb: Si on se noyait..., Si on jouait au bridge..., and so on».

La homogeneidad está estrechamente relacionada con el carácter atélico de los predicados, por lo que en principio no permite distinguir los estados de las actividades. Al respecto, Rothmayr (2009: 3-4) hace una propuesta bastante arriesgada: "Activity verbs, as homogeneous as they may seem, do not have the subinterval property. Of course, down to a certain time-span the subinterval property holds for activities: imagine I am petting the cat for 30 minutes. There are subintervals - say of about 2 seconds - where there is still some petting of the cat going on, but at a certain point the intervals get so small that it is physically impossible for an action to accur». En cualquier caso, queremos añadir que justamente 
el test de Garey para la homogeneidad y la atelicidad no se puede aplicar a los estados:

(7)

a. \#Si alguien está necesitando diez euros pero lo interrumpen, ¿̨ha necesitado diez euros?

b. \#Si alguien se está pareciendo a su padre pero lo interrumpen, ¿se ha parecido a su padre?

Por su parte, el trabajo de Dowty (1979), además de contribuir a popularizar una versión ampliada y revisada del modelo vendleriano, establece una batería de once tests de combinabilidad e implicaciones lógicas para justificar la adscripción de un verbo a una de las cuatro clases de aktionsarten. Hay, no obstante, en la propuesta de Dowty acerca del modelo de Vendler un punto bastante débil: para reconocer estados, aplica los tests de agentividad de Lakoff (1970) que incluso presenta como non-stative tests, lo que solo tiene una justificación muy parcial. Dowty, tras glosar a Vendler, distinguió por su parte cinco clases de aktionsarten, aceptando la diferencia de Carlson (1977) entre estados permanentes y estados transitorios. Dowty afina más su propuesta incluyendo el rasgo [ \pm control] que toma en cuenta el carácter agentivo o no atribuible al sujeto de la construcción y desdoblando su clasificación hasta un total de nueve o diez clases.

Las aportaciones reseñadas de ambas propuestas se hallan recogidas y sintetizadas en el siempre citado trabajo de Smith (1991) del que bien se puede afirmar que se va imponiendo al modelo vendleriano como clasificación estándar de aktionsarten: la autora asoció diversos tests adaptados de los de Dowty a las tres características semánticas propuestas por Comrie e incluyó una quinta clase, los semelfactives, que, como se puede apreciar, agota las posibilidades combinatorias de las características atribuibles a las clases eventivas, es decir, dinámicas.

(8)

\begin{tabular}{|l|c|c|c|}
\hline & {$[ \pm$ dynamicity $]$} & {$[ \pm$ telicity $]$} & {$[ \pm$ durativity $]$} \\
\hline States & - & & + \\
Activities & + & - & + \\
Accomplishments & + & + & + \\
Achievements & + & + & - \\
Semelfactives & + & - & - \\
\hline
\end{tabular}


Si tenemos en cuenta por un lado que se tiende a una división dicotómica inicial entre estados y eventos y por otro que las propiedades [-télico] y [+durativo] no son específicas de ellos ya que las comparten con otros tipos de eventos dinámicos, la única característica que permitiría distinguirlos es su [-dinamicidad], hipótesis que, como advertíamos antes, es difícilmente justificable ante ejemplos como los que hemos presentado en (5).

Por último, más allá del análisis de rasgos descrito hasta aquí, una alternativa que se puede encontrar en la bibliografía consiste en diferenciar los estados léxicos del resto de predicados en virtud de la ausencia/presencia del argumento eventivo davidsoniano. Los argumentos aportados en la bibliografía para justificar que los estados léxicos carecen de argumento eventivo (<e>) son variados. Entre ellos, podemos destacar la imposibilidad de ser interpretados en aspecto habitual, las limitaciones que presentan para ser sustituidos por verbos del tipo de 'suceder', las restricciones que presentan para tener argumentos internos desnudos, combinarse con adverbios de modo o con sintagmas locativos y temporales y su incapacidad de aparición como objeto de un verbo de percepción. De todas las evidencias presentadas para justificar esta hipótesis, tal y como ya indicamos en un trabajo anterior (cf. Cuartero Otal y Horno Chéliz, en prensa), solo parece empíricamente demostrable lo siguiente:

(i) que los estados léxicos, a diferencia del resto de predicados, se interpretan en presente simple como tales estados, y tienen bloqueadas sus posibles interpretaciones como presente actual o como presente habitual, y

(ii) que, en términos generales, los estados léxicos presentan más limitaciones que el resto de predicados para combinarse con determinados argumentos y adjuntos locativos o modales (entre otros).

Este comportamiento específico de los estados léxicos, por sí solo, no nos parece suficientemente singular como para defender la propuesta de que este tipo de predicados carece a todas luces de argumento eventivo. También es cierto que, en cualquier caso, el argumento eventivo de los estados léxicos no se comporta exactamente del mismo modo que el del resto de predicados. Sobre ello volveremos en el siguiente apartado. 


\subsection{Nuestra propuesta}

El problema que detectamos en las definiciones y caracterizaciones de los verbos estativos es que, como decíamos al inicio de este trabajo, no se suele distinguir entre la naturaleza de los verbos como ítems léxicos y la naturaleza de las oraciones en las que dichos verbos aparecen. Esto conlleva planteamientos circulares en los que los verbos estativos se caracterizan mediante ciertos rasgos necesarios y suficientes de tal modo que cuando se encuentran ejemplos en los que dichos rasgos no aparezcan, se argumenta que han dejado de ser verbos estativos. Una argumentación circular carece, así, de toda posibilidad de falsación pero igualmente de poder explicativo.

Una alternativa consiste, entonces, en tratar de hallar alguna característica que cumplan todos los verbos estativos sin excepción y que permita excluir a todos los verbos que no sean estativos. Nuestra propuesta es la siguiente: consideraremos que es estativo todo verbo cuyas construcciones en tiempo presente se tengan que interpretar necesariamente como estativas. ${ }^{6}$ Esto los diferenciará, por tanto, del resto de verbos (los «no estativos»), que en tiempo presente presentan la posibilidad de interpretarse, además de como estativos, con una lectura de presente actual, de presente habitual u otras. ${ }^{7}$ Este rasgo nos permite crear un corpus de verbos estativos estable y diferenciado.

Una vez establecido el criterio mediante el que proponemos decidir si un verbo es o no estativo, pasamos a su caracterización. Nuestra propuesta es que los verbos estativos presentan estructuras subeventivas com-

6 En el apartado siguiente se profundiza acerca del modo en el que entendemos esta 'interpretación estativa'. Básicamente, podemos considerar que se trata de una interpretación 'caracterizadora', según la cual se interpreta un objeto (o sujeto) como parte de un conjunto de elementos.

7 Adelantando lo que diremos posteriormente, podemos considerar que una oración como Juan va en bicicleta se puede entender como presente actual (ahora mismo), como presente habitual (suele ir en bici) o como estativa (pertenece al conjunto de los que van en bicicleta); por el contrario, una oración como Juan sabe alemán solo podemos interpretarla como estativa. Por ello, decimos que el verbo ir no es estativo (aunque pueda participar en oraciones que se interpreten de forma estativa, ya veremos cómo), mientras que el verbo conocer sí es estativo (aunque también pueda aparecer en oraciones no estativas, en determinadas circunstancias). 
plejas que, a pesar de que pueden tener variantes, siempre constan, al menos, de dos fases: una principal, estativa, y una anterior a esta en la que dicho estado todavía no se daba. ${ }^{8}$

A efectos prácticos, los verbos estativos se caracterizan por el hecho de que, si se combinan con determinada información gramatical, se pueden interpretar como predicados eventivos, ya que focalizan fases subeventivas distintas a la fase principal de estado. La propuesta resulta más sugerente si indicamos que, además, dichas interpretaciones son calculables. Así, como dijimos, mediante el uso de la perífrasis progresiva pueden proyectarse focalizando una fase anterior al estado, en la que este se va adquiriendo progresivamente (Estamos sabiendo poco a poco la verdad), o mediante los tiempos de pasado perfectivos se puede focalizar la subfase de transición ( $\mathrm{t}$ ) de los verbos estativos que la contienen (Esta mañana he conocido a Pedro / Ayer conocí a Pedro).

La propuesta es, en este sentido, que los verbos que cumplan con los criterios mencionados serán estados léxicos, con independencia de que aparezcan en enunciados interpretados como estativos o como eventivos. Por ello, la caracterización en rasgos ha de ser congruente con todos los contextos. Desde este punto de vista, no se puede mantener, como vimos ya en otro lugar, ${ }^{9}$ que los estados léxicos no sean agentivos, que carezcan de límites o no sean dinámicos, pues son muchos los contextos en los que los verbos admitidos en nuestro corpus de estados léxicos sí presentan estos rasgos. En realidad, el único rasgo que admitimos propio de todos los estados léxicos es el de la falta de delimitación. De hecho, los verbos estativos son predicados atélicos, no solo por no estar delimitados desde el lexicón, sino porque además no son delimitables por su argumento interno en la sintaxis. Este rasgo los distingue de todos los demás tipos de predicados, salvo de las actividades no delimitables como perseguir (de las que se distingue, no lo olvidemos, porque en presente solo los estados léxicos son interpretados sin ambigüedad alguna como estados).

8 Renunciamos, como ya hemos indicado, a aceptar la diferenciación entre estados permanentes y estados transitorios en el lexicón, que consideramos empíricamente no motivada.

9 Para un análisis pormenorizado sobre la inadecuación de estas caracterizaciones cf. Cuartero Otal y Horno Chéliz, en prensa. 
Un asunto distinto supone decidir si los estados léxicos cuentan o no con el argumento eventivo davidsoniano (<e>). Nuestra propuesta es que todo predicado, incluidos los estados, presenta un argumento eventivo que se refiere al evento en sí. A dicho argumento eventivo se vinculan todos los adjuntos que añaden información sobre el evento, incluido lugar y tiempo. Por otra parte, consideramos que dicho argumento eventivo se ha de saturar con la información aspectual adecuada. En términos configuracionales, podemos relacionar, por tanto, este argumento eventivo con el Sintagma Aspectual oracional. Desde esta perspectiva, los estados léxicos presentan argumento eventivo, del mismo modo que lo presenta cualquier tipo de predicado, o no podrían generar predicación oracional.

Una vez dicho esto, también podemos aclarar el comportamiento especial que los estados léxicos presentan frente al resto de predicados (su interpretación no ambigua en presente, sus evidentes restricciones en cuanto al tipo de adjuntos que puede presentar, etc.). Nuestra propuesta es que los verbos estativos también presentan argumento eventivo que se proyecta ya saturado con la interpretación estativa, si la que se proyecta es su fase principal, mientras que si se proyecta cualquiera de sus fases subeventivas anteriores (no estativas), dicho argumento eventivo se proyecta sin saturar.

Esta propuesta también da cuenta del hecho de que los estados léxicos en presente no puedan interpretarse más que como estados (ya que su argumento eventivo aparece saturado desde el lexicón con esa interpretación), mientras que el resto de predicados deben saturar su interpretación en el marco de la oración (mediante aspecto habitual, presente actual, estativo, etc.). Asimismo, damos una explicación a las restricciones combinatorias de los estados léxicos en presente, que no estarían motivadas por la ausencia de argumento eventivo, sino por una saturación específica de este. Una evidencia de ello es que los verbos estativos en tiempos distintos al presente (con <e> sin saturar) no presentan dichas restricciones, del mismo modo que los predicados no estativos en contextos de estatividad (como veremos a continuación) sí las presentan.

Hasta aquí un breve resumen de nuestra propuesta, tal y como ya la habíamos presentado en Cuartero Otal y Horno Chéliz (en prensa). Nuestro propósito en el apartado siguiente es comprobar si esta propuesta sobre la naturaleza de los predicados léxicos es compatible con la configuración oracional de los enunciados estativos. 


\section{Enunciados estativos}

\subsection{La interpretación de los enunciados estativos}

En esta ocasión, nuestro propósito es apuntar algunas líneas generales sobre cómo se forman y cómo se interpretan los enunciados estativos de predicación verbal. Para ello, hemos de comenzar distinguiendo un tipo de enunciados, seguramente el más representativo de los estativos, a los que vamos a llamar "enunciados clasificadores» —en adelante EECC - ( y a los que también se suele llamar «enunciados caracterizadores»). Para definirlos, podemos utilizar la teoría de conjuntos y decir que un EC adscribe un determinado participante (en este caso x, el sujeto) a un determinado conjunto (función extensional del predicado) y lo caracteriza atribuyéndole una determinada propiedad (función intensional del predicado). Estamos pensando en enunciados como los siguientes: ${ }^{10}$

(9)

a. Juan sabe francés ('pertenece al conjunto de los franco-parlantes' / 'es francoparlante')

b. Juan vende coches ('pertenece al conjunto de los vendedores de coches' / 'es vendedor de coches')

c. Juan no se enfría nunca ('pertenece al conjunto de personas de constitución fuerte' / 'es de constitución fuerte')

d. Juan come carne ('pertenece al conjunto de personas que comen carne' / 'no es vegetariano')

Nótese de los ejemplos de (9) que estos EECC se pueden formar a partir de predicados con cualquier tipo de aktionsart: un predicado estati-

10 En la bibliografía al respecto, este tipo de enunciados se han denominado «Individual Level Predicates" (predicados de nivel individual o, simplemente, predicados de individuo). En este trabajo, renunciamos a denominarlos "predicados" puesto que, como intentaremos probar en esta sección, no consideramos que se trate de un asunto especificado en el léxico, sino en la sintaxis (en línea con el trabajo de Arche 2004, aunque ella no tiene problema en denominarlos, pese a todo, predicados). Su naturaleza composicional nos ha hecho preferir un término como «enunciado» que resulta más transparente. Por otra parte, aceptamos que se aplican a individuos (o a clases de individuos, no a estadios), pero al denominarlos «clasificadores» o "caracterizadores» creemos ser más explícitos acerca de su aplicación concreta. También podríamos hablar de «enunciados de propiedad», acercándonos así a la propuesta de Chierchia (1995) que los llamó "predicados de propiedad». 
vo, como en (9a), un predicado de realización, como en (9b), un predicado de transición en su versión de logro, como en (9c), o un predicado de actividad, como en (9d). Esto es, los predicados de (9b) a (9d), a pesar de lexicalizar eventos, aquí se están empleando para caracterizar individuos: han llegado a la estativización mediante abstracción de los estados concretos a partir de una lectura habitual. ${ }^{11}$

Por otro lado, admitimos en la misma línea de Arche (2004) que los EECC no necesariamente se caracterizan por ser predicaciones permanentes, pese a lo que pudiera parecer y lo que se ha asumido no pocas veces en la bibliografía al respecto (por ejemplo, en Manninen 2001). En los ejemplos de (10) se observa como en ocasiones la pertenencia a un conjunto (la caracterización) puede resultar de naturaleza transitoria: ${ }^{12}$

a. Juan sabía francés de joven

b. Juan vendía coches antes de conseguir este nuevo empleo

c. Juan de pequeño no se enfriaba nunca

d. Juan comía carne antes de conocerme

Es más, estos enunciados, pese a lo que tan a menudo se afirma, suelen admitir la aparición de la perífrasis progresiva, sin perder por ello su condición de enunciados estativos. En esta ocasión, la interpretación va a variar en virtud de la naturaleza léxica del predicado principal: si el verbo

11 Para profundizar sobre las diferencias entre la interpretación de (9a) y el resto de ejemplos de (9), en especial en relación con las condiciones de verdad, cf. Krifka y otros (1995).

$12 \mathrm{Al}$ aceptar que los enunciados de (10) son EECC igual que los de (9) y al desvincular esta clasificación de la cualidad de permanencia, estamos descartando pruebas habitualmente utilizadas para discriminar si un determinado predicado funciona o no como clasificador. Así, consideramos que el hecho de que un enunciado admita o no sintagmas locativos y temporales o que aparezca o no en oraciones introducidas por «siempre que» no ayuda, pese a lo que se suele admitir en la bibliografía (cf., entre otros, Manninen 2001), a distinguirlos. Esto nos obliga, claro está, a redefinir ambas categorías, pero tiene la ventaja de que no hemos de explicar los enunciados de (10) como ejemplos de predicados de estadio, con el problema añadido de tener que aceptar que hay o bien dos entradas homófonas distintas o bien un proceso sintáctico de cambio en la interpretación. Por encima de estas cuestiones está, por supuesto, el hecho de que las propiedades gramaticalmente relevantes de los enunciados de (9) son las mismas que las de los enunciados de (10), tal y como se ve en (11) - (13). 
es estativo, la interpretación es fundamentalmente gradual (11a-b), y si no lo es, la interpretación suele ser temporal (11c-e):

a. ??Juan está sabiendo francés últimamente

b. Juan está sabiendo cada vez más francés

c. Juan está vendiendo coches últimamente ('es vendedor de coches últimamente')

d. Juan se está enfriando bastante últimamente ('últimamente está menos sano')

e. Juan está comiendo carne últimamente ('está siendo carnívoro últimamente')

Desde el punto de vista de su comportamiento gramatical, se ha observado en la bibliografía (Arche 2004) como los EECC no admiten la aparición de complementos predicativos de sujeto. De ahí la agramaticalidad de una oración como (12a) y la pérdida del valor estativo (y, por ende, clasificativo), de las oraciones de (12b-12d). ${ }^{13}$ En esto, los EECC se diferencian de los enunciados eventivos, como los de (13):

a. *Juan \{sabe / sabía\} francés contento

b. \# Juan \{vende / vendía $\}$ coches contento (no interpretable como 'Juan $\{$ es/era\} vendedor de coches')

c. \# Juan no se $\{$ enfría / enfriaba\} nunca feliz (no interpretable como 'Juan $\{$ es/era\} de naturaleza fuerte')

d. \# Juan \{come / comía\} carne hambriento (no interpretable como 'Juan no \{es/era\} vegetariano')

a. Juan aprende francés contento

b. Juan está vendiendo coches enfadado

c. Juan se come la carne por las mañanas encantado de la vida

Otra característica que se puede comprobar de estos enunciados es que, en ellos, los sujetos plurales se tienden a interpretar de modo genérico (todos los jóvenes, todos los farmacéuticos, todos los gatos, todos los vegetarianos en general). La lectura existencial (estos jóvenes, estos farmacéuticos, estos gatos, estos vegetarianos) es posible, pero está mucho más restringida contextualmente que la genérica:

13 Es importante resaltar que la mala construcción de las oraciones de (12) —o su pérdida de interpretación como EECC - no se debe a que no se puedan interpretar, sino a que se da una restricción gramatical. Prueba de ello es que, si no utilizamos el complemento predicativo, se puede parafrasear sin problemas. 
(14)

a. Los jóvenes \{saben / sabían\} francés

b. Los farmacéuticos no \{venden / vendían tabaco

c. Los gatos no se \{enfrían / enfriaban\} nunca

d. Los vegetarianos no $\{$ comen / comían $\}$ carne

Hasta aquí la caracterización de los EECC. En cierta medida, se podría decir que esta interpretación de los EECC es la que se ha tenido por prototípica, la esperable de un enunciado estativo. De ahí que no pocos autores hayan considerado que un "estado» y un EC son exactamente lo mismo, afirmando que los estados (sin precisar más) no son eventos, o que no pueden llevar complementos predicativos (entre otros, Demonte y Masullo 1999 o De Miguel y Fernández Lagunilla 2004). ${ }^{14}$ A pesar de ello, no es una novedad en absoluto admitir que existen determinados enunciados estativos que no cumplen las características arriba descritas: se trata de aquellos que vamos a denominar «enunciados situativos» (en adelante EESS), para evitar las connotaciones que conlleva el término «enunciados de estadio» propuesto por Arche para esta segunda categoría. Consideremos ahora los siguientes ejemplos: ${ }^{15}$

a. Juan reside en Madrid

b. La carretera recorre la costa

c. La lámpara cuelga del techo

Estos enunciados difieren de los anteriores, en distintos sentidos, sin dejar por ello de ser enunciados estativos. Constátese, en primer lugar, que no se comportan como los anteriores ante la perífrasis progresiva: un predicado como residir, con esta perífrasis, admite una lectura temporal que implica últimamente (16b), pero nunca una gradual que implique poco a poco, lo que contrasta con el comportamiento de los enunciados

14 Un interesante análisis sobre cómo se suele obviar la distinción entre tipos de estados en los estudios sobre el comportamiento de los complementos predicativos de sujeto es el de Martínez Linares 2004.

15 Del mismo tipo serían vivir o permanecer o alzarse, ejemplos que De Miguel y Fernández Lagunilla, en su trabajo de 2004, relegan a nota, negando su naturaleza estativa (en el caso de vivir) o aludiendo a su naturaleza pseudocopulativa (en el caso de permanecer y alzarse). 
clasificadores tal y como vimos en (11). Por otro lado, cuando en el enunciado estativo el que aparece no es un verbo léxicamente estativo, la reinterpretación temporal no está disponible: o bien el resultado no es congruente, como le ocurre a (16c), o bien equivale sin ningún matiz al presente simple (16d):

a. ???Juan (poco a poco) está residiendo en Madrid

b. Juan (últimamente) está residiendo en Madrid

c. \#La carretera está recorriendo la costa

d. La lámpara está colgando del techo (= La lámpara cuelga del techo)

Otra diferencia es que estos enunciados admiten la aparición de complementos predicativos del sujeto, siempre que se tengan en cuenta las restricciones que puede imponer la semántica:

a. Juan reside feliz en Madrid

b. La carretera recorre sinuosa la costa

c. La lámpara cuelga torcida del techo

Además, los sujetos plurales se tienden a interpretar como referenciales (estos niños, estas carreteras, estas lámparas). La lectura genérica (todos los niños, todas las carreteras, todas las lámparas en general) es, esta vez, la que está restringida contextualmente:
a. Los niños residen en Zaragoza
b. Las carreteras recorren la costa
c. Las lámparas cuelgan del techo

En la gran mayoría de los trabajos sobre aspectualidad se ha defendido explícita o implícitamente la propuesta de Carlson (1977), de modo que, una vez vinculada la interpretación estativa básica (la denominada "de individuo») a propiedades de naturaleza permanente, se consideraba que la otra posible interpretación (la denominada "de estadio») debía tener la característica específica de la transitoriedad, lo que, a la vista de ejemplos como (15b) o los que añadimos en (19), puede considerarse dudoso. Consideramos, por tanto, que la permanencia y la transitoriedad de las propiedades no son los rasgos que permiten diferenciar los EECC frente a los EESS que venimos mostrando aquí: 
a. El ecuador pasa por el sur de Colombia

b. El Museo del Prado se encuentra en Madrid

c. Las coordenadas se situan lejos de la costa.

Con independencia de esta naturaleza no necesariamente contingente, admitimos la propuesta de Arche (2004) de que existen dos tipos de enunciados estativos: aquellos que aquí hemos denominado clasificadores, que se comportan de un modo canónico con respecto a lo que - de acuerdo con la bibliografía - se puede esperar de un enunciado estativo, y estos otros, a los que hemos denominado situativos y que, a pesar de ser estativos, se comportan de modo muy similar a los predicados eventivos. ${ }^{16}$

Para dar cuenta de las diferencias presentadas, algunos autores (Carlson $1977^{17}$ o Chierchia 1995, entre muchos otros) dan cuenta de la existencia de dos tipos de predicados estativos ya en el lexicón. En concreto, una de las propuestas más aceptadas al respecto (cf. Diesing 1992 o Katz 2003 por citar solo algunos) ha sido considerar que los «estados de individuo» carecen de argumento eventivo, mientras que los «estados de estadio" sí que tendrían argumento eventivo. No aceptamos esta propuesta aquí ya que consideramos que no consigue explicar, al menos, los siguientes aspectos: ${ }^{18}$

(i) cuál es exactamente la naturaleza de la estatividad, si se considera que hay estados con argumento eventivo (los «de estadio») y sin argumento eventivo (los «de individuo");

16 Hay bastantes autores que señalan una clase aspectual híbrida entre los estados y las actividades: Carlson (1981) los llamó dynamics, Quirk et al. (1985), los llamaron stances. A su vez, Rothmayr (2009) distingue aquí dos grupos: el de los verbos de posición, que considera estativos «normales», y el de los verbos de postura, que ella considera eventivos.

17 Hay que hacer constar, sin embargo, que Carlson (1977) consideraba la existencia de "predicados ambiguos».

18 Al menos desde Mourelatos (1978), es habitual encontrar en la bibliografía (cf., por ejemplo, Manninen 2001: 27) referencias constantes a la relación que se puede establecer entre la diferencia "predicados de estadio" frente a "predicados de individuo" y la diferencia léxica entre «nombres de masa» frente a «nombres contables». Parece relevante, por ello, advertir que, del mismo modo que nosotros tratamos de defender que esta diferencia en la interpretación de los enunciados es sintáctica, también existen quienes han sugerido que la diferencia entre los dos tipos de nombres pueda no ser léxica sino de combinatoria (cf. al respecto el trabajo de Borer 2005). 
(ii) mediante qué mecanismos se explica que al estativizarse los predicados eventivos pierdan su argumento eventivo; ${ }^{19}$

(iii) en qué condiciones un predicado eventivo recibe al estativizarse la interpretación de clasificador y en qué condiciones recibe la de situativo y

(iv) por qué la interpretación como clasificador es más habitual que la interpretación como situativo.

En un intento de dar respuesta a esas cuatro preguntas, la propuesta que exploraremos en el siguiente epígrafe se basa en considerar que la diferencia entre estos dos tipos de enunciados no tiene fundamentos de carácter léxico sino sintáctico. Esto es, que en el léxico resulta relevante si el predicado es estativo o no, pero no el tipo de interpretación que recibirá el enunciado en el que participe.

\subsection{Una explicación a partir de nuestra definición de los predicados estativos}

De acuerdo con nuestra propuesta, los predicados estativos se proyectan con su argumento eventivo saturado por la interpretación estativa, mientras que los eventivos se proyectan con el argumento eventivo sin saturar, lo que permite que un enunciado como Juan va en bicicleta al trabajo pueda ser interpretado de tres maneras distintas: como única ocurrencia de la situación (ahora mismo monta una bicicleta para llegar al trabajo), como conjunto habitual de ocurrencias (suele ir en bicicleta al trabajo) o como recurrencia caracterizadora (frente a todos los demás que van en coche).

Por otro lado, como hemos visto en el epígrafe anterior, los estados léxicos participan por lo general en enunciados que se interpretan como EECC. Así podemos aceptar que para que un enunciado cualquiera se interprete como EC, la posición de argumento eventivo debe encontrarse saturada: con los predicados estativos esta es la interpretación «natural» mientras que con los predicados no estativos, es necesario que se halle saturada en la combinatoria mediante mecanismos

19 No parece demasiado elegante considerar (cf. Krifka y otros 1995) que existen dos entradas distintas homófonas para cada verbo en virtud de si se ha estativizado o no. 
pragmáticos y gramaticales. ${ }^{20}$ Frente a la hipótesis que considera la ausencia de argumento eventivo, la nuestra tiene varias ventajas explicativas:

(i) ofrece una perspectiva homogénea de los verbos estativos, de modo que todo verbo estativo se proyecta con el argumento eventivo saturado por naturaleza;

(ii) explica que los predicados no estativos puedan participar de enunciados caracterizadores habiendo saturado con una interpretación estativa la posición de SAsp.; y

(iii) justifica que la interpretación como enunciado estativo clasificador sea la más natural tanto si se trata de predicados estativos como de predicados eventivos (con los primeros, es una consecuencia obvia de su propia proyección; con los segundos es una consecuencia del mecanismo de estativización, pues esa saturación del argumento eventivo, además de estativizar el predicado, le proporciona la interpretación como EC).

Queda pendiente, sin embargo, la explicación de cómo tiene lugar la interpretación de los EESS, ya que tal y como los hemos descrito hasta aquí, puede parecer que estamos cayendo en una contradicción. Por un lado, su comportamiento es hasta cierto punto similar al de los enunciados eventivos ( $\mathrm{y}$ admiten complementos predicativos, propician lecturas referenciales, etc.), lo que, en cierta medida, justifica que son enunciados en los que el argumento eventivo no se encuentra saturado con la interpretación de estado. Por otro lado, los EESS son enunciados estativos y nuestra propuesta predice que esa interpretación estativa depende de que haya tenido lugar la saturación del argumento eventivo. Y ello se aplica tanto a los EESS con predicados estativos (del tipo Juan reside en Madrid) cuya saturación se produce desde el léxico, como a aquellos con predicados eventivos (del tipo La lámpara cuelga del techo) cuya saturación se produce en la combinatoria.

Comencemos por el primero de los escenarios: se construyen predicados estativos con interpretación de EESS a partir de verbos como per-

20 Detallar el modo concreto sobre cómo se produce esta saturación excede el ámbito de este breve artículo. El lector interesado puede ver una propuesta un tanto más explícita en Horno Chéliz (2006). 
manecer, residir, vivir, yacer, habitar, etc. Lo que tienen en común todos estos predicados es que para resultar gramaticales en la sintaxis necesitan aparecer o con una preposición léxica o con un adjetivo:

a. *Juan reside / Juan reside en Barcelona

b. *El libro permanece / El libro permanece \{sobre la mesa, intacto\}

c. \#Juan vive / Juan vive \{en Madrid, solo\}

La aparente contradicción de los EESS se puede solucionar afirmando que los EESS presentan dos propiedades fundamentales: por un lado son enunciados estativos y por otro son predicados locativos, interpretados como EESS. De acuerdo con nuestra propuesta, en los ejemplos de (20), en los que el verbo es estativo, la estatividad la proporciona el argumento eventivo del predicado verbal que se encuentra saturado por naturaleza, mientras que la interpretación de ES la proporciona el argumento eventivo libre que presenta el otro predicado que aparece obligatoriamente en la oración: o bien la preposición léxica o bien el adjetivo. ${ }^{21}$ De este modo, insistimos en la naturaleza composicional de la interpretación de los EESS: una evidencia a favor de esta propuesta es que si estos predicados pueden aparecer en un enunciado sin SP o sin adjetivo añadido (piénsese en un verbo como vivir en un enunciado como iviven!), se interpretan necesariamente como EECC ('están vivos' o 'pertenecen al conjunto de los vivos'), pues el único argumento que presentan (el del verbo) ya está saturado desde el léxico. ${ }^{22}$

21 Obviamente, para aceptar esta propuesta es necesario admitir que tanto los adjetivos como las preposiciones léxicas presentan argumento eventivo. El lector interesado puede revisar Horno Chéliz (2002), donde encontrará una propuesta en este sentido, en especial en lo que se refiere a la naturaleza de la preposición.

22 Por otro lado, y aunque aquí no podemos profundizar adecuadamente en este aspecto, esta propuesta puede dar cuenta también de ejemplos como Juan entiende solo lo que quiere. En ellas, la posible interpretación como «evento habitual» se podría justificar a partir del evento subordinado que aparece en la oración ('cada vez que quiere entenderlo, lo entiende'). Otro asunto distinto serían ejemplos como Juan desconfía de los taxistas. En este caso, también creemos que la lectura habitual aparece como efecto de la composición al igual que en los casos del tipo de Juan es cruel con Maria, donde parece haber una lectura distinta a la estativa por efecto del complemento (cf. Arche 2004). No obstante, este asunto requiere de un estudio más detallado del que aquí podemos ofrecer. 
Otro asunto algo distinto supone dar explicación a los ejemplos en los que con un predicado eventivo se construye un ES. Considérense oraciones como las de (21). Se trata de distintos EESS, que, a diferencia de lo que ocurría con los ejemplos de (20), solo presentan un predicado verbal, por lo que la interpretación situativa no puede justificarse a partir de la coexistencia de un nuevo elemento predicativo: ${ }^{23}$

a. Las carreteras recorren la costa

b. Las lámparas cuelgan del techo

c. La tela esconde el regalo

Nótese, sin embargo, que en todos estos ejemplos el predicado no estativo requiere de un proceso de ensamble para poder presentar una lectura de estadio. Dicho de otro modo, cuando estos predicados presentan su sujeto léxico en la posición de sujeto sintáctico, en su versión estativa su interpretación es de EC, como en (22): ${ }^{24}$

a. Este tren recorre la costa ('este tren se caracteriza por recorrer la costa')

b. Esa máquina cuelga lámparas ('esta máquina se caracteriza por colgar lámparas')

c. Los perros esconden huesos ('los perros se caracterizan por esconder huesos')

23 Otros predicados que participan en este tipo de enunciados son encontrar (El Museo del Prado se encuentra en Madrid), situar (Las coordenadas se situan lejos de la costa), rodear (La valla rodea el jardín), limitar (La valla limita el jardin), atravesar (La carretera atraviesa las montañas), etc. Todos ellos (en contra de lo afirmado en Horno Chéliz 2002) son predicados lexicalizados como no estativos, que reciben en la sintaxis dicha interpretación. Caso especial representa un verbo como alzarse. Pese a que evidentemente se puede relacionar con el predicado eventivo (causativo) alzar, la voz alzarse parece encontrarse en un proceso de lexicalización, dado que se comporta como un predicado estativo y solo admite participar en un enunciado de estadio en combinación con otro predicado: ${ }^{*} \mathrm{La}$ estatua se alza, frente a La estatua se alza majestuosa.

24 Algo similar ocurre con los verbos de percepción del tipo de oler. Así en una oración como Juan no huele porque está enfriado, donde el sujeto corresponde al experimentante de la sensación de oler, se interpreta de modo caracterizador ('Juan se caracteriza por no oler'). Por el contrario, si se produce una alternancia tal que el objeto pasa a ser el sujeto del predicado (como en La rosa huele; Juan huele), la consecuencia es doble: (i) por un lado, se requiere de un elemento adicional para su comprensión (caracterizador): La rosa / Juan huele (bien / mal), con independencia de si aparece de forma explícita o mediante un mecanismo que genera información implícita; y (ii) en segundo lugar, la proposición pasa a ser interpretada no como caracterizador, sino como situativo ('a la rosa / a Juan le ocurre que produce un determinado olor'). 
En todos los ejemplos de (22) la interpretación es de EC, fruto de la estativización ( = saturación del argumento eventivo). Para conseguir la interpretación de estadio, como ocurre en las oraciones de (21), es necesario que la posición sintáctica de sujeto se rellene mediante un argumento o adjunto distinto: un path [en el caso de (21a)], el objeto interno [como en (21b)], o el instrumental [como en (21c)]. Insistimos con ello en que la lectura de estadio se debe a un proceso de carácter sintáctico y no léxico.

Por otro lado, es especialmente interesante a este respecto el hecho de que el comportamiento de los EESS va a ser diferente en virtud de si se ha producido una alternancia con un elemento como el "tema» o el «instrumento» o con un elemento adicional distinto, como puede ser el "camino». Así, obsérvense las oraciones de (23). En ellas se comprueba como la perífrasis progresiva presenta una distinta interpretación en virtud de este parámetro: en (23a), donde en la posición de sujeto aparece un camino, la oración resulta agramatical, mientras que (23b-c), donde en la posición de sujeto aparece un tema, no solo son gramaticales, sino que además tienen exactamente el mismo significado que los enunciados en presente simple:

a. *Las carreteras están recorriendo la costa

b. Las lámparas están colgando del techo (= Las lámparas cuelgan del techo)

c. La tela está escondiendo el regalo (= La tela esconde el regalo)

El hecho de que este comportamiento dispar dependa del tipo de elemento que se encuentra en la posición de sujeto es comprobable en los siguientes términos: imaginemos una situación en la que alguien está criticando al gobierno local porque la costa está mal comunicada, a lo que se le responde con la frase: «Hombre, esto no es del todo cierto, el gobierno está haciendo cosas. De hecho, las carreteras están recorriendo la costa». Como se ve, en este ejemplo, la oración ya no es agramatical, sino que se muestra como perfectamente posible. Ahora bien, en este caso las carreteras ya no se interpretan como camino, sino más bien como instrumento. De ahí la gramaticalidad del resultado.

Como conclusión de este apartado, podemos decir que la propuesta que presentamos sobre la naturaleza de los enunciados estativos es la siguiente: 
- La diferencia entre los EECC y los EESS es de carácter composicional y no léxico.

- Un estado léxico genera por naturaleza un EC.

- Un verbo no estativo puede estativizarse en la sintaxis, recibiendo de este modo una interpretación de EC.

- Para que un estado léxico participe en un ES es necesario que se encuentre en combinación con una preposición léxica o un adjetivo.

- Por último, para que un verbo no estativo genere un ES se requiere un proceso de estativización junto con un proceso de ensamble de algún tipo.

\section{Conclusiones}

Este trabajo ha tratado de esbozar una propuesta sobre la naturaleza de la estatividad verbal. En los estudios sobre aspecto y aktionsarten esta cuestión es una de las más recurrentes pero menos estudiadas y, precisamente por ello, todavía es una de las más confusas. Creemos, de este modo, que resulta absolutamente necesario realizar un estudio amplio y detenido sobre su naturaleza y sus características.

La primera conclusión fundamental de este trabajo es que es necesario distinguir de forma nítida los estudios sobre estatividad a nivel léxico de los estudios sobre enunciados estativos. En el breve recorrido histórico que hemos realizado se observa como uno de los principales problemas ha sido, precisamente, la enorme confusión de niveles que caracteriza en general al estudio de la estatividad.

En el ámbito de la estatividad léxica, nos situamos dentro del modelo del Lexicón Generativo, según el cual cada predicado presenta una serie de fases eventivas que posteriormente focalizará en virtud del aspecto gramatical utilizado. Así, hemos considerado que los estados léxicos son aquellos que focalizan por naturaleza una fase estativa. Por otro lado, siguiendo unas sencillas reglas asociadas a la categoría gramatical de aspecto, los estados léxicos pueden focalizar fases no estativas previstas desde el lexicón. Nuestra aportación es considerar, en contra de lo que se suele aceptar en la bibliografía más reciente, que los estados léxicos no 
carecen de argumento eventivo. Ahora bien, aceptamos que dicho argumento se comporta de modo especial con respecto al resto de predicados verbales. Y este comportamiento especial depende en nuestra opinión de que los verbos estativos presentan el argumento eventivo saturado con la interpretación de estado desde el lexicón.

En el ámbito de los enunciados estativos, por otra parte, consideramos que la estatividad oracional pasa por una saturación (desde el léxico o en la combinatoria) de un argumento eventivo. Dicha saturación, es, además, responsable de una determinada interpretación de esos enunciados: la interpretación clasificativa. De este modo, la posible interpretación situativa siempre depende de determinados procesos sintácticos y de combinatoria (combinación de predicados y ensamble entre otros).

Muchas son, a partir de aquí, las líneas de investigación que va a ser necesario desarrollar, como hemos ido apuntando a lo largo de toda nuestra exposición. No obstante, en cualquier tipo de estudio sobre la estatividad, creemos que es imprescindible que se establezca de forma nítida cuál es el ámbito que interesa al investigador: los predicados que lexicalizan estados o los enunciados que se relacionan con situaciones de estatividad.

\section{Bibliografía}

AlbertuZ, F. J. (1995): «En torno a la fundamentación lingüística de la Aktionsart», Verba, 22, 285-337. Citado por la publicación electrónica en: <webs. uvigo.es/albertuz/aktionsart.pdf $>$.

ARCHE GARCÍA-VALDECASAS, M. ${ }^{a}$ J. (2004): «Propiedades aspectuales y temporales de los predicados de individuo", ms. Tesis doctoral presentada en la Universidad Complutense de Madrid. Citado por la publicación electrónica en: <http://eprints.ucm.es/tesis/fll/ucm-t28003.pdf>.

Bertinetto, P.-M. (1997): Il dominio tempo-aspettuale. Demarcazioni, intersezioni, contrasti, Turín, Rosenberg \& Sellier.

Borer, H. (2005): Structuring Sense, Oxford, Oxford University Press.

CARLSON, G. (1977 [1980]): Reference to Kinds in English, Nueva York, Garland Press.

CARLSON, L. (1981): «Aspect and Quantification», Sintax and Semantics, 14: 31-64. Chierchia, G. (1995): «Individual-Level predicates as inherent generics», en G. Carlson y F. Pelletier (eds.), The Generic Book, Chicago, University of Chicago Press: 176-223. 
Coll-Florit, M., I. Castellón y S. Climent (2008): «Sobre la natura dels estats. Una revisió basada en corpus», Sintagma. Revista de lingüistica, 20: 21-36. Publicación electrónica en: <http://dialnet.unirioja.es/servlet/ articulo?codigo $=2916992>$.

Comrie, B. (1976): Aspect: An Introduction to the Study of Verbal Aspect and Related Problems, Cambridge, Cambridge University Press.

Croft, W. (2000): Verbs: Aspect and Argument Structure, ms. Citado por la publicación electrónica en: <http://www.unm.edu/ -wcroft/WACpubs. html>.

Cuartero Otal, J. (2006): «Hacia otro modelo de análisis de la aspectualidad», Moenia, 11: 197-228.

- (2007): «Sobre estados y clases de estados», en J. Cuartero Otal y M. Emsel (eds.), Vernetzungen: Bedeutung in Wort, Satz und Text. Festschrift für Gerd Wotjak zum 65, Geburtstag, Fráncfort, Peter Lang: 111-122.

- y M. ${ }^{a}$ C. Horno ChÉlIz (en prensa): «Estados, estatividad y perífrasis», en J. Cuartero, L. García y C. Sinner (eds.), Las relaciones entre el tiempo, el aspecto y el modo de acción. Las perífrasis verbales, Múnich, Peniope.

Davidson, D. (1967): "The Logical Form of Action Sentences», en Nicholas Rescher (ed.), The Logic of Decision and Action, Pittsburgh, University of Pittsburgh Press: 81-95.

De Miguel, E. (1999): «El aspecto léxico», en Ignacio Bosque y Violeta Demonte (dirs.), Gramática Descriptiva de la Lengua Española, vol. 2, Madrid, Espasa-Calpe: 2971-3060.

- y M. Fernández Lagunilla (2004): «Un enfoque subeventivo de la relación entre predicados secundarios y adverbios de manera», Revue Romane, 39.1: 24-44.

Demonte, V., y P. J. Masullo (1999): «La predicación: Los complementos predicativos», en I. Bosque y V. Demonte (dirs.), Gramática Descriptiva de la Lengua Española, Madrid, Espasa: 2461-2523.

DOWTY, D. (1979): Word Meaning and Montague Grammar, Dordrecht, Kluwer. García Fernández, L. (2006): "A Stativistic Theory of Lexical Aspect and its Impact on Grammatical Aspect», en L. Brugè (ed.), Studies in Spanish Syntax, Venecia, Cafoscarina: 61-103.

Garey, H. B. (1957): «Verbal aspects in French», Language, 33: 91-110.

Horno Chéliz, M. ${ }^{a}$ C. (2002): Lo que la preposición esconde. Estudio sobre la argumentalidad preposicional en el predicado verbal, Zaragoza, Prensas Universitarias de Zaragoza (Knowledge, Language, Communication, 1).

- (2006): «Sintagmas Genéricos en posición de objeto», Revista Virtual de Estudos da Linguagem-ReVEL, v. 5, n. 8. Publicación electrónica en: 
$<$ http://www.revel.inf.br/site2007/_pdf/8/artigos/revel_8_sintagmas_genericos_ en_posicion_de_objeto.pdf>.

JACKENDOFF, R. S. (1987): «The status of thematic relations in linguistic theory», Linguistic Inquiriy, 18: 369-412.

KATZ, G. (2003): «Event arguments, adverb selection, and the Stative Adverb Gap», en E. Lang, C. Maienborn y C. Fabricius-Hansen (eds.), Modifying Adjuncts (Interface Explorations 4): 455-474.

KennY, A. (1963): Action, emotion and Will, Humanities Press.

KLEIN, W. (1994): Time in Language, Londres/Nueva York, Routledge.

Krifka, M., F. J. Pelletier, G. Carlson, A. ter Meulen, G. Chierchia y G. LiNK (1995): «Genericity: an Introduction», en G. Carlson y F. J. Pelletier (eds.), The Generic Book, Chicago, U. P.: 1-124.

LAKOFF, G. (1970): «Linguistics and Natural Logic», Synthese, 22: 151-271.

LYONS, J. (1977): Semantics. Vol. 1, Cambridge, Cambridge University Press.

LYS, F., y K. MOMmER (1986): «The problem of aspectual verb classification: a two-level approach", Chicago Linguistic Society, 22: 216-230.

Maienborn, C. (2003): Die logische Form von Kopula-Sätzen, Berlín, AkademieVerlag.

MANninen, S. (2001): «A Minimalist Analysis of Stage Level and Individual Level Predicates", Working Papers in Linguistics, 1: 27-41.

Martínez Linares, M. (2004): «En torno a los predicativos descriptivos del sujeto y los "estados" "de estadio" como predicativos primarios", Estudios de Lingüistica: El verbo: 331-362.

Mourelatos, A. P. D. (1978): «Events, processes, and states», Linguistics and philosophy, 2: 415-434.

Pustejovsky, J. (1991): "The Syntax of Event Structure», en B. Levin y S. Pinker (eds.), Lexical and Conceptual Structure, Oxford, Blackwell: 47-81.

- (1995): The Generative Lexicon, Cambridge (Mass.), MIT Press.

Quirk, R., S. Greenbaum, G. Leech y J. Svartvik (1985): A Comprehensive Grammar of English, Londres, Longman.

Rothmayr, A. (2009): The Structure of Stative Verbs, Ámsterdam, John Benjamins.

SASSE, H.-J. (2002): «Recent Activity in the Theory of Aspect: Accomplishments, Achievements, or just non-Progressive State?», Linguistic Typology, 6/2: 199-271.

SMITH, C. (1991 [1997]): The Parameter of Aspect, Dordrecht, Kluwer.

Vendler, Z. (1957 [1967]): «Verbs and Times», en Z. Vendler, Linguistics and Philosophy, Ithaca NY, Cornell University Press: 97-121.

VETTERs, C. (1996): Temps, aspect et narration, Ámsterdam/Atlanta, Rodopi. 


\section{CUESTIONES PENDIENTES DE LA TIPOLOGÍA SEMÁNTICA PARA EL ANÁLISIS DE LOS EVENTOS DE MOVIMIENTO*}

IRAIDE IBARRETXE-ANTUÑANO (Universidad de Zaragoza. Grupo Sylex)

\section{El movimiento y la semántica tipológica}

Según el Diccionario de la Real Academia, el movimiento se define de la siguiente manera:

1. m. Acción y efecto de mover.

2. m. Estado de los cuerpos mientras cambian de lugar o posición.

En esta definición se recogen dos de los puntos principales de cómo percibimos el movimiento, como un desplazamiento o como la ausencia del movimiento. El concepto de movimiento parece existir codificado en

* La investigación subyacente a esta aportación forma parte del proyecto HUM2007-64200/FILO subvencionado por el Gobierno de España. 
todas las lenguas del mundo, es decir, todas las lenguas parecen dedicar ciertos mecanismos lingüísticos para expresar el movimiento. Sin embargo, cabe en este momento hacerse una pregunta fundamental: ¿expresamos y percibimos el movimiento todos los humanos de igual manera?

Dentro de la lingüística, esta pregunta ha recibido diferentes respuestas según el modelo teórico que se haya adoptado. Por un lado, las teorías «universalistas» (cf. Landau y Jackendoff 1993) que postulan que el movimiento se expresa igualmente en cualquier lengua, y por otro lado, las teorías relativistas (cf. Choi y Bowerman 1991; Levinson 2003; Levinson y Wilkins 2006), que defienden que las lenguas sí que influyen a la hora de describir el movimiento. En este artículo nos vamos a centrar en la última posición, más concretamente vamos a basar nuestra discusión en la teoría de los patrones de lexicalización de Talmy, que pasamos a describir en la siguiente sección.

\subsection{La tipología de Talmy}

Talmy $(1991,2000)$ en su teoría de los patrones de lexicalización distingue entre dos tipos de elementos: los elementos semánticos, que serían componentes conceptuales que caracterizan a un determinado evento, y los elementos superficiales, que serían los diferentes recursos lingüísticos que una lengua tiene para expresar los elementos semánticos. Los primeros serían universales, ya que describen en dominio conceptual, y los segundos particulares para cada lengua. Según Talmy, la relación entre los elementos semánticos y los elementos superficiales no es necesariamente de una correspondencia uno a uno, es decir, a veces un elemento semántico necesita para ser expresado un único elemento superficial, pero muchas veces esas correspondencias no tienen por qué ser así. Podemos tener que un elemento superficial codifica dos o tres elementos semánticos, o al contrario, que un único elemento semántico necesita varios elementos superficiales. A estas correspondencias entre unos elementos y otros Talmy las denomina «estrategias de empaquetamiento».

En el caso concreto de los eventos de movimiento, que Talmy (1991) define como situaciones que contienen movimiento o permanecen en una situación estacionaria, los elementos semánticos que define son los siguientes: Figura: entidad que realiza el movimiento; Base: fondo 
sobre el cual se mueve la Figura; Movimiento: la presencia o la ausencia de movimiento en sí misma; Camino: ${ }^{1}$ trayectoria que sigue la Figura; Causa: agente que causa el movimiento; y Manera: forma en la que se desarrolla el movimiento. Los cuatro primeros son principales porque pertenecen exclusivamente a los eventos de movimiento, de estos, el más importante, el que debe aparecer siempre para que se pueda considerar un evento de movimiento es el del Camino. Los dos últimos son secundarios porque no son propios exclusivamente de este tipo de eventos.

Veamos un par de ejemplos que ilustran cada uno de estos componentes:

$\begin{array}{llll}\text { El niño } & \text { salió } & \text { corriendo } & \text { de la habitación } \\ \text { Figura } & \text { Movimiento } & \text { Manera } & \text { Base } \\ & \text { Camino } & & \end{array}$

$\begin{array}{llll}\text { El papel } & \text { se cayó } & \text { al suelo } & \text { por el viento } \\ \text { Figura } & \text { Movimiento } & \text { Base } & \text { Causa } \\ & \text { Camino } & & \end{array}$

En (1), el niño corresponde al elemento semántico de la Figura, el verbo principal salió "fusiona» dos componentes a la vez, el Movimiento y el Camino, el gerundio corriendo expresa la Manera y, finalmente, el sintagma preposicional de la habitación se ocupa de la Base. El ejemplo (2) tiene los mismos componentes salvo por uno, el sintagma preposicional por el viento que expresa la Causa.

Según acabamos de ver más arriba, en teoría, las posibles estrategias de empaquetamiento que existen podrían ser infinitas, ya que las posibilidades de combinación entre estos elementos no tendrían límite. Sin embargo, y este es uno de los puntos interesantes desde la perspectiva tipológica, parece ser que las lenguas del mundo tienden a seguir mayoritariamente dos estrategias en su expresión más característica del evento de movimiento. Estos serían los dos patrones de lexicalización propuestos

1 Hemos utilizado el término Camino en vez de otros como "trayectoria», "dirección» o "direccionalidad», primero para que no se confunda con otros términos dentro de la lingüística cognitiva (por ej. Langacker trajector), y segundo, porque el concepto de Talmy de Path es mucho más complejo y rico de lo que una etiqueta como las de arriba puede abarcar. 
por Talmy. Por un lado, tendríamos las lenguas de marco verbal que fusionan el Movimiento y el Camino en el verbo principal, y la Manera, si es que aparece, en una expresión aparte (un sintagma preposicional, un adverbio, un gerundio...). Por otro lado, las lenguas de marco satélite que siguen la estrategia contraria: el Movimiento y la Manera vienen lexicalizados en el verbo principal, y el Camino fuera del verbo, en el "satélite» (véase sección 1.2). Los ejemplos de Talmy en (3) y (4) ilustran estos dos patrones respectivamente.

$\begin{array}{rll}\text { La botella } & \text { salió } & \text { flotando } \\ & \text { Movimiento } & \text { Manera } \\ & \text { Camino } & \\ \text { The bottle } & \text { floated } & \text { out } \\ & \begin{array}{l}\text { Movimiento } \\ \text { Manera }\end{array} & \text { Camino } \\ & \end{array}$

A pesar de la utilidad desde el punto de vista tipológico de estos dos patrones para explicar cómo se expresa el movimiento en un gran número de lenguas (véase el apéndice en Strömqvist y Verhoeven 2004), la teoría de Talmy no está exenta de problemas. Veamos algunos de los más conocidos y debatidos en la siguiente sección.

\subsection{Cuestiones problemáticas}

Uno de los aspectos más controvertidos de la teoría de Talmy, y que más atención está recibiendo desde fuera del propio modelo, es el concepto de satélite. Talmy (1985: 102) define el satélite como un constituyente gramatical inmediato, siempre que no sea un sintagma nominal, flexión, o auxiliar. Ejemplos de satélite serían las partículas del inglés, los prefijos verbales rusos, los afijos no flexivos del atsugewi o los coverbos chinos. La existencia de satélites, como hemos visto en la sección anterior, es una característica de las lenguas de marco de satélite. Sin embargo, en ciertas lenguas de marco verbal, como en el chantyal (Noonan 2003) y en el euskara (Ibarretxe-Antuñano 2004a), también existen ciertos elementos que se asemejan mucho a las funciones y a la definición de los satélites y que forman construcciones muy parecidas a las típicas de las lenguas de otro grupo. Veamos algunos ejemplos en (5) y (6). 


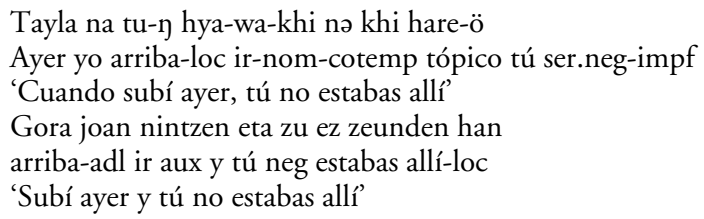

Según la teoría de Talmy ninguna de estas dos lenguas podría tener satélites, pero la expresión $t u-\eta$ (arriba-loc) del chantyal y gora (arriba-adl) del euskara parecen tener funciones muy similares. Como solución a estos problemas, diferentes autores han propuesto que el concepto de satélite se amplíe, y pase a designar cualquier elemento adjunto al verbo como, por ejemplo, los sintagmas preposicionales (Beavers 2008; Beavers, Levin y Tham, en prensa; Croft el al., en prensa; Nikitina 2008).

Otro de los aspectos problemáticos ha sido la lexicalización de elementos semánticos en los verbos principales. En la descripción que hemos dado más arriba, se decía que en las lenguas de marco verbal, los verbos principales no lexicalizaban la Manera, sino el Camino. Sin embargo, como se muestra en (7) y (8), la manera sí que puede lexicalizarse en los verbos principales.

$\begin{array}{lll}\text { La niña } & \text { corrió } & \text { hacia su casa } \\ & \begin{array}{l}\text { Movimiento } \\ \text { Manera }\end{array} & \\ \text { La pelota } & \begin{array}{l}\text { rodó } \\ \text { Movimiento }\end{array} & \text { hasta el río } \\ & \text { Manera } & \end{array}$

Lo que no parece estar permitido en estas lenguas es que el verbo principal sea a la vez de Manera y describa un evento télico, es decir, que señale el destino final de la Figura como en una frase del inglés The girl ran into the house (véase Aske 1989; Cuartero Otal, en prensa; Morimoto 2001). En estos casos, si el verbo principal es de Manera, la lectura no sería télica sino que se interpretaría como una actividad, como, por ejemplo, en (9), en donde se entiende que la niña está corriendo en la casa, por dentro, pero no que va de fuera de la casa al interior corriendo. Para poder tener una lectura así, obligatoriamente tendríamos que lexicalizar la Manera fuera del verbo principal como en (10), tal y como predice la teoría. A este tipo de restricción se le conoce con el nombre de restricción del cruce de límites (Slobin y Hoiting 1994). 
La niña corrió

Movimiento

Manera

La niña entró

Movimiento

Camino (a)dentro de su casa

corriendo en la casa

Manera

Un tercer problema que ha sido discutido ampliamente en la literatura ha sido la insuficiencia de la dicotomía de Talmy para dar cuenta de lenguas que tienen estructuras que no se pueden clasificar ni en el grupo de las lenguas de marco verbal ni en el de las lenguas de marco satélite. Las lenguas con verbos seriales (poliremia) y las lenguas con verbos genéricos son dos de estos tipos de lenguas problemáticas.

(11) Jevia táná yina xoa me

niño.def gatear.hab ir.hab habitación-def área.contenida

'El niño entra gateando en la habitación'

Buru yugung garam

vuelta correr 3sg-venir.prs

'Viene corriendo de vuelta'

Como vemos en el ejemplo (11) de la lengua africana ewe, el problema que surge en las lenguas de verbos seriales es que existen dos verbos de igual importancia que funcionan como verbos principales, uno de Manera 'gatear' y otro de Camino 'entrar' (Ameka y Essegbey, en prensa). Exactamente lo contrario ocurre en las lenguas con verbos genéricos como la australiana jaminjungan en (12); ahora lo que tenemos son verbos genéricos que tienen una función aspectual o deíctica, pero que no codifican ni la Manera ni el Camino. Esta información viene dada en unos elementos parecidos a los satélites denominados preverbos (Schultze-Berndt 2000). El resultado es el mismo, no se pueden clasificar en ninguno de los dos tipos propuestos por Talmy.

Para solucionar esta situación diversos autores (cf. Ameka y Essegbey, en prensa; Slobin y Hoiting 1994; Zlatev y Yangklang 2004) han propuesto una tercera vía que, siguiendo la terminología de Slobin (2004: 249), se suele denominar lenguas de marco equipolente o equivalente. En este grupo, los componentes de Camino y Manera se expresan a través de formas gramaticales equivalentes y se incluyen las lenguas de verbos seriales (niger-congo, hmong-mien, sino-tibetana, tai-kadai, mon-khmer, austronésicas), las lenguas de verbos bipartitos (algonquiano, athabaskano, 
hokan, klamath-takelman), y las lenguas de verbos genéricos (jaminjungan), entre otras.

Finalmente, el cuatro problema que vamos a repasar en este artículo es la cuestión de la variabilidad interna que existe entre las lenguas que pertenecen a cada uno de los dos (o tres) patrones de lexicalización. Las lenguas en estos grupos no se comportan de la misma forma cuando describen los diferentes componentes semánticos, especialmente los de Manera y Camino. Vamos a ilustrar esta variabilidad con el euskara. Según se puede observar en (13), esta lengua sigue el patrón de lexicalización de marco verbal, el verbo, irten 'salir' lexicaliza el Camino y la manera viene expresada fuera en una expresión adverbial, hegaka 'volando'.

$$
\begin{aligned}
& \text { Eta erlauntzatik erle guztiak irten ziren hegaka } \\
& \text { y colmena.abl abeja todas.abs salir aux volando } \\
& \text { 'Y todas las abejas salieron de la colmena volando' }
\end{aligned}
$$

Además de las características de lexicalización, autores como Slobin (1996, 1997, 2004) han descrito los estilos narrativos propios de los eventos de movimiento en estas lenguas. Según este autor y sus colaboradores (Özçalişkan y Slobin 2003), las lenguas de marco verbal no suelen describir el componente de Manera a no ser que sea discursivamente relevante. Este comportamiento lo atribuyen al menos a dos posibles razones. Por un lado, a la falta de recursos lingüísticos numerosos y suficientemente expresivos para describir la Manera; es decir, estas lenguas tienen naturalmente elementos lingüísticos para caracterizar a este componente semántico, pero estos suelen describir aspectos genéricos de la Manera (por ej., en español correr, saltar) sin entrar en mucho más detalle, sin describir específicamente modos de andar, saltar o correr (por ej., en inglés lope 'correr dando pasos largos y relajados', strut 'andar con un cierto aire de dignidad o importancia, dando pasos seguros y con la cabeza en alto'). Por otro lado, el hecho de que la Manera se exprese fuera del verbo hace que la descripción del evento de movimiento sea más compleja y por lo tanto, discursivamente más cargada. Con respecto al componente del Camino, las lenguas de marco verbal suelen dar esta información en el verbo principal, y como máximo en una expresión complementaria. Suelen tener estilos retóricos más estáticos que dinámicos, ya que las trayectorias no se suelen describir sino inferir de los contextos discursivos. 
A pesar de que muchas lenguas de marco verbal se ciñen a esta caracterización, hay muchas otras, como el euskara, que se comportan de forma diferente. El euskara tiene un repertorio de más de 800 expresiones ideofónicas que caracterizan en gran detalle y de forma muy rica la Manera de movimiento, es decir, que no hay una falta de recursos lingüísticos (Ibarretxe-Antuñano 2006a). Al mismo tiempo, esta lengua tampoco respeta la tendencia a describir el Camino escuetamente; al contrario, en euskara el verbo suele tener varios elementos complementarios que le dan a la descripción del evento del movimiento una gran dinamicidad como en (14), en el que el verbo erori 'caer' tiene tres elementos:

\section{Danak amildegitikan behera erori zian ibai batera} todo.abs.pl precipicio.abl.loc abajo.adl caer.perf aux río un.al 'Todos se cayeron del precipicio a abajo a un río'

Para poder captar esta variabilidad interna se han propuesto las escalas o continuos de saliencia ${ }^{2}$ de Manera (Slobin 2004) y de Camino (Ibarretxe-Antuñano 2004b, 2009a). En estas escalas, las lenguas ocuparían diferentes posiciones según el grado de foco y elaboración de los componentes del evento de movimiento. Las lenguas entonces se situarían entre dos polos, el polo de saliencia alta y el polo de saliencia baja. La idea que subyace a estos continuos es que hay una relación directa entre la codificación del componente semántico, Manera o Camino, y los recursos lingüísticos de una lengua: cuantos más recursos haya para codificar ese elemento, más probabilidades hay de que la lengua ocupe un lugar más cercano a la saliencia alta.

\section{Otras cuestiones abiertas: más allá de la semántica tipológica}

Hasta ahora nos hemos centrado en algunos problemas que planteaba la teoría de Talmy con respecto a los eventos de movimiento. En la mayoría de los casos, estos problemas tenían una solución dentro de la gramática. Sin embargo, las cuestiones que vamos a tratar en esta sección

2 Se utiliza el anglicismo "saliencia» con el sentido de accesibilidad cognitiva para mantener el término acuñado por Slobin (2004). 
tienen un cariz diferente, ya que se trata de tendencias discursivas cuya explicación parece quedarse fuera de la gramática. Los tres casos que se van a discutir surgen del análisis de los eventos de movimiento en euskara, pero es posible que futuras investigaciones revelen que estos mismos problemas se puedan dar en otras lenguas. Tal y como reza el título de esta sección, las planteamos como cuestiones «abiertas" por lo que cada apartado en vez de terminar con una solución acaba con preguntas de reflexión.

\subsection{La construcción de Camino Completo}

Hemos mencionado ya en la sección anterior que el euskara es una lengua que tiende a describir el componente de Camino en gran detalle. Una de las construcciones ${ }^{3}$ que se suele utilizar frecuentemente en estos eventos es la que denominamos "Camino Completo" (Ibarretxe-Antuñano, en prensa), y que se definiría como la tendencia a expresar lingüísticamente en la misma frase el origen y el destino del movimiento translacional, incluso cuando uno de estos componentes puede entenderse como pleonástico. Lo interesante de esta construcción es que se utiliza siempre que el Camino está "delimitado conceptualmente», es decir, cuando la situación del origen y del destino se conceptualizan como puntos fijos en el espacio, y como resultado la distancia que hay entre ellos (Camino) se ve como una trayectoria restringida y delimitada por estos dos puntos fijos. El foco de atención en estos casos no está en los dos puntos delimitadores, el origen y el destino, sino en el Camino delimitado por ellos.

Un ejemplo de la construcción de Camino Completo sería la expresión amildegitikan behera (precipicio.abl.loc abajo.adl) en el ejemplo (14) de más arriba, y que reproducimos aquí como (15).

(15) Danak amildegitikan behera erori zian ibai batera todo.abs.pl precipicio.abl.loc abajo.adl caer.perf aux río un.al 'Todos se cayeron del precipicio a abajo a un río'

3 El témino "construcción» en esta sección se utiliza en el sentido de la Gramática de Construcciones de Goldberg (1995), es decir, como un emparejamiento entre forma y significado. 
En este evento de movimiento la trayectoria es descendente y viene marcada explícitamente no solamente en el verbo (erori 'caer') y en la expresión ibai batera ('a un río'), sino también en la información de la construcción de Camino Completo, que nos denota una trayectoria vertical.

La construcción de Camino Completo tiene unas características formales muy bien definidas. Por un lado, siempre tiene el mismo orden y composición, es decir, primero se menciona el origen que suele ser un lugar específico con la marca de caso ablativo (amildegitikan) ${ }^{4}$ y después el destino que suele ser un nombre espacial con la marca de adlativo (behera). ${ }^{5}$ Además, es una unidad indivisible: es imposible insertar ningún otro tipo de elemento entre el origen y el destino. Por ejemplo, si al ejemplo en (15) quisiéramos añadirle un adverbio como bapatean 'de repente', no podríamos ponerlo en medio de estos dos elementos sino en cualquier otra parte como vemos en (16).

(16) ( $\sqrt{ }$ bapatean) amildegitikan (*bapatean) behera ( $\sqrt{ }$ bapatean) erori zian $(\sqrt{ }$ bapatean) de.repente precipicio.abl.loc de.repente abajo.adl de.repente caer.perf aux de.repente

'De repente se cayeron del precipicio a abajo'

El uso de este tipo de construcciones no está restringido solamente a este tipo de desplazamiento descendente sino que puede darse con todo tipo de trayectorias, como por ejemplo, hacia fuera en (17) o hacia dentro en (18).

(17) Pelota U formako figura baten erditik kanpora urtetzen da pelota.abs u forma.adn figura una.gen medio.abl fuera.adl salir.hab aux 'La pelota sale del medio de la figura con forma de U al exterior'

Pasillo ospeletik barrura sartuko zarete ilunetan pasillo sombrío.abl dentro.adl entrar.fut aux oscuro.loc 'Y entraréis del pasillo sombrío al interior a oscuras'

4 El uso del locativo -an es exclusivamente enfático, no espacial.

5 Es importante señalar que el uso de un lugar específico y del nombre espacial es solamente una de las posibilidades que tiene la realización de la construcción de Camino Completo. Como se muestra en Garai e Ibarretxe-Antuñano (2002), los elementos que ocupan el origen y el destino pueden ser de todo tipo y con significados tanto físicos como metafóricos. Lo que hay que tener en cuenta es que es una unidad indivisible y que se focaliza en la trayectoria o Camino descrito entre estos dos puntos. 
Pero quizás lo más importante de esta construcción, y que es realmente lo que hace que sea una cuestión abierta, es el buscar una explicación al uso que hacen los hablantes nativos del euskara de la misma. En los eventos de movimiento en los que se dan trayectorias completas como las que hemos descrito en los ejemplos de más arriba, los hablantes nativos tienden mayoritariamente a utilizar esta construcción. Lo interesante es que su uso no es un requerimiento gramatical, es decir, podrían, y de hecho lo hacen, mencionar solamente el origen del movimiento o el destino del movimiento, pero en su gran mayoría prefieren esta construcción. Los datos que tenemos de hablantes que tienen el euskara como segunda lengua (Ibarretxe-Antuñano 2004c), muestran que, a pesar de tener una competencia máxima en esta lengua (nivel EGA correspondiente al nivel C1/ALTE nivel 5), ninguno de ellos utiliza esta construcción. Entonces, ipor qué se utiliza la construcción de Camino Completo?, jes un rasgo tipológico del euskara para los eventos de movimiento pero su requerimiento sería pragmático en vez de gramatical?

\subsection{La omisión verbal}

La segunda cuestión abierta está relacionada con lo que llamamos «omisión verbal», es decir, la ausencia total o parcial del verbo. En el sistema verbal vasco, se suele distinguir entre verbos sintéticos —el verbo léxico con información sobre el tiempo, modo y estructura argumental- y verbos analíticos o perifrásticos -el verbo léxico participial con información sobre el aspecto + el verbo auxiliar con información del tiempo, modo y estructura argumental (cf. Hualde y Ortiz de Urbina 2003: caps. 3.5, 4.1, 4.5).

Como hemos comentado en trabajos anteriores (Ibarretxe-Antuñano $2004 d$ ), una de las características que tiene el sistema verbal vasco desde el punto de vista sintáctico es que muestra un alto grado de elipsis y de gapping sintáctico (Lappin 1996; Lobeck 1995), tanto posterior (Gastañaga 1977) como anterior. Además, el euskara también permite otros casos de gapping en los que no hay un antecedente sintáctico, bien porque este se encuentra más allá de la coordinación o porque el gapping se produce sobre elementos que no tienen homólogos sintácticos. Estos serían casos de gapping pragmático como el que vemos en (19). 
(19) Nire bi anaiak atzerrian izan dira abuztuan. Mikel Nepalera joan da, baina ez du espero zuenik aurkitu. Ez da harritzekoa, udan Nepal aldea turistaz beterik egoten da eta. Joxe berriz Indiara $[x x x]$, eta askoz errazago izan zaio bertako cultura ezagutzea.

'Mis dos hermanos han estado en el extranjero en agosto. Mikel fue al Nepal, pero no encontró lo que esperaba. No es de extrañar, ya que el Nepal está lleno de turistas durante el verano. Joxe, sin embargo, [fue] a la India, y le fue mucho más fácil conocer la cultura del lugar' (traducción nuestra)

Como explica Amundarain (2003: 875), en este ejemplo hay dos tópicos en contraste (Mikel y Joxe) con remas similares, en los que el segundo rema (Indiara 'a la India') contrasta con el primero (Nepalera 'a Nepal'). En otras palabras, son casos en los que el antecedente es discursivo, no sintáctico.

Pero las posibilidades de omisión verbal no acaban aquí, en la explicación pragmática. En euskara se pueden dar casos en los que simplemente el verbo se ha omitido pero sin tener ni un antecedente sintáctico ni un antecedente discursivo como en el caso anterior. Las frases en (20) y (21) ilustran esta situación.

... beste euskaldunentzat bukaturik utzi nuena Italia aldera $[x x x]$ baino lehen otro vascos.ben terminado dejar aux.1sg.lo.que Italia lado.adl xxx antes 'Lo que dejé terminado para otros vascos antes de [irme] a Italia' (Mendiburu)

(21) Ziztu bizian desagertu da palmondoen artetik, ur putzuetan zipriztinak eginez bere txozarantz oinutsik [xxx]

salivazo vivo.loc desaparecer aux palmera.pl.gen entre.abl agua charco.pl.loc salpicaduras.pl.abs haciendo su choza.dir descalzo

'Desapareció de repente entre las palmeras, [se dirigió] hacia su choza descalzo, pisando por todos los charcos' (Sarrionandia)

$\mathrm{Al}$ igual que en el caso anterior, la omisión verbal no es un requerimiento gramatical, el verbo o parte de él se puede o no mencionar, pero los hablantes nativos tienden a omitirlo en sus descripciones de los eventos de movimiento.

Entonces, la cuestión abierta de esta sección: ¿cómo explicamos esta omisión verbal? ¿Acaso influye el hecho de que el euskara es una lengua SOV y, por lo tanto, la información del verbo se puede omitir ya que viene dada por los elementos (espaciales) que le anteceden? 


\subsection{Los ideófonos de Manera de movimiento}

Finalmente, vamos a retomar uno de los puntos que mencionábamos al final de la sección 1.2, los recursos lingüísticos del euskara para la descripción de la Manera. El euskara es una lengua que, al igual que otras como el japonés (Kakehi, Tamori y Schourup 1996), tiene un inventario de ideófonos muy numeroso, se han contabilizado más de 4000 ejemplos (Ibarretxe-Antuñano 2006b).

Como ocurre también en este tipo de lenguas (Ibarretxe-Antuñano 2006a; Ohara 2003; Sugiyama 2005), una gran parte de estos ideófonos se pueden utilizar para describir diferentes aspectos de los eventos de movimiento, y en especial para describir la Manera. Veamos un ejemplo en (22).

\section{Eta Aitor biriboraka lurrera bota eban y aitor rodando suelo.al tirar aux \\ 'Y tiró a Aitor rodando al suelo'}

En este ejemplo, el ideófono biriboraka 'dar vueltas sin control' funciona como un adverbio y aportaría la información correspondiente a la forma de moverse. Si el euskara es una lengua que tiene abundantes recursos para la descripción de la Manera, y seguimos la definición de la Escala de Saliencia de Manera de Slobin (2004), que dice: «cuanto más accesible y fácil de codificar sea el componente semántico de la Manera en una lengua, más posibilidades hay de que dicha lengua sea una lengua de saliencia de Manera alta», entonces, el euskara tendría que ser una lengua de saliencia de Manera alta.

El problema viene cuando al revisar los datos del uso de los ideófonos en la descripción de los eventos de movimiento vemos que a pesar del gran número que existe, solamente se utiliza una porción muy pequeña (Ibarretxe-Antuñano 2009b). En los datos orales provenientes de las historias de la rana encontramos diez ejemplos — dindilako 'colgado'; dindilizka, dilinda 'colgando'; ffrrffrrzz, brrrsssttt 'pasar volando a toda velocidad y de repente'; kuskur 'encogido'; rostean 'velozmente'; biriboraka 'dar vueltas sin control'; plisti plasta 'patullar, chapotear'; taka taka 'andar con pasos pequeños y cortos'- y en los datos escritos de novelas solamente ocho casos - tirriki-tarra$k a$ 'moverse con pesadez, despacio, arrastrándose'; arrapaladan 'muy rápido y sin control'; draz draz draz 'arrastrando los pies'; brau 'de repente'; dzanga 
'bucear, tirarse al agua'; ttapa ttapa 'andar con pasos pequeños y cortos'; trostan 'trotando'; tipi tapa 'andar con pasos pequeños y regulares'.

Los ideófonos se utilizan en los eventos de movimiento para dar expresividad a la descripción como en el ejemplo (23), en donde se utiliza tirrikitarraka 'moverse con pesadez, despacio, arrastrándose' cuando se podría haber dicho astiro o geldiro 'despacio' en su lugar. La expresividad es uno de los rasgos tipológicos de uso típico en estas palabras (Voeltz y Kilian-Hatz 2001). Pero también se utilizan porque como en el caso de biriboraka 'dar vueltas sin control' en (22) más arriba, esta es la única palabra en euskara, o al menos la más común, para designar este tipo de movimiento.

Tirriki-tarraka sartu gara Interstate 80ko trafikoaren suge amaigabean ide entrar aux interstante 80 .adn tráfico.gen serpiente interminable.loc

'Nos metimos poco a poco y lentamente en la Interestatal 80 , que era como una columna de tráfico interminable'

Aún y todo, el resultado final es que a pesar de ser una lengua que en teoría debería ser de saliencia de Manera alta, el euskara no se puede incluir en este grupo. Pero, ¿por qué?, ¿qué factores pueden explicar este comportamiento? Por un lado, podríamos decir que realmente la Manera no parece atraer la atención de los hablantes y, por lo tanto, no es discursivamente relevante (Slobin 1997: 455; Özçalişkan y Slobin 2003: 264). Pero, por otro lado, también podemos pensar en otro tipo de razones. Los ideófonos tienen un estatus bastante poco reconocido en la gramática vasca en general, ya que no hay apenas estudios y se les suele erróneamente relacionar exclusivamente con contextos muy específicos, principalmente con el habla infantil y la literatura oral (Lecuona 1964: 135). También pueden intervenir factores sociolingüísticos, ya que se suelen relacionar con hablantes mayores y rurales, lo que conlleva ciertas connotaciones negativas para el resto de los hablantes (Kabuta 2001). Sea como fuere, la cuestión queda de momento abierta.

\section{Conclusiones}

En este artículo hemos repasado brevemente los fundamentos de la teoría de los patrones de lexicalización de Talmy, al mismo tiempo que hemos evaluado algunos de los puntos más débiles de la misma. Este modelo ha sido y sigue siendo de gran utilidad desde un punto de vista de la semántica 
tipológica, ya que ayuda a dilucidar algunas de las características semánticas de los eventos de movimiento y a agrupar a las lenguas en dos clases según estas características. A pesar de su conveniencia, incluso en campos de lingüística aplicada como la traducción o la adquisición de lenguas, hemos señalado también algunos de los problemas que se le suelen achacar a este modelo y las soluciones que se han dado hasta el momento: la ambigüedad del concepto de satélite, el tipo de información descrito en el verbo principal y la insuficiencia a la hora de dar cuenta de las diferencias intratipológicas. Sin embargo, lo que sobre todo queríamos mostrar en este trabajo es que hay cuestiones que dada su naturaleza no gramatical, sino discursiva o pragmática, no se han tenido tan en cuenta en otros estudios. Estas cuestiones son importantes porque a pesar de ser opcionales, es decir, no son requerimientos gramaticales sino que el hablante puede o no utilizar estos elementos, la ausencia de los mismos hace que la descripción del evento de movimiento no resulte del todo "nativa». Nos hemos concentrado en tres casos que surgen del estudio de los eventos de movimiento en euskara: la construcción de Camino Completo, la omisión verbal y la utilización de ideófonos de Manera. No hemos dado una respuesta ni una solución al porqué de estas características, de ahí el nombre del trabajo, "cuestiones abiertas», pero sí que hemos querido incidir en la importancia de estos elementos. Si estamos intentando explicar cómo se describen los eventos de movimiento, qué herramientas lingüísticas utilizamos para caracterizarlos y cómo nos influyen a la hora de fijarnos en diferentes aspectos de un mismo evento, no podemos olvidarnos de todos estos rasgos discursivos. Futuras investigaciones en este campo no solamente ayudarán a seguir trabajando en esta dirección, sino a comprobar si todas las lenguas tienen dichos rasgos.

\section{Bibliografía}

AMEKA, F., y J. EsSEgBey (en prensa): «Serialising languages: Satellite-framed, verb-framed, or neither», en L. Hyman e I. Maddieson (eds.), African comparative and historical linguistics: Proceedings of the 32th annual conference on African linguistics, Lawrenceville, NJ, AW P.

Amundarain, I. (2003): «Coordination», en J. I. Hualde y J. Ortiz de Urbina (eds.), A Grammar of Basque, Ámsterdam, John Benjamins: 844-892.

AsKe, J. (1989): «Path predicates in English and Spanish: A closer look», Annual Meeting of the Berkeley Linguistics Society, 15: 1-14. 
BEAVERS, J. (2008): «On the nature of goal marking and delimitation: evidence from Japanese», Journal of Linguistics, 44: 183-316.

- B. LeVIN y S. W. ThAM (en prensa): «The typology of motion expressions revisited», Journal of Linguistics, 46.3.

CHOI, S., y M. Bowerman (1991): «Learning to express motion events in English and Korean: The influence of language-specific lexicalization patterns», Cognition, 41: 83-121.

Croft, W., J. BarĐal, W. Hollmann, V. Sotirova y C. TaOka (en prensa): «Revising Talmy's typological classification of complex event constructions», en H. C. Boas (ed.), Contrastive Construction Grammar, Ámsterdam/Filadelfia, John Benjamins.

Cuartero Otal, J. (en prensa): "Clases aspectuales de verbos de desplazamiento en español», Verba.

Garai, K. J., e I. IbarRetXe-Antuñano (2002): «From X to Y: The 'complete path' construction in Basque», Odense Working Papers in Language and Communication, 23: 289-311.

GastañagA, L. G. (1977): «Gapping Basque Constituents», en W. Douglass et al. (eds.), Anglo American Contributions to Basque Studies: Essays in Honor of Jon Bilbao, Reno, Desert Research: 169-175.

GoldberG, A. E. (1995): Constructions: A Construction Grammar Approach to Argument Structure, Chicago, The University of Chicago Press.

Hualde, J. I., y J. Ortiz de Urbina (2003): A Grammar of Basque, Ámsterdam/Filadelfia, John Benjamins.

IBARRETXE-ANTUNAANO, I. (2004a): "Motion events in Basque narratives», en S. Strömqvist y L. Verhoeven (eds.), Relating Events in Narrative: Typological and Contextual Perspectives, Nueva Jersey, Lawrence Erlbaum: 89-111.

- (2004b): «Language typologies in our language use: The case of Basque motion events in adult oral narratives», Cognitive Linguistics, 15.3: 317349.

- (2004c): «Motion events in second language acquisition: Spanish and Basque», comunicación presentada en el congreso EUROSLA. Universidad del País Vasco-Euskal Herriko Unibertsitatea, septiembre 2004.

- (2004d): «Dicotomías frente a continuos en la lexicalización de los eventos de movimiento", Revista Española de Lingüistica, 34.2: 481-510.

- (2006a): Sound symbolism and motion in Basque, Múnich, LincomEuropa.

- (2006b): Hizkuntzaren bihotzean: Euskal onomatopeien hiztegia, Donostia, Gaiak.

- (2009a): «Path salience in motion events», en J. Guo et al. (eds.), Crosslinguistic Approaches to the Psychology of Language: Research in the Tradition of Dan Isaac Slobin, Nueva York, Psychology Press: 403-414. 
IBARRETXE-ANTUÑANO, I. (2009b): «Lexicalisation patterns and sound symbolism in Basque», en J. Valenzuela, A. Rojo y C. Soriano (eds.), Trends in Cognitive Linguistics: Theoretical and Applied Models, Hamburgo, Peter Lang: 239-254.

- (en prensa): «Basque: Going beyond verb-framed typologies», Linguistic Typology.

KabuTA, N. S. (2001): «Ideophones in Cilubà», en F. K. E. Voeltz y C. KilianHatz (eds.), Ideophones, Ámsterdam, John Benjamins: 139-154.

KaKeHI, H., I. TAMORI y L. Schourup (1996): Dictionary of Iconic Expressions in Japanese, Berlín, M. Gruyter.

LANDAU, B., y R. JACKENDOFF (1993): "What' and 'where' in spatial language and spatial cognition", Behavioral and Brain Sciences, 16: 217-238.

LAPPIN, S. (1996): "The interpretation of ellipsis», en S. Lappin (ed.), The Handbook of semantic theory, Oxford, Blackwells: 145-175.

LeCuOna, M. (1964): Literatura oral vasca, Donostia, Auñamendi.

LEVINson, S. (2003): Space in Language and Cognition. Explorations in Cognitive Diversity, Cambridge, Cambridge University Press.

- y D. Wilkins (2006): Grammars of Space, Cambridge, Cambridge University Press.

LOBECK, A. (1995): Ellipsis. Functional heads, licensing, and identification, Nueva York/ Oxford, Oxford University Press.

Morimoto, Y. (2001): Los verbos de movimiento, Madrid, Visor.

NikitinA, T. (2008): «Pragmatic factors and variation in the expression of spatial goals: The case of into vs. in», en A. Asbury, J. Dotlačil, B. Gehrke y R. Nouwen (eds.), Syntax and Semantics of Spatial P, Ámsterdam/Filadelfia, John Benjamins: 175-209.

Noonan, M. (2003): "Motion events in Chantyal», en E. Shay y U. Seibert (eds.), Motion, direction, and location in languages. In honor of Zygmunt Frajzyngier, Ámsterdam/Filadelfia, John Benjamins: 211-234.

OHARA, K. H. (2003): «Manner of motion in Japanese: not every verb-framed language is poor in manner», Comunicación presentada en el 8th ICLC, Universidad de La Rioja, España.

ÖZÇALIȘKAN, Ş., y D. I. SLOBIN (2003): «Codability Effects on the Expression of Manner of Motion in Turkish and English», en A. S. Özsoy, D. Akar, M. Nakipoğlu-Demiralp, E. Erguvanlı-Taylan y A. Aksu-Koç (eds.), Studies in Turkish linguistics, Estambul, Boğaziçi University Press: 259-270.

SCHUltZe-Berndt, E. (2000): Simple and complex verbs in Jaminjung: A study of event categorisation in an Australian language, MPI Series in Psycholinguistics, n. 14, Wageningen, Holanda, Ponsen \& Looijen. 
Slobin, D. I. (1996): "Two ways to travel: Verbs of motion in English and Spanish», en M. Shibatani y S. A. Thompson (eds.), Grammatical Constructions. Their Form and Meaning, Oxford, Clarendon Press: 195-317.

- (1997): «Mind, code, and text», en J. Bybee, J. Haiman y S. A. Thompson (eds.), Essays on language function and language type: Dedicated to T. Givón, Ámsterdam, John Benjamins: 437-467.

- (2004): «The many ways to search for a frog», en S. Strömqvist y L. Verhoeven (eds.), Relating Events in Narrative. Typological and Contextual Perspectives, Hillsdale, NJ, LEA: 219-257.

- y N. Hoiting (1994): «Reference to movement in spoken and sign languages: Typological consideration", Proceedings of the 20th Annual Meeting of the Berkeley Linguistics Society: 487-503.

StrömQvist, S., y L. Verhoeven (eds.) (2004): Relating Events in Narrative: Typological and Contextual Perspectives, Nueva Jersey, Lawrence Erlbaum.

SugiYAMA, Y. (2005): «Not all verb-framed languages are created equal: The case of Japanese", Proceedings of the 31st Annual Meeting of the Berkeley Linguistics Society: 299-310.

TALMY, L. (1985): «Lexicalization patterns: Semantic structure in lexical forms», en T. Shopen (ed.), Language typology and semantic description. Vol. 3: Grammatical categories and the lexicon, Cambridge, Cambridge University Press: 136-149.

- (1991): «Path to realization: A typology of event conflation», Proceedings of the 17th Annual Meeting of the Berkeley Linguistics Society, 17: 480-519.

- (2000): Toward a Cognitive Semantics, Cambridge, MA, MIT Press.

Voeltz, F. K. E., y C. Kilian-Hatz (2001): Ideophones, Ámsterdam, John Benjamins.

ZlateV, J., y P. YangkLang (2004): «A third way to travel. The place of Thai in Motion-event typology», en S. Strömqvist y L. Verhoeven (eds.), Relating Events in Narrative: Typological and Contextual Perspectives, Hillsdale, NJ, LEA: 159-190. 


\title{
VERBOS Y CONSTRUCCIONES EN EL ESPACIO COGNITIVO-FUNCIONAL DEL SIGLO XXI*
}

\author{
RiCARDO MAIRAL-USÓN \\ (UNED) \\ FRANCISCO GONZÁLVEZ-GARCÍA \\ (Universidad de Almería)
}

\section{Introducción}

A finales de los años setenta, Carter $(1988)^{1}$ postuló que las configuraciones sintácticas de un predicado pueden predecirse a partir de su estructura argumental y así llegó a identificar un conjunto de regularidades (linking regularities) que se formularon en torno a una serie de principios, que, a su vez, formaban parte de lo que se conoció como algoritmos de enlace. Como exponentes de este axioma metodológico, se inscriben

* Este trabajo forma parte de los siguientes proyectos de investigación financiados por el Ministerio de Ciencia e Innovación: FFI2008-05035-C02-01 y HUM200765755.

1 Nótese que la versión que citamos es la de 1988, si bien, como señalan Levin y Rappaport (2005: 3), Carter presentó este trabajo en 1976, por lo que la referencia temporal que empleamos al comienzo de la frase no es incorrecta. 
un conjunto de teorías de raigambre tanto formal como funcional que se clasificaron como "proyeccionistas», pues mantienen que la semántica de un predicado determina en gran medida su configuración sintáctica o, dicho de otra forma, que la información presente en una entrada léxica se proyecta hacia la sintaxis. Así, estos modelos desarrollan algoritmos de enlace que constan de un conjunto de operaciones o principios que dan cuenta de las relaciones sistemáticas entre el componente léxico y el gramatical. Esto implica, entre otras cosas, el desarrollo de teorías bien articuladas para la representación de la estructura argumental de un predicado (cf. Levin 1985) y, además, el abandono progresivo de las construcciones que pasan a desempeñar un papel ancilar. Las siguientes teorías ilustran esta orientación proyeccionista: la Teoría de Principios y Parámetros (cf. Chomsky 1986, 1988), la Gramática Funcional de S. C. Dik (1997a, 1997b), el modelo léxico de Levin y Rappaport Hovav (2005), la semántica conceptual de Jackendoff (1990, 2002), y la Gramática del Papel y la Referencia (de aquí en adelante, GPR) (Van Valin y LaPolla 1997; Van Valin 2005, 2008).

Como respuesta a esta argumentación y en el ámbito de la Lingüística Cognitiva, surge un conjunto de enfoques que se han agrupado de forma más o menos estrecha en torno a lo que se ha dado en llamar una familia de Gramáticas de Construcciones ${ }^{2}$ ( $\mathrm{GxC}$ de ahora en adelante). Tal y como su propia denominación indica, la familia de enfoques construccionistas (véanse Fried y Östman 2005; Gonzálvez-García y Butler 2006, y Goldberg 2006, entre otros, para una exposición detallada de las diferentes formulaciones que integran dicha familia) se caracteriza por reivindicar la centralidad de las construcciones como unidades teóricas dotadas no solo de estatus propio, sino muy especialmente de un significado y/o función inherentes. Esta posición contrasta de pleno con la con-

2 Esta denominación agrupa versiones diferentes que, de hecho, han cristalizado en teorías que comparten precisamente la noción de construcción, si bien divergen en un número notable de presupuestos. Cumple reseñar el caso de las gramáticas neoconstruccionistas de Borer (1994, 2001), Hale y Keyser (1997) o Marantz (1997) (véase Goldberg 2006: 205-213 para un análisis de las diferencias entre estos enfoques y la(s) Gramática(s) de Construcciones), o los trabajos de Culicover (1999) y Culicover y Jackendoff (2005), entre otros. Para un tratamiento exhaustivo de estas dos formas de entender las relaciones léxico-sintaxis, remitimos al lector al trabajo de Gonzálvez-García y Butler (2006). 
cepción de las construcciones propugnada en la lingüística chomskiana, como meros artefactos taxonómicos, de cierta utilidad para la descripción lingüística, pero carentes de estatus teórico y valor explicativo (Chomsky 1995: 170, 2000: 8). Más específicamente, en las GxCs, se defiende que las construcciones tienen existencia propia con relativa independencia de las piezas léxicas (y muy especialmente de los verbos) con las que estas se fusionan dando lugar a expresiones concretas (Goldberg 1995, 1996: 3-4, 2006). En otras palabras, el rasgo definitorio de un enfoque construccionista consiste en aceptar que el conocimiento que un usuario tiene de su lengua se articula en torno a una vasta red de construcciones con múltiples relaciones entre sí o "constructicón" (Goldberg 2003: 223), lo que implica la existencia de una división no marcada ('soft') entre ambos componentes. En este sentido, es preciso puntualizar que la formulación de la $\mathrm{GxC}$ de Fillmore, Kay, Michaelis y Sag, recientemente denominada "Gramática de Construcciones Basada en el Signo» ('Sign-Based Construction Grammar'), sí que defiende abiertamente una separación entre léxico y gramática (cf. Sag 2007; Fillmore et al., en preparación).

En este contexto, todo parece indicar que estamos ante dos formas excluyentes de analizar las relaciones entre léxico y sintaxis. Sin embargo, lejos de aceptar esta afirmación tenemos como objetivo en este trabajo identificar cuáles son las líneas esenciales que separan a estos dos paradigmas en torno a dos cuestiones fundamentales que se plantean en el propio título de este trabajo: el alcance teórico de la noción de construcción y el grado de granularidad que deberían alcanzar las representaciones léxicas. Al debatir sobre estas dos cuestiones, iremos introduciendo, si bien con trazos necesariamente muy gruesos, nuestras propias ideas que forman parte del Modelo Léxico Construccional (en lo que sigue, MLC), ${ }^{3}$ un modelo que aporta una descripción exhaustiva de todos los niveles necesarios para la construcción del significado, incluso de aquellos que van más allá de los aspectos puramente gramaticales, a saber, incorpora aspectos centrales de la teoría de la implicatura conversacional en el nivel 2 o nivel pragmático, describe los parámetros esenciales del significado

3 Para una información actualizada sobre los últimos desarrollos del Modelo Léxico Construccional (MLC), remitimos al lector a la siguiente página web <www.lexicom.es> y las referencias allí incluidas. 
ilocutivo en el nivel 3 y los principios analíticos que gobiernan el significado discursivo en el nivel 4 (véase la arquitectura general del MLC en el Anexo 1) (cf. Mairal-Usón y Ruiz de Mendoza 2009; Ruiz de Mendoza y Mairal-Usón 2008).

\section{La noción de construcción: entre la composicionalidad, la no-composicionalidad y la granularidad}

Una revisión detallada de la noción de «construcción» nos lleva inexcusablemente a definir su naturaleza. Si tuviéramos que destacar uno de los factores más elocuentes en torno a la naturaleza de la noción de 'construcción', destacaríamos, por encima de otros, los grados de composicionalidad que debe reunir una construcción para ser catalogada como tal. En este sentido, de un lado, establecemos una clara línea divisoria entre algunos enfoques proyeccionistas tales como la GPR, e incluso también destacados enfoques construccionales como la «Gramática de Construcciones Basada en el Signo» (cf. Sag 2007), que defienden el requisito de la no composicionalidad como conditio sine qua non para el estatus de la noción de construcción. De otro lado, a diferencia de la formulación original de construcción formulada en Goldberg (1995), entre otros, la última versión de la GxC de Goldberg (2006), la denominada GxC Cognitiva, al igual que otros modelos de raigambre cognitivista (por ej. la GxC Radical de Croft 2001, y la Gramática Cognitiva de Langacker 2008), dejan de otorgar preeminencia absoluta a la idiosincrasia y formulan una concepción de la noción de construcción basada en la frecuencia de uso que resulta excesivamente laxa, como demostraremos más adelante. Finalmente, como reza el título de esta sección, las generalizaciones que se recogen en una construcción están sujetas a diferentes grados de 'granularidad' en su descripción. En este sentido, se reivindica una mayor relevancia de la semántica verbal, especialmente a nivel explicativo - frente a la supremacía de la semántica construccional propugnada en la $\mathrm{GxC}$ de Goldberg $(1995,2006)$ _ al postularse construcciones íntimamente ligadas a una clase verbal y/o un verbo en particular, como defienden entre otros Boas $(2008,2009)$ y Croft $(2001,2003)$, un aspecto que está muy en consonancia con lo desarrollado en el MLC. 


\subsection{La no composicionalidad}

Como mencionábamos en la introducción, para los modelos proyeccionistas la interfaz léxico-sintaxis pasa inevitablemente por la búsqueda de los principios u operaciones que regulan este enlace, tarea que ha desembocado en el desarrollo de lo que se ha denominado «algoritmos de enlace». Un ejemplo elocuente es la GPR, que propone un algoritmo de enlace bidireccional, a saber, que funciona desde la semántica a la sintaxis y viceversa. ${ }^{4}$ Este algoritmo de enlace consta de dos fases: una primera fase semántica, que contiene una serie de principios universales (por ej., las estructuras lógicas, la asignación de macropapeles, la elección del argumento sintácticamente privilegiado o sujeto lógico, etc.); y una segunda fase sintáctica, que recoge aquellos aspectos idiosincráticos de una lengua, por ej., el inventario de plantillas sintácticas propias de las construcciones de la misma. Adicionalmente, se formulan principios tales como el Principio Restrictor de la Compleción (the Completeness Constraint), que estipula que todos los argumentos presentes en una estructura lógica deben tener un correlato en la sintaxis, principio que evidencia la defensa de un isomorfismo estructural entre el léxico y la sintaxis. Pero, ¿dónde están las construcciones en este modelo?, ¿no deberían formar parte de la fase sintáctica del enlace que se ocupa de las cuestiones específicas de una lengua?

En efecto, Van Valin (2005: 131-134) expande el formato del algoritmo de enlace propuesto originalmente en versiones previas e incorpora un módulo nuevo, que incluye los esquemas construccionales (constructional schemas).

En la GPR, estos esquemas construccionales recogen el conjunto de propiedades morfológicas, sintácticas, semánticas y pragmáticas que de manera global expresan un significado único, el significado propio de la construcción: «[...] are specific constellations of morphosyntactic, semantic, and pragmatic properties, and accordingly the constructional templates representing them are in effect instructions to the grammar on

4 Por razones de espacio es imposible hacer justicia a toda la complejidad de este algoritmo, por lo que remitimos al lector a Van Valin (2005). 


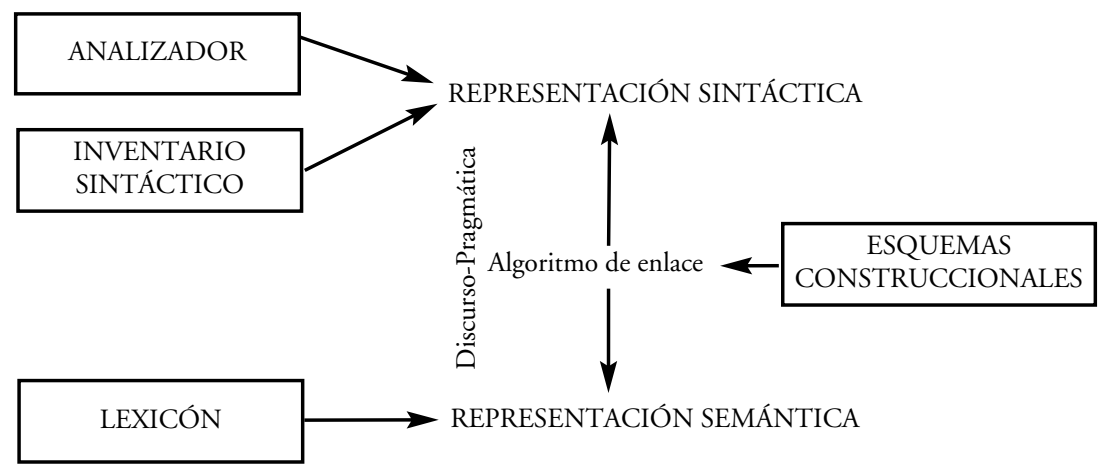

Figura 1. El algoritmo de enlace de la GPR con la inclusión de los esquemas construccionales

how these properties should be combined in different forms» (Van Valin y LaPolla 1997: 432) (la cursiva es nuestra). Además, es imposible omitir o alterar cualquiera de estas propiedades sin vulnerar su significado, lo que demuestra el carácter no composicional de estos esquemas construccionales. Al formar parte del algoritmo de enlace, que está formulado por principios de validez interlingüística (por ej., la asignación de los macropapeles), los esquemas construccionales incorporan los rasgos específicos de una construcción en una lengua determinada si bien descrita mediante principios que tienen validez universal. En este sentido, Van Valin (2007: 236-238) advierte de la falta de adecuación tipológica de las construcciones propuestas por Goldberg (2006) (cf. infra). Por lo que se refiere a la representación de estos esquemas construccionales, Van Valin y LaPolla (1997: 432-433) reconocen como una tarea pendiente el desarrollo de un formalismo con el mismo grado de explicitud que el propuesto para la estructura jerárquica de la cláusula y las estructuras lógicas. Veamos el siguiente ejemplo de la construcción impersonal con «se» en español, que adaptamos de González Vergara $(2006 b, 2009) .^{5}$

5 Para un tratamiento riguroso y exhaustivo de las construcciones con se en español, remitimos al lector a los trabajos de González Vergara (2006a, 2006b, 2009), a quien seguimos en esta parte. Para un análisis de este mismo fenómeno desde una perspectiva construccional, remitimos a los trabajos de Pedersen (2005) y Gonzálvez-García (2006). 
CONSTRUCCIÓN: Impersonal con se

SINTAXIS

Plantilla sintáctica: núcleo con nodo AGX.

Modulación argumental: reducción en 1 del número de posiciones del CORE.

Modulación de PSA: ningún argumento es seleccionado como PSA.

Enlace: omisión del actor.

MORFOLOGÍA

Verbo: voz activa.

Morfema verbal de persona: $3 .^{\text {a }}$ persona singular invariable.

Morfema «se» invariable en el nodo AGX del núcleo.

SEMÁNTICA

El primer argumento de la estructura lógica no está especificado.

Si la estructura lógica presenta un padecedor, este debe ser [+animado].

PRAGMÁTICA

Estructura focal: foco oracional por defecto.

Fuerza elocutiva: no especificada.

Hemos reiterado que no podemos omitir ninguna de estas propiedades pues entonces alteraríamos el significado total de la construcción. Por ejemplo, si en la sintaxis uno de los argumentos fuera seleccionado como argumento sintácticamente privilegiado, entonces la construcción adquiriría un significado diferente, un valor variable entre el reflexivo y el incoativo:

(1) Se quemaron los insurgentes.

En el nivel morfológico, si conjugamos el verbo en una persona diferente a la tercera del singular, estaríamos ante una estructura agramatical. Además, si alteramos la invariabilidad del morfema "se», entonces la estructura resultante tendría otro significado diferente, a saber, lo que se ha descrito como «significado de interés»:

a. *Se castigué a los insurgentes.

b. \#Me castigué a los insurgentes.

Finalmente, si alteramos las condiciones en el nivel semántico, igualmente obtendremos estructuras que poco tienen que ver con el significado de la construcción impersonal con «se». Por ejemplo, si la estructura 
lógica contiene un argumento marcado con el rasgo [-animado], la estructura resultante deja de tener un valor impersonal para adquirir un significado pasivo o incoativo:

(3) a. Se quemó a los insurgentes (= alguien quemó a los insurgentes).

b. Se quemó la casa (= la casa sufrió el evento de quemarse).

Veamos, pues, la representación de esta construcción como parte del algoritmo de enlace, donde los números hacen referencia a los requisitos que impone la propia construcción: 1 , la elección del tipo de plantilla del núcleo con un nodo AGX; 2, la modulación de la plantilla que pasa a tener un solo argumento; 3 , indica que no se produce asignación del argumento sintácticamente privilegiado (sujeto lógico); en el plano morfológico, 4, 5 y 6 hacen referencia a la voz del verbo, a la conjugación del morfema de persona y a la presencia del clítico en el nodo AGX respectivamente; 7 representa la formalización de los requisitos pragmáticos que impone la construcción (cf. González Vergara 2006a, 2006b y 2009, para una exposición detallada y original de las construcciones no reflexivas con se).

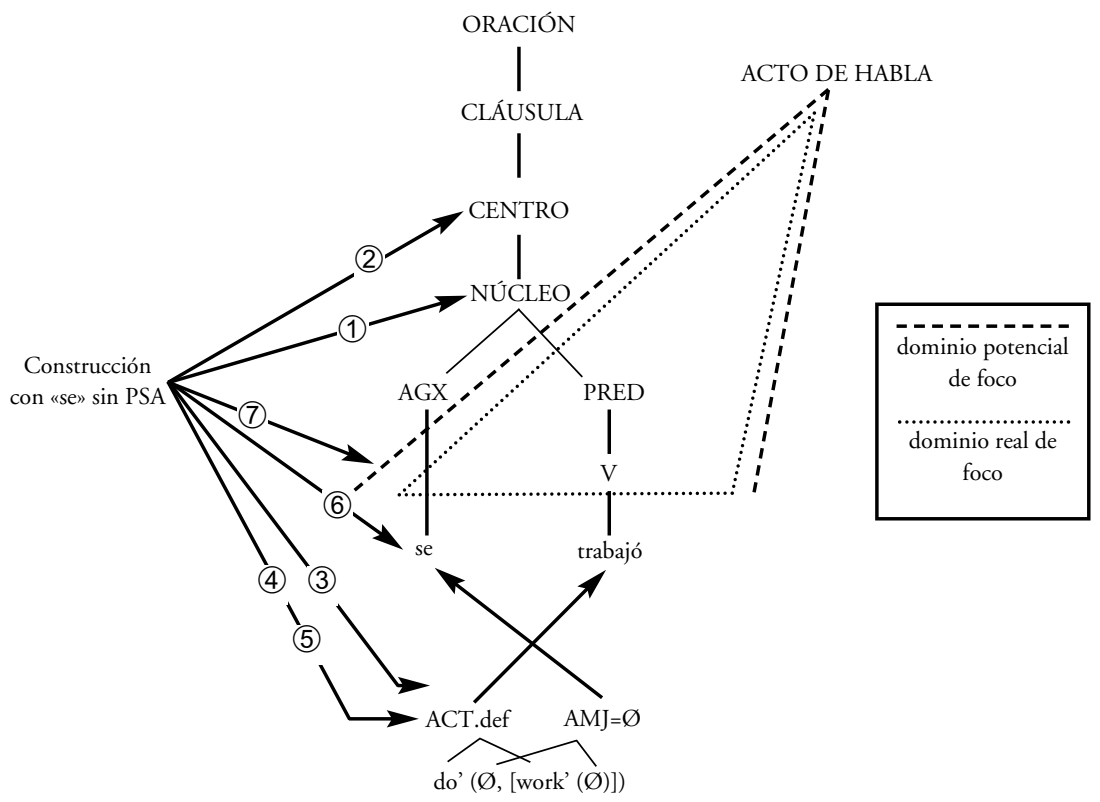

Figura 2. La construcción con «se» impersonal (adaptada de González Vergara 2009) 
Siguiendo esta misma concepción no-composicional de las construcciones, la GxC de Fillmore et al. (en preparación), quienes, en consonancia con los requisitos de elegancia que estipulan que las generalizaciones tengan el mayor nivel de abstracción posible, no admiten redundancia alguna a la hora de establecer el inventario de construcciones. Por consiguiente, en esta formulación de la $\mathrm{GxC}$ solo tiene cabida una concepción no composicional de la noción de construcción y no las configuraciones de bajo nivel como las ejemplificadas en (6), cuyas propiedades pueden predecirse, según estos autores, de construcciones de alto nivel (e. g. la construcción transitiva, atributiva, etc.).

\subsection{El tránsito hacia una noción composicional}

En sus primeros trabajos, Goldberg (1995: 7, 1996: 68, 2003: 219) nos ofrece una definición de la noción de construcción que podemos resumir como sigue:

$\mathrm{C}$ is a CONSTRUCTION iff ${ }_{\text {def } \mathrm{n}}$ is a form-function pair, such that some aspect of the form or some aspect of the function is not strictly predictable from C's component parts. (Goldberg 1998: 205, la cursiva es nuestra).

La definición en cuestión gira en torno al criterio de idiosincrasia o no composicionalidad como diagnóstico del estatus de construcción. A modo de ilustración, consideremos los ejemplos reproducidos en (4)-(5) tomados del inglés y del español:

(4) She sneezed the napkin off the table.

(5) El amor es lo que tiene.

Según Goldberg (1995, 2006), una expresión como la ejemplificada en (4) se considera una construcción, entre otras razones porque la interpretación de movimiento causado de dicha expresión no puede predecirse del significado léxico de los elementos que la componen. En otras palabras, dicha interpretación la aporta la construcción de movimiento causado ('X hace que Y se mueva hacia Z') y no el verbo sneeze, cuya semántica léxica en sí misma no implica movimiento causado alguno más allá de la mera expulsión de aire a través de las fosas nasales con un estornudo. De 
modo análogo, en el caso de (5), nos encontramos con lo que, a simple vista, parece ser una expresión atributiva identificadora del tipo «Peter is the boss» / «Pedro es el jefe». Sin embargo, este enunciado, más que aportar información esencial para identificar un referente (e.g. «El amor es lo que mueve el mundo», «Love is what makes the world go round»), expresa una evaluación positiva (o negativa) por parte del sujeto hablante acerca de una situación o estado de cosas, que se da por válida por los interlocutores (i. e. "El amor es así, nos guste o no») (véanse Halliday y Matthiessen 2004: 228; Moreno Cabrera 1982: 232 y Fernández Leborans 1999: 2372-2379, entre otros, para más detalle sobre la distinción entre caracterización e identificación en la atribución, así como Gonzálvez-García 2007 para un estudio detallado de esta construcción en inglés y español).

Recientemente, y en sintonía con el marcado carácter cognitivista así como el énfasis en el uso lingüístico ('usage-based') y la experimentación psicolingüística de la GxC Cognitiva (Goldberg 2006), se añade a la definición original esta otra que reproducimos a continuación:

Any linguistic pattern is recognized as a construction as long as some aspect of its form or function is not strictly predictable from its component parts of from other constructions recognized to exist. In addition, patterns are stored as constructions even if they are fully predictable as long as they occur with sufficient frequency (see Ch. 3 for discussion) (Goldberg 2006: 5, la cursiva es nuestra).

La propia Goldberg ha explicado la expansión de la definición de construcción en la $\mathrm{GxC}$ Cognitiva en los siguientes términos:

[...] [The definition of a construction] is only broadened from my 1995 definition insofar as I now explicitly allow for fully compositional constructions. In 1995, I focused on non-compositionality for purely methodological reasons: we know we need a construction when it's not strictly predictable. Since then psycholinguistics has provided evidence that we store forms, even if they are compositional. Exactly how much exposure is required before we can say something is "stored" is a topic I'm very interested in (Gurevich and Goldberg, forthcoming; Casenhiser y Goldberg, 2005; Boyd et al., to appear) (Gonzálvez-García 2008: 353, cursiva en el original).

A la luz de esta definición de construcción cabe resaltar dos aspectos importantes para la discusión que aquí nos ocupa: en primer lugar, el requisito de la no composicionalidad deja de ser explícitamente condi- 
ción sine qua non para el estatus de construcción, al menos, como avanzábamos en la sección 2, en las formulaciones de las $\mathrm{GxC}$ de orientación cognitivista (e. g. Goldberg, la GxC Radical de Croft (2001), la Gramática Cognitiva de Langacker, el modelo de marcos semánticos de Boas (2008, 2009), etc.; véase Goldberg 2006: 214-215, 224 para más deta1le). Todo ello está en consonancia con la importancia que se le concede en estas formulaciones de la GxC a las configuraciones de bajo nivel. En palabras del propio Langacker:

[...] lower-level schemas, expressing regularities of only limited scope, may on balance be more essential to language structure than high-level schemas representing the broadest generalizations (Langacker 2000: 3, la cursiva es nuestra).

En virtud de ello, se acepta que expresiones con un alto grado de frecuencia puedan considerarse, a pesar de su transparencia sintácticosemántica, como construcciones. Considérense, a tales efectos, los ejemplos de (6a-d) en inglés y español.
a. I love you.
b. I'm lovin' it. (McDonalds slogan).
c. ¿Qué tal estás?
d. No (lo) sé.

En segundo lugar, esta definición comporta que cualquier elemento léxico y/o gramatical, independientemente de su grado de abstracción y/o su complejidad morfosintáctica (desde un morfema como «-er», pasando por palabras, expresiones idiomáticas, hasta configuraciones comparativas como «the sooner, the better»), a excepción de configuraciones noveles sin frecuencia alguna (Goldberg, comunicación personal), es susceptible de ser tratado como una construcción (véase Schönefeld 2006, así como Gonzálvez-García y Butler 2006, entre otros, para algunas matizaciones acerca del alcance del concepto de construcción dentro de las $\mathrm{GxC}$ de orientación cognitivista). Así las cosas, según Goldberg (2006: 18), "the network of constructions captures our grammatical knowledge in toto, i.e. it is constructions all the way down» (cursiva nuestra), aserto que le lleva a identificar once construcciones en el análisis del siguiente enunciado:

(7) A dozen roses, Nina sent her mother!

(Ejemplo tomado de Goldberg 2006: 21) 
En nuestra opinión, y en una línea muy similar a Fillmore et al. (en preparación), entendemos que esta extensión de la noción de construcción hacia enunciados composicionales implica el tratamiento de las mismas irrestrictamente pues perdemos de vista el peso específico que cada uno de los niveles de descripción gramatical desempeña en la descripción y representación de las construcciones. Si bien podemos admitir que cualquier uso convencionalizado en la lengua puede llegar a ser una construcción en sí misma, lo que es verdaderamente esencial para un modelo lingüístico es especificar cómo podemos proporcionar una descripción detallada de todos aquellos niveles de descripción que forman parte de la construcción del significado, tarea que conlleva un compromiso por presentar los principios analíticos que concurren en aquellos niveles que van más allá del puramente gramatical, por ej., el nivel pragmático, ilocutivo y discursivo. Curiosamente, las $\mathrm{GxC}$ al uso (por ej., Goldberg 1995, 2006) han infradesarrollado estas tres dimensiones del significado. En otras palabras, en vez de perderse en disquisiciones taxonómicas en torno a si un determinado constructo es o no una construcción (véase, por ejemplo, Bod 2009: 130), el desafío real es ofrecer un modelo de construcción del significado que nos permita describir con precisión cada una de las construcciones independientemente de si esas son idiomáticas, composicionales o no composicionales. Por ejemplo, hemos analizado casos en los que la implicatura puede tener una motivación construccional. Consideremos el equivalente en español de la construcción What's $X$ Doing $Y$ ? descrita por Kay y Fillmore (1999):

¿Qué hace ese niño? / Pero ¿qué hace ese niño? / Pero ¿qué hace ese niño con las tijeras?

La construcción (Pero) ¿qué hace $X(Y)$ ? sugiere que el hablante piensa que hay algo mal en la situación descrita; este valor fácilmente nos ayuda a activar un significado adicional de queja. Desde nuestro punto de vista, lo que realmente destaca en esta construcción es la importancia que posee el elemento Y para garantizar su significado. Cuanto mayor sea la elaboración de este elemento, más se refuerza la idea de que algo está mal en la situación descrita: Pero ¿qué hace ese niño en la cocina con las tijeras cortando el mantel? Esto sucede así porque la construcción implica que, puesto que el hablante puede aportar tanta información sobre la 
situación, ya sabe qué está pasando y no puede estar efectuando una pregunta meramente informativa. Existen otras construcciones relacionadas con (Pero) ¿qué hace X (Y)?, con implicaciones semánticas parecidas y una misma base interpretativa:

(Pero) ¿qu'- Vpretperf Y?

a. Pero ¿quién ha usado mi cámara?

b. Pero ¿dónde se ha metido ese niño?

c. Pero ¿en qué has invertido tu dinero?

La diferencia con (Pero) ¿qué hace X $(Y)$ ? reside en que en estos ejemplos la descripción de la situación que se evalúa como indebida se obtiene a partir de una presuposición construccional, mientras que en (Pero) ¿qué hace $X(Y)$ ? la descripción es explícita. En esencia, el MLC analiza todo este tipo de enunciados mediante la convencionalización de inferencias guiadas pragmática o lingüísticamente sobre la base de situaciones o escenarios de bajo nivel.

\subsection{Las mini-construcciones}

El concepto de semántica construccional adquiere un nuevo valor en las propuestas más recientes de Boas $(2008,2009)$ y Croft (2003). Concretamente, Boas reivindica la necesidad de postular generalizaciones con un grado mayor de granularidad que las construcciones abstractas de la GxC de Goldberg, o «mini-construcciones». Estas contienen detallada información semántica, pragmática y sintáctica acerca de los tipos de argumentos semánticos susceptibles de aparecer con un determinado sentido convencionalizado de un verbo (Boas 2008: 127). En el caso de la construcción resultativa, las mini-construcciones especifican qué tipo de elementos léxicos concretos pueden aparecer como sintagmas postverbales y como frases resultativas, respectivamente (e.g. "wipe something clean», «wipe something dry», etc.).

(10) He wiped it clean/dry/smooth $/{ }^{*}$ damp $/{ }^{*}$ dirty $/{ }^{*}$ stained $/{ }^{*}$ wet.

(Ejemplo tomado de Green 1972, citado en Boas 2003: 136)

(11) a. The soldier struck the civilian dead.

b. ??The soldier hit the civilian dead.

c. ${ }^{*}$ The soldier injured the civilian dead.

(Ejemplos tomados de Boas 2003: 137) 
En virtud de ello, y como el propio Boas (2008: 127) reconoce, las mini-construcciones son en principio equiparables a las construcciones específicas de una clase verbal a la par que las construcciones específicas de un verbo en particular propugnadas en Croft (2003), en tanto que ponen de manifiesto las notables restricciones semántico-pragmáticas (propias de las colocaciones léxicas) entre el verbo principal y sus elementos integrantes, especialmente el sintagma nominal postverbal y la frase resultativa (véase Boas 2003: 159-213 para una exposición detallada de la formalización de las mini-construcciones y su distribución en inglés). Más concretamente, Croft coincide con Boas en reivindicar un papel más importante para la semántica verbal en detrimento de la semántica construccional. Así por ejemplo, en el caso de la construcción ditransitiva (e. g. "Pat sent Bill a fax»), este autor refuta la validez de un análisis de polisemia construccional argumentando lo siguiente:

$[\ldots]$ the modulation of the possessive relation specified by each constructional sense - actual, enabling, and negative transfer of possession - matches a semantic component of these verbs (Croft 2003: 55).

No obstante, debe subrayarse que, si bien Goldberg reconoce que la semántica verbal no es irrelevante, en su modelo la semántica construccional sigue teniendo un peso relativamente mayor $y$, en ningún caso, acepta esta autora que ello sea óbice para seguir postulando la existencia de la polisemia construccional. En palabras de la propia Goldberg:

I agree with Croft (and Paul Kay, Frederike Van der Leek, Seizi Iwata, Jean-Pierre Koenig have all made the same point previously) that once you know that a verb can appear in a given construction, it's pretty straightforward to figure out the meaning of the complex. But I don't feel that that undermines the polysemy analysis because it's important to distinguish «decoding» and "encoding» conventionalization. It's a fact about the English ditransitive construction that it can be used with certain classes of verbs and not others: the encoding is conventional (Gonzálvez-García 2008: 356).

La defensa que Goldberg hace de las construcciones con un considerable nivel de abstracción (como es el caso de las construcciones de estructura argumental) debe entenderse en último término como un interés en generalizaciones robustas que arrojen luz, por ejemplo, acerca de las relaciones de construcciones en el constructicón (Goldberg 1995: 5; 2003: 3; 2006: 33). 
Una de las cuestiones que surge es la de si es posible reconciliar de forma coherente las definiciones con alto grado de abstracción de Goldberg con la información de grano fino recogida en las mini-construcciones. Según Boas (comunicación personal), la respuesta es afirmativa. Ambas definiciones son necesarias a efectos de la codificación (o producción) y descodificación (o interpretación) de un enunciado (véase Fillmore 1988: 504-505). Más concretamente, la primera operación entraña un grado mayor de dificultad que la segunda y, por tanto, precisa de información más detallada, que no puede formularse a nivel de las construcciones abstractas, sino únicamente a nivel de las mini-construcciones. En otras palabras, ejemplos como (12) y (13) no presentan dificultad alguna para el hablante que conoce el significado de los elementos individuales que aparecen en estas. Sin embargo, desde el punto de vista de su generación, dichos ejemplos plantean una cierta dificultad para los usuarios de la lengua, en tanto que requieren un conocimiento de grano fino de qué verbo(s) puede(n) combinarse con qué sintagma nominal postverbal y/o con qué frase resultativa, tal y como se ejemplifica en (12) y (13) en inglés y español:

(12) a. Hill suffocated Kim to death $/{ }^{*}$ dead.

b. This will make you sleepy/*asleep/*to sleep.

c. This will put you *sleepy/*asleep/to sleep.

a. Él se quedó/*puso parapléjico tras el accidente.

b. Se han vuelto locos ${ }^{*}$ contentos $/{ }^{*}$ muy enfadados.

c. Se han quedado ${ }^{*}$ locos/contentos/muy enfadados.

Toda esta reflexión apunta hacia un planteamiento muy similar al formulado en el MLC pues por una parte destaca el papel insoslayable de la semántica verbal y explicita los mecanismos restrictores que permiten la presencia de un verbo con determinadas construcciones. A tal efecto, el MLC formula un inventario de restricciones internas y externas (internal y external constraints) que actúan como principios constrictores de la subsunción, un mecanismo de creación de significado consistente en la incorporación restringida de elementos de estructura semántica de un nivel inferior en otros de nivel superior (Ruiz de Mendoza y Díez 2002; Ruiz de Mendoza y Mairal-Usón 2008; Mairal-Usón y Ruiz de Mendoza 2008 y 2009). ${ }^{6}$ Por ejem-

6 En el MLC, el Principio de Derogación (Override Principle) de Michaelis (2003), definido en el contexto de la coerción construccional, no es sino una forma específica del referido principio de la subsunción que es más general. Según el Principio de Derogación, el 
plo, en el nivel de la gramática nuclear, las restricciones internas especifican las condiciones bajo las que una representación léxica puede modificar su configuración interna. Las restricciones externas surgen de la posibilidad o imposibilidad de efectuar operaciones metafóricas o metonímicas de alto nivel con las piezas léxicas implicadas en un proceso de subsunción. Este es un aspecto realmente novedoso pues supone aplicar la teoría de la metáfora y la metonimia al análisis de cuestiones gramaticales, por ej., las alternancias diatéticas (Ruiz de Mendoza y Mairal-Usón 2007).

\section{Pero ¿qué papel desempeña la semántica verbal?}

A la luz de las propuestas proyeccionistas, parece lógico aventurar que la entrada léxica de un predicado constituye el punto de arranque en el algoritmo de enlace. En este sentido, la GPR toma como punto de partida la estructura lógica, el formalismo que se utiliza para representar a las entradas léxicas en el lexicón. Al igual que otros sistemas de descomposición léxica, tales como las plantillas léxicas ('event structure templates') de Levin y Rappaport (Rappaport y Levin 1998; Levin y Rappaport 2005) o las estructuras conceptuales de Jackendoff (1990), la GPR propone un inventario de estructuras lógicas basadas en la noción de aktionsart de Vendler (1967) y establece las siguientes distinciones: estados, actividades, logros, realizaciones, realizaciones activas, semelfactivos y sus correspondientes causativos. Los estados y las actividades son primitivos $\mathrm{y}$, de hecho, entran como definiens en la representación de los logros, semelfactivos, realizaciones y realizaciones activas. Por lo que se refiere al formalismo propiamente dicho, una estructura lógica consta de un primitivo marcado en negrita seguido de una comilla (pred'), las variables representadas como $x, y, z$, y un conjunto de operadores del tipo BECOME, INGR, SEML.7 Consideremos las siguientes entradas léxicas para los verbos correr y aprender, que designan una actividad y una realización:

significado de una pieza léxica se ha de adaptar necesariamente al de la estructura a la que se incorpora, lo que constituye en sí mismo una prueba contundente a favor de la superioridad de las construcciones como elementos determinantes de la interpretación de un enunciado. En el MLC, se busca además definir qué principio permite esta adaptación de significado.

7 Para una descripción más detallada del componente léxico, remitimos al lector al trabajo de Mairal-Usón y Cortés (2008) y Mairal-Usón y Van Valin (2001). 

a. do' $(\mathrm{x},[$ run' $(\mathrm{x})])$
b. BECOME have' $(x, y)$

Como Van Valin y LaPolla (1997: capítulo 3) reconocen, los primitivos de cada una de estas estructuras lógicas reclaman una descomposición semántica de grado más fino. Además, si bien todas estas distinciones aspectuales gozan de una validez tipológica (cf. Van Valin 2006), estas adolecen de un componente semántico que incluya aquellos aspectos del significado de una palabra que, a pesar de no tener visibilidad sintáctica, forman parte del significado del mismo. En esencia, estas estructuras reclaman una definición más explícita sobre el estatus ontológico de cada uno de los primitivos a la par que la cobertura de la definición alcance aspectos que trasciendan el ámbito gramatical. Como argumentamos abajo, en esta línea se encuadra el trabajo del MLC, que propone la noción de estructura lógico conceptual como una extensión de las estructuras lógicas (cf. Mairal-Usón y Periñán-Pascual 2009; Mairal-Usón y Ruiz de Mendoza 2008).

Por lo que se refiere a las formulaciones elaboradas en el seno de la $\mathrm{GxC}$, algunos autores como Boas $(2003,2008)$ o Iwata (2008), aun reconociendo las virtudes del tratamiento de Goldberg de la estructura argumental (Goldberg 1995: 7-23, 101-108) con respecto a análisis alternativos, han puesto de manifiesto algunas insuficiencias de dicho análisis a la hora de dar buena cuenta de un elenco de datos más amplio. Así por ejemplo, Boas (2003, 2008: 120) señala acertadamente que las estructuras de las entradas léxicas para los verbos de comunicación en el enfoque de Goldberg, tal y como se especifican en (15), resultan adecuadas para explicar la aceptabilidad de los enunciados de (16a), pero no los de (16b) (Boas 2003: 105):
a. talk $<$ talker $>$.
b. speak $<$ speaker $>$.
c. whisper $<$ whisperer $>$.
d. grumble $<$ grumbler $>$.
e. murmur $<$ murmurer $>$.
(Ejemplos tomados de Goldberg 1995: 189)
f. sigh $<$ sigher $>$
(Ejemplo tomado de Boas 2003: 106)

(16) a. Miriam talked/spoke/whispered/grumbled/murmured/sighed (to Joe).

b. Miriam talked/*spoke/?whispered $/{ }^{*}$ grumbled $/{ }^{*}$ murmured $/$ ?sighed herself blue in the face.

(Ejemplos tomados de Boas 2008: 120) 
El aspecto clave de la argumentación de Boas está en que las entradas léxicas de Goldberg adolecen de una abstracción excesiva e incluso de circularidad, resultando por tanto inadecuadas para explicar las restricciones de selección, de colocación, etc., entre una construcción y sus elementos integrantes (especialmente el sintagma nominal postverbal y la frase resultativa). Una situación análoga encontramos en el caso de la construcción con way (Goldberg 1995: 199-218) y las extensiones metafóricas de la construcción ditransitiva, como se refleja en (17) y (18), respectivamente:

(17) Miriam talked/*spoke/?whispered/?grumbled/*murmured/sighed her way into the office.

(18) Miriam whispered $/{ }^{*}$ talked $/{ }^{*}$ spoke/*grumbled/?murmured/?sighed Joe a fairy tale. (Ejemplos tomados de Boas 2008: 122)

Una generalización importante que sucede de la observación de los enunciados reproducidos en (17) y (18) es que aunque los verbos en cuestión son semánticamente afines, algunos de estos pueden integrarse con la construcción con way o la construcción ditransitiva, mientras que otros no (Boas 2008: 122).

Siguiendo esta línea de argumentación, Iwata (2008) y Boas (2008, 2009), entre otros, defienden que no basta con examinar el significado de un verbo de forma aislada a fin de determinar si puede aparecer en un marco sintáctico o no, a la par que reivindican que el análisis de las alternancias sintácticas no puede quedar circunscrito al lexicón si se quiere responder al requisito de incluir algo más que simplemente semántica verbal de forma aislada. Además, Iwata (2008) mantiene que el hecho de que un verbo sea susceptible de mostrar una alternancia entre dos marcos sintácticos diferentes simplemente significa que dicho verbo tiene dos construcciones específicas de un verbo (Iwata 2008: 37; véase también Baker y Ruppenhofer 2002: 27 para una posición similar). En una línea muy afín, Boas (2009) demuestra de forma convincente que las clasificaciones verbales basadas en criterios sintácticos tales como las alternancias de valencia sintáctica o la estructura de eventos resultan poco efectivas para dar buena cuenta del comportamiento de un número de verbos más completo de los manejados por los autores proyeccionistas, así como de las idiosincrasias lingüísticas de grano fino que estos exhiben. La razón fundamental, según Boas, es que estos enfoques no pueden explicar las restricciones de colocación existentes entre el verbo, de un lado, y el ele- 
mento postverbal así como la frase resultativa, de otro (Boas 2003: 164). Esta afirmación es rigurosamente cierta si bien no nos tiene que llevar a invalidar un modelo de representación basado en la noción de aspecto léxico.

Recientemente, la Semántica de Marcos de Fillmore (Fillmore 1982; véase Petruck 1996 para una exposición detallada), cuyos rasgos fundamentales pueden sintetizarse como sigue, desempeña un papel destacado en la GxC Cognitiva de Goldberg (2006):

A word's meaning can be understood only with reference to a structured background of experience, beliefs, or practices, constituting a kind of conceptual prerequisite for understanding the meaning. Speakers can be said to know the meaning of the word only by first understanding the background frames that motivate the concept that the word encodes. Within such an approach, words or word senses are not related to each other directly, word to word, but only by way of their links to common background frames and indications of the manner in which their meanings highlight particular elements of such frames (Fillmore y Atkins 1992: 76-77) (la cursiva es nuestra).

Más concretamente, Goldberg (2006) defiende que existe una relación estrecha entre verbos, construcciones y marcos semánticos. En este sentido, Goldberg (2009) mantiene que Fillmore estaba en lo cierto al afirmar que la única restricción que pesa sobre el significado de un verbo es que debe codificar un marco semántico, entendido como una unidad cultural (Enfield 2002). Según Goldberg (2009: 2) un marco semántico de predicación puede definirse «as a generalized, possibly complex state or event that constitutes a cultural unit». Además, aunque Goldberg reconoce que parecen existir notables excepciones a las restricciones de lo que puede constituir el significado de un verbo, esta autora sostiene que al menos puede postularse el siguiente principio:

The Conventional Frame constraint: «For a situation to be labeled by a verb, the situation or experience may be hypothetical or historical and need not be directly experienced, but it is necessary that the situation or experience evoke a cultural unit that is familiar and relevant to those who use the word" (Goldberg 2009: 11).

En segundo lugar, la cuestión de la selección del argumento postverbal no está tampoco exenta de problemas. Tal y como apunta Boas (2003: 113-116), en función de las entradas léxicas postuladas en el modelo de Goldberg para los verbos de ingestión [cf. (19)], resulta difícil, 
si no imposible, predecir el tipo de expresiones que pueden aparecer como argumentos postverbales de dichos verbos en diferentes construcciones, como se ilustra en (20):

(19) eat: < eater eaten $>$.

(20) a. Pat ate/chewed/*devoured/swallowed.

b. Pat ate/chewed/devoured/swallowed his food.

c. Pat ate/chewed/*devoured/?swallowed his food up.

d. Pat ate/*chewed $/{ }^{*}$ devoured $/{ }^{*}$ swallowed his plate clean.

(Ejemplos tomados de Boas 2003: 114)

En otras palabras, la entrada léxica de eat, tal y como se postula en (19), es insuficiente para explicar por qué otros verbos de la misma clase verbal (e.g. devour, chew, swallow, etc.) exhiben notables asimetrías con respecto a las construcciones con que pueden fusionarse, siendo las restricciones particularmente evidentes en el caso de la construcción resultativa [cf. (20d)]. Así las cosas, Boas (2008: 125) concluye que estos ejemplos «suggest that semantic classes will have to be defined more precisely. Once this step is accomplished, it may be possible to accurately determine a verb's range of argument based on its semantic class membership" (véase Boas 2008 y Ruiz de Mendoza y Mairal-Usón 2007 y 2008 para propuestas similares).

En esencia, curiosamente tanto la GPR como la GxC parecen coincidir en la falta de granularidad en la representación de la información léxica. Podríamos concluir que no basta con afirmar que la semántica verbal se reduce a actualizaciones de la semántica construccional como es el caso en la $\mathrm{GxC}$, o a manifestaciones aspectuales como es el caso de la GPR, sino que se hace necesaria la inclusión de información sintáctica y semántica más detallada en la entrada léxica de un verbo a fin de poder predecir satisfactoriamente su distribución con una variedad de construcciones diferentes, solventándose así los problemas que surgen con el enfoque de Goldberg a la hora de abordar aspectos tales como las restricciones de selección, las restricciones de colocación, la postulación de definiciones de clases semánticas adecuadas para los correspondientes mecanismos de enlace, o el estatuto ontológico de los primitivos que conforman las definiciones, etc. (Boas 2008: 126; Mairal-Usón y Periñán-Pascual 2009).

Hemos visto que Goldberg (2006), al seguir la Semántica de Marcos de Fillmore (1982), invoca una dimensión conceptual y enciclopé- 
dica del significado de una palabra. La cuestión todavía pendiente es determinar cómo podemos formalizar esta orientación, que podemos hacer igualmente extensible al formato de representación de los enfoques proyeccionistas. En este sentido, encajan las investigaciones más recientes del MLC, que abogan por una semántica ontológica (cfr. infra).

Un primer intento en esta línea es el trabajo de Boas (2008). Un aspecto fundamental en el enfoque que propone este autor acerca de la clasificación verbal es que la información de marcos semánticos determina de forma directa la posibilidad de que un verbo aparezca o no en una determinada construcción. Combinando aspectos esenciales de la Semántica de Marcos, la descriptividad verbal, el análisis componencial y FrameNet (Fillmore et al., 2003; <http://framenet.icsi.berkeley.edu>), Boas propone una metodología para identificar las unidades relevantes de significado de forma sistemática. Más concretamente, este autor postula una distinción entre un componente más genérico o nuclear y un elemento modificador (compuesto de rasgos semánticos y descriptores), que sirve para distinguir la semántica de las unidades léxicas en un mismo marco de forma más precisa. Este enfoque, dotado de una considerable granularidad de análisis, en el que las unidades léxicas se describen con respecto a los marcos semánticos que evocan, ofrece una clasificación de las clases verbales bastante refinada a la par que coherente. Además, aunque la información sintáctica está presente en este enfoque, esta no se considera necesariamente un indicador de pertenencia a una clase semántica, evitándose así algunos de los inconvenientes de los que adolecen, por ejemplo, los análisis proyeccionistas.

En una línea muy similar, podríamos encuadrar la investigación más reciente del MLC, que postula una semántica ontológica como soporte epistemológico de las entradas léxicas. Así, se formulan estructuras lógico conceptuales pues estas no están formadas por unidades léxicas sino por conceptos que, a su vez, forman parte de una ontología, denominada "FunGramKB» (<www.fungramkb.com>) (Mairal-Usón y Periñán-Pascual 2009; Periñán-Pascual y Mairal-Usón 2009). En consecuencia, el significado de una pieza léxica se define en relación a un marco de conocimiento o esquema conceptual, del que, con la ayuda de un motor de inferencia, podemos derivar conocimiento extralingüístico (cf. Mairal- 
Usón y Periñán-Pascual 2009). ${ }^{8}$ Así, como mostramos en el Anexo 2, la base del MLC es ahora una ontología a la que se conectan los diferentes lexica de cada una de las lenguas, por lo que el MLC postula un paradigma ontológico o conceptual para la representación de las entradas léxicas.

\section{Conclusiones}

En las páginas anteriores hemos ofrecido una visión necesariamente breve de las principales analogías y diferencias entre los enfoques proyeccionistas de un lado y las llamadas GxCs de otro. Una de las divergencias más notables que hemos puesto de relieve en nuestra exposición estriba en que mientras los enfoques proyeccionistas asumen que la representación léxica de un verbo determina en su totalidad la realización morfosintáctica de sus argumentos, los enfoques construccionistas defienden que un gran número de los aspectos de la interpretación de la estructura argumental de un verbo quedan fuera del alcance de la entrada léxica del mismo, debiendo explicarse en términos de las construcciones. Otra diferencia de especial importancia radica en que los modelos proyeccionistas sostienen que los criterios sintácticos son suficientes para definir las clases verbales, mientras que las GxCs postulan que dichos criterios no son del todo idóneos ni eficientes para establecer de forma coherente y sistemática una clasificación semántica de las clases verbales que haga justicia a la complejidad de los datos y su inherente idiosincrasia.

Otra línea que centra gran parte del debate está relacionada con la naturaleza composicional o no composicional de las construcciones, lo

8 Recientemente, Evans (2009) ha propuesto un enfoque denominado «Teoría de los Conceptos Léxicos y los Modelos Cognitivos» ("Theory of Lexical Concepts and Cognitive Models»), que, al igual que el MLC, parte de una distinción entre el sistema lingüístico (i. e. el conocimiento lingüístico que codifican las palabras) y el sistema conceptual (i. e. el conocimiento no lingüístico al que las palabras nos permiten acceder). Este enfoque coincide con el MLC en prestar especial atención a los procesos de construcción de significado. Para el tema que aquí nos ocupa, una diferencia fundamental radica, no obstante, en que el enfoque de Evans (2009) aúna elementos de diferentes teorías y/o modelos exclusivamente dentro del ámbito de la Lingüística Cognitiva, mientras que el MLC tiende un puente de unión entre la Lingüística Cognitiva (e. g. Goldberg, Lakoff) y modelos funcionales como la GPR (Van Valin 2005, 2008). 
que nos lleva, además irremisiblemente, a replantear el papel de la semántica verbal. Mientras que para los enfoques proyeccionistas (y también la versión de la $\mathrm{GxC}$ de Fillmore) las construcciones deben estar sujetas al principio de la no-composicionlidad, en el seno de las GxCs, especialmente entre la GxC Cognitiva de Goldberg (2006), el enfoque de marcos semánticos de Boas $(2008,2009)$, la GxC Radical de Croft $(2001,2003)$ y el enfoque léxico-construccional de Iwata (2008), entre otros, existen sustanciales analogías y divergencias que conviene traer a colación. Estos enfoques coinciden en abogar por otorgar un papel esencial a los datos reales de uso lingüístico, la frecuencia de uso, lo que les lleva a aceptar la existencia de constructos totalmente composicionales pero con un alto índice de frecuencia como construcciones, así como la importancia de factores de índole psicolingüístico a la hora de explicar las propiedades de forma y significado de los elementos lingüísticos. Todos estos modelos aceptan que para dar buena cuenta del significado de un enunciado, se hace necesario recurrir a construcciones de diversos grados de abstracción (o alto nivel), de un lado, y de especificidad (o bajo nivel), de otro. Estos modelos, de marcada orientación cognitivista, difieren, no obstante, en el peso específico que otorgan a la semántica construccional en general y a las construcciones de estructura argumental abstractas (e.g. la $\mathrm{GxC}$ de Goldberg 2006) o, en cambio, a la semántica verbal y a las mini-construcciones (o construcciones específicas de una clase verbal e incluso de un verbo, etc.) (e. g. Boas 2008 y 2009; Croft 2001 y 2003; Iwata 2008). Estos últimos autores, al igual que muchos de los modelos proyeccionistas, entienden que el enfoque de Goldberg otorga un papel excesivamente preponderante a las construcciones, poniendo de relieve que el análisis de esta autora adolece de cierta circularidad a la hora de explicar la fusión entre semántica verbal y construccional (Iwata 2008: 20). Así pues, se defiende no solo el mayor grado de plausibilidad psicológica de las construcciones de bajo nivel, sino también la necesidad de establecer parámetros semánticos de impacto semántico para optimizar el análisis de la interacción dinámica entre semántica verbal y semántica construccional. En cualquier caso, el caballo de batalla de los modelos construccionistas consiste en establecer un equilibrio adecuado entre verbos y construcciones al nivel de granularidad que requiera un elemento lingüístico o enunciado en un contexto determinado. Este espíritu de reconciliación entre semántica verbal y semántica construccional a lo largo de un amplio 
espectro de diferentes niveles de granularidad es el que preside el tratamiento de la fusión entre plantillas léxicas y plantillas construccionales en el MLC, un modelo de orientación ontológica (o conceptual) que proporciona una visión detallada de todos aquellos niveles de representación así como del tipo de operaciones conceptuales que deberían formar parte de una teoría que aspira a explicar cómo se construye el significado.

\section{Bibliografía}

Baker, C., y J. Ruppenhofer (2002): «FrameNet's Frames vs. Levin's Verb Classes», en J. Larson y M. Paster (eds.), Proceedings of the $28^{\text {th }}$ Annual Meeting of the Berkeley Linguistics Society, Berkeley, University of California Linguistics Department: 27-38.

BOAS, H. C. (2003): A Constructional Approach to Resultatives, Stanford, California, CSLI Publications.

- (2008): «Determining the structure of lexical entries and grammatical constructions in Construction Grammar", Annual Review of Cognitive Linguistics, 6: 113-144.

- (2009): «Methods for finding proper types of constructional generalizations», Conferencia Plenaria pronunciada en la Tercera Conferencia Internacional de AFLiCo, 27-29 de mayo de 2009, Universidad de París 10, Nanterre.

BoD, R. (2009): «Constructions at work or at rest?», Cognitive Linguistics, 20.1: 129-134.

BORER, H. (1994): «The projection of arguments», en E. Benedicto y J. Runner (eds.), Functional projections. University of Massachusetts Occasional Papers in Linguistics, 17, GLSA, Amherst, University of Massachusetts: 19-48.

- (2001): «Exo-skeletal vs. endo-skeletal explanations: syntactic projections and the lexicon», Trabajo presentado en la Conferencia «Explanations in Linguistics», San Diego, California.

CARTeR, R. J. (1988): «Some Linking Regularities», en B. Levin y C. Tenny (eds.), Lexicon Project Working Papers, 25, Center for Cognitive Science, Cambridge, MA, MIT: 1-92.

Сномsку, N. (1986): Knowledge of language: its nature, origins and use, Nueva York, Praeger.

- (1988): Language and Problems of Knowledge, Cambridge, MA, MIT Press.

- (1995): The Minimalist Program, Cambridge, MA, MIT Press.

- (2000): New Horizons in the Study of Language and Mind, Cambridge, MA, Cambridge University Press.

Croft, W. (2001): Radical Construction Grammar: Syntactic Theory in Typological Perspective, Oxford, Oxford University Press. 
Croft, W. (2003): «Lexical Rules vs. Constructions: A False Dichotomy», en H. Cuyckens, T. Berg, R. Dirven y K. Panther (eds.), Motivation in Language. Studies in Honour of Günter Radden, Ámsterdam/Filadelfia, John Benjamins Publishing Company: 49-68.

Culicover, P. (1999): Syntactic Nuts: Hard cases, syntactic theory, and language Acquisition (Foundations of Grammar, vol. 2), Oxford, Oxford University Press.

- y R. JaCKendoff (2005): Sympler syntax, Oxford, Oxford University Press.

DIK, S. C. (1997a): The Theory of Functional Grammar, Part 1: The Structure of the Clause (Functional Grammar Series, 20), K. Hengeveld (ed.), Berlín/Nueva York, Mouton de Gruyter.

- (1997b): The Theory of Functional Grammar, Part 2: Complex and Derived Constructions (Functional Grammar Series, 21), K. Hengeveld (ed.), Berlín/Nueva York, Mouton de Gruyter.

Enfield, N. (2002): «Cultural Logic and Syntactic Productivity: Associated Posture Constuctions in Lao», en N. Enfield (ed.), Ethnosyntax, Oxford, Oxford University Press: 231-258.

Evans, V. (2009): How Words Mean: Lexical Concepts, Cognitive Models, and Meaning Construction, Oxford, Oxford University Press.

FERNÁNDEZ LEBORANS, M. J. (1999): «La predicación: Las oraciones copulativas», en I. Bosque y V. Demonte (dirs.), Gramática descriptiva de la lengua española, Vol. 2 (Las construcciones sintácticas fundamentales. Relaciones temporales, aspectuales y modales), Madrid, Espasa-Calpe: 2357-2460.

Fillmore, C. J. (1982): "Frame Semantics», en Linguistic Society of Korea (ed.), Linguistics in the Morning Calm, Seúl, Hanshin: 111-138.

- (1988): "The Mechanisms of 'CG'", en S. Axmaker, A. Jaisser y Helen Singmaster (eds.), Proceedings of the Fourteenth Annual Meeting of the Berkeley Linguistics Society, Berkeley, Berkeley Linguistics Society: 35-55.

- y B. T. ATKINS (1992): «Towards a Frame-based Lexicon: the Semantics of RISK and its Neighbors», en A. Lehrer y E. F. Kittay (eds.), Frames, Fields and Contrasts, Hillsdale, NJ, Lawrence Erlbaum Associates: 75-102.

- C. R. Johnson y M. R. L. Petruck (2003): «Background to FrameNet», International Journal of Lexicography, 16.3: 235-250.

- P. Kay, L. A. Michaelis e I. SAG (en preparación): Construction Grammar, Stanford, CSLI Publications.

Fried, M., y J-O. ÖstMan (2005): «Construction Grammar: A thumbnail sketch», en M. Fried y J-O. Östman (eds.), Construction Grammar in a Cross-Language Perspective (Constructional Approaches to Language, 2), Ámsterdam/Filadelfia, John Benjamins Publishing Company: 11-86.

GoldberG, A. E. (1995): Constructions: A Construction Grammar approach to argument structure, Chicago/Londres, Chicago University Press.

- (1996): "Construction Grammar», en E. K. Brown y J. E. Miller (eds.), Concise Encyclopedia of Syntactic Theories, Oxford, Elsevier: 68-71. 
GoldBerG, A. E. (1998): "Patterns of experience in patterns of language», en M. Tomasello (ed.), The New Psychology of Language (Cognitive and Functional Approaches to Language Structure), vol. 1, Mahwah, NJ, Lawrence Erlbaum: 203-219.

- (2003): "Constructions: A new theoretical approach to language», Trends in Cognitive Sciences, 7.5: 219-224.

- (2006): Constructions at Work: The Nature of Generalization in Language, Nueva York, Oxford University Press.

- (2009): "Verbs, Constructions and Semantic Frames», en M. Rappaport Hovav, E. Doron e I. Sichel (eds.), Syntax, Lexical Semantics and Event Structure, Oxford, Oxford University Press. Disponible en: <http://www. princeton.edu/ adele/Publications_files/Frames6-16-08\%20copy.pdf>.

GonZÁlez Vergara, C. (2006a): «La Gramática del Papel y la Referencia: Una aproximación al modelo», Revista Onomázein, 14: 101-140.

- (2006b): «Las construcciones no reflexivas con "se": Una propuesta desde la Gramática del Papel y la Referencia», Tesis doctoral inédita, Madrid, Universidad Complutense de Madrid.

- (2009): «One rule to rule them all: Logical structures for Spanish non-reflexive "se" constructions", en L. Guerrero, S. Ibáñez Cerda y V. A. Belloro (eds.), Studies in Role and Reference Grammar, México, Universidad Nacional Autónoma de México: 361-379.

GonZÁlveZ-García, F. (2006): «Passives without Actives: Evidence from Verbless Complement Constructions in Spanish», Constructions, SV1-5/2006, Heinrich-Heine-Universität Düsseldorf: 1-65.

- (2007): "That's a construction for you: Las construcciones es lo que tiene(n): Grammaticalization via subjectification in attributive clauses in English and Spanish", IJES: International Journal of English Studies, 7.1: 65-99.

- (2008): «Construction Grammar Works: An interview with Adele E. Goldberg», Annual Review of Cognitive Linguistics, 6: 345-360.

- y C. S. Butler (2006): «Mapping Functional-Cognitive Space», Annual Review of Cognitive Linguistics, 4: 39-96.

Green, G. (1972): «Some Observations on the Syntax and Semantics of Instrumental Verbs», Chicago Linguistic Society Proceedings, 8: 83-97.

HALE, K., y J. KeYSER (1997): "On the complex nature of simple predicators", en A. Alsina, J. Bresnan y P. Sells (eds.), Complex predicates, Stanford, CSLI Publications: 29-65.

Halliday, M. A. K., y C. Matthiessen (2004): An Introduction to Functional Grammar, Londres, Edward Arnold.

IWATA, S. (2008): Locative Alternation: A lexical-constructional approach, Ámsterdam/Filadelfia, John Benjamins Publishing Company. 
JACKENDOFF, R. (1990): Semantic Structures, Cambridge, MA, MIT Press.

- (2002): Foundations of Language: Brain, meaning, grammar, evolution, Oxford, Oxford University Press.

KAY, P., y C. J. FILLMORE (1999): «Grammatical Constructions and Linguistic Generalizations: The 'what's X doing Y' Construction», Language, 75: 1-33.

LANGACKER, R. W. (2000): «A dynamic usage-based model», en M. Barlow y S. Kemmer (eds.), Usage-Based Models of Language, Stanford, CSLI Publications: 1-63.

- (2008): Cognitive Grammar: A Basic Introduction, Nueva York, Oxford University Press.

LevIN, B. (1985): «Lexical Semantics in Review: An Introduction», en B. Levin (ed.), Lexical Semantics in Review, Lexicon Project Working Papers, 1, Center for Cognitive Science, Cambridge, MA, MIT: 1-62.

- y M. RAPAAPORT HOVAV (1995): Unaccusativity: At the Syntax-Lexical Semantics Interface, Linguistic Inquiry Monograph, 26, Cambridge, MA, MIT Press.

- y M. Rappaport Hovav (2005): Argument Realization, Research Surveys in Linguistics Series, Cambridge, Cambridge University Press.

Mairal-Usón, R., y R. D. JR. VAN VAlin (2001): «What Role and Reference Grammar can do for Functional Grammar», Revista Canaria de Estudios Ingleses, 42: 137-166.

- y F. J. CORTÉs (2008): «Modelos teóricos del estudio del léxico: los modelos funcionales», en Elena de Miguel (ed.), Panorama de la Lexicología, Barcelona, Ariel: 247-280.

- y F. Ruiz DE MendozA (2008): «Internal and external constraints in meaning construction: the lexicon grammar continuum», en T. Gibert Maceda y L. Alba-Juez (eds.), Estudios de Filologia Inglesa: Homenaje a la Dra. Asunción Alba Pelayo, Colección Varia, Madrid, UNED: 219-237.

- y F. RuIZ DE MenDOZA (2009): «Levels of description and explanation in meaning construction», en C. S. Butler y J. Martín Arista (eds.), Deconstructing Constructions, Ámsterdam/Filadelfia, John Benjamins Publishing Company: 153-198.

- y C. Periñán-PAsCual (2009): «The anatomy of the lexicon component within the framework of a conceptual knowledge base», Revista Española de Lingüistica Aplicada, 22: 217-244.

MARANTZ, A. (1997): «No escape from syntax: don't try morphological analysis in the privacy of your own lexicon», en A. Dimitriadis y L. Siegel (eds.), University of Pennsylvania Working Papers in Linguistics, 4.2, Filadelfia: 201-225.

MiCHAELIS, L. (2003): «Word meaning, sentence meaning, and syntactic meaning», en H. Cuykens, R. Dirven y J. R. Taylor (eds.), Cognitive Approaches to Lexical Semantics, Berlín/Nueva York, Mouton de Gruyter: 93-122. 
Moreno Cabrera, J. C. (1982): «Atribución, ecuación y especificación: tres aspectos de la semántica de la cópula en español», Revista Española de Lingüistica, 12:2: 229-245.

Pedersen, J. (2005): «The impersonal se-construction in Spanish. Constructional variation and change», Constructions, 1/2005, Heinrich-Heine-Universität Düsseldorf: 1-49.

Periñán-Pascual, C., y R. Mairal-Usón (2009): «Bringing Role and Reference Grammar to natural language understanding», Procesamiento del Lenguaje Natural, 43: 265-273.

PetrucK, M. (1996): «Frame Semantics», en J. Verschueren, J.-O. Östman, J. Blommaert y C. Bulcaen (eds.), Handbook of Pragmatics, Ámsterdam/Filadelfia, John Benjamins Publishing Company: 1-13.

Rappaport Hovav, M., y B. Levin (1998): "Building Verb Meanings», en M. Butt y W. Geuder (eds.), The Projection of Arguments: Lexical and Compositional Factors, Stanford, CSLI Publications: 97-134.

Ruiz de MendozA, F. J., y O. Díez (2002): «Patterns of conceptual interaction", en R. Dirven y R. Pörings (eds.), Metaphor and Metonymy in Comparison and Contrast, Berlín/Nueva York, Mouton de Gruyter: 489-532.

- y R. MAIRAL-UsÓN (2007): «High-level metaphor and metonymy in meaning construction», en G. Radden, K. M. Köpcke, Th. Berg y P. Siemund (eds.), Aspects of Meaning Construction in Lexicon and Grammar, Ámsterdam/Filadelfia, John Benjamins Publishing Company: 33-49.

- y R. MAiraL-UsÓN (2008): «Levels of description and constraining factors in meaning construction: an introduction to the Lexical Constructional Model», Folia Linguistica, 42.2: 355-400.

SAG, I. (2007): «Sign-Based Construction Grammar: An Informal Synopsis», Manuscrito no publicado, Stanford, Stanford University.

SCHÖNEFELD, D. (2006): «Constructions», Constructions, SV1-1/2006, Heinrich-Heine-Universität Düsseldorf: 1-39.

Van Valin, R. D. JR. (2005): Exploring the Syntax-Semantics Interface, Cambridge, Cambridge University Press.

- (2006): «Some universals of Verb semantics», en R. Mairal y J. Gil (eds.), Linguistic Universals, Cambridge, Cambridge University Press: 155-178.

- (2007): «Review of Adele E. Goldberg Constructions at work: the nature of generalizations in language, Oxford, Oxford University Press", Journal of Linguistics, 43: 234-240.

- (ed.) (2008): Investigations of the Syntax-Semantics-Pragmatics Interface, Ámsterdam/Filadelfia, John Benjamins Publishing Company.

- y R. J. LaPolla (1997): Syntax: Structure, meaning and function (Cambridge Textbooks in Linguistics), Cambridge, Cambridge University Press.

Vendler, Z. (1967): «Verbs and times», en Z. Vendler, Linguistics in Philosophy, Ithaca, Cornell University Press: 97-121. 


\section{Anexo 1}

\section{Arquitectura global del Modelo Léxico-Construccional}

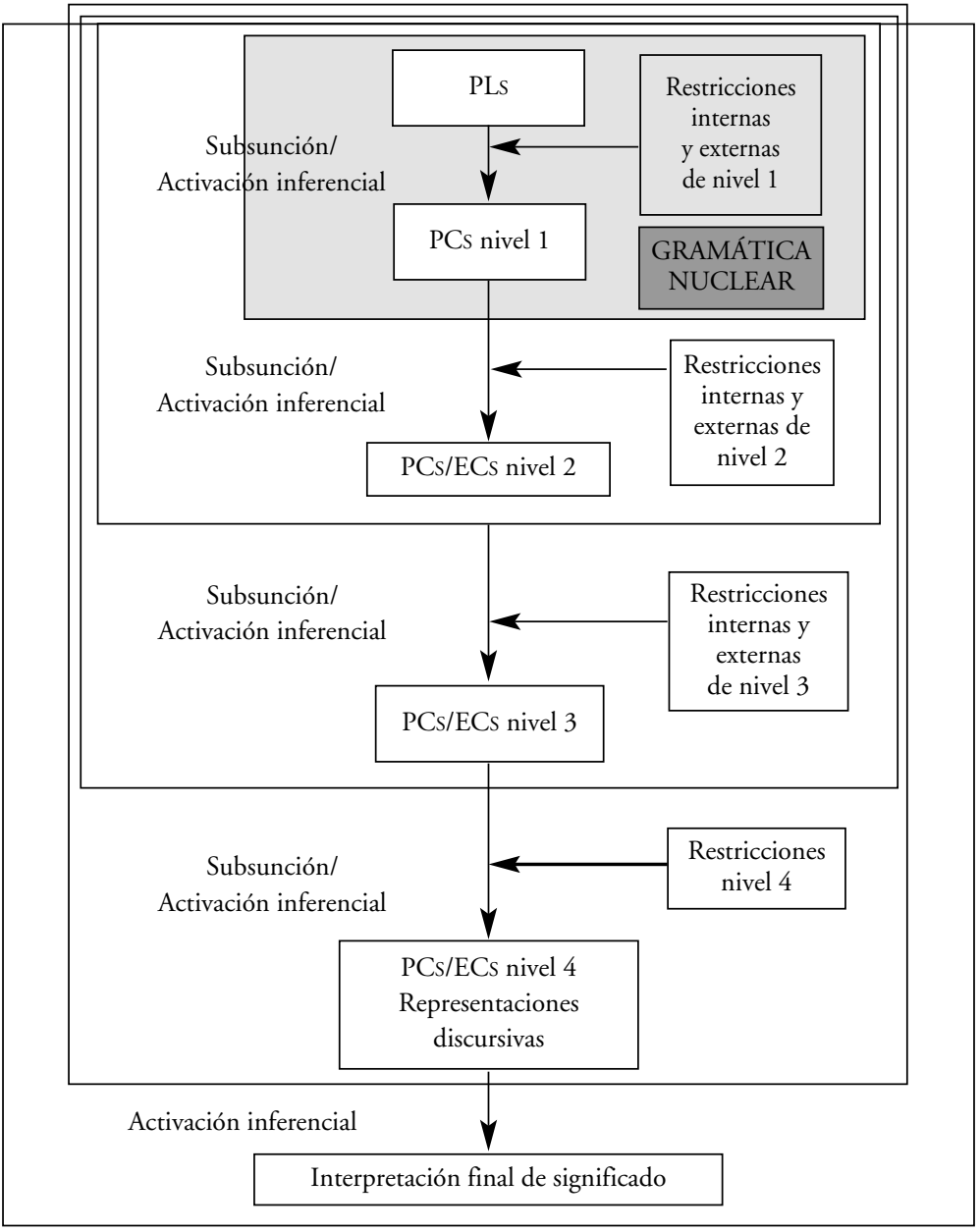

$\mathrm{PL}=$ plantilla léxica; $\mathrm{PC}=$ plantilla construccional $; \mathrm{EC}=$ Estructura conceptual

Subsunción = incorporación restringida de estructuras conceptuales de un nivel a las del nivel inmediatamente superior (como consecuencia, la estructura de nivel superior queda parametrizada)

Activación inferencial (cueing) = activación de estructura conceptual implícita a partir de estructuras conceptuales de un nivel inferior (por ej. por medio de una metonimia situacional) 


\section{Anexo 2}

\section{La orientación conceptual del MLC}

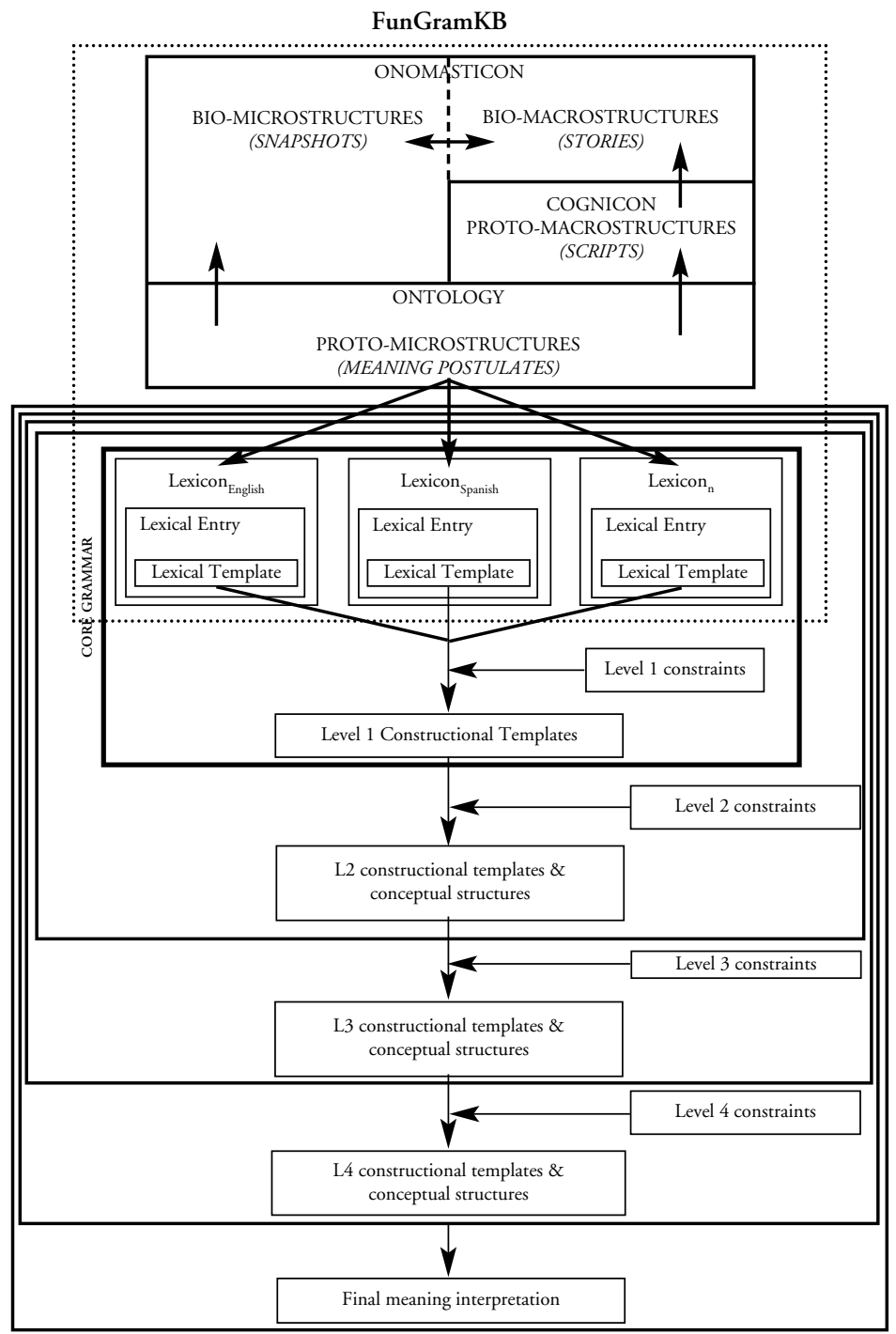

Lexical Constructional Model 


\title{
OBSERVACIONES SOBRE LA PROYECCIÓN ARGUMENTAL*
}

\author{
JUAN ROMERO \\ (Universidad de Extremadura)
}

Tanto los enfoques proyeccionistas como los neoconstructivistas derivan la realización sintáctica de la estructura argumental a partir de la interpretación semántica. En el primer caso, son las propiedades semánticas de los elementos léxicos las que determinan tanto el número de argumentos asociados a cada pieza como la posición en la que se proyectan. En el segundo caso son las propiedades del evento, representado por medio de una cierta estructura funcional, las que definen los huecos en los que deben proyectarse los argumentos para recibir la interpretación que se les asigna.

En este trabajo argumentaré que unos y otros fracasan a la hora de explicar la proyección argumental. Este fracaso se debe bien a problemas

* Agradezco sus comentarios y su amabilidad durante el Sylex a Mamen Horno, José Val y José Luis Mendívil, así como a todos los participantes en las jornadas. Agradezco también sus comentarios a Violeta Demonte, Olga Fernández Soriano y Norberto Moreno. Finalmente, Javier Ormazabal puede reclamar la coaturía de gran parte del trabajo. Este trabajo está parcialmente financiado por las Ayudas a Grupos de Investigación del Gobierno Vasco GIC07/144-IT-210-07 y el proyecto «Estructura Argumental y la arquitectura de la gramática» del MEC FFI2008-04786. 
de sub o sobregeneración o bien a su incapacidad para predecir el comportamiento intercategorial de la proyección argumental. En su lugar, propondré un modelo de proyección que no está basado en la interpretación de los argumentos, asunto que queda para los componentes interpretativos, sino en las restricciones de selección codificadas por medio de los rasgos formales de los elementos léxicos y, muy especialmente, en la categorización.

\section{Modelos proyeccionistas}

Como señala Borer (2005a, 2005b), los modelos proyeccionistas adolecen de graves problemas de subgeneración. Estos modelos se basan en la existencia de ciertos primitivos semánticos que determinan la estructura sintáctica a partir de su significado eventivo básico. Primitivos semánticos como CAUSA, CAMBIO o ESTADO no solo proporcionan el significado que describen los elementos léxicos, sino que también están vinculados necesariamente a la inserción de argumentos con una interpretación específica. Así, si un elemento léxico EL codifica CAUSA como parte de su significado, deberá insertar a su vez un argumento que realice la función de causante o agente. Si EL participa, por ejemplo, de la alternancia causativo-incoativa, la proyección argumental de la variante incoativa se proyectará a partir de un elemento léxico distinto $\mathrm{EL}_{2}$. Como consecuencia, es necesaria una polisemia masiva para dar cuenta del comportamiento de prácticamente todos los verbos. Considérese por ejemplo el caso de oler (1).
a. huele mal
b. aquí huele a rosas
c. tu novio huele
d. el perro olía a los niños
e. a tu novio le huelen los pies
f. el catador les huele los jamones (escuchado en una factoría de jamones)

De acuerdo con el modelo proyeccionista, cada uno de los verbos que aparecen en las oraciones de (1) es un elemento léxico distinto. El problema de esta explicación radica en que el significado del verbo es siempre el mismo, un evento de oler, excepto por lo que atañe al significado asociado a cada una de las distintas estructuras argumentales. Por 
tanto, en ausencia de diferencias sustantivas de significado, las explicaciones proyeccionistas se vuelven circulares.

Frente a esta concepción, numerosos autores han planteado que existen razones para pensar que la interpretación de los argumentos se lleva a cabo sobre posiciones fijas en la estructura (Baker 1988, 1996; Hale y Keyser 1993; Pesetsky 1995; Borer 2005; Ramchand 2008). Chomsky (1995) observa en este sentido que, dado que la interpretación de los argumentos es predecible a partir de la estructura, resulta innecesario especificar en los elementos léxicos esta información. En consecuencia, el Programa Minimalista relega la interpretación de las relaciones predicado-argumento a los componentes interpretativos, donde estas relaciones se leen en la estructura formada por la computación sintáctica. En (1d), por ejemplo, el papel agentivo del sujeto se puede derivar de su proyección en $(\mathrm{Esp}, \mathrm{S} v)$ y el de paciente del objeto de su proyección en la posición de complemento de V. En la medida en que la interpretación semántica pueda derivarse de la posición estructural, no hay razón para que esta información forme parte de las entradas léxicas.

Una segunda objección a los sistemas proyeccionistas procede del hecho de que no pueden explicar las diferencias de proyección intercategoriales. Así, una misma estructura léxico-conceptual puede expresarse por medio de dos elementos léxicos de distinta categoría, por ejemplo, destruir y destrucción (Grimshaw 1990). Como puede observarse en los ejemplos de (2) y (3), sus requisitos de proyección son, sin embargo, radicalmente distintos:

(2) a. el presidente destruyó la documentación

b. *el presidente destruyó

c. *la documentación destruyó

d. *destruyó

a. la destrucción del presidente de la documentación

b. la destrucción del presidente

c. la destrucción de la documentación

d. la destrucción

El contraste entre (2) y (3) plantea al menos dos cuestiones. La primera es: ¿por qué es posible suprimir todos los argumentos de un predicado cuando la ELC se asocia a un nombre y no cuando se asocia a un verbo? Esto es, ¿por qué no podemos expresar un evento de destrucción 
como forma oracional no argumental (2d) (como sí podemos hacer, por ejemplo, cuando decimos llueve) pero sí como forma nominal (3d)?

La segunda pregunta es: ¿por qué la modificación de la ELC, y la consiguiente generación de un nuevo elemento léxico, conlleva al menos con mucha frecuencia cambios en la morfología de la palabra y esas mismas modificaciones no afectan en absoluto a la morfología del sustantivo? Por ejemplo, la ELC asociada a la oración de (2c) podemos volverla gramatical transformando el verbo en un participio pasivo (4). Sin embargo, esa misma ELC no causa ninguna transformación sobre la correspondiente forma nominal (3c).

(4) la documentación fue destruida

La primera pregunta plantea un problema muy grave, porque los procedimientos que alteran las redes temáticas no se aplican sobre los elementos léxicos, sino sobre sus estructuras argumentales. La solución que aportan los modelos proyeccionistas es en términos de restricciones sobre la naturaleza de las relaciones temáticas. Así, el hecho de que haya verbos que no participan de la alternancia causativo-incoativa se deriva de la naturaleza de la causación, que sea, por ejemplo, inherente o no lo sea. Sin embargo, esta explicación predice en contra de los hechos que destrucción nunca va a poder prescindir de su causa. Así, la raíz destru- tiene de hecho asociada una ELC con cero argumentos, concretamente la que aparece en (3d). Nótese que (3d) permite tanto una lectura eventiva (5) como resultativa.

(5) la destrucción fue metódica

Asimismo, sabemos que sintácticamente es posible construir una oración sin ningún argumento, apoyada únicamente en un sujeto expletivo (la mencionada llueve). En consecuencia, no está claro cómo en un modelo proyeccionista podemos evitar asociar la ELC de (3d) a una raíz verbal y que la oración resultante sea gramatical.

La segunda cuestión tiene que ver con un hecho interlingüísticamente muy estable: los sustantivos, a diferencia de los verbos, no alteran su forma morfológica en función de los argumentos que proyectan. La morfología verbal está plagada de morfemas cuya única o principal función es 
la de subrayar la eliminación o adición de un argumento a la raíz verbal. Así, en unas u otras lenguas encontramos morfología pasiva, causativa, anticausativa, incoativa, aplicativa, etc., asociada a los elementos de categoría $\mathrm{V}$, pero no encontramos nada similar en el caso de los elementos de categoría nominal.

Nótese que los modelos proyeccionistas pueden de hecho captar estas diferencias haciendo referencia a las distinciones categoriales, ya que las proyecciones argumentales son únicas para cada pieza léxica. Sin embargo, la cuestión categorial es ajena a las relaciones temáticas, por lo que se introduciría como un elemento ad hoc. Además, una vez introducido en el sistema es lícito plantear si sigue siendo necesario contar con las ELC para dar cuenta de la proyección argumental y se pone por tanto en cuestión la validez global del programa proyeccionista.

\section{Neoconstructivismo y modelos mixtos}

Los distintos modelos neoconstructivistas hacen depender la red argumental de la estructura sintáctica, ya sea por medio de una estructura funcional universal (Borer 2005a, 2005b), de una estructura eventiva (Ramchand 2008) o introduciendo los argumentos mediante composición semántica (Pylkkänen 2008). En consecuencia, no son los elementos léxicos los que determinan la proyección, sino que esta está restringida bien por nuestro conocimiento del mundo (Borer 2005a, 2005b) o bien por alguna propiedad especificada en los elementos léxicos pero no directamente relacionada con la proyección argumental, como puede ser la aktionsart.

Los modelos puramente neoconstructivistas, como el de Borer, están sujetos a problemas de sobregeneración. Comencemos con una oración como (6).

(6) *la funcionaria me bastó esos documentos

En contra de Borer (2005a, 2005b), no importa cuánto retorzamos nuestro sistema conceptual, no podemos asignar una interpretación a la oración, a pesar de que no podemos excluirla en base a nuestro conocimiento del mundo, ya que su paráfrasis analítica es perfectamente interpretable y gramatical (7). 
(7) la funcionaria hizo que me bastaran esos documentos

Nótese que de acuerdo con Borer no podemos hacer referencia a ninguna propiedad del listema porque el listema carece de propiedades formales. El modelo de Borer, en consecuencia, sobregenera construcciones transitivas a partir de verbos estativos, cuyo comportamiento es sistemáticamente inacusativo. Es muy importante subrayar que los verbos estativos no son, desde un punto de vista semántico, incompatibles con un agente o una causa [tal y como se ejemplifica en (7)] y, en consecuencia, no puede tratarse como una restricción semántica. Volveremos sobre este asunto en la sección 4.

Ramchand (2008) plantea esta misma crítica de sobregeneración a partir de ejemplos como (8).

(8) *John slept the baby

Ramchand bloquea este tipo de formaciones por medio de una matriz de rasgos formales con la que los elementos léxicos especifican las estructuras argumentales con las que son compatibles. En consecuencia, dada una cierta matriz $M$ para un elemento léxico EL1, y dadas las restricciones formales $\mathrm{RF}$ asociadas a una lengua $\mathrm{L}$, esperamos que L sea capaz de expresar el conjunto de posibilidades permitidas, y solo ese conjunto, por la intersección de M y RF para EL1. Sin embargo, al tratarse de una restricción semánticamente definida, este tipo de condiciones está sujeto a lo que podemos denominar el problema de la traducción. Considérese el ejemplo de (9) en español paralelo al de (8).

(9) Juan durmió al niño

La gramaticalidad de esta oración conlleva que la intersección de $\mathrm{M}$ y RF en español permita lo que no permite en inglés. Dado que no podemos invocar nuestro conocimiento del mundo, ya que la experiencia del sueño o de hacer dormir a un niño no parece que ofrezca grandes posibilidades de variación intercultural, en el análisis de Ramchand esta variación solo puede atribuirse a factores puramente lingüísticos. Sin embargo, tanto el inglés como el español poseen una alternancia sintácticamente productiva tanto entre predicados causativos e incoativos, como entre 
predicados inergativos e inacusativos, por lo que no parece que el contraste entre (8) y (9) pueda plantearse tampoco en esos términos. ${ }^{1}$

Finalmente, las teorías puramente constructivistas plantean un problema general desde el punto de vista de la adquisición. Como hace explícito Borer (2005a: 31), el almacén de listemas que constituye la enciclopedia es «a list of all arbitrary pairings of sound and meaning, where by sound we mean a phonlogical index, and by meaning we refer to the appropriate package of conceptual properties associated with such an index». Esto es, si los elementos léxicos no determinan la sintaxis, entonces carecen de rasgos formales, en la más pura tradición saussureana. De acuerdo con esta concepción esperamos que el proceso de adquisición esté únicamente restringido por nuestra habilidad cognitiva para generar conceptos, sin que el lenguaje imponga restricciones adicionales. Sin embargo, hay razones para pensar que este enfoque es incorrecto. Considérese el caso de la adquisición de términos de color. Por un lado, sabemos que el sistema visual humano es capaz de hacer distinciones en función del color desde las primeras horas de vida y a los pocos meses esas distinciones abarcan la totalidad de los colores básicos (véase, por ejemplo, Wyler 1992 y las referencias allí citadas). En consecuencia podemos asumir sin riesgo que el paquete de propiedades conceptuales asociadas al color está apropiadamente fijado antes de que el niño comience a producir lenguaje. Por otro lado, los términos de color, especialmente en la cultura occidental, tienen una presencia masiva en la educación de los niños. En lo que podemos considerar un caso de riqueza extrema de estímulo, a los niños se les

1 Este contraste plantea, asimismo, un problema a los enfoques proyeccionistas, que tendrían que postular una diferencia de significado entre sleep y dormir. Asimismo, obsérvese que la situación contraria también se da. Considérese el par crecer-grow ejemplificado en (i).

(i) a. Peter grew the tomatos

b. *Peter creció los tomates

Este caso también es interesante porque crecer tiene en español dos nominalizaciones diferentes: crecimiento y crecida, la primera con lectura de proceso y la segunda con lectura resultativa. Fábregas (en prensa), dentro del modelo de Ramchand (2008), propone que la primera nominalización se obtiene cuando el verbo toma un undergoer como sujeto, mientras que en la segunda toma un path. Esto mostraría que la aktionsart de crecer es perfectamente compatible con la alternancia causativo-incoativa, como ocurre en inglés. 
presentan lápices de colores, piezas de construcción que solo se diferencian por el color, etc. Esta es la razón por la cual los niños empiezan a usar en sus oraciones términos de color desde muy pronto. Sin embargo, es sabido que los niños utilizan estos términos para "aderezar» las oraciones sin darles ningún valor semántico. Desde este punto de vista, los sistemas conductistas/conexionistas no solo fracasan en explicar el caso general de pobreza de estímulo, sino que incluso fracasan en el caso particular de la riqueza de estímulo. Esto es, en aquellos casos en los que el estímulo es extraordinariamente rico, estos modelos fracasan al predecir una rápida adquisición que, de hecho, no tiene lugar.

Así pues, si un listema no es más que la asociación de un significante y un significado, ¿por qué los niños se demoran tanto en establecer esa asociación en el caso de los términos de color? La respuesta a esta cuestión debe hallarse en que los listemas contienen de hecho algo más que sonido y significado, deben estar lingüísticamente categorizados para poder formar parte del lexicón. Dado que el lexicón es un componente del lenguaje y no, por ejemplo, de la visión, esperamos que este tipo de categorización esté sujeta a condiciones puramente lingüísticas. En este trabajo asumiré que estas condiciones son del tipo descrito por Uriagereka (1996), jerarquías de implicación que categorizan los elementos léxicos de acuerdo a niveles de complejidad. Estas jerarquías por un lado responden al proceso de adquisición, de forma que los elementos más complejos se adquieren en primer lugar (Principio del Subconjunto, Subset Principle), y por otro lado tienen una correspondencia con propiedades sintácticamente activas como la animacidad o la diferencia entre elementos contables e incontables.

No es evidentemente mi pretensión haber demostrado que los modelos proyeccionistas o neoconstructivistas son erróneos. El objetivo de estas dos secciones era mostrar que cualquier análisis de la proyección sintáctica basado en cuestiones interpretativas plantea problemas de principio que solo puede resolver mediante mecanismos ad hoc. No se trata de una crítica novedosa, de hecho, es una reflexión que se encuentra en la base de gran parte de los modelos propuestos, los llamados modelos mixtos, como los de Ramchand (2008) o Rothstein (2004), etc. 
En las dos siguientes secciones voy a proponer un modelo de proyección argumental en el que la interpretación de la estructura temática no desempeña ningún papel. Este modelo consta de dos elementos. Por un lado, propondré, siguiendo a Hale y Keyser (1993), que las categorías léxicas definen la forma de proyectar de los elementos léxicos. Por otro lado, argumentaré que las posibilidades de proyección de estos elementos están restringidas por sus restricciones de selección, que, por razones de adquisición, están a su vez constreñidas por propiedades visibles en la computación sintáctica, esto es, por los rasgos que definen las relaciones sintácticas.

\section{Categorías y proyección}

En las secciones anteriores hemos visto como sustantivos y verbos difieren considerablemente en su forma de proyectar. Mientras que las nominalizaciones son compatibles con cualquier estructura argumental, los verbos están extraordinariamente restringidos. De hecho, la modificación de la estructura argumental de un verbo suele ir acompañada (y condicionada) por cambios morfosintácticos que en el caso de las nominalizaciones nunca se dan. Dado que verbos y sustantivos comparten una misma semántica básica y una vez proyectados interpretan su red temática del mismo modo, parece razonable pensar que el significado no es el desencadenante de la proyección argumental.

Como alternativa a los modelos semánticos, voy a proponer que la proyección de los elementos léxicos se deriva de su categoría. Esto es, voy a entender la categorización como una definición axiomática de la proyección de acuerdo a las siguientes reglas:
a. $\mathrm{V} \rightarrow[\mathrm{V} \mathrm{SX}]$
b. $\mathrm{N} \rightarrow \mathrm{N}$
c. $\mathrm{P} \rightarrow[\mathrm{SY}[\mathrm{P} S \mathrm{SX}]]$

Hale y Keyser (1993) motivan estas reglas de dos formas distintas. Por un lado, sostienen que existe una correspondencia entre estas reglas y la interpretación de las categorías. Por otro lado, conciben esta caracterización como una manera de restringir las posibilidades de proyección argumental adecuándola a los datos empíricos que nos ofrecen las len- 
guas, por ejemplo, en lo que respecta al número máximo de argumentos posibles en una oración. ${ }^{2}$ Aquí voy a adoptar únicamente la segunda de las dos motivaciones. De este modo, sobre la generalización representada por el esquema X-barra, las categorías léxicas codifican las distintas opciones de proyección disponibles: núcleo $(\mathrm{N})$, núcleo-complemento $(\mathrm{V})$ y especificador-núcleo-complemento $(\mathrm{P})$.

De acuerdo con las reglas de (10) y asumiendo que el argumento externo se proyecta como especificador de una categoría funcional independiente $v$, este sistema predice la existencia de los siguientes patrones verbales:
a. Inacusativo $\left[{ }_{\mathrm{SV}} \mathrm{V} \mathrm{SX}\right]$
b. Di-inacusativo $\left[{ }_{S V} V\left[{ }_{S P} S X[P, P S Y]\right]\right]$
c. Transitivo $\left[{ }_{S v} S Z\left[{ }_{v} v[S\right.\right.$ V V SX]]]
d. Ditransitivo $\left.\left[_{S v} \mathrm{SZ}_{{ }_{v}} v\left[_{\mathrm{SV}} \mathrm{V}\left[_{\mathrm{SP}} \mathrm{SX}\left[{ }_{\mathrm{P}}, \mathrm{P} S \mathrm{SY}\right]\right]\right]\right]\right]$

Por lo que respecta a los verbos impersonales (llover) y los verbos inergativos, adoptaré la propuesta de Hale y Keyser de que se trata respectivamente de verbos inacusativos y transitivos con el complemento incorporado. Con respecto al caso de los verbos ditransitivos (11d), este modelo los trata como verbos con un solo argumento interno, con la propiedad de que este argumento es complejo, esencialmente como propone Kayne (1983). En la medida en que esta clase de verbos sean iguales que los verbos que subcategorizan una cláusula reducida, predecimos que estarán sujetas a propiedades como las siguientes: (i) que el complemento se comporte como un constituyente (12a) y (ii) que el verbo solo licencie un complemento (12b).

(12) a lo que considero es a María inteligente

b. *se lo considero

Las dos predicciones se cumplen. Considérese el caso de las cláusulas pseudoescindidas (13).

(13) a. lo que envió fue un libro a María

b. *lo que le envió fue un libro a María

2 Obsérvese que modelos como el de Ramchand o Pylkkänen predicen la posibilidad de estructuras argumentales que sintácticamente no están atestadas en ninguna lengua. 
De las dos posibles construcciones de la alternancia dativa, en la variante preposicional los dos argumentos internos se comportan de hecho como un único constituyente. En consecuencia, este modelo hace la predicción correcta siempre y cuando la variante dativa se derive de la variante preposicional (Baker 1988; Larson 1988; Ormazabal y Romero 2007, 2010a).

Por lo que respecta a la segunda condición, esta clase de verbos está restringida por la Restricción de Concordancia de Objeto (Ormazabal y Romero 2007). Esta restricción es una generalización sobre la Restricción de Persona Caso (Bonet 1991) que recoge el hecho de que cuando el argumento dativo está representado por medio de un sistema de concordancia, el objeto solo puede ser de tercera persona (14).
a. ${ }^{*} \mathrm{te}_{\mathrm{ACC}} \mathrm{le}_{\mathrm{DAT}}$ enviaron (a ti) (a él)
b. te ${ }_{\text {DAT }} l_{\text {ACC }}$ enviaron

El hecho de que (14b) no suponga un contraejemplo para la propuesta presente se sigue de que los clíticos acusativos son en realidad determinantes incorporados sobre el verbo (véase Roca 1996 y Ormazabal y Romero 2010). Como es sabido (Baker 1988), la incorporación es incompatible con el Caso y la concordancia, por lo que el verbo puede establecer estas relaciones con el objeto indirecto.

En las siguientes subsecciones analizaremos brevemente cuáles son las consecuencias de este modelo con respecto a las diferencias de proyección entre el verbo y el sustantivo (sec. 3.1), el Caso (sec. 3.2) y la naturaleza de las categorías léxicas (sec. 3.3).

\subsection{Proyección nominal y proyección verbal}

De acuerdo con (10b) los sustantivos no proyectan. Para combinarse con sus argumentos semánticos requieren de la participación de una proyección funcional que en español se manifiesta explícitamente por medio de la preposición de (15).

$$
\left[_{S P} \text { destrucción }\left[{ }_{P} \text {, de }\left[{ }_{S D} \text { la documentación }\right]\right]\right]
$$

Esta diferencia en la manera de proyectarse explica gran parte de las diferencias que encontramos entre la proyección argumental de los 
sustantivos y los verbos. Da cuenta de por qué los sustantivos no requieren ningún argumento y no se modifican en función de la estructura argumental que se proyecte: dado que $\mathrm{N}$ no se proyecta, no puede imponer restricciones de proyección sobre su red temática. Nótese que también explica por qué el sustantivo puede relacionarse con argumentos con los que $\mathrm{V}$ no puede hacerlo (lo que subraya la naturaleza composicional de las relaciones temáticas). En concreto, existe una relación argumental específica de los sustantivos: la relación de posesión (16).

(16) $\mathrm{su}_{\mathrm{POS}}$ estructura molecular

Además, se puede hablar de otro papel temático ausente en la red argumental de los verbos en el caso de la relación que establecen adjetivos relacionales (o SSPP, de moléculas) como molecular en (16), cuyo significado suele parafrasearse en términos de "relativo o perteneciente a».

Los verbos, al proyectarse obligatoriamente, están mucho más restringidos a la hora de establecer relaciones argumentales. En concreto, como argumentan Hale y Keyser (1993), V está limitado a la proyección que selecciona y al argumento del núcleo que, a su vez, lo selecciona $(v)$, ya que son las únicas relaciones locales que puede establecer. Esto es, al tomar un complemento, $\mathrm{V}$ tiene muy limitadas sus posibilidades combinatorias: puede tomar un complemento complejo (SP) o uno simple y, de manera local, puede relacionarse con el especificador de $v$, lo que da un total de tres argumentos, que es la totalidad de argumentos con los que el verbo se relaciona en las lenguas naturales. ${ }^{3}$

Finalmente, esta hipótesis explica por qué, a diferencia de lo que ocurre con verbos y preposiciones, no hay lenguas que permitan la incorporación de un sustantivo sobre otro sustantivo (Baker 2003). En un modelo que no diferencia estructuralmente la forma de proyectar de estas categorías se trata de un hecho notable, ya que que la incorporación solo

3 Esta generalización explica por qué un verbo como apostar con cuatro argumentos semánticos ( $w$ apuesta $x$ con $y$ a $z$ ) solo realiza sintácticamente tres.

Por otro lado, algunas lenguas bantúes como el Kinyarwanda parecen escapar a esta generalización permitiendo múltiples argumentos aplicados (Kimenyi 1980). 
parece estar restringida por condiciones estructurales. Según el modelo propuesto en (10) esto es exactamente lo que ocurre. Mientras que la documentación se proyecta como complemento de $\mathrm{V}$, para combinarse con destrucción (15) requiere de la intermediación de un elemento preposicional. En consecuencia, no se dan las condiciones configuracionales necesarias para que haya incorporación.

En suma, la hipótesis de la proyección categorial deriva las asimetrías entre verbos y sustantivos tanto con respecto al número y naturaleza de los argumentos, como con respecto a la relación estructural que establecen con los mismos. Estas asimetrías se derivan a partir de la definición axiomática de las categorías en términos de proyección de acuerdo con las reglas de (10).

\subsection{Caso verbal y Caso nominal}

Con respecto a los procedimientos de legitimación argumental, los verbos y los sustantivos también exhiben notables diferencias intra e interlingüísticamente. Es especialmente llamativo el Caso, ya que se trata de una propiedad muy ligada a los elementos léxicos, como se puede ver en el dispar comportamiento de los verbos inergativos e inacusativos. La estructura verbal asigna relaciones de Caso distintas al tema y al agente y, además, estas relaciones están sujetas a una enorme variación, no solo en cuanto al parámetro de la ergatividad, sino también en lo que respecta a otros casos como el dativo o el objetivo.

Nada de esto lo encontramos en el caso del sustantivo. Los argumentos del nombre se manifiestan uniformemente por medio del caso genitivo (que posiblemente no es más que una forma de realización de la preposición por medio de la que $\mathrm{N}$ se relaciona con sus argumentos). De nuevo las diferencias de proyección entre una y otra categoría explican esta asimetría de una manera natural. Mientras que los argumentos del verbo se generan en posiciones específicas, los argumentos del nombre lo hacen todos por medio de la misma relación. En consecuencia, las relaciones de Caso pueden representar las diferencias estructurales de su relación con el verbo (véase, por ejemplo, Levin 1983), pero no pueden hacerlo en el caso de los sustantivos. 


\subsection{Sobre la naturaleza de las categorías léxicas}

Como observa Baker (2003), las categorías léxicas carecen de una clara interpretación dentro de los modelos lingüísticos actuales, no hay ningún principio gramatical que haga referencia a las categorías léxicas ni existe una forma natural de dar cuenta de las diversas características morfosintácticas a las que se asocian. Tampoco presentan propiedades semánticas homogéneas que permitan predecir la adscripción categorial de una palabra en función de su significado. Esto ha llevado a numerosos autores a proponer que la categorización léxica es, de hecho, un proceso sintáctico en el que la categoría es una marca del tipo de proyección extendida en la que se inserta el elemento léxico (véase especialmente Marantz 1997 y Borer 2005a). Esto es, damos el nombre de categoría a determinadas combinaciones de rasgos formales que afijamos a los elementos léxicos radicales de las clases abiertas de palabras. Se trata de una visión coherente con el Programa Minimalista, ya que en este modelo las etiquetas categoriales no desempeñan ningún papel en la derivación sintáctica. Además, se trata de un paso natural que ya configura nuestra concepción de las categorías funcionales.

Sin embargo, la hipótesis de que la categorización léxica se lleva a cabo en el curso de la derivación adolece de problemas desde mi punto de vista insuperables. En primer lugar, las observaciones de Chomsky en «Remarks on Nominalization» siguen a día de hoy vigentes y mucho más en el espíritu del Programa Minimalista. Marantz (1997) para resolver este problema sostiene que en realidad no es tal porque la derivación oracional está sujeta a los mismos problemas de falta de productividad o idiosincrasia semántica que la formación de palabras. Sin embargo, se trata de una crítica en la dirección errónea, ya que mientras que en el diccionario se trata de propiedades esperables, no es así en el caso de la sintaxis. Por la propia naturaleza de la Gramática Universal esperamos que la aparición de estos problemas delate la presencia de aspectos que deben ser solucionados en nuestro análisis sintáctico, pero no así en el del léxico.

Borer, más consciente de este problema, adopta una perspectiva distinta. Según ella, "while form is unstructured, in the relevant sense, this is not of course the case for the form, formation, and formed, each of which encodes the existence of some grammatical structure which is non- 
coercible and subject to strict computational principles» (Borer 2005a: 13). Esto es, los procesos morfológicos derivativos generan elementos léxicos con propiedades categoriales, que no son en este modelo sino el reflejo de que una cierta computación sintáctica ha tenido lugar sobre el elemento radical. Es en este sentido en el que Borer puede afirmar que the form es equivalente a formation. Así pues, la caracterización categorial se deriva sintácticamente pero genera nuevos elementos léxicos a los que nuestro conocimiento del mundo puede dotar de nuevos significados en convergencia con Chomsky (1970).

No obstante, el problema de este análisis es que no explica para qué son necesarias las categorías, ¿por qué, como dice Baker, las lenguas dedican tantísimos recursos únicamente para determinar la información categorial si esta información carece de valor sintáctico? Resulta asimismo poco probable que se puedan explicar las asimetrías que hemos visto en términos de los rasgos formales asociados a cada categoría (número, género, persona, etc.). El modelo categorial propuesto en (10) proporciona una razón de ser a la propia existencia de las categorías que, por un lado, da cuenta de las asimetrías entre verbos y sustantivos y, por otro lado, es perfectamente compatible con el hecho de que las categorías carezcan interlingüísticamente de propiedades semánticas o morfosintácticas homogéneas. La categorización desde este punto de vista es una instrucción acerca del modo de proyectarse de los elementos léxicos. Esta visión es, por otro lado, perfectamente consistente con la que asociamos a las categorías funcionales y que sirve para diferenciar, por ejemplo, elementos $q u$ interrogativos y no interrogativos.

\section{Restricciones de selección y proyección argumental}

Desde el modelo de Aspectos las restricciones de selección se entienden como una restricción adicional sobre los marcos de subcategorización de los elementos léxicos. En este trabajo, siguiendo a Uriagereka (1996) voy a asumir que únicamente pueden utilizarse como restricciones de selección aquellas propiedades que tengan una correspondencia morfosintáctica, tales como la animacidad o la aktionsart. Dado que la estructura argumental es irrelevante por lo que respecta a la proyección de los elementos léxicos, la única posible restricción que podemos imponer al 
número de argumentos es por medio de la relación entre núcleos. Asimismo, también es posible imponer restricciones sobre el tipo de argumento por medio de los rasgos formales que participan de relaciones como concordancia y Caso.

De acuerdo con este modelo todos los verbos deben proyectar obligatoriamente un objeto. Siguiendo a Hale y Keyser (1993) asumiré que cuando esta restricción aparentemente no se cumple se trata de casos de incorporación del objeto. Si el verbo no contiene ninguna indicación específica, entonces esperamos que se proyecte con todas las estructuras argumentales disponibles (11), tal y como describíamos en el caso de oler (1). Además de la del objeto, existen dos posiciones cuya proyección debe explicarse de manera general, la proyección del argumento interno indirecto (sec. 4.1) y la del argumento externo (sec. 4.2). Por último (sec. 4.3) trataré algún caso particular de cómo este sistema restringe el abanico de posibilidades de proyección en aquellos elementos léxicos en los que, de hecho, los datos empíricos lo exigen.

\subsection{El argumento interno indirecto}

Una de las propiedades fundamentales de este modelo es que el verbo toma obligatoriamente un complemento y solo uno. Este complemento puede ser simple, un SN, o complejo, un SP. Asumiendo que lo que quiera que subyaga al Marcado Excepcional de Caso es correcto, el elemento que se interpreta como tema puede ocupar tanto la posición de complemento, como la de especificador del complemento. Puesto que la proyección léxica no está semánticamente motivada, este modelo no distingue estructuralmente entre argumentos y adjuntos y, en consecuencia, predice que cualquier verbo va a poder tomar, al menos, dos argumentos internos. Esto es, $\mathrm{V}$ siempre puede legitimar dos argumentos internos ya que, en realidad, sintácticamente está tomando un único argumento que tiene la propiedad de tomar a su vez dos argumentos.

Esta predicción parece correcta y da cuenta del comportamiento ambiguo de benefactivos, locativos y otros elementos que se caracterizan por no ser argumentos desde el punto de vista semántico, pero sí participan en alternancias típicamente argumentales. Por ejemplo, considérese el par de (17). 
a. Pedro preparó un pastel (para María)

b. Pedro le preparó un pastel a María

El elemento benefactivo en (17a) es un adjunto, pero en (17b) se comporta como un argumento del verbo. De acuerdo con este modelo, el paso de adjunto a argumento es, simplemente, una posibilidad del sistema, dado que la generación en la base de la estructura de (17a) es idéntica a la de un verbo ditransitivo (18).

$$
\text { ... [ }{ }_{S V} \text { preparó }\left[{ }_{S P}\right. \text { un pastel [P, para María]]] }
$$

De este modo, cuando el núcleo del SP lo ocupa una preposición aplicativa, esta se incorpora sobre $\mathrm{V}$ y da lugar a la construcción dativa (véase Ormazabal y Romero en prensa para la discusión de otras alternativas). Dado que en español todos los verbos admiten un dativo, podemos establecer la siguiente generalización:

Generalización del Argumento Interno Indirecto:

Si un verbo solo puede tomar dos argumentos, los dos serán internos.

Esto es, cuando a un verbo concreto nunca le podemos añadir un tercer argumento, entonces sus dos argumentos serán internos. Esta es, por ejemplo, la situación típica de los verbos estativos.

\subsection{El argumento externo}

El argumento externo se proyecta como especificador de una categoría funcional $v \mathrm{y}$, en consecuencia, su presencia solo puede restringirse si las propiedades formales de $\mathrm{V}$ son de algún modo incompatibles con las de $v$. Con respecto a la proyección del argumento externo es necesario dar cuenta de los siguientes casos: (i) aquellos verbos que nunca lo proyectan, (ii) aquellos que pueden o no proyectarlo y, finalmente, (iii) aquellos que en las oraciones activas deben proyectar el argumento externo.

La primera situación se da típicamente en los verbos estativos, lo que sugiere, en la línea de Grimshaw (1990) o Borer (2005b), que la especificación $[-v]$ puede estar relacionada con la aktionsart de los elementos léxicos. Supongamos en consecuencia que aquellos verbos cuyo aspecto interno no está evaluado (ni son télicos, ni son durativos) deben necesariamente estar especificados como $[-v](20)$. 
(20) a. *la secretaria le bastó los documentos

b. *María le adora mis hijos

c. ${ }^{*}$ Los alumnos le saben tu respuesta

Nótese que la agramaticalidad de (20) no se deriva de ningún problema semántico. Para todas las oraciones es perfectamente posible encontrar una interpretación perfectamente acorde con nuestro conocimiento del mundo. Esto es, la decisión que sitúa los predicados estativos en el grupo de los inacusativos no es semántica, sino léxica. Evidentemente, al tratarse de una restricción universal, suponemos que habrá alguna explicación en términos de interfaz, pero dado que no responde a razones composicionales, probablemente se trate del interfaz entre los sistemas cognitivos y el lexicón, esto es, se trata de un problema de categorización, como el que veíamos en la sección 2 para los términos de color. Así pues, si un elemento léxico lleva asociado ciertos valores aspectuales, entonces se caracterizará como $[-v]$. Esta idea encuentra apoyo en el comportamiento de otros verbos inacusativos.

Considérese el asunto desde el punto de vista de Borer: si se trata de un problema aspectual, ¿por qué hacer referencia a un valor $[-v]$ ? Considérese ahora el caso de los verbos inacusativos no estativos como caer o quedar (21).
a. *he caído los exámenes al suelo
b. *he quedado las llaves en casa

En español las oraciones de (21) resultan agramaticales excepto en algunos dialectos del oeste peninsular en los que estos verbos extienden su significado para cubrir parte de los valores de los transitivos tirar y dejar. El hecho de que en algunos dialectos estas oraciones sean interpretables muestra que no plantean ningún problema semántico. La razón por la que estas oraciones se rechazan en la mayoría de los dialectos es que existen otras palabras para expresar esos significados. Así, podemos decir que lo que hace agramatical el uso transitivo de caer es la existencia del verbo tirar, esto es, el Principio de Exclusividad Mutua. Ahora bien, ¿cómo se codifica este principio en el lexicón? Una manera de hacerlo es por medio de la especificación $[-v]$. Esto es, los predicados télicos son perfectamente compatibles con la presencia de un argumento externo y su especificación como inacusativos no puede estar vinculada a su aktion- 
sart. El hecho de que en algunos dialectos sea posible utilizar transitivamente estos predicados subraya la naturaleza arbitraria, léxica, de su caracterización inacusativa.

En la medida en que esta explicación sea correcta, los verbos de las clases (ii) y (iii) se pueden igualmente derivar por medio de los valores que asignemos al rasgo $[v]$. Sobre los verbos que pueden o no expresar el argumento externo volveremos en la siguiente sección. Por lo que respecta a los verbos que obligatoriamente deben representar el argumento externo, lo primero que es necesario destacar es precisamente que solo tienen esa obligación en el caso de las oraciones activas. Es muy importante recordar que las construcciones pasivas implican la existencia semántica de un agente, pero no así su representación sintáctica. Esto es, considérense las oraciones de (22).
a. el barco se hundió
b. el barco fue hundido

El verbo hundir participa de la alternancia causativo-incoativa. En (22a), en su lectura incoativa, no se implica la existencia de un agente. Desde el punto de vista semántico, hundir se comporta como un verbo inacusativo. En la pasiva (22b), por el contrario, se sobreentiende la presencia de un agente, que puede o no recupererase por medio de un SP. Así pues, no se puede establecer una relación directa entre la existencia de un argumento semántico y su proyección sintáctica (aunque véase, por ejemplo, Baker, Johnson y Roberts 1989 para una propuesta alternativa). Del mismo modo, obsérvese que la interpretación incoativa sí que es posible en el caso de las nominalizaciones. Así, expresiones como (3c), la destrucción de la documentación, no requieren de la intervención de un agente o un causante más de lo que puede requerirlo hundir en (22a). En suma, no parece que especificar un cierto elemento léxico como $[+v]$ pueda derivarse semánticamente $y$, en consecuencia, debe tratarse como una idiosincrasia léxica. De hecho, a la luz de ejemplos como los de (23), la asignación del rasgo $[+\nu]$ parece más una tendencia que una restricción absoluta.

(23) a. los documentos se han destruido

b. estas herramientas ya se han utilizado 
La oración de (23a) puede interpretarse como equivalente a se han echado a perder y la de (23b) como que se trata de herramientas usadas. Si estas interpretaciones son correctas, la posibilidad de una lectura incoativa no puede restringirse salvo por razones que afectan a nuestro conocimiento del mundo (Borer 2005a, 2005b) o por el Principio de Exclusividad Mutua en los casos mencionados anteriormente para los inacusativos télicos.

\subsection{Restricciones de selección y estructura argumental}

En esta sección vamos a tratar aquellos casos en los que un verbo puede alternar de manera sistemática entre una construcción causativa y una incoativa y otros casos relacionados. Considérese el contraste clásico entre romper y cortar ejemplificado en (24) y (25).

(24) a. Mateo rompió la ventana

b. la ventana se rompió

a. Mateo cortó el pan

b. *el pan se cortó

Levin y Rappaport (1995) observan que los verbos que no entran en la alternancia causativo-incoativa son aquellos que requieren un agente intencional, interno, en su significado básico. En la medida en que esta generalización sea correcta, se puede codificar en el elemento léxico por medio de un rasgo de persona/animacidad. No obstante, hay una diferencia crucial entre unos modelos y otros. Desde un punto de vista formal, en un análisis semánticamente motivado es el propio argumento el que debe satisfacer la propiedad descrita; sin embargo, en uno basado en la restricción de selección lo único que esperamos es que el rasgo se coteje. Considérese ahora el ejemplo de (26) frente a (25a).

(26) Mateo se cortó

La interpretación de (26) es puramente incoativa, ya que si se tratara de una construcción impersonal con se en cualquier otro caso debería aparecer precedido de la preposición a (27).

(27) a Mateo se le cortó 
La diferencia entre (25b) y (26) radica en el estatus formal del objeto: en (26) es animado y en (25b), por el contrario, no. Esto es, no es un problema de la especificación de $[v]$, sino del rasgo de persona. Sin entrar en detalles, supongamos que el rasgo de persona codificado en $\mathrm{V}$ lo puede cotejar el objeto animado, bien en el especificador de ST, o bien en alguna posición intermedia. De algún modo, podemos considerarlo como un caso de person displacement.

Este tipo de asimetrías es precisamente lo que no esperamos en un modelo semántico de la proyección, pero sí en uno categorial. Las propiedades de los predicados pueden proceder de distintas fuentes, incluso temáticas, pero, una vez que se codifican en el elemento léxico, únicamente pueden expresar relaciones formales. Así, el rasgo de animacidad que codifica el evento de causación en cortar como un evento de causación interna, en la computación sintáctica lo puede cotejar un SN distinto del causante ya que en la derivación se trata simplemente de un rasgo formal. Nótese, finalmente, que el rasgo de persona está implicado en numerosas relaciones gramaticales y es morfológicamente visible, lo que lo hace relevante en términos de adquisición.

De hecho, el ejemplo de cortar no es ni mucho menos un caso aislado. Las llamadas construcciones reflexivas se comportan exactamente del mismo modo. Tómese un verbo como lavar (28).

a. Juan lavó la ropa

b. Juan se lavó

Kayne (1975) estableció claramente que el clítico de (28b) no es un reflexivo anafórico y, por tanto, se trata de una construcción inacusativa. Al igual que en el caso anterior, la construcción de (28b) está limitada a objetos animados (29) (descartar la lectura pasiva). ${ }^{4}$

4 Reinhart y Siloni $(2004,2005)$ argumentan que no se trata de un inacusativo, sino de un inergativo. Sus argumentos se basan en su incapacidad para aceptar la cliticización en/ne y de entrar en construcciones relativas reducidas; asimismo, tampoco permiten la inversión simple o los dativos posesivos en hebreo, ni aparecen marcados en genitivo en ruso en las oraciones negativas. El problema es que no toman en consideración el hecho de que hay un rasgo extra de animacidad, que no aparece en otros inacusativos. Si consideramos las pruebas de inacusatividad en español, su comportamiento es ambiguo. Acep- 
a. *la ropa se lavó ayer

b. *los platos se han lavado esta mañana

Además de estos contextos de alternancia, este rasgo parece estar en el centro del análisis de los verbos psicológicos, ya que los experimentantes son necesariamente humanos. Considérense los ejemplos de (30), basados en Marantz (notas de clase, 1999).

a. green tea calmed Mary (*about the exam)

b. Peter calmed Mary (about the exam)

Supongamos que calm tiene un rasgo de persona que en (30b) coteja Peter. Si es así, entonces es necesario explicar cómo lo coteja Mary en (30a) y, al mismo tiempo, green tea sube a la posición de sujeto. Considérense las oraciones equivalentes en español con el objeto pronominalizado (31).

a. el ruido le asustó (*con el examen)

b. Mateo la asustó (con el examen)

Como puede verse, en (31a) el objeto se pronominaliza por medio del clítico dativo le, mientras que en (31b) se utiliza el clítico acusativo la. Hay, sin embargo, razones para pensar que el experimentante se proyecta como complemento de $\mathrm{V}$ en las dos oraciones. En primer lugar, en contra de lo que ocurre en el caso de los argumentos internos indirectos, el clítico no puede doblarse (32).

*el ruido le asustó a Sara

En segundo lugar, en las nominalizaciones el experimentante se proyecta uniformemente como tema (33) (véase Grimshaw 1990).
a. el susto de Sara por el ruido
b. *el susto del ruido

tan la formación de participio absoluto (i), pero rechazan la sustitución por de todo (Treviño 2000) (ii).

(i) El niño se lavó y una vez lavado el niño pudimos salir de viaje

(ii) *Ayer se lavaron niños, niñas, abuelos, abuelas... se lavó de todo.

Esta asimetría se puede explicar si de hecho se trata de un inacusativo, pero la expresión de todo (y la cadena que forme) no puede cotejar el rasgo de animacidad que exige $\mathrm{V}$. 
Finalmente, en las construcciones absolutas es el experimentante el que desencadena la concordancia de género y número con el participio pasivo (34).
a. asustada Sara
b. *asustado el ruido

De acuerdo con el modelo de proyección categorial el análisis es el siguiente. Los argumentos se proyectan como se muestra en (35), lo que da lugar a la realización directa de (36).

$\left[{ }_{\mathrm{SV}}\right.$ asust- ${ }_{\mathrm{SP}}$ Sara $\left[{ }_{\mathrm{P}}\right.$, con $\left[{ }_{\mathrm{SD}}\right.$ el ruido] $\left.\left.]\right]\right]$

Sara se asustó con el ruido

Para explicar (31a) utilizaremos un análisis paralelo al de Belletti y Rizzi (1988). En primer lugar, incorporamos la preposición de (35) y formamos una construcción inacusativa aplicativa (véase Ormazabal y Romero 2010 y las referencias que allí se mencionan). Este tipo de construcciones en español desencadenan concordancia dativa en una proyección SX posiblemente con contenido aspectual. ${ }^{5}$ Dado que el objeto es personal, el propio objeto y no el complemento de la preposición coteja esta concordancia esencialmente del mismo modo que hemos visto anteriormente en el caso de cortar o lavar. Dado que el objeto ha cotejado sus rasgos, el complemento de $\mathrm{P}$ queda libre para subir a la posición de sujeto (37).

$$
\left[_{\mathrm{ST}} \text { el ruido }\left[_{\mathrm{T}}, \mathrm{T}\left[_{\mathrm{SX}} \text { a Sara }\left[{ }_{\mathrm{X}} \mathrm{X}\left[_{\mathrm{SV}} \text { asustó }+\mathrm{P}\left[{ }_{\mathrm{SP}} h_{\mathrm{a} \text { Sara }}\left[{ }_{\mathrm{P}}, h_{\mathrm{P}}\left[h_{\text {el ruido }}\right]\right]\right]\right]\right]\right]\right]\right]
$$

De este modo, podemos explicar la agramaticalidad de la presencia de con el examen en (31a) ya que la posición en la que debemos generarlo está ocupada por el ruido antes de su ascenso a la posición de sujeto ora-

5 Desde el trabajo pionero de Tenny (1987) en la bibliografía han aparecido numerosos argumentos que relacionan el movimiento de objeto con propiedades aspectuales de la oración, específicamente con la telicidad. También puede argumentarse que el tipo de objeto afecta a la interpretación aspectual. Así, mientras que en (i) con un objeto inanimado la lectura es de actividad, cuando el objeto es animado (ii) la interpretación corresponde a un logro (iterativo).

(i) empujó el coche/la caja

(ii) empujó al niño 
cional. Finalmente, (31b) se genera insertando una proyección $S v$ cuyo especificador está ocupado por el agente del evento. Se trata por tanto de una construcción transitiva. Para terminar, considérense los ejemplos de (38).

a. Mateo le gusta

b. She likes Mateo

Las oraciones de (38a) y (38b) expresan un mismo contenido semántico, pero los argumentos están representados por relaciones gramaticales inversas. La explicación de esta asimetría está relacionada con el hecho de que en inglés el argumento aplicado sube a posición de sujeto en las oraciones pasivas (39b), pero no así en español (39a).

(39) a. el libro le fue enviado a María

b. Mary was sent a book

La proyección argumental subyacente es la misma para (38a) y (38b), Mateo ocupa la posición de tema y el experimentante la de argumento interno indirecto, como se muestra en los ejemplos de (40).

(40) a. Mateo le gusta a Sara

b. Mateo gusta a todo el mundo

En (39a) vemos que el dativo, a diferencia de lo que ocurría en (32), sí puede ser doblado por un SN y en (39b) se puede observar que la presencia del pronombre dativo no es obligatoria. En suma, la diferencia entre gustar y asustar se encuentra en la presencia de un rasgo de selección de animacidad en el caso de asustar, pero no en el de gustar, lo que explica por qué el objeto de asustar debe ser necesariamente animado, pero no el de gustar y explica asimismo el diferente comportamiento de los argumentos a lo largo de la derivación sintáctica.

\section{Conclusión}

La tesis central de este trabajo es que la proyección argumental no está semánticamente motivada. Los argumentos se proyectan en la sintaxis de acuerdo con procedimientos estrictamente categoriales ajenos a las 
relaciones temáticas con que los sistemas semánticos interpretarán la descripción estructural formada en el curso de la computación sintáctica. Aunque de una manera muy programática, se han presentado argumentos tanto desde el punto de vista de la proyección, como desde el de la adquisición que muestran que los modelos semánticamente motivados están sujetos a problemas que difícilmente pueden resolver si no es recurriendo a propiedades ad hoc.

Como alternativa he propuesto un modelo de proyección basado en reglas que definen axiomáticamente las categorías léxicas. La proyección en consecuencia se realiza automáticamente en función de la categoría de los elementos léxicos y su interpretación queda fuera del ámbito de la sintaxis. Finalmente, la proyección puede restringirse por medio de restricciones de selección. Estas restricciones están determinadas por medio de los rasgos formales de los elementos léxicos y, muy especialmente, por medio del rasgo de animacidad, que está en el centro no solo de las relaciones de concordancia, sino también de aspectos de la interpretación como la definición del experimentante.

Una de las ventajas de este sistema es que al disociar proyección sintáctica y relaciones predicado-argumento, la gramática puede disponer de distintos procedimientos para interpretar las relaciones argumentales. Esto es, tanto en los modelos proyeccionistas como en los constructivistas la proyección sintáctica está íntimamente ligada a la interpretación de las relaciones argumentales. Esa correspondencia debe seguirse de alguna propiedad del sistema que hace que los argumentos se proyecten de una manera y no de otra, ya que en caso contrario esperaríamos encontrar interlingüísticamente una variedad de posibilidades que, de hecho, no encontramos. Todas las lenguas parecen representar sus argumentos esencialmente del mismo modo, al menos en términos de jerarquía relativa.

\section{Bibliografía}

BAKER, M. C. (1988): Incorporation: a theory of grammatical function changing, Chicago, University of Chicago Press.

- (1996): «On the structural position of Themes and Goals», en J. Roorick y L. Zaring (eds.), Phrase structure and the lexicon, Dordrecht, Kluwer: 7-34.

- (2003): Lexical categories, Cambridge, Cambridge University Press. 
BaKer, M. C., K. Johnson e I. Roberts (1989): «Passive Arguments Raised», Linguistic Inquiry, 20: 219-251.

Belletti, A., y L. Rizzi (1988): «Psych-verbs and theta theory», Natural Language and Linguistic Theory, 6: 291-352.

BONET, E. (1991): Morphology after Syntax: Pronominal Clitics in Romance, tesis doctoral, MIT.

Borer, H. (2005a): In name only, Oxford, Oxford University Press.

- (2005b): The normal course of the events, Oxford, Oxford University Press.

Chомsкy, N. (1970): «Remarks on nominalization», en R. A. Jacobs y P. S. Rosenbaum (eds.), Readings in English Transformational Grammar, Cambridge, Waltham.

- (1995): The Minimalist Program, Cambridge, MIT Press.

FÁBREGAS, A. (en prensa): «A syntactic account of affix rivalry in Spanish nominalisations", en A. Alexiadou y M. Rathert (eds.), Nominalizations across languages and frameworks, Berlín, Mouton de Gruyter.

GrimshaW, J. (1990): Argument structure, Cambridge, MIT Press.

Hale, K., y S. J. KeYSer (1993): "On argument structure and the lexical expression of syntactic relations», en Hale y Keyser (eds.), The View from building 20: essays in linguistics in honor of Sylvain Bromberger, Cambridge, MIT Press: 53-109 [también publicado en (2002): Prolegomenon to a Theory of Argument Structure, Cambridge, MIT Press].

KAYNE, R. (1975): French Syntax, Cambridge, MIT Press.

- (1983): Connectedness and Binary Branching, Dordrecht, Foris.

KimenYI, A. (1980): A Relational Grammar of Kinyarwanda, Berkeley y Los Ángeles, University of California Press.

LARSON, R. (1988): "On the Double Object Construction», Linguistic Inquiry, 19.3: 335-391.

LEVIN, B. (1983): On the nature of ergativity, tesis doctoral, MIT.

- y M. Rappaport Hovav (1995): Unaccusativity: At the Syntax-Lexical Semantics Interface, Cambridge, MIT Press.

MARANTZ, A. (1997): «No escape from Syntax: Don't try morphological analysis in the privacy of your own lexicon", en A. Dimitridades, L. Siegel et al., Proceedings of the 21 $1^{\text {st }}$ Anual Penn Linguistics Colloquium: 201-225.

Ormazabal, J., y J. Romero (2007): «The Object Agreement Constraint», Natural Language and Linguistic Theory, 25.2: 315-347.

- (2010): «Objects clitics and agreement», ms. UPV-U. de Extremadura.

- (en prensa): "The derivation of dative alternations», en M. Duguine, S. Huidobro y N. Madariaga (eds.), Argument Structure and Syntactic Relations from a Cross-Linguistic Perspective, Ámsterdam-Filadelfia, John Benjamins.

PeseTsky, D. (1995): Zero syntax, Cambridge, MIT Press. 
PYLKKänen, L. (2008): Introducing Arguments, Cambridge, MIT Press.

Ramchand, G. C. (2008): Verb Meaning and the Lexicon. A First-phase Syntax, Cambridge, Cambridge University Press.

Reinhart, T., y T. Siloni (2004): "Against the Unaccusative Analysis», en A. Alexiadou, E. Anagnostopoulou y M. Everaert (eds.), The Unaccusativity Puzzle, Oxford, Oxford University Press: 159-180.

- y T. SilONi (2005): «The Lexicon-Syntax Parameter: Reflexivization and Other Arity Operations», Linguistic Inquiry, 36.3: 389-436.

RocA, F. (1996): «Morfemas objetivos y determinantes: los clíticos del español», Verba, 23: 83-119.

RothsteIn, S. (2004): Structuring events: a study in the semantics of lexical aspect, Oxford, Blackwell.

TENNY, C. (1987): The aspectual interface hypothesis, tesis doctoral, MIT.

TrEviNo, E. (2000): «A morphosyntactic property for split intransitivity», Conferencia, I. U. Ortega y Gasset.

URIAGEREKA, J. (1996): «Warps: some thoughts on categorization», Cuadernos de Lingüistica del I. U. Ortega y Gasset, 4: 1-38.

WYLER, S. (1992): Colour and language: colour terms in English, Tubingen, Narr. 



\title{
POR DEBAJO DE LA PALABRA, SILENCIO. LA SINTAXIS COMO INTERFAZ Y LA NATURALEZA DEL LÉXICO*
}

\author{
José LuIs MENDÍvil GIRÓ \\ (Universidad de Zaragoza. Grupo Sylex)
}

\begin{abstract}
Ahora que los ladros perran, ahora que los cantos gallan, ahora que albando la toca las altas suenas campanan; y que los rebuznos burran y que los gorjeos pájaran, y que los silbos serenan y que los gruños marranan, y que la aurorada rosa los extensos doros campa, perlando líquidas viertas cual yo lágrimo derramas y friando de tirito si bien el abrasa almada, vengo a suspirar mis lanzos ventano de tus debajas.

Gabriel García Márquez, Vivir para contarla
\end{abstract}

* La investigación subyacente a esta aportación forma parte del proyecto HUM2007-64200/FILO subvencionado por el Gobierno de España. Deseo agradecer los comentarios a una versión previa de Cedric Boeckx, Sandrine Deloor, Antonio Fábregas, Mamen Horno, Carlos Piera, David Serrano y José Francisco Val, quienes no son responsables de lo que aquí se afirma. 


\section{Introducción}

Aunque la presente aproximación se inscribe en los modelos llamados antilexicistas, en el sentido de que rechaza tanto la existencia de un léxico gramaticalmente estructurado como la de un componente morfológico capaz de crear palabras, no comparte la conclusión típica de dichos modelos de que las palabras son epifenómenos (p.ej. Julien 2007). Más bien al contrario, y de acuerdo con desarrollos teóricos recientes (Boeckx 2008, Ott 2009), la presente aportación sitúa a la palabra como el rasgo central y distintivo del lenguaje humano. La aparente paradoja que esto entraña se resuelve precisamente con la hipótesis central que pretendo desarrollar: que las palabras no son unidades léxicas, sino que son en realidad construcciones sintácticas y que dichas construcciones sintácticas son la unidad mínima de conexión entre el sistema conceptual-intencional y el sistema sensorio-motor. ${ }^{1}$

La primera parte de la hipótesis — que las palabras son construidas en la sintaxis - no es en absoluto original (p.ej. Baker 1988, Marantz 1997, Julien 2002, Borer 2005a y 2005b) y debe afrontar las mismas serias objeciones que se le pueden oponer a cualquier teoría que pretenda ignorar el evidente comportamiento dispar de las palabras y de las construcciones sintácticas, tanto desde el punto de vista sintáctico como semántico - e incluso fonológico- (véanse Anderson 1992 o Williams 2007). La segunda parte de la hipótesis (esa que se formula en el título con el dictum "por debajo de la palabra, silencio») pretende evitar esas objeciones al estipular que en realidad lo que hace «especiales» -i. e. léxicas- a las construcciones sintácticas que llamamos palabras es que son las unidades mínimas del lenguaje humano en las que se establece una conexión directa entre el sentido y el sonido, entre el significado y la forma fonológica. Se implica entonces que los morfemas tradicionales (incluyendo las raíces léxicas) carecen, por emplear la expresión saussureana, de

1 En lo sucesivo asumimos el esquema básico de la Facultad del Lenguaje (FL) esbozado en Hauser, Chomsky y Fitch (2002) en el que el sistema computacional o sintaxis, que forma la FL en sentido estricto (FLE), es distinto formalmente de los sistemas conceptual-intencional (C-I) y sensorio-motor (S-M), que también forman parte de dicha FL, pero entendida en sentido amplio (FLA). 
plano de la expresión y que son entonces de naturaleza puramente morfológica. Únicamente las palabras estarían conectadas con los sistemas articulatorio perceptivos. Como las palabras son concebidas en el presente modelo como construcciones sintácticas, se sigue entonces que la sintaxis es la auténtica y única interfaz entre el sentido y el sonido. La conclusión principal será entonces que el léxico de una lengua no está formado por emparejamientos de sentido y sonido, sino únicamente por palabras fonológicas organizadas en paradigmas que, a través de la sintaxis, se relacionan con el sistema conceptual. Ese rasgo crucial de la palabra de ser a la vez una construcción sintáctica y la unidad mínima de emparejamiento con la fonología sería entonces la fuente de las evidencias que apuntan robustamente a una cierta discontinuidad entre la llamada sintaxis léxica y la sintaxis propiamente dicha (o sintaxis frasal) y que son las que están detrás de la llamada hipótesis lexicista.

La presente aproximación es antilexicista en el sentido de que no acepta la distinción entre sintaxis léxica y sintaxis frasal y sustenta la visión de un único sistema computacional ciego a la frontera léxica, y en un sentido aún más radical, en el sentido de que se niega que exista un léxico propiamente dicho. Pero si las palabras son vinculaciones sistemáticas entre computaciones sintácticas y formas fonológicas memorizadas, en cierto modo emerge una nueva forma de lexicismo en el que la aparente discontinuidad entre los dos tipos de sintaxis no es sino una consecuencia de la arquitectura de la conexión del (único) sistema computacional con el sistema sensorio-motor en el lenguaje humano.

Si esto es así, entonces la característica afirmación chomskiana de que la sintaxis es el núcleo esencial y distintivo del lenguaje humano no es contradictoria con la afirmación de que es la palabra el núcleo esencial y distintivo del lenguaje humano, ya que la palabra es primordialmente una construcción sintáctica.

Por otra parte, la concepción de la palabra como una forma fonológica permite introducir en un modelo antilexicista del lenguaje y del léxico una teoría morfológica basada en el modelo de palabra y paradigma (como por ejemplo el desarrollado por Anderson 1992 o Stump 2001), más adecuada empíricamente, en nuestra percepción, que modelos morfemáticos como el de la Morfología Distribuida. 


\section{Más allá de la controversia lexicismo versus antilexicismo}

La idea de que una lengua consiste en el emparejamiento sistemático de sonidos y sentidos es de sentido común. De hecho, tal idea aparece recurrentemente en la obra de los que probablemente sean los dos lingüistas más influyentes de la historia: Ferdinand de Saussure y Noam Chomsky.

La manera más común de substanciar esa idea es el recurso al léxico. En todas las aproximaciones teóricas el léxico consiste precisamente en eso: una colección de representaciones fonológicas que se emparejan con una colección de sentidos o significados. Esta propiedad del léxico, ejemplarmente representada en la teoría del signo lingüístico saussureano, se repite en todas las aproximaciones al lenguaje, independientemente de su orientación e independientemente de la teoría del léxico que haya detrás de cada una. El léxico, como repositorio elemental de unidades con substanciación material (típicamente fónica) y conceptual, es pues un elemento imprescindible en la modelización de qué es una lengua y en nuestra concepción de qué implica que una persona conoce una lengua.

Incluso en el ámbito generativista, más proclive a concebir la sintaxis como el componente central del lenguaje humano, el papel del léxico es crucial. En cualquiera de sus modelos el llamado sistema computacional (la sintaxis) se nutre de un léxico del que toma los ítems que luego combina para construir estructuras mayores. Por supuesto que la manera en cómo sucede esto es objeto de viva controversia y es el centro de la disputa entre aproximaciones lexicistas y no lexicistas. En las primeras la palabra tiene un estatus especial en tanto en cuanto tiene propiedades que no tienen las construcciones sintácticas, de manera que se asume que de alguna manera la derivación de la estructura interna de las palabras y la de otros objetos sintácticos mayores sucede en módulos distintos de la gramática. En las segundas se suele asumir que las palabras son formadas por la propia sintaxis, de manera que la propia palabra no es un objeto derivacional privilegiado o especial, al menos en lo que a la arquitectura de la gramática respecta, dado que tanto las palabras como las frases se tratan como el resultado del mismo sistema computacional (la sintaxis).

En todo caso, es evidente que incluso en las llamadas aproximaciones no lexicistas se presume un léxico (un emparejamiento sistemático de 
sentidos y sonidos) previo a la computación sintáctica, aunque en este caso no formado por palabras, sino por unidades menores.

La idea central de esta aportación es que dicha presunción es errónea. La alternativa que se propone es que en el lenguaje humano no hay un emparejamiento sentido-sonido previo a la sintaxis. $O$ en otras palabras, que sentido y sonido no se emparejan directamente, sino solo a través de la sintaxis. Esto implica que la interfaz entre el sentido y el sonido no es el léxico, sino la propia sintaxis. Esto no es novedoso si pensamos en las oraciones como vínculos sistemáticos entre pensamientos y cadenas de sonidos (es de hecho la definición de Chomsky del lenguaje), pero sí si pensamos en el ámbito léxico. Lo que se plantea es pues una manera más radical de implementar esa idea vaga (aunque esencialmente correcta) de que la sintaxis es un medio de relacionar sistemáticamente pensamientos y sonidos. ${ }^{2}$

Esta aproximación es en cierto modo paralela al reciente modelo denominado «nanosintaxis» (desarrollado esencialmente por M. Starke), en el que se parte de la asunción de que los nudos sintácticos básicos son frecuentemente submorfémicos. La consecuencia de esto, para dicho modelo, es que «morphemes and words can no longer be the spellout of a single terminal. Rather, a single morpheme must 'span' several syntactic terminals, and therefore corresponds to an entire syntactic phrase» (<http://nanosyntax.auf.net/whatis.html $>$ ).

Si los morfemas son realización de estructuras sintácticas complejas, según la aproximación nanosintáctica se sigue que entonces «entire syntactic phrases are stored in the lexicon (not just terminals) and it also means that there cannot be any lexicon before the syntax -i.e. syntax does not 'project from the lexicon'» (<http://nanosyntax.auf.net/whatis.html>).

Aunque en las páginas siguientes defenderé que, en efecto, la sintaxis no se proyecta del léxico, propondré también una alternativa a la afirma-

2 No estoy en posición de argumentar que realmente no existen esas conexiones previas a la sintaxis; lo que se propone es que en el caso de que existan, son irrelevantes para la sintaxis, esto es, son inaccesibles al sistema computacional (aunque pudieran haber tenido un papel en la evolución del lenguaje, o puedan tenerlo en el lenguaje infantil o en ciertos síndromes afásicos). 
ción, aparentemente contradictoria, de que son las estructuras sintácticas completas las que se almacenan en el léxico.

En trabajos recientes de visión general, tanto Williams (2007) como Ackema y Neeleman (2007) plantean serias objeciones a las teorías antilexicistas, especialmente al modelo de la Morfología Distribuida (MD) (Marantz 1997; Embick y Noyer 2007). Como señala Williams (2007), la hipótesis lexicista no implica necesariamente que se renuncie a emplear la sintaxis para explicar la estructura interna de las palabras, sino que se afirma que la sintaxis que explica la estructura interna de las palabras es, al menos en parte, distinta de la que explica la estructura de la oración. El planteamiento de Ackema y Neeleman es explícito: "Are the generative systems that produce words and phrases identical or distinct?» (2007: 325). Su conclusión se decanta igualmente por la segunda opción. La presente aproximación pretende mostrar una vía, en desarrollo incipiente, que permitiría mantener el principio minimalista de que solo hay un tipo de sintaxis (evitando así la redundancia inherente a los modelos lexicistas), a la vez que evita los problemas empíricos y teóricos de las teorías sintactistas más desarrolladas, como la MD respecto de las palabras morfológicamente complejas o la teoría exoesquelética de Borer (2005a, 2005b) en lo que respecta a la estructura argumental y eventiva, así como algunas implicaciones de la aproximación nanosintáctica.

Es evidente que la hipótesis nula es que únicamente hay un componente generativo en el lenguaje. Puesto que no cabe dudar de la capacidad generativa de la sintaxis, la introducción de mecanismos generativos en la morfología y en el léxico genera redundancia. Por su parte, como ha argumentado extensamente Borer (2005a y 2005b), la introducción de información sobre la estructura eventiva y argumental en las entradas léxicas es igualmente costosa, en la medida en que favorece la visión de la división del trabajo con un mayor peso en la capacidad de «almacenar» que en la de "calcular». Por supuesto, la adopción de la hipótesis lexicista no es una renuncia gratuita a la elegancia teórica, sino el resultado de la necesidad de adecuación descriptiva de la teoría y, fundamentalmente, una manera de limitar la inadecuada sobregeneración de los modelos sintactistas. Así, y sin ánimo de exhaustividad, entre los principales argumentos a favor de una teoría lexicista se encuentran los siguientes: 
- Fenómenos de integridad léxica, que hacen invisible la estructura interna de la palabra a operaciones sintácticas (hipótesis de integridad léxica, HIL).

- Productividad limitada de muchos procesos derivativos y compositivos.

- Fenómenos de significado estructural, en los que el comportamiento diferente de diversas clases de palabras (especialmente verbos) se asocia a primitivos de significado léxico diferentes.

La presente aproximación sugiere que la hipótesis de que la palabra es la unidad mínima de emparejamiento con el sistema S-M podría ofrecer un marco de explicación a ese carácter aparentemente restringido e idiosincrásico de la sintaxis interna de la palabra dentro de un contexto puramente antilexicista.

\section{La sintaxis como interfaz}

La hipótesis central de esta aportación es que el sistema computacional no combina unidades léxicas (ya sean morfemas o palabras), sino que computa únicamente categorías funcionales. ${ }^{3}$ La primera implicación de dicha hipótesis entonces es que la operación sintáctica básica es la categorización. Definiremos categorización como el ensamble (merge) de un concepto (tomado del sistema conceptual con el que interactúa la FLE) y una categoría funcional básica. Las categorías funcionales básicas pertenecen al sistema computacional y categorizan sintácticamente (lexicalizan) a sus complementos (los conceptos).

La concepción de la sintaxis como un sistema de interfaz es natural en la tradición minimalista reciente. Boeckx (2008) es especialmente explícito al respecto y expone y desarrolla un modelo del que el presente es una variante más radical:

3 Esta idea es coherente con el modelo «exoesquelético» de Borer (2005), según el cual las unidades léxicas (listemas) carecen de estructura gramatical y se limitan a modificar las estructuras. La diferencia con dicho modelo radica en que negamos que existan listemas como emparejamientos de forma y sentido independientemente de la sintaxis. 
At the most basic level of description natural language syntax can be characterized as an interface system, providing the meeting ground between 'sound/sign' (more accurately, the mental systems responsible for externalization, henceforth PHON) and 'meaning' (the mental systems giving rise to thought, hereafter SEM). Natural language syntax operates on unites that are standardly characterized as bundles of features. Such features are lexicalized concepts. Syntax creates ever-larger molecules by combining featural atoms through iterated use of Merge. Such molecules, the expressions generated by syntax, provide instructions to PHON and SEM (Boeckx 2008: 63, cursiva añadida).

Como puede observarse, el modelo descrito implica que la sintaxis es la interfaz entre tres sistemas en realidad: los que el autor denomina PHON y SEM y, además, el léxico formado por "conceptos lexicalizados» (véase el gráfico explícito en Boeckx 2008: 64). La propuesta que hemos formulado se aparta de esa concepción en el sentido de que afirma que la operación de ensamble es también la responsable de crear los propios conceptos lexicalizados (por medio de la categorización de un concepto). La consecuencia es un modelo aún más simple en el que la sintaxis media directamente entre SEM y PHON. La implicación más relevante de este paso es la eliminación del léxico de la FLE, aunque al precio de asumir que las propias categorías funcionales básicas, las categorizadoras, son parte de la FLE, esto es, forman un léxico puramente funcional o gramatical integrado en el sistema computacional.

Los modistae (véase Bursill-Hall 1971) afirmaban que los términos latinos dolor y doleo tenían un mismo significado pero distintos modi significandi, a la vez que afirmaban que los significados no eran relevantes para la gramática, que se habría de centrar en los distintos modos de significar. Cuando afirmamos que una categoría funcional toma como complemento un concepto y lo hace sintácticamente computable, lo que queremos decir es que la función esencial de la sintaxis es precisamente la de establecer computaciones entre conceptos por medio de categorías funcionales. En otras palabras, afirmamos que la sintaxis es el único medio de combinar conceptos entre sí para producir conceptos nuevos y más complejos. También asumimos pues que los conceptos no forman parte de la FLE y no tienen por tanto propiedades lingüísticas. Una carencia esencial de los conceptos es precisamente que no están conectados con el sistema articulatorio perceptivo. Lo que haya de común desde el punto de vista léxico entre dolor y doleo, aunque es obviamente crucial para 
entender esas palabras y las estructuras en las que se inserten, no es una unidad lingüística, esto es, no es un emparejamiento sonido/sentido. En otras palabras, afirmamos que en latín la raíz dol- no significa nada, puesto que no tiene conexión con concepto alguno. Por decirlo en términos más crudos, dol- en latín (y en español) es lingüísticamente inservible, puesto que solo las palabras relacionan una forma y un significado.

Nótese que esto implica, en contra de los modelos habituales, que el sistema computacional, la sintaxis, no se "alimenta» de unidades léxicas (sean estas concebidas como raíces, morfemas o conceptos lexicalizados), sino que directamente computa conceptos por medio de categorías funcionales. Nuestra hipótesis más concreta es que la conexión entre los conceptos y los sonidos (esto es, las representaciones fonológicas) está mediada por la sintaxis y que únicamente los conceptos categorizados, esto es, las palabras, pueden tener una relación con el componente fonológico.

Por simplificar la exposición asumiremos que existen tres familias de categorías funcionales básicas o categorizadoras: $N, V$ y $A$. Estas familias de categorías remiten claramente a las clases de palabras clásicas, esto es, nombres, verbos y adjetivos. Siguiendo la teoría de las categorías léxicas de Baker (2003) asumiremos que nombres, verbos y adjetivos son las únicas categorías léxicas que existen y que son universales. Pero $N, V$ y $A$ no son categorías léxicas, sino que son categorías funcionales que toman un concepto y lo convierten en una unidad léxica. Así pues, $N, V$ y $A$ son categorías funcionales que toman conceptos como complementos y los convierten en objetos sintácticos. En otras palabras podría decirse que las categorías funcionales básicas hacen a los conceptos "visibles» para la sintaxis y, a través de esta, aquellos se vinculan mediatamente al sistema $\mathrm{S}$-M. Podría decirse entonces que las categorías funcionales $N, V$ y $A$ son diferentes instancias de lo que Chomsky (2005) denomina edge-feature. ${ }^{4}$ En este sentido, la categoría sintáctica es la propiedad que hace computable a un concepto.

4 «For an LI [ítem léxico] to be able to enter into a computation, merging with some SO [objeto sintáctico] [...], it must have some property permitting this operation. A property of an LI is called a feature, so an LI has a feature that permits it to be merged. Call this the edge-feature (EF) of the LI» (Chomsky 2005: 5). 
El propio Baker se pregunta qué es lo que lleva una categoría. Observa (2003: 265-267) que tanto la gramática tradicional como las teorías lexicistas responden a esa pregunta que lo que lleva una categoría, esto es, que lo que está categorizado, son las raíces o los temas léxicos, mientras que los constructivistas como Borer o los partidarios de la MD (e incluso los funcionalistas como Hopper y Thompson 1984) vienen a decir que son las estructuras sintácticas las que llevan categoría (las root phrases de la $\mathrm{MD})$. Pues bien, la alternativa propuesta es diferente a las dos líneas de respuesta: lo que está categorizado, lo que lleva categoría son los conceptos. La respuesta del propio Baker no es muy clara. Su aproximación es claramente sintactista, pero concibe las categorías $(A, N$ y $V)$ como inherentemente asociadas a los lexemas (salvo en el caso de los verbos, que deriva siempre de adjetivos). Se dice compatible con Marantz (2000) (Baker 2003: 269, n. 2), pero niega disponer de evidencia para la separación sistematica entre $n, v$, a y las raíces léxicas. Este problema de la MD recibe una explicación en el presente modelo en el sentido de que siempre resulta natural postular que en toda categoría léxica hay un componente sintáctico (la categoría) y uno puramente conceptual. ${ }^{5}$

La primera operación de la sintaxis es por tanto la de convertir conceptos en palabras $(N, V \mathrm{o} A)$. Las "palabras sintácticas», en condiciones que pueden variar de lengua a lengua, se materializan, esto es, se emparejan con representaciones fonológicas ("palabras fonológicas») y dichas representaciones eventualmente se memorizan. Existe pues un léxico para cada lengua, pero es puramente morfológico/fonológico, esto es, es una parte de S-M.

Este modelo predice que la interpretación de toda palabra siempre tiene una parte composicional (al menos concepto y categoría). Ninguna palabra es un átomo sintácticamente, aunque pueda serlo morfológicamente. Sin embargo, ello no implica que todas las palabras tengan que ser composicionales sin residuo. Lo típico es que no lo sean. Este hecho se sigue precisamente de la propiedad que singulariza a las palabras, esto

5 Observa Baker (2003: 270) que la ausencia de contenido de las categorías léxicas (que serían derivativas en el modelo de la MD) hace que se tengan que establecer como axiomas la selección entre ellas, mientras que su modelo, que, como el presente, les atribuye propiedades, los establece como teoremas. 
es, el ser las unidades mínimas de vinculación entre sentido y sonido (esto es, las unidades mínimas de memorización lingüística). ${ }^{6}$

En función de las lenguas, esto es, de su historia morfológica, se determinará el momento de la materialización, esto es, el momento en el que se establece la conexión entre la derivación sintáctica y la forma fonológica.

En esencia, pues, la hipótesis de la sintaxis como interfaz implica que una palabra es una forma fonológica (típicamente un paradigma de formas fonológicas) que se asocia memorísticamente a un fragmento de derivación sintáctica. El papel de la morfología en un modelo de este tipo es el de un interfaz entre la derivación sintáctica y la forma fonológica. La morfología en este modelo no está pues distribuida, ya que los nudos terminales de las derivaciones sintácticas no están constituidos por morfemas ni raíces léxicas, sino por conceptos y categorías funcionales. En los apartados siguientes consideramos con más detalle cómo se implementa un modelo así y en los apartados 6 y 7 volvemos al lugar de la morfología y de las propias palabras en el seno de la gramática.

\section{Categorización y materialización}

Como se ha adelantado, las categorías funcionales básicas, que es lo mismo que decir lexicalizadoras, toman un concepto del sistema conceptual y lo proyectan por medio de ensamble en una construcción de la forma siguiente:

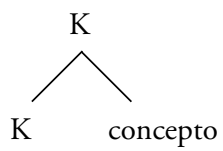

En (1) la categoría K toma como complemento un concepto y lo convierte en una instancia de $\mathrm{K}$, esto es, en una proyección sintáctica. $\mathrm{K}$ es

6 En cierto modo podría decirse que la materialización de las derivaciones mínimas implica que ciertas derivaciones sintácticas (las palabras) se almacenan en el sistema motor. 
por tanto la responsable de las propiedades de ese objeto sintáctico, mientras que el concepto, por definición, se limita a proporcionar contenido léxico conceptual. Nótese que esta operación de ensamble es asimétrica por definición, ya que solo uno de los elementos tiene categoría.

Asumiendo en lo esencial la teoría de las categorías léxicas de Baker (2003) definiremos la categoría $V$ como la categoría que toma un concepto como complemento y le añade un especificador (un sujeto). ${ }^{7}$ Por tanto, si $\mathrm{K}$ es $V$, tendremos:

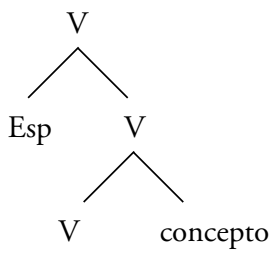

Ese sería el esquema básico de un verbo inacusativo o de un fragmento de verbo transitivo, en el sentido de que el especificador es el argumento interno del verbo. Interpretaremos $V$ como la categoría que en algunas teorías se representa como Asp (ecto) (Borer 2005b, MacDonald 2008) o Process (Ramchand 2008) y básicamente implica la relación entre el argumento interno y la fase de proceso del evento representado. Así pues, aunque por claridad y conveniencia empleo las etiquetas tradicionales $(V, N)$, estas representan a categorías funcionales interpretables y no son únicamente etiquetas categoriales.

La categorización sintáctica del concepto tiene pues dos consecuencias simultáneas: convierte un concepto no lingüístico en una unidad lingüística y, por ello mismo, lo categoriza determinando su ulterior comportamiento en la derivación (y, en última instancia, claro, su interpretación). Asumamos que el concepto del esquema anterior es el concepto que subyace a la raíz léxica del verbo destruir, sea este lo que sea. Si la construcción de (1) es seleccionada por $v$ (que corresponde a la categoría $v$ de Chomsky 1995, voz de Kratzer 1996 o Inicio en Ramchand 2008),

7 En la teoría de las categorías léxicas de Baker un verbo se define universalmente como la única categoría léxica que habilita un especificador (un sujeto). 
entonces tenemos una nueva verbalización de la derivación, con la adición de un nuevo especificador (el argumento externo o iniciador):

(3)

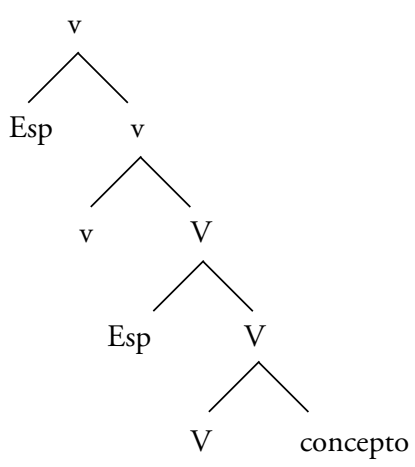

Hasta el momento tendríamos una derivación que toscamente significa que un argumento $\mathrm{X}$ inicia un proceso que le sucede al argumento Y, proceso que está definido por el concepto escogido (el de 'destrucción'). Al margen del orden de palabras (ahora irrelevante) la derivación sintáctica presentada serviría para cualquier lengua (asumiendo que todas las lenguas son configuracionales). Nótese que los nudos terminales de (3) —al margen ahora de los especificadores - no son palabras ni morfemas, esto es, ni son listemas (los emparejamientos sonido/sentido del modelo de Borer 2005a, 2005b) ni son raíces o afijos (como en la MD de Marantz 1997, 2000). De hecho, más allá del inventario de categorías funcionales (que asumimos universal y limitado), no hay léxico alguno implicado en la derivación. En otras palabras, en esta aproximación aún no hay un emparejamiento sistemático de sonidos y significados; únicamente hay entidades puramente conceptuales (tomadas del componente C-I) y categorías funcionales. Merece la pena insistir en la relevancia de este hecho: los nudos terminales de (3) no son morfemas ni son palabras, en el sentido de que no se han reclutado de un léxico que represente emparejamientos mínimos de sonido y sentido. Esta es una diferencia crucial con otras aproximaciones antilexicistas o constructivistas.

La hipótesis nuclear de la presente propuesta implica que el emparejamiento entre sentido y sonido se produce únicamente a través de la sintaxis. O lo que es lo mismo, que la sintaxis es el interfaz entre el sistema C-I y el sistema S-M. Ello implica entonces que solo una vez que un con- 
cepto está categorizado es candidato para emparejarse con una forma fonológica, esto es, para que se produzca lo que en la tradición generativista se denomina inserción léxica. ${ }^{8}$

Hay una larga disputa en el seno de la gramática generativa sobre si la inserción léxica se produce al principio o al final de la derivación. En la presente aproximación seguimos la idea — no extraña en los desarrollos teóricos minimalistas actuales- de que el momento de la inserción léxica pueda variar, dentro de unos límites estrictos, en función de las propiedades morfológicas de las lenguas. ${ }^{9}$ Si interpretamos el esquema de (3) a la luz de la morfología del español, habremos de decir que esa secuencia es impronunciable, en el sentido de que los verbos en español expresan al menos rasgos de tiempo y concordancia que no aparecen en (3). ${ }^{10}$ Así pues parece que en español (y en otras muchísimas lenguas) la derivación de un verbo (en este caso destruir) debe alcanzar también al nudo funcional $T$ (que — siguiendo el uso estándar- expresa tiempo y los rasgos phi del sujeto):

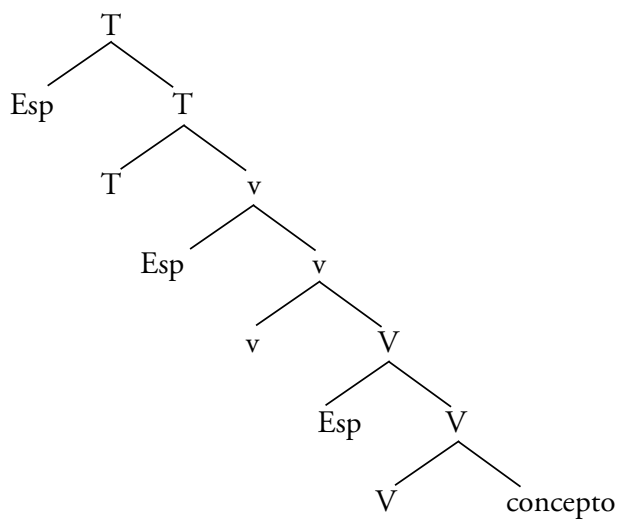
lización.

8 Según el modelo propuesto la inserción léxica equivale realmente a la materia-

9 Baker lo ha expresado con claridad: «Suppose that we leave the insertion point open, so that the insertion of a vocabulary item can take place at any point in the derivation as long as the language has an item that can realize the particular collection of syntactic formatives in question" (Baker 2003: 81).

10 Por supuesto, los argumentos situados en los especificadores, en la medida en que hayan completado su propia derivación, serán pronunciables. 
Hemos establecido como hipótesis que solo las unidades categorizadas pueden tener materialización fonológica. Sin embargo, esta es una condición necesaria pero no suficiente. El punto concreto de materialización de los núcleos de una estructura como la de (4) dependerá de la morfología de cada lengua, esto es, de la estructura morfológica de las formas fonológicas, esto es, de la extensión de sus paradigmas.

Por hipótesis, el concepto representado en (4) no sería un candidato posible para la materizalización, por lo que asumimos que se incorpora a su núcleo ( $V$ en este caso). ${ }^{11} V$ sería ya un candidato posible, pero no en español. Asumimos entonces, también siguiendo la tradición de Principios y Parámetros, que $V$ se incorpora a $v$ (movimiento de núcleo a núcleo), con un resultado aún insatisfactorio para el español, al menos para la llamada conjugación sintética. ${ }^{12}$ Así pues, únicamente un ulterior desplazamiento a $T$ reunirá bajo un mismo nudo sintáctico todos los rasgos incluidos en una forma verbal como, por ejemplo, destruyó (asumiendo, toscamente, que $T$ es pasado, perfecto y que el sujeto tiene los rasgos phi de singular y tercera persona). Solo en ese momento, en español, se puede producir la inserción léxica de la forma construyó en $T$, esto es, más propiamente, se producirá la materialización del núcleo complejo T/V/v/concepto.

Nótese que el modelo propuesto no hace sino recoger la tradición (que incluye a los partidarios de la llamada hipótesis lexicista débil) que asume que la morfología flexiva es un asunto esencialmente sintáctico. ${ }^{13}$

11 Más propiamente deberíamos decir que sufre un proceso de conflation en el sentido de Hale y Keyser (2002: cap. 1, original de 1998), con la diferencia de que para Hale y Keyser la 'conflación' es una especie de incorporación en el léxico (algo revisado en Hale y Keyser 2002: capítulo 3). Dado que no aceptamos la distinción entre sintaxis léxica y sintaxis frasal, no habría manera de distinguir los dos fenómenos. Como sugiere Baker, la conflación se podría definir como «incorporation prior to lexical insertion, resulting in categorization» (2003: 168), que es precisamente lo que observamos en el ejemplo.

12 Es posible que las formas no finitas de conjugaciones perifrásticas (como he destruido en español) sí sean candidatos para lexicalización (materialización) antes de $T$, por lo que el auxiliar se materializaría de forma independiente como realización de $T$ o de $T / v$, un asunto que dejamos simplemente apuntado.

13 Julien (2002) revisa 530 lenguas de 280 grupos genealógicos distintos y concluye que su examen de la morfología verbal apoya en un altísimo grado la hipótesis de que el orden de morfemas se determina exclusivamente desde el punto de vista sintáctico. Aun- 
También recoge el modelo esbozado la tradición reciente de intentar derivar la estructura argumental y eventiva de la derivación sintáctica (especialmente Borer 2005b). Sin embargo, como se ha señalado en el apartado anterior, la presente aportación pretende esbozar un modelo radicalmente antilexicista o, si se prefiere, un modelo en el que únicamente hay una sintaxis, insensible a módulos específicos, en este caso de acuerdo en esencia con la aproximación de la MD y sus extensiones «nanosintácticas». La única adición substancial a estas tradiciones es la hipótesis del «silencio por debajo de la palabra», lo que paradójicamente convierte a la presente aproximación en una teoría lexicista en la medida en que se rechaza que los nudos terminales de las derivaciones sintácticas sean morfemas y se niega la propia existencia de los morfemas como emparejamientos mínimos de sentido y sonido, uno de los pilares de la lingüística occidental. ${ }^{14}$

Una consecuencia de tal compromiso (compartido con la MD) es que la morfología derivativa debería tratarse de la misma manera, esto es, sin recurso a un tipo especial de sintaxis léxica o a reglas de formación de palabras. De hecho, la morfología derivativa puede resultar un fenómeno especialmente adecuado para investigar la naturaleza de las categorías gramaticales, bajo el supuesto de que los afijos derivativos son versiones más complejas de las categorías básicas $N, V$ y $A$.

Para ilustrar esto, consideremos primero la proyección de conceptos como nombres, esto es, la nominalización.

Según la teoría de las categorías léxicas de Baker (2003) lo que caracteriza a los nombres es lo que denomina criterio de identidad, esto es, la mismidad (sameness). Se refiere Baker, apoyándose en la tradición filosófica de Gupta y Geach, a que solo los nombres tienen un componente semántico que hace legítimo preguntarse si X es lo mismo que Y. Observa

que es siempre posible objetar algún análisis basado en movimientos poco justificados, no deja de ser significativo que el orden de morfemas de tal cantidad de lenguas se puede derivar de una única estructura subyacente por medio de una sintaxis en la que el movimiento y la adjunción siempre se producen hacia la izquierda.

14 En este sentido, la aproximación propuesta es compatible con la morfología "amorfa» de Anderson (1992) en tanto en cuanto a efectos de morfología, el modelo se inscribiría más bien en la familia de modelos de "palabra y paradigma». 
Baker que tanto los nombres como los verbos y los adjetivos tienen criterios de aplicación, de manera que sabiendo qué significa perro podemos identificar qué objetos son perros, sabiendo qué significa azul identificamos qué cosas son azules y sabiendo qué significa gritar reconocemos quién está gritando. Sin embargo, solo los nombres «set standards by which one can judge whether two things are the same or not» (Baker 2003: 101). Baker no asocia ese rasgo esencial de los nombres a una categoría funcional determinada, sino que emplea el recurso a los índices referenciales, basándose en la intuición de que la capacidad referencial y de cuantificación de los constituyentes nominales se basan en última instancia en ese criterio de identidad. Por su parte, Borer (2005a) desarrolla una teoría mucho más detallada y sofisticada de las categorías funcionales que hacen nombre a un nombre. Básicamente Borer argumenta que los nombres son los listemas que aparecen dominados por tres categorías funcionales: $C l$ (asificador), $C$ (antidad) y $D$ (eterminante). La categoría más cercana al listema en su modelo es $C l$, que en su teoría tiene relación directa con el número plural. Según Borer el rasgo de pluralidad tiene como efecto fragmentar una interpretación continua o incontable en una especie de retículas o particiones. La posterior especificación del nudo de cantidad superior (con un cardinal o un cuantificador) selecciona un determinado número de celdas de esa red que fragmenta la denotación del nombre. ${ }^{15}$ Borer estipula que dado que en chino y otras lenguas los nombres sin clasificador se interpretan como incontables, el valor incontable sería el valor por defecto de los nombres, esto es, el valor resultante de la ausencia de la categoría $C l$ (plural) en la derivación. El problema con esa interpretación es que en realidad entonces no queda claro cómo en ausencia de dicha categoría se nominaliza el listema seleccionado cuando obtenemos una lectura incontable (cfr. el esquema de Borer 2005a: 110, en el que la nominalización simplemente se estipula). Es interesante observar que el modelo de la nominalidad de Baker, basado en la idea (más difusa) del criterio de identidad, también se relaciona en realidad con la pluralidad y la cantidad. En efecto, por definición, la plu-

15 La interpretación contable de nombres en singular requerirá entonces de la presencia de un clasificador explícito, como es habitual en chino, o de la presencia de un clasificador que también cuantifica, como el indefinido alan en inglés, según argumenta la autora (Borer 2005a: 109 y ss.). 
ralidad es un requisito para poder contar. Pero no es el único ni el primero. Para contar, por ejemplo, perros no solo es relevante que haya una pluralidad de perros, sino también que estemos seguros de si el siguiente perro es distinto o igual al anterior (de si es el mismo o no); por su parte, los nombres incontables no se pueden contar, pero sí se pueden medir y para saber cuánta agua hay debemos estar seguros de que el agua que medimos ahora no es la misma que ya hemos medido. Por tanto, parece razonable asumir que la categoría nominal básica será la que proporcione criterio de identidad o mismidad a los nombres y sirva pues de legitimador para la categoría de número plural superior. No parece descabellado afirmar que un requisito para la pluralidad sea la singularidad, de manera que postularemos que la primera categoría nominalizadora es el número singular, que será la responsable del criterio de identidad. ${ }^{16}$ También asumiremos, sin mayor discusión, que en español el género (o, si se prefiere, la «marca de palabra») es la expresión morfológica del número singular. ${ }^{17}$ Por tanto, representaremos la nominalización de un concepto como el ensamble de un concepto a la categoría $N$ (por Número singular, que además —en español— puede ser masculino o femenino). El número plural (n), equivalente al nudo $\mathrm{Cl}$ de Borer, será pues otra categoría funcional superior que selecciona a $N$ como complemento. Así pues, la derivación de un nombre singular como gato será la siguiente:

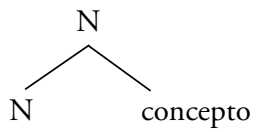

Así como en español destru- (aunque tenga un sujeto y un objeto directo) — como en (3) — no es una palabra que signifique algo, gato sí lo es, por lo que en esta lengua la materizalización se puede producir ya en

16 Remitimos a Borer (2005a) para una justificación detallada de que el nudo $C l$ (el que determina la interpretación contable) solo está presente en nombres en plural o en construcciones con clasificadores, que suelen estar en distribución complementaria. La hipótesis de que el número singular representa una categoría funcional independiente y que es responsable del criterio de identidad de Baker queda aquí esbozada informalmente y pendiente de ulterior investigación.

17 La anterior afirmación se refiere al género no interpretable. Vease Fábregas (2005) para una discusión más detallada del género interpretable (en nombres animados). 
ese momento. El modelo predice que el resultado será un nombre masculino singular incontable, algo aparentemente inadecuado. Pero nótese que los llamados nombres contables pueden usarse como incontables en casos bien conocidos de coerción como, por ejemplo, Es mucho gato para tan poco perro. ${ }^{18} \mathrm{La}$ representación de esta oración incluiría pues la de (5).

La obtención de un nombre contable implica la adición del nudo plural $n$ o la introducción de un clasificador explícito (un por antonomasia). Así, la derivación de gatos implicaría el esquema siguiente:

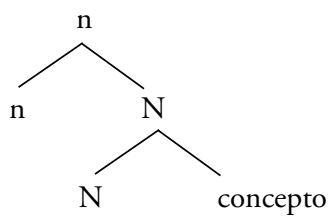

Como en el caso de (5), el concepto se incorpora a su núcleo (N) donde obtiene número singular (esto es, criterio de identidad, nominalidad - así como género morfológico-) y el complejo resultante se incorpora a $n$ donde obtendría número plural y lectura contable. Nótese que el modelo predice que en lenguas en las que no existe morfología de plural (como en chino) la obtención de un nombre contable exigirá la materialización independiente de $n$, esto es, de un clasificador.

En lo que respecta a los adjetivos, y de nuevo siguiendo la lógica de la teoría de Baker (2003), asumiremos que dichas categorías se caracterizan de forma negativa, esto es, por no tener ni sujetos ni criterio de identidad. Ello implicará pues que la categoría funcional $A$ categoriza conceptos por defecto, esto es, crea categorías léxicas que no pueden tener un sujeto y que no pueden tener criterio de identidad. ${ }^{19}$

18 Siguiendo a Borer (2005) interpretamos la coerción como el resultado de un desajuste entre el resultado de la derivación sintáctica y el conocimiento del mundo. Mucho gato es una derivación perfectamente legítima, aunque extraña semánticamente por nuestro contacto con gatos como entidades definidas y contables.

19 Baker (2003: cap. 4) muestra que la distribución y propiedades sintácticas de los adjetivos se siguen negativamente de esa caracterización, por lo que no es necesario atribuir a dicha categoría rasgos positivos de ningún tipo. 


\section{La derivación como (re)categorización}

Se decía más arriba que el presente modelo, aunque no lexicista, implica una concepción paradigmática de la morfología, y esto es así tanto en lo que respecta a la morfología flexiva como en lo que respecta a la derivativa o léxica. Ello implica entonces que analizamos los afijos derivativos como núcleos funcionales categorizadores (o recategorizadores, según los casos), esto es, como versiones más específicas (más complejas en sus rasgos constitutivos) de las categorías básicas postuladas hasta el momento $(V, v, N, n, A)$. Así, la estructura que proporcionaría interpretación a la palabra fonológica destrucción sería la de (7), que consiste en el ensamble de la derivación de (3) con el núcleo $N$, en lugar de con $T$ como en (4):

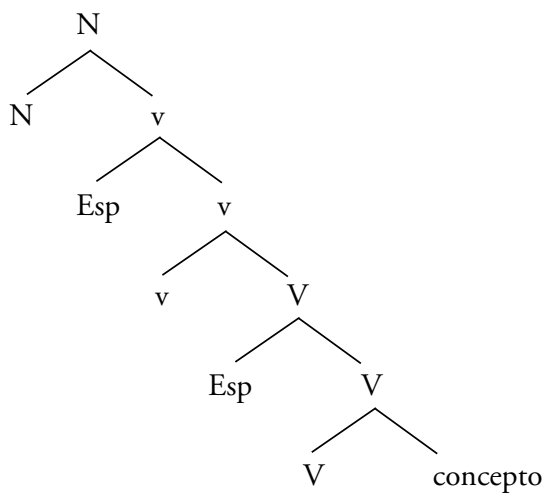

La representación de (7) pretende mostrar que destrucción, tal y como se usa en La destrucción de Anibal de Roma no es, como se seguiría de una teoría lexicista, un nombre formado sobre un verbo, con la subsecuente necesidad de postular un complejo sistema de reglas de ajuste morfológico y un no menos complejo sistema de inserción léxica que explique además la relación temática entre el nombre derverbal destrucción y sus posibles argumentos (Aníbal y Roma). El uso eventivo de destrucción implica que el concepto se ensambla con $V$, lo que crea un evento sobre un tema (Roma), que luego se ensambla con $v$, lo que crea una realización por parte de Aníbal de dicho evento, que luego se categoriza como un nombre con criterio de identidad, número singular y género 
femenino. $Y$ eso es exactamente lo que representa (7). Sabemos que en español deben alcanzarse $N$ o $T$ para que la derivación tenga representación fonológica y por ello solo cuando se obtiene el núcleo complejo $N / v / V / c o n c e p t o$ la derivación se vincula a la forma fonológica destrucción. $\mathrm{Al}$ margen ahora de muchos detalles relevantes para la derivación concreta de la oración (como por ejemplo el sistema de asignación de caso preposicional a los argumentos implicados) que omitimos, lo que la representación quiere poner de manifiesto es que en realidad el significado de destrucción (en esa oración) no se obtiene proyectando la entrada léxica de dicho nombre, ni se obtiene de la entrada léxica del verbo destruir, sino que se obtiene de la computación de un concepto sin propiedades gramaticales por medio de las operaciones básicas de la sintaxis y sus categorías funcionales. Es imposible en un trabajo de esta dimensión hacer una revisión detallada de los diversos fenómenos lingüísticos que han motivado la hipótesis lexicista y que en buena medida siguen siendo obstáculos a las teorías opuestas. Como una muestra nos centraremos especialmente en algunas objeciones que se han formulado a modelos que postulan la formación de palabras en la sintaxis (como la MD), con el objetivo de mostrar que la variante radicalmente antilexicista aquí esbozada puede resolverlas de manera natural conservando la hipótesis nula de que únicamente hay una sintaxis. Así, Ackema y Neeleman (2007: 332 y ss.) argumentan que si la sintaxis léxica y la sintaxis frasal fueran la misma, entonces sería esperable que un nombre que se incorpore a un afijo superior pudiera dejar tras de sí (stranding) sus complementos o modificadores. En efecto, esto es frecuentemente imposible. Consideremos el ejemplo de (8):

a. _ -ero de zapato de mujer

b. *Zapatero t de mujer

Objetan Ackema y Neeleman que si la estructura interna del derivado se hiciera en la sintaxis, entonces no habría manera de explicar que el ejemplo de (8b) fuera agramatical (y lo es si pretende representar el sentido de 'zapatero que repara zapatos de mujer'). La objeción es relevante, pero únicamente afectaría a las teorías «morfemáticas» que postulan que la formación morfológica de las palabras se realiza en la sintaxis, esto es, en nuestro ejemplo, que derivaran zapatero de zapato o de la raíz léxica de zapato (digamos, por caso, zapat-). Pero no es el caso del modelo que 
hemos propuesto. En efecto, una derivación como la siguiente, que subyacería a la frase de (8) sería algo así:

(9)

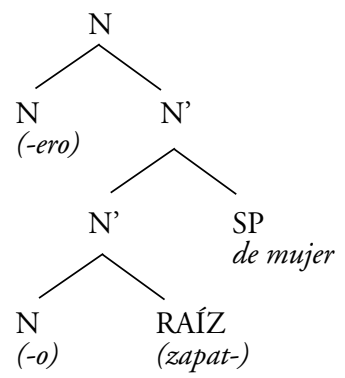

En efecto, de ser (9) un objeto sintáctico lícito, nada debería impedir la incorporación de $N$ (zapato, resultante a su vez de la incorporación de la raíz zapat- al $N-o$ ) al $N$ superior -ero, dando (8b). Toda estipulación para impedir ese proceso añadiría complejidad al sistema, eliminando la ventaja sobre la interpretación lexicista o haciéndola indistinguible de la misma. Sin embargo, el sistema diseñado en esta aportación, basado en la hipótesis de que la formación de palabras, aunque se realiza en la sintaxis, no opera con palabras ni con raíces o morfemas, puede salvar la objeción manteniendo la hipótesis nula de que únicamente hay un componente sintáctico en el lenguaje humano.

Una posibilidad, drásticamente simplificada, podría ser la siguiente:

(10)

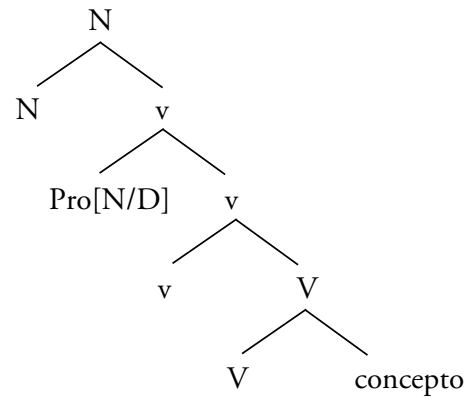

El concepto seleccionado (el mismo concepto asociado a zapato) se incorpora a $V$ formando un verbo (lo que daría cuenta de que el significa- 
do final de zapatero 'persona que repara zapatos' implica la acción de reparar o remendar zapatos). Asumimos (en este caso siguiendo a Baker 2003) que un verbo inergativo toma un $V$ atemático y que este, a su vez, es seleccionado por el $v$ que introduce un iniciador del evento (representado por un pronombre vacío pro en el esquema). Siguiendo en líneas generales la argumentación de Fábregas (2009) en relación con los derivados agentivos en -dor, podríamos estipular que el afijo -ero es la realización morfológica de un conjunto de rasgos que incluye un rasgo $D$ (que lo capacita para saturar una posición argumental, en este caso del iniciador del evento) y un rasgo $N$, que lo convierte en un nominalizador (esto es, esencialmente una marca de singular masculino). Siguiendo el modelo propuesto por Fábregas, $N$ se reensambla a $v$ tomándolo como complemento y nominalizándolo. La intención del análisis de Fábregas es dar cuenta del doble papel que parece desempeñar -dor, en el sentido de que sirve tanto como saturador del argumento externo del verbo al que nominaliza como de afijo nominalizador. En este caso el papel de -ero es el mismo, con la diferencia de que el verbo abstracto implicado en la derivación es intransitivo.

Lo relevante es que una estructura como la de (9) se asociaría en la memoria a la forma fonológica zapatero, lo que nos permite decir que la sintaxis es un sistema de cómputo que permite 'calcular' el significado de la forma aprendida combinando categorías funcionales y conceptos sin necesidad de postular una entrada léxica ad hoc. En este caso el único elemento argumental es el que aparece ligado por el afijo, mientras que no hay lugar en la derivación para un posible complemento preposicional de zapato, precisamente porque zapato no aparece como un nombre en la derivación. Ello explica adecuadamente la imposibilidad del ejemplo de (8b). La implicación más relevante es que se plantea que zapatero no deriva de zapato, sino que ambos comparten el mismo concepto de base y también parte de su forma fonológica (esto es, forman parte de un paradigma) y difieren en las categorías funcionales implicadas en su estructura interna.

Se puede objetar que esta solución únicamente sirve para derivados composicionales y en general para los productivos, lo que no evita que tengamos que postular una entrada léxica cuando el significado de un derivado no corresponde a ninguna estructura sintáctica plausi- 
ble. ${ }^{20}$ De hecho, esto último es muy frecuente. Palabras como ordenador, mechero o cerrojo parecen relacionarse con ordenar, mecha o cerrar, pero en realidad no se puede decir que tengan un análisis composicional. Nótese que el mismo problema se le impone a una teoría lexicista que cuente con reglas de formación de palabras. En tales casos lo que cabe decir en realidad es lo mismo que diría el partidario de las reglas de formación de palabras: que los conceptos correspondientes a los derivados son demasiado distintos a los conceptos correspondientes de sus (supuestas) bases. Ello simplemente implicaría que a palabras como ordenador, mechero o cerrojo subyacen estructuras sintácticas más sencillas (quizá únicamente concepto más categorizador), exactamente igual que en las palabras no derivadas. De este modo, si la sintaxis puede generar perro añadiendo género/número singular ( $-o$ ) a un concepto de cierto animal, del mismo modo puede generar mechero añadiendo género/número singular $(-o)$ a un concepto de cierto artilugio que, quizá vagamente, el hablante pueda relacionar con mecha o no, ${ }^{21}$ algo que en cualquier caso queda reflejado en el modelo por la proximidad paradigmática de las palabras fonológicas mecha y mechero. ${ }^{22}$

Baker (2003) observa que la complejidad morfológica a veces no se corresponde con complejidad sintáctica y viceversa, algo que menciona para justificar no eliminar la diferencia entre sintaxis y morfología. ${ }^{23} \mathrm{El}$ presente modelo precisamente no niega que sintaxis y morfología sean

20 O para este mismo caso, en el que no aparece representado en ningún lugar de la derivación que zapatero se refiere al que repara zapatos y no, por ejemplo, al que los limpia (o en otra interpretación, al mueble que los guarda). Nuestra interpretación es que esa información es enciclopédica y tiene que ver con las relaciones entre conceptos y no con la estructura sintáctica. Eso significa que zapatero implica el concepto de zapato y, a través de este y la estructura, el concepto de 'reparador de zapatos', etc.

21 En el caso de que se establezca la relación quizá el hablante analiza $N$ como -ero y no como $-o$.

22 En todo este trabajo se emplea la expresión paradigmático en un sentido saussureano, esto es, asociativo, incluyendo no solo la morfología flexiva, sino también la derivativa y todo tipo de semejanzas fonéticas como la rima, etc. (Véase el esquema en Saussure 1916/1983: 200, en el que se vincula enseñanza con enseña, enseñemos, pero también con aprendizaje, educación, con templanza, esperanza y con lanza, balanza).

23 "I conclude that there is not always a simple relationship between the size of a morphological unit and the complexity of the syntatic node it corresponds to" (2003: 277). 
independientes. Al contrario, lo que afirma es que lo son. La morfología en esta aproximación es puramente realizativa: por así decirlo, la estructura morfológica de una palabra "cuenta una historia» acerca de la estructura sintáctica interna de esa palabra, pero no determina dicha estructura ni siquiera la refleja directamente en muchas ocasiones. La predicción general, nada novedosa, es que a mayor estructura morfológica, mayor profundidad estructural en la sintaxis interna de la palabra, pero nada más. Esto, en cierto modo, abre la puerta de nuevo a la concepción esencialmente analógica de la formación de palabras.

Es más, el modelo que niega la entrada léxica de las palabras predice adecuadamente que diferentes hablantes pueden analizar sintácticamente de manera distinta una misma forma. De hecho, es evidente que durante nuestra vida cambiamos el análisis de las formas que aprendemos. Si alguien recién llegado a Aragón aprende la palabra laminero 'goloso' puede analizarla como un concepto (que puede ser nuevo) más un afijo de número/género (-o/a), pero si después descubre la palabra lamín 'dulce', quizá introduzca más complejidad estructural (quizá un análisis en el que -erola está implicado). Es muy plausible que el proceso de adquisición del léxico siga de hecho esa pauta, procediendo en la medida de lo posible a representar estructuralmente las palabras morfológicamente complejas, liberando memoria y reordenando y ampliando el sistema conceptual. Cuando una derivación, como por ejemplo la de (10) se asocia memorísticamente, establemente, a una forma fonológica (por ejemplo zapatero), automáticamente modifica el concepto implicado, añadiéndolo al sistema conceptual. Por ello es posible obtener conceptos nuevos a partir de palabras nuevas y conceptos viejos.

\section{Estructura sintáctica y morfología no distribuida}

Las estructuras que hemos estado considerando hasta el momento son estructuras sintácticas ordinarias, al margen de la profusión de procesos de incorporación (movimiento de núcleo a núcleo) postulados. Hemos sugerido además que la estructura morfológica no es sintáctica (esto es, jerárquica y configuracional), sino lineal y que el modelo morfológico adecuado en dicha concepción es el de palabra y paradigma, esto es, una morfología no distribuida. 
Si retomamos el ejemplo de (9) en el apartado anterior, en el que hemos asumido que se implica el mismo concepto de base que estaría implicado en la palabra zapato, aún cabría preguntarse por qué razón no se materializa simplemente con la propia palabra zapato. Aquí es donde se puede apreciar el carácter paradigmático de la teoría morfológica implicada. La estructura de (9) no es un sistema de formación de palabras, sino que es una construcción sintáctica que, por así decirlo, el hablante aporta para interpretar el significado de la palabra zapatero en un contexto dado. En el modelo que hemos propuesto, como en otros similares, la materialización de los nudos terminales implica una competencia entre formas relacionadas con un concepto dado. Así, zapato, zapatería, zapatero, zapatilla, etc., son todas formas fonológicas memorizadas que forman parte de un paradigma asociado, a través de la sintaxis, a un área conceptual determinada. La forma zapatero sería entonces la más compatible con dicha estructura de entre las que integran el paradigma, exactamente igual que sucede en las teorías realizacionales de la morfología flexiva (p. ej. Stump 2001, Stewart y Stump 2007).

Anderson (1992: 186) plantea que las reglas derivativas de formación de palabras fundamentalmente sirven para establecer las relaciones entre palabras del lexicón que forman parte del conocimiento lingüístico del hablante, y no tanto para crear o generar esas palabras. Esta visión, aunque lexicista, es compatible con el modelo que estamos desarrollando, en la medida en que se puede decir que las familias derivativas (zapato, zapatero, zapatear, zapatilla, zapateado, etc.) forman paradigmas complejos con estructura puramente morfológica y fonológica que se interpretan a la luz de la estructura sintáctica con la que se relacionan. En nuestro modelo el papel de las reglas de formación de palabras lo desempeña la propia sintaxis. El grado de transparencia y composicionalidad de los derivados dependerá por tanto de la «cantidad» de estructura con la que se interpreten. Parece razonable asumir cierta tendencia a que se establezca una correlación general entre la complejidad morfológica y la complejidad sintáctica de una palabra. Lo relevante es que esta correlación no es determinista, lo que es un problema común a las teorías basadas en las reglas de formación de palabras y a las teorías sintactistas morfemáticas, tales como la MD. La estructura morfológica de una palabra derivada no permite normalmente calcular su significado, lo que indica que un tratamiento en términos de procesos de formación de pala- 
bras (sean en la sintaxis o en el léxico) es inadecuado en la mayoría de los casos. Situar las reglas en un lado u otro no mejora por sí mismo las cosas. La hipótesis que aventuramos es que la sintaxis proporciona la estructura necesaria para interpretar las palabras complejas y, lo que es lo mismo, que es el tipo de conocimiento que se emplea para usarlas adecuadamente.

La intuición relevante es que la estructura morfológica de las palabras fonológicas sirve como un registro o un indicio de la complejidad sintáctica derivacional subyacente, como si tuviera un valor mnemotécnico.

Esta visión paradigmática de la morfología derivativa ofrece también un lugar natural para una concepción, popular en el pasado pero hoy casi olvidada, en la que los procesos analógicos son la base de la llamada formación de palabras. Anderson (1992: 189 y ss.) plantea que las reglas de formación de palabras tienen una misión doble: formar nuevas palabras y servir de modelo para analizar otras no derivadas. Pues bien, esa duplicidad sospechosa se puede resolver asumiendo que el proceso básico de formación de palabras es la analogía, en el sentido de que la estructura sintáctica subyacente a una palabra se puede emplear para formar otra sin necesidad de postular procesos específicos de formación de palabras, típicamente sobregeneradores. Por supuesto que un proceso analógico necesita un inicio generativo que después pueda servir de modelo a otros ítems creados por analogía. La sintaxis proporciona ese modelo y explica al carácter altamente composicional de términos no derivados sincrónicamente, tales como irascible, viable o impecable. El modelo sintáctico presentado emplea profusamente la derivación abstracta (no materializada) de palabras posibles, frecuentemente necesitadas en los modelos basados en reglas de formación de palabras. Esto es una virtud en tanto en cuanto dichas "palabras" forman parte central de los procesos analógicos. Es frecuente que en los grupos de derivados haya algunos ítems plenamente regulares (que son los que suelen servir de modelo para establecer la regla) y otros solo parcialmente regulares, puesto que violan algún aspecto semántico o formal de la regla. Estos segundos son los candidatos ideales para ser analizados como términos de la analogía, mientras que los primeros son los modelos del proceso analógico. Pues bien, el modelo presentado permite capturar este hecho sin necesidad de un léxico pesado, ya que en lugar de reglas o procedimien- 
tos ad hoc de formación de palabras establece que ciertos fragmentos de derivación sintáctica, en la medida en que cumplan la condición suficiente de la categorización (o recategorización), se materializan fonológicamente. Estas formas fonológicas, las palabras en sentido estricto en nuestra teoría, guardan, por así decirlo, una «memoria morfológica» de la estructura que las ha generado, que es la que se puede emplear para el establecimiento de relaciones paradigmáticas con otras formas y sus respectivas estructuras. En este sentido, la estructura morfológica de una palabra española como europeización representa una relación sistemática con la derivación que subyace a palabras como Europa, europeo,-a y europeizar, pero no necesariamente con las propias palabras. En un contexto así es suficiente el supuesto de que la estructura morfológica es estrictamente lineal y, por así decirlo, diacrítica o mnemotécnica, y en ese sentido no compartimos la visión de muchos modelos morfológicos actuales que postulan una estructura bidimensional (jerárquica y lineal) de los morfemas integrantes. Una estructura léxica o subléxica como la de (11) resulta poco ilustrativa con respecto a las propiedades sintácticas y semánticas de esa forma (europeización) y las construcciones en las que se inserta (por ejemplo, La europeización de La Argentina sucedió hace decenios), a no ser que añadamos un conjunto de reglas específicas para cada paso, indicando los procesos de selección de la base, la forma de herencia argumental, etc.:

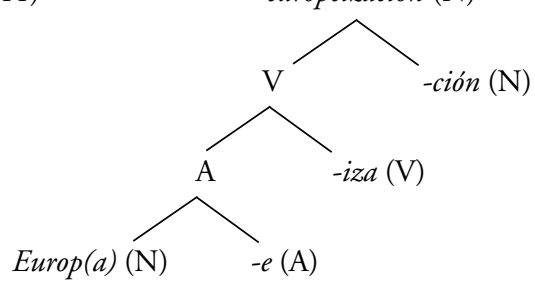

Así, por ejemplo si Europa es el $N$ inferior, tenemos que asumir que el adjetivo que lo selecciona o bien es su modificador (como en Europa moderna) o bien es predicativo y le asigna un papel temático, lo que no parece justificable. Pero si esa estructura es realmente sintáctica, un SN definido (Europa) debe llevar un papel temático y un caso. Una estructura así también viola la selección paramétrica de orden básico de 
palabras en español, que parece indicar que los núcleos preceden a sus complementos. ${ }^{24}$

La alternativa sugerida, aparentemente similar, es la siguiente:

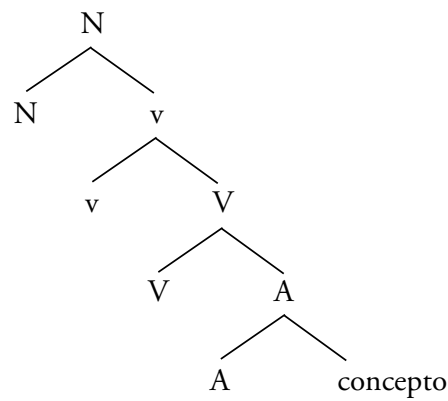

Nótese que la estructura de (12) sí es puramente sintáctica. Si la derivación se materializa en el primer ensamble, obtenemos la forma adjetival europe- (inaceptable por faltar la expresión de género en la medida en que este se determina flexivamente por concordancia, una vez que el adjetivo está ligado a un nombre en la derivación, cosa que no sucede). $\mathrm{Si}$ la derivación continúa y se materializa en $v$ (asumiendo que - $i z$ - materializa a una versión de $v$, lo que ahora es tangencial), entonces obtendríamos la forma europeiz (inaceptable por falta de los rasgos de tiempo y concordancia requeridos en nuestra lengua). Únicamente cuando se obtiene el núcleo complejo $N / v / V / A /$ concepto se puede materializar la forma europeización. En cierto sentido se representa aquí que europeización es un nombre que se relaciona sistemáticamente con (aunque no se deriva de) las palabras españolas Europa, europeo,-a y europeizar, puesto que parte esencial de la estructura interna de estas está incrustada en la derivación de (12).

24 Baker, uno de los principales instigadores de la sintaxis como explicación de la morfología, se ha manifestado al respecto con ejemplar templanza: «I have no reason to be dogmatic in this point; if good reasons came to light for saying that the adjective foggy is formed in the syntax, so much the better. For the time being, however, complicating the syntax with derivations of this kind seems likely to do more harm than good" (Baker 2003: 280). 
La tesis de que las palabras no se forman a partir de otras palabras que estamos defendiendo encuentra problemas cuando la derivación de una palabra compleja parece incluir formas completas de otras palabras, como se puede alegar en centralizar, claramente formada a partir de central y no de centro ni de céntrico. En efecto, la representación sintáctica de esa palabra tiene que incluir de alguna manera el adjetivo central. Así, por ejemplo, la siguiente:

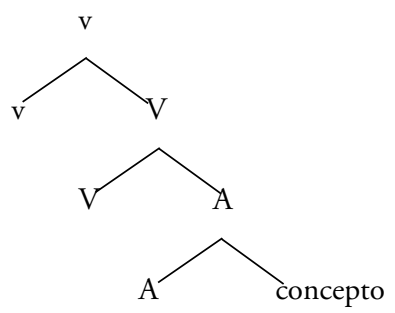

Asumimos aquí que el concepto ensamblado es el mismo que emplearíamos, con un $N$ (número singular/género), para derivar centro. Puesto que el adjetivo central no tiene marca de género de concordancia, no hay razón por la que no podría materializarse la derivación cuando el concepto se incorpora a $A$. Y en efecto, así podría ser. Pensemos en la oración El gobierno hizo centrales los servicios sociales. Dicha oración correspondería a la materialización en (13) de A/concepto como central y a la materialización de $v / V$ con un verbo causativo del tipo de hacer (asumiendo que además habría $T$ por encima del esquema de (13), así como especificadores incluyendo los argumentos). Adicionalmente, se habría de producir la concordancia de número entre el adjetivo resultativo y el argumento interno del verbo (introducido en el especificador de $V$ ). La derivación correspondiente a centralizar (en, por ejemplo, El gobierno centralizó los servicios sociales) implica pues la incorporación del adjetivo a $V / v$, algo coherente con su significado. Lo relevante ahora, y potencialmente nocivo para nuestra teoría, es que esa incorporación parece acarrear también la materialización de $A$ (esto es, el sufijo -al), del mismo modo que en el ejemplo anterior se implicaba que en europeización también se incorpora la materialización de $v / V(-i z-)$, haciendo casi inevitable inferir que centralizar se deriva de central y que europeización se deriva de europeiza(r). 
Es en este punto en el que tiene sentido la propuesta de que la morfología derivativa es paradigmática. Algunos modelos basados en reglas de formación de palabras consideran estas como reglas de redundancia (Jackendoff 1975). Si en la derivación de (13) el nudo que selecciona a $A$ es $V$, o bien $A$ se materializa y $V$ también debe hacerlo, o bien $A$ se incorpora a $V$ (y se materializan posteriormente). En este caso debemos postular que la derivación «guarda la memoria» de que $A$ tenía realización posible (central) y conserva esa información hasta que se produce la materialización en un núcleo superior ( $T$, en cuyo caso tendremos alguna forma del paradigma de centralizar, o, eventualmente, $N$, en cuyo caso tendremos centralización). Este proceso, aunque estipulativo, tiene la ventaja de que de alguna manera recoge la intuición clara de que centralizar contiene la palabra central pero sin invocar directamente a la propia palabra central. ${ }^{25}$

El presente modelo no pretende eliminar totalmente la necesidad de postular la existencia de ciertas reglas morfológicas de formación de palabras, que en cualquier caso parecen necesarias para explicar la determinación final de las palabras fonológicas que materializan los nudos terminales de la derivación. Quiere esto decir que este modelo sintactista no implica que no exista un nivel de representación morfológica en el que se determina la estructura morfológica y fonológica de las palabras. Lo que se pretende eliminar del modelo de la Facultad del Lenguaje es un módulo léxico de formación de palabras y la existencia de procesos sintácticos específicos para la construcción de palabras. Si asumimos que la sintaxis de (13) proporciona a la morfología la secuencia $T / v / V / A / c o n c e p t o$, siendo el concepto 'centro' (lo que automáticamente selecciona el paradigma formado por centro, centrar, central, centralizar, centralización, centrado, céntrico, etc.), es razonable asumir que en la construcción morfológica de la palabra que va a materializar ese nudo complejo se tenga en cuenta la palabra central, que materializa una parte de la secuencia (A/concepto), de la misma manera que si tenemos la

25 De hecho, de entre los sentidos que se pueden asociar a central, el único que aparece en centralizar es el representado en (12), esto es, un adjetivo derivado del concepto común a centro, central, centralidad, etc., y no otros propios de la palabra central (por ejemplo, un cierto tipo de jugador de fútbol). Nótese además que no se puede obtener una forma con el adjetivo en plural. 
secuencia $N / v / V / A /$ concepto se incorporarán a la forma morfológica final tanto central como centraliza (el tema verbal de centralizar), puesto que materializan ya parte de la estructura.

La conclusión esencial es pues que la morfología no está distribuida, sino que es la sintaxis la que proporciona representaciones formales para la determinación de la forma fonológica (y morfológica) que materializa ese fragmento de derivación. La hipótesis del «silencio subléxico» permite pues una vuelta a la concepción de la morfología originaria: el ámbito de la determinación de la forma fonológica de las palabras.

\section{Conceptos, raíces y palabras}

Todos tenemos la intuición de que hay una conexión estable entre, de una parte, conceptos y, de otra, raíces léxicas o temas: si oímos destruí y destrucción parece que ciertos fragmentos más o menos coincidentes de las dos palabras se relacionan con el mismo concepto. Toda la morfología, tradicional y moderna, se basa en eso. Es un hecho evidente y un modelo teórico debe captarlo de alguna manera. Pero, obviamente, debemos captar las intuiciones de los hablantes, no las de los lingüistas. La propuesta formulada implica que en realidad no hay una conexión directa sonido/sentido que explique dicha intuición. Pese a la apariencia inicial, creo que eso es una virtud más que un problema. Nótese que cualquiera que sea el concepto común subyacente a destruí, destruido y destrucción es borroso y relativamente inaccesible al hablante, cuando no inservible. ${ }^{26}$ Es un hecho que para un hablante del español la secuencia cas-, por ejemplo, es irrelevante. ¿Qué significa? Nada. La explicación más natural para ello es simplemente que la raíz cas- no es una palabra y, por tanto, no está conectada a ningún sistema conceptual y, por tanto, no puede significar nada. Claro que tras una reflexión podemos decir que cas- es la raíz de muchas palabras (casa, caserío, casita, casona, o bien casarse, casar, casación, casamiento, casada, etc.). Una teoría morfemática diría que en realidad el hablante tiene demasiadas opciones, mientras que la propuesta desarrolla-

26 Más claramente se observa esto si incluimos también en la reflexión palabras como construi y construcción, instrui e instrucción. 
da aquí dice que tiene demasiado pocas, o mejor, ninguna. Esto es así porque no hay emparejamiento sonido/sentido en el nivel morfemático y las raíces aisladas no se pueden entonces asociar a ninguna estructura interpretable ni, en consecuencia, conectar a ningún concepto. ${ }^{27}$

Pero la prueba más directa de que en realidad solo las palabras tienen representación fonológica radica en que en la inmensa mayoría de lenguas del mundo (con el inglés como una de las notorias excepciones) la mayor parte de las raíces léxicas y los afijos son simplemente impronunciables y, cuando son pronunciables, normalmente es porque coinciden con palabras.

No deja de ser cierto que la semejanza fonética entre las raíces (por ejemplo las de la familia casa, caserio, casita, casona) parece remitir a la misma zona del sistema conceptual. Si, como he postulado, no hay conexión directa entre raíces o morfemas y conceptos, ¿cómo sabe el hablante que se trata más o menos del mismo concepto? O en términos todavía más simples: ¿cómo sabe que su interlocutor se refiere al concepto de casa cuando dice la palabra casa, o cómo sabe el hablante qué palabra pronunciar cuando quiere hablar del concepto de casa? La única respuesta coherente con el modelo propuesto es que existe una capacidad de memorizar derivaciones básicas, en el sentido de que las derivaciones se siguen produciendo (no interpretamos destrucción o casa como un bloque), pero, por así decirlo, en forma de rutinas. La llamada adquisición del léxico consistiría precisamente en que ciertas derivaciones se asocian memorísticamente a representaciones fonológicas estables y otras no.

La hipótesis que planteamos es que las derivaciones mínimas (esto es, que tienen asociada muy pronto una forma fonológica, típicamente las categorizaciones) tienden a memorizarse, pero no como ítems léxicos, sino como derivaciones que se asocian a representaciones fonológicas determinadas. Nótese que la propia derivación no se memoriza; lo que se memoriza es la vinculación a una forma fonológica.

Es obvio que una lengua puramente mental, esto es, una lengua que solo se usara para el pensamiento, no tendría conexión con el sistema

27 Quizá por ello se dice que los niños dicen sus primeras palabras, y no sus primeros morfemas. 
S-M, sería una lengua sin fonología. Según este modelo, en dicha lengua tampoco existirían palabras (ni, por supuesto, morfología), sino que bastaría con los conceptos y las categorías funcionales para computar con ellas derivaciones más complejas ("palabras sintácticas» incluidas, claro está). Lo que he denominado la fase de categorización estaría presente, pero no tendría el estatus privilegiado de ser la primera fase de materialización. Cuando el lenguaje se comienza a emplear para la interacción, debe conectarse a los sistemas S-M y entonces es necesario que una determinada computación se asocie a representaciones fonológicas estables. Mi hipótesis es que el mínimo imprescindible para ello es la categorización, porque sin ella la computación de los conceptos sería imposible o muy limitada. Un concepto aislado no sirve de gran cosa, ni para el pensamiento ni para la comunicación, aunque por supuesto puede ser muy útil para que un organismo disponga de sistemas de conocimiento y de representación.

La idea básica es que la categorización (la lexicalización), que es la primera operación sintáctica, tiene como efecto hacer homogéneos formalmente conceptos que en su propia naturaleza pueden ser heterogéneos e incompatibles. Como ha sugerido Boeckx (2008), siguiendo en ello a Pietroski, la lexicalización, al imponer un formato único a todos los conceptos, permitiría a los ítems léxicos combinarse en virtud de su nuevo formato compartido, en lugar de estar limitados a su afinidad más natural (esto es, puramente semántica o conceptual). Ello permitiría que conceptos que originalmente residen en distintos módulos mentales y que posiblemente serían opacos entre sí, se puedan combinar para dar lugar a nuevos conceptos: "It is quite possible that what is at first a formal restriction on lexical items is the source of a cross-modular syntax of thought -giving rise to a full-blown language of thought, arguably the source of our Great (mental) Leap Forward at the evolutionary scale» (Boeckx 2008: 78).

En otras palabras, añade Boeckx, al poder hacer uso de un formato léxico común, el pensamiento post-léxico es más variado y más poderoso e irrestricto que el pensamiento pre-léxico, en el que los conceptos estarían, por así decirlo, atrapados dentro de sus módulos, tal y como sucedería en nuestros ancestros evolutivos y como parece que sucede en otros seres vivos. 
De hecho, siguiendo la misma línea de pensamiento, Ott (2009) da cuenta de un cierto consenso que se está generalizando en el ámbito de la psicología comparada en el sentido de que es muy probable que los seres humanos y otras especies compartan buena parte de sus sistemas conceptuales. ${ }^{28}$ Como ha puesto de manifiesto Hurford (2007: 87, citado en Ott), "some (not all) of a human system of common-sense understanding precedes a system of language, both ontogenetically and phylogenetically», lo que implicaría que dichos sistemas no son parte de la evolución del lenguaje humano, sino que anteceden a esta facultad (entendida como FLE). Parece, pues, que tanto otros animales como los propios bebés humanos tienen considerables capacidades conceptuales, pero a diferencia de lo que sucede con los adultos humanos, son incapaces de integrar esas diversas 'lenguas mentales' de la manera en que nosotros lo hacemos. Esta es la que Ott (2009) denomina la paradoja de Hauser. ${ }^{29}$ Siguiendo ideas de Boeckx y otros autores, Ott sugiere que la capacidad de asociar conceptos con palabras (la lexicalización) sería la clave para explicar esa paradoja, en el sentido de que los conceptos se harían combinables más allá de sus limitaciones modulares, dando lugar a un sistema recursivo que transcendería los límites de los dominios de los sistemas de conocimiento básico (core-knowledge domains), tales como las relaciones sociales o el razonamiento espacial:

This suggests that the crucial evolutionary novelty was in fact the mechanism of lexicalization, leading to an increase in both computational and conceptual capacities. If these speculations are on the right track, the significant cognitive gap between humans and non-linguistic animals is not the result of a profound remodeling of the pre-linguistic mind. Rather, the sudden addition of recursive syntax, paired with a capacity for lexicalization, plausibly led to the explosive emergence of symbolic thought that paved the way for modern human behavior (Ott 2009: 267, cursivas añadidas). ${ }^{30}$

28 "[T]his comparative approach has led to the emergence of a novel picture of the evolutionary origins of human cognitive function, according to which many of the building blocks of the human mind are in fact shared with other species, but tied up in a way that yields a cognitive quantum leap" (Ott 2009: 258).

29 "[A]nimals share many of the building blocks that comprise human thought, but paradoxically, there is a great cognitive gap between humans and animals» (Hauser 2008, citado en Ott 2009).

30 "When lexicalized, human concepts can freely and systematically compose, regardless of the conceptual subsystem from which they are drawn. [...] I-language expressions can combine concepts of color, sound, space, time, self, other things, action, habitation, number, etc., as well as theoretical and fictitious concepts. [...] This is because from 
Esa capacidad para lexicalizar, que es precisamente la que en el presente trabajo hemos identificado con la categorización y con la edge-feature de Chomsky, es pues una operación sintáctica sobre los conceptos, por lo que las supuestas dos novedades en la emergencia del lenguaje humano se reducirían a una: las categorías funcionales básicas que asocian los conceptos al sistema computacional. ${ }^{31}$

Resulta pues lógico que sea la primera fase de computación (la categorización) la que se asocie al componente fonológico, y es por tanto esperable que sea esa primera fase la que se memorice a efectos de interacción con otros hablantes, pero lo que se empareja no es un sentido y un sonido, sino una estructura morfo-fonológica y una estructura sintáctica. ${ }^{32}$

En la medida en que esa estructura queda asociada a una representación fonológica almacenada, es esperable que dicha forma fonológica vaya asociándose a su vez a nuevos conceptos o incluso dé lugar a la creación de nuevos conceptos, antes inaccesibles. El léxico así entendido no es pues el aducto del proceso de derivación sintáctica, sino el educto. En cierto sentido podría decirse que la sintaxis describe una especie de bucle, ya que produce derivaciones a partir de conceptos y las «devuelve» al sistema C-I creando nuevos conceptos.

Estas ideas parecen nuevas, pero solo lo son en un sentido relativo. La enseñanza fundamental de Saussure (1916) fue precisamente que las len-

the point of view of the grammatical system, radically different types of concepts are just words', once lexicalized. Put in a different way, I-languages allow the generation of domaingeneral thoughts by extracting concepts from their modular bounds, by means of lexicalization. All comparative research suggests that animals and pre-linguistic infants are incapable of representing such multimodal thoughts. [...] The proposal, then, is that the lexicalization of a concept effectively demodularizes its (Ott 2009: 264-266, cursivas añadidas).

31 En una metáfora afortunada Boeckx (2010) ha relacionado la lexicalización como el análogo mental de una moneda universal que permitiera transacciones entre sistemas antes impenetrables.

32 Es en este sentido en el que la presente propuesta entronca en general en la llamada aproximación nanosintáctica: "The essential building block of nanosyntax is the simple observation that the terminal nodes of syntactic structures have become very small as syntactic trees grew, and at some point they crossed the line to become smaller than a morpheme - terminals have become 'submorphemic'. This simple fact, noted many times, leads to profound and wide-ranging consequences once it is taken seriously" (<http://nanosyntax.auf.net/whatis.html>). 
guas no son substancia, sino forma. Las lenguas, como sistemas puramente formales, segmentarían la realidad extralingüística, haciéndola discreta. Para Saussure una lengua era esencialmente un sistema de signos, pero muy especiales. Una lengua era un conjunto de significantes, arbitrariamente delimitados entre sí, que se unían arbitrariamente a un conjunto de significantes, también arbitrariamente delimitados entre sí. Lo que un signo saussureano une, no es por tanto, un concepto y un sonido (que no tienen identidad lingüística de por sí), sino un fragmento de sonido arbitrariamente marcado como lingüístico con un fragmento de sentido también arbitrariamente marcado como lingüístico. Su hipótesis esencial era entonces que esa vinculación entre los dos planos era la que, por así decirlo, «obraba el milagro» de convertir lo no lingüístico en lingüístico.

Por supuesto, la lingüística saussureana era una lingüística externista y una lingüística de signos. En tal modelo la vinculación entre sonido y sentido, formalmente mediada, era la que convertía fragmentos lingüísticamente amorfos de sentido en unidades lingüísticas utilizables. En otras palabras, la vinculación con el significante daba realidad lingüística al significado y viceversa. Podría decirse que en ese modelo los sonidos eran los que «rescataban» a los conceptos de su lugar propio en la mente (esa 'masa amorfa de sentido') y los sacaban a la luz del lenguaje. ${ }^{33}$ El modelo presentado plantea el mismo asunto de una manera diferente. Es una concepción internista y no es una concepción basada en el signo, sino en la sintaxis, en la computación. En la propuesta que hemos desarrollado es la sintaxis la que, por así decirlo, rescata los conceptos de su lugar en la mente y en el cerebro y los hace computables. Más aún, podría decirse, como hemos visto que sugería Ott, que la sintaxis «obra el milagro» de desencapsular los sistemas conceptuales de diverso tipo y los pone al servicio de un único sistema computacional. En nuestra versión concreta, las categorías sintácticas "obran el milagro» de hacer coherentes, computables y relacionables a conceptos que por sí mismos pertenecen a sistemas cognitivos diferentes y no relacionados directamente. En otros términos, las palabras (entendiendo ahora como tales los conceptos categorizados) son las que «rescatan» de la oscuridad a los conceptos, multiplicando la

$33 \mathrm{Y}$ al contrario, los significados eran los que estructuraban a los significantes, extraídos de esa 'masa amorfa de sonido'. 
potencia de cálculo de nuestra especie de manera insospechada en el ámbito natural.

\section{Conclusiones: el léxico distribuido y la naturaleza de la palabra}

La conclusión del apartado anterior no es la esperable de una aportación no lexicista. Las teorías antilexicistas suelen concluir que las palabras son epifenómenos. Así Julien (2007), por ejemplo, afirma que «the discussion of whether complex words are formed in the syntax or prior to syntax is futile, because words as such are not formed in the grammar at all. They are not grammatical entities» (Julien 2007: 210), por lo que concluye que "the concept of 'word' has no theoretical significance in the grammar at all» (2007: 212), algo que obviamente no compartimos. Parece razonable afirmar que no hay procedimientos de formación de palabras, pero ello no implica que las palabras no se creen. Las palabras se crean en la sintaxis cuando se categorizan los conceptos, y se crean en la morfología cuando las estructuras sintácticas se materializan. Los dos tipos de palabras no coinciden necesariamente, ya que el rango de coincidencia depende de la estructura morfológica de cada lengua.

En el modelo que hemos planteado, la sintaxis determina la estructura interna de las palabras, pero crucialmente no determina la realización de cada morfema individual, cosa que debe hacer la morfología. Los morfemas no tienen independencia fonológica ni sintáctica, puesto que las unidades fonológicas significativas mínimas no son los morfemas, sino las palabras. ${ }^{34}$

La misma Julien (2007) señala que las palabras tienen apariencia de realidad psicológica en mayor medida que los morfemas, lo que resulta sorprendente si es cierto que el léxico y la sintaxis operan con morfemas y las palabras no existen. La explicación que ofrece Julien es que la causa de

34 Ese es el planteamiento de Anderson, que compartimos: "Whatever its surface plausibility, the view of words as built up out of morphemes is fundamentally flawed, and should be replaced by a rather different conception» (Anderson 1992: 3). 
que las palabras sean más accesibles al hablante tiene que ver con sus propiedades distribucionales: «since words are the minimal morpheme strings that can be used as utterances and that may be permuted more or less freely, words are the mininal linguistic units that speakers can manipulate consciously» (2007: 234). Frente a ello, afirma, "word-internal morphems, by contrast, cannot be consciously manipulated in the same way, and consequently, word internal morphemes are less salient than words in the awareness of speakers» (Julien 2007: 234). La explicación es ingeniosa, pero deja sin explicar por qué las palabras tienen ese privilegio distribucional del que los morfemas carecen. La explicación más directa es precisamente la que afirma que las palabras (los conceptos categorizados) adquieren la independencia distribucional en virtud de ser las unidades mínimas de la sintaxis que se conectan con el componente S-M. Los morfemas son precisamente eso, puras formas que, con mayor o menor precisión, «recapitulan» la estructura interna de las palabras. Las reglas morfológicas de una lengua no determinan la estructura sintáctica interna de una palabra, sino que determinan su forma.

El modelo que hemos presentado es en realidad una variante de la $\mathrm{MD}$, en la que se basa. La diferencia esencial tiene que ver con que la $\mathrm{MD}$ es en realidad un modelo morfemático, con la dificultad inherente a todos los modelos que mezclan entidades sintácticas y entidades morfológicas. En el modelo presentado la sintaxis no opera con morfemas, sino exclusivamente con categorías sintácticas, incorporando los conceptos a través del ensamble de categorización. No obstante, la teoría morfológica implicada en dicho modelo es realizacional, en el sentido de que la morfología opera con fragmentos de derivación para producir o seleccionar formas del paradigma. Así, las palabras nube y nuboso están relacionadas, pero no derivacionalmente. Las dos son construcciones sobre el mismo concepto, aunque ciertamente no expresan el mismo concepto, en virtud de la derivación de cada una.

Como dice Williams (2007), lo característico de la MD es que los nudos terminales de los árboles no son palabras, sino morfemas, de manera que en dicho modelo las oraciones están formadas directamente con morfemas sin intervención de la noción de palabra (Williams 2007: 359). El modelo esbozado en estas páginas reivindica la relevancia de las palabras, pero no como unidades léxicas, sino como fragmentos de deri- 
vación vinculados a la fonología. La cuestión es hasta qué punto esa concepción de la palabra realmente explica aquellos aspectos que sustentan la hipótesis lexicista y a la vez permite prescindir de la misma. Williams (2007: 356) los sumariza de la siguiente manera:

a. The word system provides input objects to the phrasal system (asymmetry)

b. The objects of the word system are atomic in the phrasal system (atomicity)

c. The word system and the phrasal system can have different internal syntax (internal constitution)

d. The word system is subject to a condition of 'inmmediate resolution' (locality or word-internal atomicity) which is irrelevant in the phrasal system.

Afirma Williams que, o bien los hechos de (14) no son tales, o bien "we need something like the Lexical Hypothesis» (2007: 356). El modelo antilexicista que hemos propuesto sugiere que (14a) y (14c) realmente no son hechos incuestionables al poner de manifiesto la continuidad entre la sintaxis léxica y la sintaxis frasal. Tanto (14b) como (14d), en la medida en que sean distintos, se explicarían de manera alternativa a la explicación basada en la hipótesis lexicista, precisamente a través de la hipótesis de que las palabras son fragmentos de derivación cuyos núcleos se materializan inmediatamente. La materialización (inserción léxica) hace esas derivaciones opacas a otros procesos de movimiento de núcleo o incorporación, dando cuenta de la atomicidad léxica.

Las teorías lexicistas, como las teorías tradicionales basadas en la morfología indoeuropea, parten de las palabras y las proyectan en la sintaxis. Las teorías sintactistas deshacen la palabra, arrinconándola como epifenómeno y se centran en la construcción sintáctica de las oraciones a base de morfemas. El modelo presentado pretende combinar lo mejor de las dos tradiciones: por una parte la palabra se construye sintácticamente, es sintaxis, pero por otra parte, la palabra (aunque solo como forma fonológica/morfológica) existe independientemente, como un sistema de materialización y linealización de estructuras sintácticas.

Las palabras, pues, no existen como unidades léxicas almacenadas y previas a la sintaxis, sino que existen como formas fonológicas memorizadas y organizadas en paradigmas (más o menos sistemáticos y extensos). La sintaxis forma derivaciones empleando categorías funcionales y conceptos; parte esencial de la derivación es la categorización (lexicalización) 
de los conceptos, momento en el que se accede al componente fonológico y se crea o se identifica una palabra, esto es, un fragmento de derivación asociado a una forma fonológica o a un paradigma.

\section{Epílogo especulativo}

Es importante notar que en nuestro modelo las palabras no duplican a los conceptos extralingüísticos, no los copian ni los traducen, sino que simplemente los computan sintácticamente. Cuando alguien ve un libro, suponemos que accede a su concepto de libro, no al significado de la palabra libro (que asumimos que no existe). Por tanto, cuando en vez de ver un libro oímos la palabra libro, cabe seguir suponiendo que accedemos al concepto de libro, y no al significado de esa palabra. Pero cuando usamos el lenguaje no accedemos al concepto directamente, sino a través de la estructura sintáctica de la palabra libro. Podría decirse entonces que la sintaxis contribuye a la creación de un sustituto de la representación perceptiva del propio libro. El lenguaje en realidad construye sustitutos de las percepciones y de las emociones. La oración El hombre que viste ayer proporciona complejas y sofisticadas instrucciones para sustituir en el cerebro del interlocutor la percepción pasada de tal hombre. El lenguaje permite al cerebro experimentar percepciones y estados que no son reales, y lo interesante es que lo hace a través de operaciones que emulan las operaciones perceptivas. Dichas operaciones están condicionadas por las categorías funcionales, incluyendo las básicas $(A, N, V)$ que orientan los conceptos como eventos, propiedades, objetos, etc., y las demás, como el tiempo, la cantidad, la definitud, etc. Las personas acumulan conceptos porque es lo único que entiende su cerebro y cuando piensan, lo que hacen es manipular conceptos, relacionarlos, compararlos, posicionarse respecto a ellos. Pero para ello no hacen falta más conceptos, sino categorías funcionales, sintaxis. Las personas normalmente no quieren comunicar conceptos, sino que quieren que los demás reproduzcan en sus cerebros las operaciones que hacemos con los conceptos; queremos comunicar las relaciones entre conceptos, cómo los percibimos, cómo los entendemos, cómo nos emocionan. Y por ello las palabras no se corresponden con conceptos, sino con computaciones sintácticas. Cuando le decimos a alguien He visto el libro no queremos hablar del concepto de libro ni del concepto de ver (solo los 
filósofos lo hacen), lo que queremos es reproducir en su mente la escena de nosotros mismos viendo el libro, como si ese alguien estuviera presente. La única estrategia para ello es computar conceptos con categorías funcionales y traducir fonológicamente esos cómputos. Seleccionamos los conceptos más afines a los objetos y eventos implicados y construimos estructuras empleando categorías funcionales que aporten la emulación suficiente de los estímulos perceptivos que habría tenido el oyente de estar presente, esto es, intentamos que tenga una sensación parecida a la que habría tenido de ser testigo directo del evento modificando sus propios conceptos. Ello explica que cuando entendemos la palabra andar, son los circuitos cerebrales que empleamos para andar realmente los que se activan en nosotros. Porque la palabra andar, además de su sintaxis, incluye al propio "concepto" motor de andar, no un significado o un signo del mismo.

Antes se afirmaba que una lengua que no se usara para hablar no requeriría palabras, sino que se bastaría con conceptos y sintaxis. Pero una lengua así solo daría acceso a nuestros propios conceptos y a nuestras propias experiencias. Cabe pensar que tendríamos una rica vida interior, pero casi seguro que sería diferente. Al conectar el sistema C-I con el sistema $\mathrm{S}-\mathrm{M}$ asociamos una computación (que incluye conceptos e instrucciones para interpretarlos) a una forma fonológica. Esto se puede interpretar como un sistema adicional de memoria. En el proceso de derivación asociamos un fragmento de computación (libro) a una forma fonológica. Eso no es un concepto, sino que es, por así decirlo, un punto de vista sobre un concepto, son instrucciones para computar un concepto. La computación mínima (la palabra) entra en un sistema de memoria nuevo: la forma fonológica. La forma fonológica es una traducción de la computación sintáctica en el sistema motor. Ello permite almacenar y reutilizar computaciones y aprender las computaciones de los demás. Cuando aprendemos una lengua aprendemos a hacer computaciones de conceptos a partir de lo que han hecho otros. Y eso también marca la diferencia.

\section{Bibliografía}

Ackema, P., y A. Neeleman (2007): «Morphology $\neq$ Syntax», en Ramchand y Reiss (eds.), The Oxford Handbook of Linguistic Interfaces, Oxford, Oxford University Press: 324-352. 
Anderson, S. R. (1992): A-Morphous Morphology, Cambridge, Cambridge University Press.

BAKER, M. (1988): Incorporation, Chicago, University of Chicago Press.

- (2003): Lexical Categories, Cambridge, Cambridge University Press.

Boeckx, C. (2008): Bare Syntax, Oxford, Oxford University Press.

- (2010): Language in Cognition. Uncovering Mental Structures and the Rules Behind Them, Oxford, Wiley-Balckwell.

Borer, H. (2005a): Structuring Sense. Vol. I: In Name Only, Oxford, Oxford University Press.

- (2005b): Structuring Sense. Vol. II: The Normal Course of Events, Oxford, Oxford University Press.

Bursill-HalL, G. L. (1971): Speculative grammars of the middle ages. The doctrine of partes orationis of the modistae, La Haya, Mouton.

Chomsky, N. (1995): The Minimalist Program, Cambridge MA, The MIT Press.

- (2005): «On Phases», Manuscrito, MIT.

Embick, D., y R. Noyer (2007): «Distributed Morphology and the SyntaxMorphology Interface», en Ramchand y Reiss (eds.), The Oxford Handbook of Linguistic Interfaces, Oxford, Oxford University Press: 289-324.

FÁBreGaS, A. (2005): The Definition of the Grammatical Category in a Syntactically Oriented Morphology: The Case of Nouns and Adjectives, Tesis doctoral inédita, Universidad Autónoma de Madrid.

- (2009): «Evidence for multidominance in Spanish agentive nominalizations», Manuscrito, Universidad de Tromso.

Hale, K., y S. J. Keyser (2002): Prolegomenon to a Theory of Argument Structure, Cambridge MA, The MIT Press.

Hauser, M. D., N. Chomsky y W. T. Fitch (2002): «The Faculty of Language: What Is It, Who Has It, and How It Evolve?», Science, 298: 15691579.

Hopper, P., y S. Thompson (1984): «The Discourse Basis for Lexical Categories in Universal Grammar», Language, 60: 703-752.

Hurford, J. R. (2007): The Origins of Meaning, Oxford, Oxford University Press.

JACKENDOFF, R. (1975): «Morphological and Semantic Regularities in the Lexicon", Language, 51-3: 639-671.

Julien, M. (2002): Syntactic Heads and Word Formation, Oxford, Oxford University Press.

- (2007): «On the Relation between Morphology and Syntax», en Ramchand y Reiss (eds.), The Oxford Handbook of Linguistic Interfaces, Oxford, Oxford University Press: 209-238. 
Kratzer, A. (1996): «Severing the external argument from its verb», en J. Rooryck y L. Zaring (eds.), Phrase Structure and the Lexicon, Dordrecht, Kluwer: 109-137.

MacDonald, J. D. (2008): The Syntactic Nature of Inner Aspect. A minimalist Perspective, Ámsterdam, John Benjamins.

MarantZ, A. (1997): «No Scape from Syntax», University of Pennsylvania Working Papers in Linguistics, 4-2: 201-225.

- (2000): «Reconstructing the Lexical Domain with a Single Generative Engine», Manuscrito, MIT.

OTT, D. (2009): «The Evolution of I-Language: Lexicalization as the Key Evolutionary Novelty", Biolinguistics, 3.2-3: 255-269.

Ramchand, G. (2008): Verb Meaning and the Lexicon. A First Phase Syntax, Cambridge, Cambridge University Press.

- y C. ReISS (eds.) (2007): The Oxford Handbook of Linguistic Interfaces, Oxford, Oxford University Press.

Saussure, F. (1916): Cours de linguistique générale, París, Payot (Citado por la edición de T. de Mauro y traducción de A. Alonso, Curso de linguíistica general, Madrid, Alianza, 1983).

Stewart, T., y G. STUMP (2007): «Paradigm Function Morphology and the Morphology-Syntax Interface», en Ramchand y Reiss (eds.), The Oxford Handbook of Linguistic Interfaces, Oxford, Oxford University Press: 383421.

STUMP, G. (2001): Inflectional Morphology, Cambridge, Cambridge University Press.

Williams, E. (2007): «Dumping Lexicalism», en Ramchand y Reiss (eds.), The Oxford Handbook of Linguistic Interfaces, Oxford, Oxford University Press: 353-381. 


\title{
HACIA UN ANÁLISIS SINTÁCTICO DEL GÉNERO EN ESPAÑOL
}

\author{
ANTONIO FÁbregas ALFARO \\ (Universitetet i Tromsoe) \\ ISABEL PÉREZ JIMÉNEZ \\ (CSIC-CCHS)
}

\section{La posible autonomía de la morfología}

Uno de los debates abiertos en la gramática y la lingüística actuales es el que atañe a la relación que se establece entre la morfología y la sintaxis. Más en particular, durante los últimos cuarenta años se ha intentado, desde distintas perspectivas y tradiciones gramaticales, determinar si existe un nivel gramatical independiente, llamado morfología, con primitivos y principios propios, o si este puede ser reducido a otro nivel de análisis gramatical, en concreto, a la sintaxis (McCawley 1968, Chomsky 1970, DiSciullo y Williams 1987, Lieber 1992, Halle y Marantz 1993, Emonds 2000, Borer 2005, Ramchand 2008, entre muchos otros). Incluso en las últimas teorías lexicistas, que abogan por la existencia de un módulo morfológico independiente de formación de palabras que alimenta a la sintaxis (Ackema y Neeleman 2004, Williams 2007), se observa que existe acuerdo general en que la sintaxis y la morfología poseen un lenguaje compartido con al menos los siguientes elementos comunes: 
(1) Lenguaje compartido por la morfología y la sintaxis.

a. Un vocabulario mínimo de categorías gramaticales y rasgos.

b. Un conjunto de reglas de construcción de estructuras.

c. Un conjunto de restricciones fonológicas y semánticas.

El vocabulario compartido entre sintaxis y morfología (categorías léxicas como nombre, adjetivo y verbo, posiblemente también preposición, y rasgos como 'animado', 'plural' o 'locativo', suponiendo que estos no sean reductibles a categorías de otro tipo) garantiza que, si se asume la división entre estos dos módulos, el resultado de un proceso morfológico sea comprensible para la sintaxis. Así por ejemplo, la sintaxis podrá entender que gana-dor es un sustantivo que no puede tomar complementos agentivos, porque el sufijo -dor incluido en él ya expresa esta noción. El conjunto de reglas estructurales que comparten sintaxis y morfología implica que la ramificación ternaria sea, como mucho, dudosa tanto en uno como en otro componente, y que la formación de palabras también manifieste sensibilidad por la distinción entre complementos y especificadores, por ejemplo, en la incorporación y en la estructura de los compuestos. En último lugar, tanto en el componente sintáctico como en el morfológico operan restricciones interpretativas compartidas y el resultado de los procesos morfológicos y sintácticos — de nuevo, suponiendo que sean diferentes - tiene que someterse por igual a principios prosódicos y segmentales. Todas estas coincidencias sugieren con fuerza que la sintaxis y la morfología no deben considerarse como módulos separados. Sin embargo, la razón de que exista el debate arriba citado es que, durante estos cuarenta años, se han identificado otros puntos, no menos llamativos, de divergencia entre estos dos niveles.

(2) Lenguaje específico de la morfología.

a. Dominios cíclicos a los que la sintaxis no tiene acceso.

b. Diferencias no predecibles en los rasgos que componen las piezas léxicas.

c. Clases de conjugación y declinación impredecibles para la sintaxis.

En la morfología, el dominio cíclico relevante es lo que algunos autores han llamado la palabra morfológica (DiSciullo y Williams 1987, con variaciones en Williams 2007). La existencia de este dominio, opaco para la sintaxis, explica, por ejemplo, que no sea posible referirse a un constituyente interno de un compuesto mediante un pronombre (??Este [saca[corchos $\left.{ }_{i}\right]$ los $_{i}$ saca muy bien). En segundo lugar, los rasgos que com- 
ponen las piezas léxicas son distintos en cada lengua, hecho que no puede predecirse. Piezas léxicas con significado similar poseen en distintas lenguas rasgos distintos, por ejemplo, en español sol es un sustantivo de género masculino, mientras que en alemán Sonne es un sustantivo femenino. Igualmente, dentro de una misma lengua, sustantivos semánticamente similares poseen distinto género (baldalestante). El género, por lo tanto, puede concebirse como una propiedad idiosincrásica de cada sustantivo y parece ser un buen candidato para ser un rasgo listado en el Léxico de forma individual para cada pieza del vocabulario.

Por último, la existencia de clases de conjugación y de declinación es un argumento de gran fuerza empírica a favor de considerar a la morfología como componente autónomo. Si nos concentramos en una lengua como el español o el italiano, observamos inmediatamente que la mayor parte de los sustantivos poseen un morfema terminal átono que asigna la palabra a una clase particular de declinación —-más claramente en italiano- (3). Como observó Harris (1991), este morfema que representa la clase de declinación no determina ni el género gramatical en que concuerda el sustantivo (pese a que pueda haber correlaciones que aparecen con frecuencia entre marca de palabra y género), ni tampoco su sexo biológico, ya que aparece también en los sustantivos no animados, donde esa noción no tiene sentido (4).
a. It. ragazz-a (sg.), ragazz-e (pl.)
b. It. ragazz-o (sg.), ragazz-i (pl.)
c. Esp. niñ-o, niñ-o-s
a. un-a man-o negr-a
b. est-e problem-a económic-o

La existencia de rasgos o propiedades idiosincrásicos en los sustantivos y otras clases de palabras no constituye en sí misma un argumento a favor de considerar la morfología como un componente autónomo de la gramática, pero sí lo es el hecho de que esos rasgos y propiedades no parezcan ser predecibles a partir de otras propiedades sintácticas, fonológicas o semánticas. Esto podría indicar que esos rasgos o esas propiedades han de tratarse como requisitos puramente morfológicos de una lengua concreta. Nótese que, desde este punto de vista, morfológico quiere decir 'ni sintáctico, ni fonológico, ni semántico'. En este sentido, la marca de palabra es una propiedad puramente morfológica puesto que no se han 
identificado razones fonológicas, semánticas o sintácticas que expliquen su existencia o la distribución de las distintas declinaciones.

En este trabajo intentaremos responder a la pregunta de hasta qué punto el género puede considerarse una propiedad sintáctica o una propiedad morfológica en el sentido recién indicado. Es cierto que el género es una propiedad que se asocia con los sustantivos $-\mathrm{y}$, como veremos, también con estructuras nominales más amplias - de forma, en general, idiosincrásica y no predecible. Sin embargo, propondremos que esto no impide que el género pueda considerarse como una propiedad ubicada en un nudo sintáctico independiente dentro de la estructura del sintagma nominal completo (del sintagma determinante [SD]), de forma paralela al número. Más aún, defenderemos que el género es una propiedad que aparece dentro del sintagma determinante en dos proyecciones sintácticas distintas entre las que se producen interacciones (Fábregas y Pérez Jiménez 2008). Es esta doble presencia dentro del sintagma determinante la que permite explicar algunas de las diferencias que existen entre género y número.

Este trabajo pretende establecer las bases para un tratamiento del género como una propiedad sintáctica que está doblemente presente en la estructura funcional del sintagma determinante. En la medida en que, según argumentaremos, el género puede considerarse como una propiedad de los sintagmas completos, nuestra propuesta apoya la idea construccionista de que las propiedades que se habían entendido tradicionalmente como léxicas se obtienen en el curso de la derivación sintáctica.

El artículo se estructura de la siguiente manera. En el apartado segundo se describirán algunas de las propiedades del género y se hará explícito en qué manera el género se comporta de manera distinta a una propiedad del sustantivo considerada generalmente como sintáctica, el número. En este apartado introduciremos lo que constituirá la base empírica de este trabajo, las "discordancias de género internas al sintagma nominal». En el apartado tercero se mostrará como la propuesta de Fábregas y Pérez Jiménez (2008) más arriba mencionada puede explicar las propiedades del género que se habrán descrito, sin necesidad de postular que el género es una propiedad exclusivamente léxica de los sustantivos. En el apartado cuarto se harán explícitas las conclusiones. 


\section{Algunas propiedades del género en español}

Se acepta de manera general, ya al menos desde Hockett (1958) y Greenberg (1978), que el valor de género de un sustantivo está fijado de manera inherente (con algunas excepciones, por ejemplo, en el caso de los sustantivos animados), mientras que su valor de número permite una alternancia sistemática entre dos o más valores. Así, parece adecuado en el lenguaje corriente decir que un sustantivo está en singular o en plural (o dual, trial y paucal, según las lenguas), pero en cambio que es masculino o femenino (o neutro, o que pertenece a una clase de palabras determinada, según las lenguas). En términos de Chomsky (1995: 235-241), el género sería un rasgo intrínseco del sustantivo, inherentemente asociado a él y sin variación posible en su valor, mientras que el número sería un rasgo opcional, cuyo valor puede variar en virtud del contexto sintáctico en que el sustantivo aparece. Lo que esta concepción implica para algunos modelos sintácticos recientes en los que las propiedades morfosintácticas de las palabras se conciben como nudos sintácticos independientes - fundamentalmente cuando se trata de propiedades interpretables para el componente semántico del lenguaje- es que el número se considera una información gramatical que no se asocia exclusivamente al sustantivo en sí, sino a toda la proyección nominal en que este aparece. El número se proyecta, en estos modelos, en un nudo sintáctico independiente dentro de la estructura del sintagma nominal $(\mathrm{SNum})^{1}$ (véase Ritter 1991, Alexiadou et al. 2007: cap. 3, entre otros, para argumentos a favor de esta propuesta). Por el contrario, el género se concibe como una propiedad idiosincrásica de los sustantivos (un 'rasgo' del sustantivo) que se codifica en su entrada léxica y que no encabeza ninguna proyección sintáctica funcional dentro de la estructura nominal extendida (dicho de otro modo, el género es una propiedad del «lexema» o «raíz» del sustantivo — véase Ralli 2003 para una implementación reciente de esta idea desde una perspectiva lexicista—).

1 Pese a que en algunas lenguas el número se puede codificar mediante lexemas alomórficos (mouse 'ratón', mice 'ratones'), o puede ser una propiedad intrínseca de algunas piezas léxicas: pluralia tantum. Sobre estos sustantivos en los que el valor de número parecería impuesto léxicamente, véase Fábregas (2005), donde se argumenta que en ellos el número está impuesto por su valor semántico — ya que denotan objetos dobles, agrupaciones o masas- Volveremos sobre esto más adelante. 
Hay distintas razones por las que el género se ha considerado una propiedad no sintáctica de un elemento léxico (un sustantivo) frente a la visión alternativa que lo podría considerar una propiedad de un sintagma nominal completo, y por tanto de un objeto construido mediante la sintaxis, como se suele pensar en el caso del número. En primer lugar, como acabamos de mencionar, los sustantivos admiten variación en número dependiendo de propiedades contextuales, mientras que la variación en género está mucho más restringida (y no tiene una motivación clara; por ejemplo, el sustantivo criatura carece de ella mientras que el sustantivo niño la posee). En segundo lugar, el número es una propiedad gramatical con repercusiones para la sintaxis, más allá de la concordancia con determinantes y adjetivos. Por ejemplo, en contextos de elipsis nominal, las discordancias de número entre el sustantivo antecedente y el sustantivo elidido son posibles y pueden recuperarse (los trajes de María y el de Juan). Por el contrario, las discordancias de género no se permiten en contextos de elipsis (*el hijo de María y la de Juan).

En los siguientes apartados analizaremos las semejanzas y diferencias que existen entre la propiedad género y la propiedad número y concluiremos que, si bien existen diferencias entre ambas categorías, el género puede concebirse, en paralelo al número, como una propiedad del sintagma nominal completo y que encabeza su propia proyección sintáctica.

\subsection{El género como propiedad de los sintagmas}

Como se ha señalado más arriba, es habitual entender el género como una propiedad de los sustantivos individuales. Así, una palabra como balda es de género femenino y una palabra como estante es masculina. El género que cada una posee es una propiedad idiosincrásica que no influye en absoluto en los contextos sintácticos en que pueden aparecer, si bien se trata de una propiedad que participa, al igual que el número, en procesos sintácticos como la concordancia. Así, por ejemplo, *Quiero comprar estante es agramatical de igual forma que lo es *Quiero comprar balda. Por el contrario, el número parece ser una propiedad que trasciende al sustantivo en sí, e influye decisivamente en los contextos sintácticos en que este puede aparecer: Quiero comprar \{estantes/baldas\}. Este tipo de diferencia ha llevado a pensar que el género es un rasgo del 
sustantivo mientras que el número es una propiedad sintáctica del sintagma determinante (recogida en la forma de un núcleo que encabeza un sintagma independiente, el SNum). Si bien ha de reconocerse la diferencia que se ha señalado entre el comportamiento del género y del número, es igualmente cierto que existen casos que muestran que el valor del género no depende exclusivamente del sustantivo, sino de una estructura sintáctica mayor en la que el sustantivo se encuadra.

Consideremos los ejemplos de (5) y (6), donde aparece el sustantivo cabeza. Este sustantivo, de género femenino (Me duele la cabeza), se comporta en ciertas expresiones (como en cabeza de familia) para algunos hablantes como masculino (5), y para otros como sustantivo común en cuanto al género (6).

(5) El cabeza de familia de los López es \{tacaño/tacaña\}.

(6) $\quad\{\mathrm{El} / \mathrm{la}\}$ cabeza de familia de los López es $\{$ tacaño/tacaña\}.

La misma alternancia se encuentra en casos como cabeza de lista, cabeza de cartel, cabeza de pelotón, etc. Este tipo de casos han sido habitualmente clasificados como 'locuciones nominales' o 'compuestos sintagmáticos'. Una de las razones por las que no consideramos que sea posible clasificar estos casos como locuciones es que el complemento preposicional que acompaña al sustantivo no está fijado: Juan es el cabeza de esta familia; El cabeza de la familia a la que recibimos ayer ha remitido este escrito al juez; El anterior cabeza de familia. No es posible, por las mismas razones, que esta construcción sea un compuesto sintagmático, ya que si lo fuera tendríamos material sintáctico regular y productivo en el interior de un compuesto —artículos, posesivos, adjetivos, oraciones de relativo, etc.—, lo cual es imposible conforme a la Hipótesis de la Integridad Léxica (Lapointe 1980). ${ }^{2}$ Asimismo, la misma noción de compuesto sintagmático es proble-

2 Alternativamente, si se comprobara que la Hipótesis de la Integridad Léxica no es correcta, no podríamos tratar estos casos como compuestos sintagmáticos, pues en tal caso los compuestos serían reanalizados como sintagmas. Nótese también que, aun si se aceptara que la morfología opera con construcciones y no con unidades (como se propone en la Gramática de Construcciones, Goldberg 1995), sería necesario establecer una diferencia entre las construcciones que admiten especificación mediante otras construcciones (como nuestro caso) y las que no la admiten (locuciones y compuestos prototípicos). 
mática y los morfólogos admiten de forma explícita que es un término descriptivo más que un concepto explicativo (Val Álvaro 1999).

Desde un punto de vista pre-teórico, los hechos parecen claros: en los ejemplos mencionados, cabeza se toma como un sustantivo relacional que designa la entidad más importante dentro de un grupo o una colectividad y exige, por su semántica, un sintagma preposicional obligatorio. En este caso es un sustantivo masculino (común para otros hablantes). Nótese que aquí no es posible hablar de personificación o metonimia en sentido estricto (Nunberg 1978), ya que el sustantivo para algunos hablantes es masculino incluso si se refiere a un referente femenino - en efecto, no parece anormal decir El cabeza de lista volverá a ser Luisa Fernanda Rudi-.

¿Cuál es la relevancia de estos datos para una teoría del género? Creemos que estos hechos pueden tomarse como evidencia para pensar que el género puede entenderse como una propiedad implementable en la sintaxis mediante un núcleo sintáctico que forma parte del sintagma nominal, al que llamaremos aquí, siguiendo a Borer (2005), Clasificador (SClasificador). Este núcleo - debido a su naturaleza sintáctica — codifica el valor de género que pueden tener estructuras sintagmáticas como cabeza de familia, etc. Así, casos como cabeza de chorlito, cabeza de familia, etc., son estructuras, sintagmas, con un valor de género, valor que vendría codificado en una proyección independiente, el SClasificador. El mismo análisis, por tanto se extenderá fácilmente a los sustantivos como niño/niña, y otros que permiten alternancia de género (barco/barca), y también a toda locución nominal. La intuición que intentamos captar es que niño/niña o cabeza $a_{\text {fem }} /$ cabeza $a_{\text {masc }}$ (de familia) son el mismo sustantivo pero en sintagmas diferentes, igual que casalcasas pueden considerarse el mismo sustantivo pero en estructuras sintácticas diferentes. En nuestra propuesta, ese es el análisis para el género de todos los sustantivos, admitiendo que para el resto de casos existe una relación idiosincrásica entre el valor del Clasificador y el nombre o estructura nominal. ${ }^{3}$

3 Nótese que esto tiene interés con respecto a la posición de los SP seleccionados por los sustantivos de semántica relacional, ya que implica que estos están presentes ya cuando se introduce el género del sustantivo. Con respecto a la estructura que presentaremos en la sección tercera de este mismo trabajo, estos hechos empíricos implican que los SP de los sustantivos relacionales están en una posición muy baja de la estructura, seleccionados como argumentos internos de la raíz:

$[\mathrm{N}$ [Clasificador $[\sqrt{ }[(\mathrm{P}) \mathrm{SN}]]]]$. 


\subsection{Discordancias de género en el interior del sintagma nominal}

En el apartado anterior hemos concluido que el género puede considerarse como una propiedad codificada en una proyección sintáctica independiente dentro de la estructura del sintagma determinante. Consideremos ahora los ejemplos de (7). En (7) aparecen casos de secuencias también consideradas habitualmente 'locuciones' o 'compuestos sintagmáticos' donde aparece un adjetivo acompañando al nombre. El adjetivo concuerda en femenino con el sustantivo.
a. mala cabeza
b. cabeza hueca
c. cabeza rapada
d. mala bestia
e. hormiguita hacendosa
f. picha loca

También en estos casos creemos que debe rechazarse el análisis como locuciones nominales o compuestos sintagmáticos. Además de las razones apuntadas ya y del hecho de que estos son términos descriptivos usados en la tradición más que conceptos explicativos, existen otras razones para descartar ese análisis. La primera de ellas es que la combinación de los sustantivos y los adjetivos en estos casos no tiene las propiedades semánticas de las locuciones - es decir, no se da un significado demotivado-. Por ejemplo, el significado de bestia es el mismo en la combinación mala bestia que en los casos en que el sustantivo aparece sin adjetivos — es decir, 'persona ruda, de poca inteligencia, que ejerce la fuerza bruta'- Otra propiedad de las locuciones es que no admiten la sustitución de sus componentes por otros semejantes, salvo que se dé cambio de significado. Esto no sucede tampoco en nuestro caso. El significado de mala bestia no es diferente del de, por ejemplo, bestia parda; si consideráramos cualquiera de ellos una locución deberíamos considerar también que el resto son tales, con el resultado de que se multiplicarían innecesariamente locuciones con significado muy próximo en español. Un caso semejante, agravado por el mayor número de adjetivos que pueden aparecer en la construcción, es el de picha loca (7f), donde loca puede ser sustituido por brava, floja, fría, muerta, corta, inquieta, triste y otros muchos, como se puede comprobar en los corpus. El problema reproduce lo que hemos observado previamente en el caso de los sintagmas preposicionales que se combinan con cabeza. 
Analizar estas estructuras como compuestos sintagmáticos —en la medida en que se entiende esta categoría - tiene todos los problemas que otros autores han observado en estos casos (véase Val Álvaro 1999): entre ellos destaca el hecho de que estos compuestos serían objetos morfológicos en cuyo interior se debe admitir una operación sintáctica, la concordancia, lo cual contradice las predicciones de la Hipótesis de la Integridad Léxica. Más bien parece que en estos casos nos encontramos ante un caso de colocación -Bosque 2005- que permite la alternancia de unos pocos adjetivos; las colocaciones, frente a las locuciones y los compuestos, se construyen en la sintaxis mediante reglas sintácticas productivas.

Lo que nos interesa destacar de los ejemplos de (7) es que, cuando aparecen dentro de un SD completo, el determinante puede tener género masculino (8).
a. un mala cabeza
b. un cabeza hueca
c. el cabeza rapada
d. este homiguita hacendosa

Dicho de otro modo, lo que estos ejemplos muestran es que hay dos valores de género conviviendo en el mismo sintagma; uno manifestado en la concordancia del núcleo nominal con el adjetivo, y otro manifestado en el artículo. Nos referiremos a este tipo de casos como discordancias de género internas al sintagma nominal.

En contraste con estas discordancias de género internas al sintagma nominal, no es posible en español la discordancia de número entre el determinante y el sustantivo, incluso cuando la semántica podría en principio hacerla posible — por ejemplo, porque el sustantivo sea colectivo y denote una pluralidad- (9). Esta propiedad se interpreta frecuentemente como una constatación de que el número dentro de un sintagma nominal es una propiedad de todo el conjunto - no solo del sustantivo que lo encabeza- y, como tal, debe estar respetada en todas las proyecciones sintácticas del sustantivo. Por ello, cuando se construye el sintagma determinante, el valor de número debe ser el mismo que posea el sustantivo. ${ }^{4}$

4 Existen también discordancias de género y de número externas al sintagma nominal, que no trataremos aquí. En casos como Su majestad está muy cansado, el nombre que aparece en el SD sujeto es femenino pero el atributo tiene género masculino. En 
a. *Este pantalones / estos pantalones / este pantalón

b. *Estos ejército / este ejército

Lo que los ejemplos de (8) indican, por tanto, es que dentro de la proyección nominal hay dos valores de género y no uno solo. Nótese que las discordancias del tipo señalado no se dan solo con sustantivos como los de (8), sino que se obtienen de forma general en español con ciertos sustantivos referidos a animales y cosas que pueden ser aplicados a personas si se interpretan de forma figurada; en tales casos, admiten tanto el masculino como el femenino (10), dependiendo exclusivamente del referente al que aludan (11). ${ }^{5}$
a. Esta rata / este rata $($ rata $=$ tacaño $)$
b. Esta bestia / este bestia (bestia = persona burda y poco educada)
c. Este plasta $/$ esta plasta $($ plasta $=$ persona pesada $)$
a. $\{$ Este / *esta $\}$ plasta es mi hermano.
b. $\{$ Esta / *este\} plasta es mi hermana.

Obsérvese, en relación con los ejemplos de (8) y (10), que en la misma construcción pueden coexistir adjetivos que concuerdan en el género del sustantivo con otros que concuerdan en el género que muestra el determinante. En (12) el adjetivo prenominal concuerda en femenino - el género que posee el sustantivo bestia como tal pieza léxica del espa-

\footnotetext{
ejemplos como Esa gente nos están masacrando, el SD sujeto tiene número singular, pero el verbo aparece en plural. Para un tratamiento general de este tipo de discordancias basado en la existencia de dos tipos de rasgos nominales en el interior del SN, véase Wechsler y Zlati (2000) (no obstante, esa dicotomía de rasgos se entiende de forma distinta a como la entendemos en Fábregas y Pérez Jiménez 2008 y en este trabajo). En Demonte, Fernández Alcalde y Pérez Jiménez (2009) se analizan en concreto las discordancias de número que se observan en español en casos como los arriba mencionados y en estructuras como La osadía y temeridad traen problemas, también sobre la base de que existen dos tipos de rasgos nominales en el SD.

5 Es importante señalar, al mismo tiempo, que para los ejemplos tratados en esta sección, como el cabeza rapada, el cabeza hueca, este rata, no puede proponerse un análisis donde habría un nombre nulo masculino que impondría la concordancia al determinante y del que los sustantivos o estructuras nominales cabeza rapada, cabeza hueca o rata serían aposiciones. Esto es, no puede proponerse el siguiente análisis: $\left[\operatorname{Det}_{\mathrm{MASC}}[\mathrm{N}]_{\mathrm{MASC}}[\mathrm{N}]\right]$. Nótese que cuando el artículo indefinido aparece con estructuras apositivas como un poeta pintor, un coche escoba, etc., adopta, en contextos de elisión nominal, la forma uno, que indica la presencia del $\mathrm{N}$ elidido (Un poeta pintor y uno filósofo; Un coche escoba y uno cabeza de pelotón), cosa que no sucede en los casos que nos ocupan.
} 
ñol_ y el posnominal, en masculino —el género referencial de todo el sintagma exhibido en el determinante-.

(12) Juan es un mala bestia asqueroso.

Por tanto, en la misma construcción pueden coexistir dos géneros, como muestra la concordancia. Defenderemos que estas discordancias, y el distinto comportamiento de la categoría número, se explican si dentro del sintagma determinante (esto es, de la proyección nominal completa que incluye el determinante) existen dos nudos sintácticos independientes que albergan información de género y que, en ciertas ocasiones muy restringidas, pueden divergir en su contenido. Una, el SClasificador, al que ya hemos aludido en la sección anterior. Otra, más alta en la jerarquía funcional del sintagma determinante, que denominaremos SGénero.

Para terminar esta sección, queremos señalar que los nombres y estructuras nominales que aquí hemos considerado se diferencian de sustantivos como artista, testigo, etc., en que los sustantivos como rata, bestia, etc., pueden ser claramente clasificados como sustantivos femeninos mientras que para sustantivos como artista o testigo no puede afirmarse que tengan un género determinado. Los nombres comunes como artista admiten la combinación con el artículo masculino y femenino por igual y, asimismo, admiten adjetivos que exhiben siempre el valor de género del determinante.

(13) a. el artista incomprendido / la artista incomprendida

b. el colega americano / la colega americana

c. el testigo ciego / la testigo ciega

3. El género en la estructura sintáctica del sintagma nominal

En esta sección presentaremos nuestro análisis, según el cual, como ya hemos anticipado en las secciones anteriores, (i) el género es una proyección sintáctica dentro de la estructura del sintagma determinante, y (ii) existen dos proyecciones de género en el interior del sintagma determinante, el SClasificador y el SGénero. Así, defenderemos que lo que se llama resumidamente 'género' en el análisis gramatical corresponde en 
realidad a dos nudos sintácticos diferentes que interactúan entre sí. Según nuestra propuesta de análisis, las asimetrías entre el comportamiento del género y el de otras propiedades gramaticales, como el número, no justifican que el género deba considerarse una propiedad estrictamente léxica de los sustantivos, o una propiedad morfológica en el sentido que lo es la marca de declinación (recuérdese apartado 1). Nuestro análisis continuará las ideas expuestas en Fábregas y Pérez Jiménez (2008) y se encuadra en la línea de otros trabajos anteriores donde se defiende la existencia de una proyección sintáctica asociada con el género (Picallo 1991, Di Domenico 1997 — para aquellas instanciaciones del género que son interpretables semánticamente-, Bernstein 1993 — donde se defiende una proyección que aloja el género y la marca de palabra-). Contra la idea de que el género sea una proyección sintáctica independiente argumentan explícitamente Panagiotidis (2002), Alexiadou (2004), entre otros, aunque sus argumentos — según los entendemos — van más bien encaminados a defender que la marca de palabra no es un reflejo de los rasgos sintácticos de género; no obstante, la propuesta de que el género es una propiedad de las raíces o de los Ns encuentra problemas en el hecho de que un mismo sustantivo exhiba dos o más géneros sin demotivación del significado (niño-niña).

\subsection{Los dos géneros del dominio nominal}

La intuición fundamental de nuestra propuesta es, como acabamos de señalar, que lo que descriptivamente llamamos género es en realidad una simplificación que reúne en un solo término dos facetas del comportamiento gramatical de los grupos nominales. Por una parte, con 'género' nos estamos refiriendo a una propiedad que poseen los sustantivos (o estructuras nominales, cf. cabeza de lista) en español, que a menudo - pero no siempre- se manifiesta en una marca morfológica, que en algunos casos se traduce en una noción determinada en el componente semántico, y cuyo valor, en general, parece estar seleccionado por cada sustantivo o estructura nominal particular. Este género se codifica en un nudo específico, SClasificador, perteneciente al área sintáctica del sustantivo. Por otra parte, 'género' refiere a una propiedad sintáctica que interviene en la identificación de la referencia de los sintagmas determinantes. Este 'género' se codifica en un nudo específico, SGénero, perteneciente al 
área del determinante. La función de este nudo es próxima al papel que desempeñan los artículos definidos, los cuantificadores o los adjetivos ordinales.

En una representación arbórea, el SGénero está dominando tanto al adjetivo como al sustantivo, mientras que el Clasificador está dominado por el nudo que define una estructura como sustantivo. ${ }^{6}$ Así, en la estructura del SD, se diferencian dos áreas sintácticas, un "área determinante» donde se codifican las propiedades orientadas al discurso y a la referencia, y un «área nominal» donde se define la intensión del sustantivo y sus propiedades morfosintácticas (véase Alexiadou et al. 2007 para una justificación de esta línea de análisis y para una revisión de los distintos nudos funcionales que se han propuesto en la estructura del SD; recuérdese también la nota 3 ).

$\left[{ }_{\mathrm{SD}}\right.$ Determinante $\left[{ }_{\mathrm{SG} e ́ n}\right.$ Género $\left[\left[_{\mathrm{SNum}}\right.\right.$ Número $\left[_{\mathrm{SA}}\right.$ Adjetivo $\left[{ }_{\mathrm{S} \mathrm{n}} \mathrm{n}[\right.$ SClasificador $\left.\left.\left.\left.\left.]\right]\right]\right]\right]\right]$

El género, en tanto que propiedad idiosincrásica de los sustantivos (y estructuras nominales del tipo de cabeza de lista), es una propiedad sintáctica codificada en el SClasificador y se comporta, de hecho, como lo hacen los clasificadores en otras lenguas. El papel del género como clasificador parece claro con los sustantivos animados, donde puede considerarse que el género tiene una relación inmediata con el sexo biológico, ${ }^{7}$ y también en aquellos casos donde el valor de género introduce diferencias de significado como la que se da entre el nombre del árbol y el nombre del fruto (manzano/manzana, castaño/castaña, cerezo/cereza), así como en los casos en que implica una diferencia de tamaño (cesto/cesta), una diferencia entre contable y masa (leño/leña) o incluso entre nombre

6 La estructura que se representa en (14) se diferencia solo mínimamente de la propuesta en Fábregas y Pérez Jiménez (2008); los cambios introducidos están motivados por los datos empíricos discutidos en el presente trabajo. La evidencia a favor de esta estructura, que se basa en la propuesta de Cinque (2005), con la adición de las proyecciones de género, está proporcionada en Fábregas y Pérez Jiménez (2008).

7 No en todos los casos, sin embargo. Entre los sustantivos referidos a seres animados donde la información de género no refleja el género biológico se encuentran los nombres epicenos, y, además, víctima, persona, testigo (hasta hace poco; ahora se utiliza con más normalidad la testigo); esta situación es normal entre los nombres animados referidos a grupos o colectivos, como gente, afición, peña, alumnado, electorado, entre otros. 
concreto y nombre abstracto (banco/banca). De hecho, como señalan Alexiadou et al. (2007, cap. 3), género es un término utilizado para referirse a distintas propiedades semánticas de los nombres en distintas lenguas. En algunas lenguas, el género refleja animacidad, tamaño, forma, material, etc. (véase también Corbett 1991). Incluso algunos autores, como Panagiotidis (2002), por ejemplo, han defendido que el género es siempre semánticamente interpretable, a diferencia del Caso: «there are no languages attested with Gender systems of a purely formal nature». Fuera de los casos recién descritos, donde parece que el valor de género se asocia a una propiedad semántica sistemática de los sustantivos, no parece que sea inadecuado hablar de selección idiosincrásica. El hecho de que la relación entre el valor del SClasificador y el sustantivo sea fija e idiosincrásica no impide considerar el género como una propiedad introducida en la sintaxis por un nudo independiente (hay otros casos de selección léxica idiosincrásica que implican una relación entre nudos sintácticos, como es el caso de determinados verbos que seleccionan sintagmas preposicionales regidos). La selección léxica, empero, no contradice los casos en que la diferencia es sistemática, ya que una base puede seleccionar léxicamente un valor determinado por su compatibilidad con ciertas nociones semánticas.

Así, en la estructura de (14), el SClasificador —que contiene un valor de género- restringe el significado del sustantivo del mismo modo que un complemento restringe el del verbo que lo selecciona. Es así posible, entre otras cosas, que el sustantivo designe una clase de seres humanos o de plantas y el género especifique que se trata de un macho - frente a una hembra - o de un árbol — frente a un fruto- o de una entidad contable o no.

Como se ha señalado en el párrafo anterior, en numerosos estudios descriptivos y teóricos (véase Corbett 1991 para un panorama general) se ha destacado la estrecha relación que se establece entre género y animacidad de la entidad denotada. Generalmente, se señala que, cuando se consideran solo los sustantivos animados, la marca de género tiende a regularizarse. En los datos que hemos considerado en el apartado 2.2, la generalización crucial es que todos los casos en que se constatan discordancias de género en el interior del sintagma nominal deben tener, forzosamente, una interpretación animada. Retomaremos esta cuestión más adelante. 
Otros autores (Borer 2005) han destacado, en cambio, la correspondencia entre el género y el carácter contable o no contable de los sustantivos. Nótese asimismo que todos los casos de discordancia de 2.2 se interpretan como sustantivos contables (pese a que no todos los nombres animados son contables: considérese gente). Volveremos también más adelante sobre esta propiedad.

Consideremos ahora la posición que ocupan el sustantivo y el SClasificador con respecto al determinante. En el nivel de estructura donde se introduce el Clasificador, por debajo de los cuantificadores y determinantes, el sustantivo denota un conjunto de propiedades y posee intensión, pero no referencia. En la teoría de los tipos semánticos, el sustantivo representa aquí un predicado monoargumental (es decir, una función $<e, t>$ ) y denota una propiedad que posee una clase particular de entidades. Por tanto, el valor de género especificado en el Clasificador, seleccionado idiosincráticamente por un sustantivo o estructura nominal, podrá aportar información al conjunto de propiedades que denota el sustantivo, pues se encuentra en el área adecuada, pero no tendrá ninguna influencia sobre la referencia.

Por el contrario, el SGénero se encuentra en el área del determinante. El valor de género codificado en el SGénero contribuye a determinar las propiedades referenciales del sintagma nominal en su conjunto y no altera la clase de seres denotada por el sustantivo. El papel del género codificado en el SGénero es crucial en la concordancia con predicados que tienen que identificar un sujeto de predicación, y también, de manera más crucial en español, con los pronombres y anáforas.

En la mayoría de los casos, el valor de género asociado al determinante - que permite identificar la referencia del sintagma completodebe coincidir con el del sustantivo con el que se combina, ya que las propiedades referenciales del determinante se definen sobre la clase de seres denotados por el sustantivo. No obstante, los valores de género codificados en el SGénero y en el SClasificador no tienen por qué coincidir necesariamente en todos los casos, como ya observábamos en Fábregas y Pérez Jiménez (2008). Analizaremos la interacción entre esos dos nudos en la siguiente sección. 


\subsection{Acuerdos y desacuerdos}

\subsubsection{Acuerdos}

Dado que el SClasificador y el SGénero son núcleos diferentes con propiedades distintas, como hemos explicado en las secciones anteriores, esperamos que puedan existir casos de interacción o acuerdo entre ambos nudos y casos en que sus valores sean divergentes.

Así, en casos como la niña, donde la referencia del sintagma se define en parte atendiendo a la clase de seres que denota el sustantivo que actúa como su núcleo, la función del SGénero es reducir el conjunto de posibles referentes a los que tienen el mismo valor de género que el sustantivo que encabeza el sintagma nominal y seleccionar un elemento de ese conjunto. En este tipo de caso, se produce concordancia entre el valor del diacrítico que se contiene en el SGénero y en el SClasificador. El subíndice I indica el valor particular del género y la relación que se establece entre los núcleos relevantes en esta construcción.

(15) $\left[\mathrm{SD} \quad\left[\right.\right.$ SGén Gén $_{\mathrm{I}} \quad\left[\mathrm{SNúm} \ldots \quad\left[\mathrm{Sn} \quad\left[\right.\right.\right.$ SClas $\quad$ Clas $\left.\left.\left.\left.\left._{\mathrm{I}}\right]\right]\right]\right]\right]$

Este acuerdo se produce cuando el sustantivo no tiene interpretación metafórica; en este caso, el valor de género del SGénero tiene que ser idéntico al del SClasificador, ya que la referencia del sintagma nominal se define sobre la clase de seres que denota el sustantivo. En la mesa o la niña, el referente del sintagma es uno de los miembros de la clase de seres denotada por el sustantivo mesa o niña. Si suponemos, asumiendo una semántica extensional, que estos sustantivos denotan un conjunto —el conjunto de elementos de los que se puede predicar que son mesas o son niñas-, el determinante ajusta su referencia sobre ese conjunto y no sobre un conjunto diferente de seres.

\subsubsection{Desacuerdos}

Cuando el valor del SGénero y del SClasificador son diferentes, se producen las discordancias examinadas en la sección 2.2.

En estos casos, la referencia del sintagma determinante y la denotación del sintagma nominal son independientes una de la otra; es decir, el sintagma determinante se refiere (es decir, remite referencialmente) a una 
entidad que no pertenece a la clase de objetos denotada por el sustantivo, y se obtiene una lectura figurada. Así, en los ejemplos como un rata asqueroso o un mala bestia violento, etc., la denotación estricta del grupo nominal que contiene el clasificador no se usa para identificar al referente, y no hay concordancia entre el diacrítico contenido en Gén y el de Clas. Esto da lugar a la situación de (16), donde los subíndices representan distintos valores de género.

(16) $\left[\mathrm{SD} \quad\left[\right.\right.$ SGén Gén $_{\mathrm{I}} \quad\left[\right.$ SNúm... $\quad\left[\mathrm{Sn} \quad\left[\right.\right.$ SClas $\quad$ Clas $\left.\left.\left.\left.\left._{\mathrm{II}}\right]\right]\right]\right]\right]$

El valor del SGénero determina la selección de un referente masculino o femenino, pero es completamente independiente del valor que tenga el SClas como tal.

Nuestra propuesta puede hacerse más clara si comparamos los sustantivos que permiten discordancias de género, como rata y plasta, con otros que no la permiten, como maravilla y desastre. Sustantivos como maravilla o desastre pueden tomarse como nombres de cualidad predicativos que expresan propiedades de su sujeto y no se usan para clasificarlos en el interior de clases bien definidas, en lo que se asemejan a los casos de 2.2. Así, de la misma manera que en Juan es un rata no clasificamos a Juan en el grupo de las ratas, sino que predicamos de él la propiedad de ser tacaño, en Esta propuesta es una maravilla no decimos que la propuesta forme parte de la clase de las maravillas, sino que, más bien, le atribuimos una propiedad, la de ser maravillosa. Hay una diferencia crucial entre los dos tipos de sustantivos, sin embargo. Los sustantivos que permiten discordancias de género exigen siempre una interpretación animada y humana, es decir, solo pueden referirse o atribuirse a seres humanos. No puede decirse, en efecto, *Esta medida económica es \{un/una\} rata. Por el contrario, los sustantivos del tipo de maravilla, que no permiten discordancias de género, no están especificados para entidades humanas, como muestra la gramaticalidad de Esta medida económica es \{un desastreluna maravilla\}.

Si bien la explicación de este hecho cae fuera de los límites de este trabajo, las ideas desarrolladas en Fábregas y Pérez Jiménez (2008) permiten explicar esta asimetría. La idea fundamental del análisis defendido en ese trabajo es que todo rasgo debe tener interpretación semántica en algún punto de la estructura. El clasificador es interpretable en su posi- 
ción de partida, como complemento del sustantivo, cuando proporciona información acerca de la denotación del sustantivo, sea porque lo hace contable (y, por ello, remite a las propiedades mereológicas del sustantivo) o sea porque el sustantivo es animado (y en tal caso, refiere a su género biológico). Por ello, cuando un sustantivo no posee información mereológica o sobre la animacidad (como sucede con maravilla), el valor semántico del SClasificador no puede interpretarse en el dominio del Sn y, dicho de un modo un tanto laxo, necesita asimilarse al SGénero, para adquirir interpretación semántica a través de la referencia. Esto fuerza en tales casos al SClasificador a desplazarse al dominio del determinante; este desplazamiento obliga necesariamente a las dos proyecciones a tener el mismo valor, lo cual hace imposible que haya discordancia con sustantivos como maravilla. En rata, donde hay interpretación animada obligatoria del clasificador, en cambio, el Clasificador no necesita asimilarse al SGénero y, por tanto, la discordancia es posible. Nuestra generalización es, pues, (17):

(17) Con discordancia de género, la interpretación del sustantivo debe ser necesariamente animada.

Nótese, por ejemplo, que el sustantivo plasta se refiere a una entidad no animada - y además, no contable - en su uso recto, pero en ese uso no admite discordancia de género (*Toda la mesa estaba llena de un plasta asqueroso / Toda la mesa estaba llena de una plasta asquerosa). En cambio, en su uso metafórico, donde sí admite la discordancia, debe tener interpretación animada (El plasta ha llegado — referido a una persona-) y por ello rechaza los sustantivos no animados $\left({ }^{*}\right.$ Este plasta es ilegible — referido a un libro-).

En lo que respecta a los sustantivos del tipo de artista, testigo, etc., pueden considerarse en nuestro análisis casos de sustantivos que, como tales piezas léxicas, no están asociados a ningún valor de género y toman la información de género a partir del nudo SGénero donde se define la información referencial. En otras palabras, el SClasificador en estos sustantivos está presente, pero carece de valor. Dado que el valor del SClasificador está seleccionado idiosincráticamente por cada sustantivo particular, es también posible que ciertos sustantivos seleccionen la ausencia de valor; por el contrario, dado que el SGénero no está seleccionado idiosin- 
cráticamente y es necesario para satisfacer una función independiente, la referencia, este valor es imprescindible. Este valor se impone al resto del sintagma y es el único que tanto el determinante como los adjetivos pueden tomar. Algunos autores, como Ralli (2003), han capturado una intuición semejante al decir que en casos como el/la artista los sustantivos están infraespecificados para el género y es el determinante el que refleja el género de todo el sintagma.

Podemos dar cuenta en este punto de los casos mencionados en (12) - y de otros casos similares como Juan es un bala perdida simpático; Pedro es un mala bestia peligrosísimo; Álvaro no es más que un cabeza bueca alto y guapo- donde aparecen adjetivos en estructuras con discordancia entre el género asociado con el clasificador del sustantivo y el género del determinante. En estos casos, según nuestra propuesta, lo que sucede es que el adjetivo concuerda en género con el SGén o con el SClas según si aporta propiedades relativas al referente del sintagma o propiedades que se atribuyen la clase de objetos denotada por el sustantivo. Es decir, la concordancia que toma el adjetivo depende estrictamente de cuál es la aportación que tiene para la semántica del grupo nominal.

Cuando el adjetivo concuerda con el valor de género contenido en el SClasificador, se interpreta necesariamente en relación a la clase de seres que denota el sustantivo (malo con respecto a bestia, hacendoso con respecto a hormiguita, etc.).

$$
\text { [SD [SGén Gén } \left.\left.\left.{ }_{I} \quad\left[\mathrm{SNúm} \ldots\left[\begin{array}{lllll}
\mathrm{SA} & \mathrm{A}_{\mathrm{II}} & {[\mathrm{Sn}} & {[\mathrm{SClas}} & \mathrm{Clas}_{\mathrm{II}}
\end{array}\right]\right]\right]\right]\right]
$$

En cambio, si la concordancia se establece con el SGénero, el adjetivo no aporta información sobre la clase de seres denotados (no se habla de una bala simpática, por ejemplo). Proponemos que, en estos casos, el adjetivo ocupa una posición más elevada, que se introduce en la estructura una vez que se ha comenzado a definir la referencia del grupo nominal, es decir, después de que se ha introducido el SGénero.

$$
\left[S D \text { [SA } A_{I}[S G e ́ n\right.
$$

$$
\text { Gén }{ }_{\mathrm{I}}[\mathrm{SNúm} . . .[\text { Sn [SClas }
$$

$\left.\left.\left.\left.\left.\mathrm{Clas}_{[I}\right]\right]\right]\right]\right]$

La propuesta de que los adjetivos que concuerdan con el valor de género especificado en el SGén y atribuyen propiedades al sintagma completo están en una posición más elevada encuentra confirmación en el 
orden estricto en el que deben aparecer con respecto a los adjetivos que aportan rasgos que denotan una clase de seres particular. Obsérvese en (20) que, en los casos de discordancias, los adjetivos que concuerdan con el determinante han de ser necesariamente externos a los que concuerdan con el valor de género que el sustantivo selecciona, hecho que se había interpretado anteriormente como prueba de que estas estructuras son cuasi-compuestos o locuciones.
a. Juan es un cabeza hueca peligroso.
b. *Juan es un cabeza peligroso hueca.
c. Juan es un antipático mala bestia.
d. *Juan es un mala antipático bestia.

Recuérdese que no podemos explicar estas restricciones aludiendo a que el grupo formado por el primer adjetivo y el sustantivo forman una locución o compuesto sintagmático, por las razones observadas en apartados anteriores.

\section{Conclusiones}

En este trabajo hemos descrito el fenómeno empírico que hemos denominado "discordancias de género en el interior del dominio nominal». La intención de estas páginas no es tanto llevar a cabo un análisis exhaustivo del género como establecer unas bases que permitan encuadrar las preguntas que surgen en torno a esta categoría desde una nueva perspectiva. Nuestra contribución fundamental al problema es, según creemos, la de diferenciar dos funciones diferentes del género - la de establecer la intensión del sustantivo y la de colaborar a la determinación de la referencia- y mostrar que los adjetivos dentro del dominio nominal concuerdan con cada uno de estos dos valores en función de cuál sea su papel semántico y sintáctico.

De nuestra propuesta se siguen ciertas conclusiones que pueden orientar la investigación sobre el género de una forma distinta a como se ha venido haciendo hasta ahora. Por un lado, el género como diacrítico léxico —el SClasificador- puede ser entendido como una proyección baja del sustantivo que establece con el nombre una relación de especificación semántica análoga a la que los complementos establecen con los 
verbos. Esto puede dar pie a una serie de estudios acerca de la forma en que esta especificación contribuye a codefinir la semántica del sustantivo. Por el contrario, el género como índice empleado para identificar la referencia - el SGénero- interactúa con el determinante y otros elementos que desempeñan un papel discursivo, y puede ser tomado como la base de una teoría sobre la anáfora entre oraciones distintas.

Por último, volvamos a la pregunta con la que abríamos este trabajo, a saber, si se puede entender que el género proporciona datos a favor de mantener una separación entre morfología y sintaxis. Nuestro trabajo solo alude a una parte de este problema general, particularmente acerca de la cuestión de si el género puede considerarse una propiedad de las piezas léxicas y no de los sintagmas. Hemos argumentado que debe entenderse como una propiedad de los sintagmas, y no de los sustantivos individuales. Sin embargo, hay un aspecto del problema del género que no hemos tratado. Este se refiere a la relación que se establece entre la desinencia o marca de palabra de un sustantivo y el valor de género contenido en el SClasificador. Se establecen discordancias entre estos dos elementos en un gran número de casos (como muestran ejemplos del tipo de mano, moto, planeta o programa). Nuestro análisis permite distintas vías de análisis de esta situación, entre ellas la posibilidad de que la desinencia represente el valor de género del Clasificador pero, por razones que están por determinar, el SGénero no se 'comunique' en estos casos con él. Una vez más, el análisis particular de este fenómeno pertenece al futuro.

\section{Bibliografía}

Ackema, P., y A. NeELEman (2004): Beyond Morphology, Oxford, OUP.

AleXiadou, A. (2004): «Inflection class, gender and DP internal structure», en G. Müller et al. (eds.), Exploration in Nominal Inflection, Berlín, Mouton de Gruyter: 21-50.

- L. Haegeman y M. STAVrou (2007): Noun phrases in the generative perspective, Berlín, Mouton de Gruyter.

Bernstein, J. (1993): «The Syntactic Role of Word Markers in Null Nominal Constructions", Probus, 5: 5-38.

BORER, H. (2005): Structuring sense. Vols. 1 (In name only) y 2 (The natural course of events), Oxford, OUP. 
Bosque, I. (2005): "Combinatorio y significación: algunas reflexiones», en Redes. Diccionario combinatorio del español contemporáneo, Madrid, SM: LXXV-CLXXI.

Chомsкy, N. (1970): «Remarks on Nominalization», en Roderick A. Jacobs y Peter S. Rosenbaum (eds.), Readings in English Transformational Grammar, Waltham (Mass.), Ginn: 184-221.

- (1995): The Minimalist Program, Cambridge (Mass.), MIT Press.

CinQue, G. (2005): «Deriving Greenberg's Universal 20 and its exceptions», Linguistic Inquiry, 36: 315-332.

CorbetT, G. (1991): Gender, Cambridge, CUP.

Demonte, V., H. Fernández Alcalde e I. Pérez Jiménez (2009): "Singular DPs with plural denotation and the features of D", manuscrito CSICCCHS. Comunicación presentada en el «Workshop on Nominal and Verbal Plurality», U. París 8 - CNRS; París, noviembre de 2009.

Di Domenico, E. (1997): Per una teoria del genere grammaticale, Padova, Unipress.

DiSciullo, A.-M., y E. Williams (1987): On the definition of word, Cambridge (Mass.), MIT Press.

Emonds, J. (2000): Lexicon and Grammar. The English Syntacticon, Berlín, Mouton de Gruyter.

FÁBREGAS, A. (2005): La definición de la categoría gramatical en una morfología orientada sintácticamente, tesis doctoral, Instituto Universitario Ortega y Gasset / UAM.

- e I. PÉreZ JimÉnez (2008): «Gender agreement on adverbs in Spanish», Journal of Portuguese Linguistics, 7:2: 7-25.

GoldBerg, A. (1995): Constructions: A Construction grammar approach to argument structure, Chicago, University of Chicago Press.

GreenberG, J. (1978): «How Does a Language Acquire Gender Markers?», en J. Greenberg (ed.), Universals of Human Language, vol. 3, Stanford, Stanford University Press: 49-82.

Halle, M., y A. Marantz (1993): «Distributed Morphology and the pieces of inflection", en K. Hale y J. Keyser (eds.), The View from Building 20, Cambridge (Mass.), MIT Press: 111-176.

HARRIS, J. W. (1991): «The exponence of gender in Spanish», Linguistic Inquiry, 22: 27-62.

HoCKeTt, C. F. (1958): A Course in Modern Linguistics, Nueva York, MacMillan. LAPOINTE, S. (1980): A Theory of Grammatical Agreement, Amherst, University of Massachusetts.

Lieber, R. (1992): Deconstructing morphology, Chicago, Chicago University Press. 
MCCAWLEY, J. (1968): «Lexical insertion in a transformational grammar without deep structure», Chicago Linguistic Society, 4: 71-80.

Nunberg, G. (1978): The Pragmatics of Reference, Bloomington (Indiana), Indiana University Linguistics Club.

Panagiotidis, P. (2002): Pronouns, clitics and empty nouns, Ámsterdam, John Benjamins.

Picallo, C. (1991): "Nominals and Nominalization in Catalan», Probus, 3: 279-316.

Ralli, A. (2003): "Grammatical gender assignment in Modern Greek nouns», en A. Anastasiadi-Symeonidi, A. Ralli y D. Cheila-Markopoulou (eds.), Gender, Atenas, Patakis: 57-99.

RAMCHAND, G. (2008): First Phase Syntax, Oxford, OUP.

RitTeR, E. (1991): "Functional categories in noun phrases: evidence from Modern Hebrew», en S. Rothstein (ed.), Syntax and Semantics 25: Perspectives on Phrase Structure, Nueva York, Academic Press: 37-62.

Val Álvaro, J. F. (1999): «La composición», en I. Bosque y V. Demonte (dirs.), Gramática descriptiva de la lengua española, Madrid, RAE/EspasaCalpe: 4757-4842.

WeChSLER, S., y L. ZlatiĆ (2000): «A theory of agreement and its application to Serbo-Croatian», Language, 76:4: 799-832.

Williams, E. (2007): «Dumping lexicalism», en G. Ramchand y C. Reiss (eds.), The Oxford handbook of linguistic interfaces, Oxford, OUP: 353-382. 


\title{
EL GÉNERO EN LOS SUSTANTIVOS: ¿FLEXIÓN Y/O DERIVACIÓN?**
}

\author{
DAVID SERRANO-DOLADER \\ (Universidad de Zaragoza)
}

El MAESTRO: ¿Cómo? Usted es incapaz de hacer el análisis de una oración tan sencilla como La alondra canta. En su tarea ha escrito: "Alondra, sustantivo masculino singular».

EL ALUMNO: Sin duda. Y yo mantengo enérgicamente «masculino»; porque entre las alondras, sólo cantan los machos.

(Jespersen 1975: 274)

En 1994, Théophile Ambadiang advertía, con toda razón, que «el análisis de la morfología flexiva del español no alcanza el grado de precisión y de sistematización que se observa en lo que se refiere a la morfología derivativa» (Ambadiang 1994: 13). Aunque la situación ha

* El equilibrio inestable del género entre los fenómenos flexivos y los derivativos se pone ya de manifiesto en los títulos de diversos artículos que han abordado directamente esta cuestión a lo largo de los años. Dos botones de muestra: Murillo (1999) titula su contribución "La marcación del género en los sustantivos del español: entre la flexión y la derivación»; y Lliteras (2008) titula un reciente trabajo «Del género derivativo al género flexivo». 
mejorado sensiblemente en los últimos años, son muchos aún los aspectos que requieren todavía atención específica. Uno de ellos es, precisamente, el del género, tema que, por lo menos en principio, parece integrarse en este ámbito de la flexión. La acotación de nuestro ámbito de análisis, centrada en el género de los nombres, tiene fácil justificación ya que el género es básicamente un rasgo del sustantivo, a partir del cual se extiende a otras categorías que disponen también de variación genérica. ${ }^{1}$

El contraste entre parejas del tipo chico/chica, niño/niña o perro/perra - ejemplos que suelen ofrecerse como representantes canónicos de la variación genérica nominal en español- parece confirmar inicialmente que el tema que abordaremos es el estudio flexivo del género de los sustantivos en español. Ahora bien, pares como manzanalmanzano o naranjalnaranjo hacen pensar más bien en que nos movemos en el terreno de la morfología léxica. En suma, no es de extrañar que, en el caso de la marcación genérica, haya llegado a hablarse — de forma híbrida — de «derivación seudoflexiva». ${ }^{2}$

Se abren, por lo tanto, incógnitas de amplio alcance: ¿podemos sostener que el género de los sustantivos se integra, en parte, en la flexión y, en parte, en la derivación?; ‘ ‘tiene sentido defender que el género nominal no es estrictamente hablando ni un fenómeno flexivo ni un fenómeno derivativo?

1 «[...] los rasgos flexivos [...] tienen una motivación distinta en nombres y adjetivos. Así, por ejemplo, la presencia de los rasgos de género en los adjetivos se suele considerar como el resultado de procesos que suponen, en definitiva, la expansión de dichos rasgos desde un nombre o un SN hacia todos los determinantes que se encuentran en su dominio o a los que rige [...], a pesar de que no tienen siempre ni necesariamente los mismos exponentes en nombres y adjetivos. [...] el género es esencialmente un rasgo del nombre a partir del cual se expande» (Ambadiang 1994: 19-20).

2 «Derivació pseudoflectiva. Els morfemes que apareixen als substantius abans dels del nombre, i que són iguals formalment que els de gènere dels adjectius [...] corresponden, d'una banda, a les categories masculí i femení inherents en tot substantiu, però de l'altra no poden considerar-se com introduïts a través d'un procés de flexió, pel mateix carácter inherent que té el gènere en aquests mots. La relació entre mots masculins i femenins amb el mateix radical és més aviat semblant a la relació de derivació, o, més generalment, a la relació entre elements lèxics difererents amb morfemes comuns» (Mascaró 1986: 34-35). 
En fin, la compleja situación que acabo de exponer se recoge, por lo menos en parte, en el capítulo que se dedica al género en la Nueva Gramática de la Lengua Española de la RAE: ${ }^{3}$

Es muy polémica la cuestión de si existe o no en español un morfema flexivo de género, en el sentido de un segmento al que corresponda esa información morfológica. Si bien la tradición gramatical solía inclinarse por esta opción, particularmente en los numerosos casos en los que la vocal /o/ caracteriza a los sustantivos masculinos y la vocal /a/ a los femeninos, se reconoce hoy en día que sus inconvenientes son mayores que sus ventajas. [...] existen sustantivos masculinos terminados en - $a$ (día), femeninos terminados en -o (mano), de uno u otro género terminados en -e (héroe, serie), en - $i$ (alheli, huri) o en -u (impetu, tribu), además de muchos terminados en consonante marcados inherentemente para uno de los dos géneros. Son igualmente numerosos los sustantivos comunes en cuanto al género terminados en vocal o en consonante. Así pues, está hoy más extendido entre los morfólogos el análisis que atribuye a ciertas terminaciones el carácter de MARCAS SEGMENTALES o MARCAS DE PALABRA, lo que las capacita para ciertos procesos fonológicos y morfológicos sin convertirlas en depositarias de información genérica. Uno de esos procesos es la supresión en la formación de derivados. Por ejemplo, la segmentación Carl-os permite explicar derivados como carl-ismo o Carl-it-os (también Carl-itos [...]) sin considerar que -os es un morfema de género. De igual manera, segmentaciones como cas- $\underline{a}$, libr$\underline{o}$, mont-e o Merced-es permiten prever formas del tipo de cas-ona, libr-ote, montec-ito o mont-ecito y de Merced-itas ([...]) sin asignar necesariamente información genérica a los segmentos que se subrayan. [...]. Se considera, por tanto, que estos nombres no contienen un morfema flexivo de género, sino que poseen género inherente. Tampoco poseen marca de género los nombres comunes, los ambiguos y los epicenos ([...]). Por el contrario, resulta natural considerar como

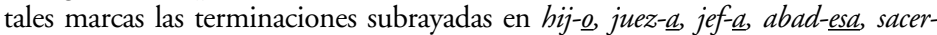
dot-isa, gall-ina, leon- $\underline{a}$ y otros sustantivos que designan personas o animales. En estos ejemplos, se produce, en efecto, una alternancia flexiva entre la forma masculina y la femenina (hijo/hija, juez/jueza, abad/abadesa), lo que justifica considerar la terminación como morfema de género. En algunas de estas alternancias,

3 Puesto que la Nueva Gramática de la Lengua Española de la RAE se publica en diciembre de 2009, en las fechas en las que redactamos este artículo no está aún accesible. Sí ha visto la luz, como pre-publicación, precisamente su capítulo 11, titulado «El género». Las referencias que aquí damos a dicho capítulo deben tomarse, por lo tanto, como meramente informativas: el ponente de la Gramática, Ignacio Bosque, nos confirma en comunicación personal que están previstos ciertos cambios en la redacción definitiva de este capítulo dedicado al género. No obstante, se hayan modificado o no parcialmente en la versión definitiva de la Gramática, creemos que las palabras que aquí recogemos tienen valor en sí mismas y, particularmente, para ilustrar el estado de la cuestión que estamos presentando. Por otra parte, será interesante cotejar la versión que ahora ofrecemos con la que definitivamente aparece en la versión impresa de la Gramática académica. 
solo aparece la marca distintiva de género en la forma femenina (abadlabadesa; escritor/escritora). Si bien algunos gramáticos han propuesto que las variantes correspondientes en masculino contendrían un morfema vacío o nulo de género, no parecen existir argumentos empíricos que lo justifiquen (RAE [prepublicación - en prensa], parágrafo 11.2b).

Llegados a este punto, parece que la pregunta que planteamos en el título de este artículo queda ya más que justificada: «El género en los sustantivos: ¿flexión y/o derivación?».

Lo cierto es que hay casos extremos en los que parece que la asignación al campo de la flexión o al campo de la derivación está justificada y resulta coherente. Y ello se puede defender tanto desde la postura cientifica del lingüista que analiza dichos casos como desde postulados más bien pedagógicos. Así, no es extraño que ante una pregunta del siguiente tipo - planteada, por ejemplo, a alumnos de un primer ciclo universitario-:

Fíjese en la alternancia cest-o/cest-a y naranj-o/naranj-a. ¿Es la misma que se da entre cuñad-o/cuñad-a o buen-o/buen-a?» (Varela Ortega 2005: 38).

pueda responderse, sin que a nadie cause extrañeza, algo tan claro como:

No; en los dos primeros pares (cest-o/cest-a y naranj-o/naranj-a), la variación de la terminación vocálica produce palabras con distinto significado. En los dos segundos (cuñad-o/cuñad-a y buen-o/buen-a), las desinencias -o y - a son sufijos flexivos que marcan la variación de género — es decir, son morfemas gramaticales - y no forman palabras distintas sino formas de la misma palabra (Varela Ortega 2005: 109). ${ }^{4}$

4 Este tipo de explicación, que reconoce tanto una marcación flexiva como una marcación derivativa del género en español, está ampliamente representada en los escasos manuales de morfología española que incluyen prácticas directamente concebidas para alumnos universitarios. En la misma línea del ejercicio de Varela ya citado, en el libro de García-Page (2008) se plantea directamente la siguiente pregunta: «¿Existe la misma relación morfológica en los pares alumno/alumna y castaño/castaña? ¿Y en los pares barco/barca y cuchillo/cuchilla?». La respuesta dada por este lingüista acaba recapitulando: «En conclusión, no existe la misma relación morfológica entre los pares señalados. Solo cabe hablar de oposición genérica en el primer caso [i. e. alumnolalumna] y de formación derivativa en el segundo [i. e. castaño/castaña]. La segmentación en las dos últimas series [i. e. barco/barca y cuchillo/cuchilla] que promueve la vocal final de palabra como marca formal de género del tipo barc-o, cuchill-o, etc., es, en nuestra opinión, bastante artificiosa: no hay oposición genérica genuina, cada uno de los sustantivos del par remite a un sustantivo único. Nosotros nos sumamos, así, a la tradición que habla de "género inherente» (barco, cuchillo, etc.)» (García-Page 2008: 141). 
Dicho de otro modo: si todos los casos de variación genérica del español respondieran, o bien al esquema opositivo chic-o/chica-a, o bien al esquema manzan-a/manzan-o, no parece que hubiera grandes dificultades -más allá de las que se derivaran de la (in)adecuación a los postulados teóricos de base que siga una determinada corriente lingüística- en llegar a aceptar que la primera de las parejas ejemplifica un proceso flexivo mientras que la segunda ejemplifica un proceso derivativo. El problema radica en que ni formalmente ni desde el punto de vista del contenido hay regularidad en la línea que parecen marcar los ejemplos que ahora comentamos. Formalmente, sabemos bien que la variación genérica en español está muy lejos de responder a una relación biunívoca estable (del tipo -o para el masculino, $-a$ para el femenino). Desde el punto de vista del contenido, es también conocida la innumerable casuística en la que se puede caer para delimitar los significados de aquellas parejas que - oponiéndose en cuanto a su género de modo $-o$ masculino/- $a$ femenino- no tienen correlato con referidos sexuados o animados. ${ }^{5}$

Si no se quiere caer en una casuística excesiva que desbarate la propia validez del concepto de género, para tratar de dar coherencia y, en la medida de lo posible, homogeneidad al tratamiento del género en español es necesario intentar presentar una explicación globalizadora. En esta línea, han sido varias las propuestas formuladas por diversos estudiosos, a las que además podemos añadir alguna propia. En concreto, y sin ánimo

5 Millán Chivite (1994) establece una exhaustiva tipología semántica del contenido de la oposición de género no sexuado en español, llegando a distinguir veintidós modalidades o tipos de género no sexuado, algunos de los cuales se subdividen, a su vez, en varios subtipos y subgrupos. No obstante, refunda esos tipos concretos en tres oposiciones generales (basadas, inicialmente, en propuestas de Hjelmslev) en las que caben tanto el género sexuado como el no sexuado: oposición compacto/discreto (que se realiza en varias oposiciones concretas: ente individual/colectivo, árbol/producto, todo/parte, exento/ incorporado, acción/acto); oposición limitado/ilimitado (que admite múltiples concreciones: proceso físico/proceso mental, objeto/materia, persona/no persona, entidad bási$\mathrm{ca} /$ color representativo....); oposición concentración/expansión (asumida mediante dos parejas específicas: macho/hembra, efecto/causa). La multiplicidad de relaciones semánticas que - aparente o realmente- se ponen en juego en los contrastes de género ha llevado a algunos autores a considerar que, en el fondo, más que valores semánticos específicos, el género tiene un solo significado de marca de 'oposición, contraste': «[...] after all, gender DOES have some meaning in Spanish. It has to be a strictly relational one, signifying in fact only opposition, contrast at its purest, without the slightest allusion to any particular semantic substance» (García 1970: 50). 
alguno de exhaustividad, nos vamos a referir a cuatro posibles acercamientos globalizadores al tratamiento de género en español:

1) Admitir conjuntamente que todas las manifestaciones de género en español son, o bien fenómenos flexivos (incluidos los casos extremos aparentemente no flexivos del tipo manzan-a/manzan-o), o bien fenómenos derivativos (incluidos los casos extremos aparentemente no derivacionales del tipo chic-o/chic-a).

2) Asumir, en la descripción y análisis del género nominal, el concepto de marca de palabra.

3) Proponer un análisis basado en esquemas configuracionales (estructura flexiva de palabra) más que en identificaciones de morfemas concretos.

4) Presentar una caracterización no-discreta del género nominal que vaya desde casos prototípicamente flexivos hasta casos prototípicamente derivativos.

Dada la complejidad del tema, y ante las obligadas limitaciones de extensión de un artículo como el que aquí presentamos, lo que pretendo simplemente es dejar sobre la mesa alguna reflexión sobre estas cuatro posibles explicaciones globalizadoras del género en español. Por otra parte, soy consciente también de que la rapidez con la que obligatoriamente hemos de pasar sobre este tema dejará abiertas muchas brechas y dudas, e incluso frontales y obvias discrepancias, tanto en lo que se refiere a nuestras rápidas valoraciones sobre algunos de los acercamientos arriba mencionados como en lo referido a nuestras propias propuestas de descripción y análisis. ${ }^{6}$

6 Por otra parte, hemos de advertir que no entraremos en la historiografía del tratamiento del género en los estudios de gramática española. Simplemente hacemos notar que la identificación del género flexivo es - contra lo que podría parecer dada la situación actual - un paso posterior al tratamiento del género como fenómeno derivativo. De hecho, la tradición gramatical española excluyó la variación de género en los sustantivos mayoritariamente hasta bien entrado el siglo XX: «Compete a la gramática del idioma la identificación de un nuevo género flexivo diferenciado de otro género derivativo previo y el reconocimiento de las propiedades gramaticales que distinguen uno y otro tipo de género en los sustantivos. La descripción de esta doble naturaleza morfológica del género en español exigió un profundo reajuste en las descripciones gramaticales del género heredadas de otras épocas. Tales modificaciones se manifiestan con relativa claridad en el estudio historiográfico de la disciplina» (Lliteras 2008: 127). Advertimos que, no obstante, los casos a los que afecta historiográficamente esta delimitación entre género flexivo y género derivativo no coinciden con las propuestas que vamos a formular en este artículo. 
Retomaré ahora cada una de las cuatro posibles posturas que acabo de presentar.

1) Admitir conjuntamente que todas las manifestaciones de género en español son, o bien fenómenos flexivos (incluidos los casos extremos aparentemente no flexivos del tipo manzan-a/manzan-o), o bien fenómenos derivativos (incluidos los casos extremos aparentemente no derivacionales del tipo chic-o/chic-a).

Una aproximación descriptiva apoyada únicamente en la correlación de desinencias y de rasgos de género podría llevar a proponer una caracterización única para tales pares, sea en el sentido de interpretarla como flexiva en todos los casos, sea para interpretarla como derivativa en todos los casos.

Según la primera interpretación posible, la manifestación típicamente flexiva de chic-o/chic-a se amplía a todos aquellos pares de palabras cuyos miembros presentan proximidad semántica y terminaciones idénticas (tipo manzan-almanzan-o pero también barc-o/barc-a, huert-a/huerto...). En consecuencia, todos estos nombres manifestarían moción y desinencias flexivas de género en español.

Según la segunda interpretación posible, la organización característica de pares del tipo manzan-a/manzan-o, barc-o/barc-a, huert-a/huert-o... se ampliaría también a pares tradicionalmente interpretados como flexivos (tipo chic-o/chic-a). En la medida en que se asume que el contraste de los pares del tipo manzan-almanzan-o es claramente derivativo se piensa que el tipo chic-o/chic-a debe ser interpretado de la misma manera para evitar una innecesaria y heterogénea caracterización bifurcada. ${ }^{7}$

La interpretación semántica de las terminaciones de todas estas palabras indicaría, según los casos, conceptos opositivos como los de

7 «Lo que tradicionalmente conocemos como morfemas de género pueden ser considerados como unos elementos clasificadores nominales. [...] Si se consideran estas variaciones morfológicas como procesos derivacionales, en los que a partir de una base con un rasgo semántico determinado se puede crear una nueva forma con otro rasgo, nada impide incluir el sufijo femenino - $a$ (por ejemplo, niñ-a), que indica sexo femenino, entre los sufijos derivacionales. El morfema de sexo femenino $\{-a\}$ sería equiparable a los morfemas derivacionales, también de sexo femenino -ina (gall-ina), -esa (cond-esa), -isa (sacerdot-isa) o -iz (actr-iz). [...] La aparición de un morfema de sexo $\{-$ a $\}$ no es un proceso flexivo gramatical, sino un cambio léxico derivacional» (Moreno Fernández y Ueda 1986: 95). 
'macho/hembra', 'pequeño/grande', 'fruta/árbol', etc.; y ello vale tanto si se adopta la primera explicación (i. e. todo es flexión) como la segunda (i. e. todo es derivación).

Ambas descripciones son, desde luego, homogeneizadoras. Lo cual no quiere decir que sean coherentes ni si quiera intuitivamente aceptables.

No podemos ahora argüir por extenso frente a este tipo de posturas. Baste señalar, por ejemplo, que estos tipos de palabras no se comportan de la misma manera en la coordinación léxica: chico + chica = chicos pero manzana + manzano $\neq$ manzanos (ni manzanas); o que los referentes son de la misma naturaleza en chicolchica y no así en manzanalmanzano; o que la orientación de las relaciones entre masculinos y femeninos son muy variadas de un tipo a otro; o que no se aclara suficientemente el carácter monomorfemático o bimorfemático del masculino y/o del femenino correspondiente. ${ }^{8}$ Amén, claro está, de que estas generalizaciones solo atañen en todo caso a aquellos pares de palabras cuyos miembros contrastan regularmente en la moción de género.

2) Asumir, en la descripción y análisis del género nominal, el concepto de marca de palabra.

Aunque la caracterización de las denominadas marcas de palabra -que han recibido muchos otros nombres también- varía de unos autores a otros en cuanto a la naturaleza, a la motivación y a la forma de las mismas, a grandes rasgos podemos decir que el concepto de marca de palabra señala a elementos morfológicos — aunque su estatuto como morfemas es más que discutible - cuyas únicas propiedades gramaticales son relativas a su forma fonológica y a su distribución en la palabra. Segmentos, pues, de carácter meramente fonológico que no aportan valores ni semánticos ni sintácticos. Son entonces, como señala la propia RAE en su próxima Gramática, ciertas terminaciones que están capacitadas para ciertos procesos fonológicos y morfológicos — por ejemplo la supresión en la formación de derivados - sin convertirse, no obstante - y para lo que ahora nos atañe-, en depositarias de información genérica.

8 Puede verse una justificada crítica a estas propuestas en Ambadiang (1994: 95101; y 1999: 4880-4882). 
Lo cierto es que el concepto de marca de palabra es sugerente, en la medida en que permite marginar la supuesta — y compleja— relación entre las vocales finales de las palabras y su supuesto estatuto de marcadores de género; pero, a la vez, no llega a resolver el problema (simplemente lo soslaya) del género en los sustantivos españoles. En palabras de Ambadiang:

[...] el concepto de marca de clase o de palabra es interesante en la medida en que nos permite dar cuenta de los constituyentes e incluso de la estructura de los nombres sin que sea necesario asociar los segmentos vocálicos finales de estos últimos con sus rasgos de género. Sin embargo, no resuelve el problema relativo al lugar del género en los sustantivos. [...] los diferentes autores no determinan siempre de manera unívoca si el género es un rasgo del radical o del nombre, en la medida en que algunos lo consideran como un rasgo inherente en el nombre mientras que otros prefieren caracterizarlo como un rasgo del radical (Ambadiang 1994: 72).

Este tipo de interpretación no suele dar cuenta convincentemente de la correlación —no regular pero sí muy extendida— entre los segmentos vocálicos finales $-o$, $-a$ y el género masculino y femenino respectivamente.

Por otra parte, no queda claro, en muchos casos, para qué categorías o clases de palabras puede usarse el concepto marca de palabra y, en todo caso, el grado de justeza descriptiva y analítica seguramente no sería el mismo en las diferentes categorías en las que fuera (o no) aplicable. Una extensión sin límites del campo de aplicación de tal concepto traería consigo, por otra parte, casi una disolución de la morfología entendida en sentido estricto o, cuando menos, dar una primacía (que en absoluto resulta evidente) en el análisis de los finales de palabra al aspecto fonético sobre el morfológico.

Por otro lado, el problema último radica en que la aplicación del concepto de marca de palabra no tiene, en el fondo, el valor generalizador que en principio se le supone:

[...] los segmentos que pueden ser marcas de palabra en la fonología no lo son necesariamente en la morfología (así, los segmentos vocálicos finales de los adverbios), y los que resultan ser marcas de palabra en la morfología flexiva no se comportan de un modo uniforme en la derivación (Ambadiang 1994: 84).

En suma, el concepto de marca de palabra o marca de clase es sugerente aunque a la vez no menos controvertido. Es un intento de sistema- 
tización formal que se apoya en —o lleva inexcusablemente hacia- una simplificación excesiva de los datos objeto de análisis. Que la Gramática de la RAE — según se desprende del capítulo sobre género ya pre-publicado - vaya a acogerlo no le salvaguarda de ser, cuando menos, discutible. Allí mismo se acaba por reconocer que en muchos casos (hijo/hija, juez/jueza, abadlabadesa) se da en realidad una alternancia flexiva entre la forma masculina y la femenina, lo que justifica considerar la terminación como morfema de género. El concepto de marca de palabra, en todo caso, puede revestir interés más en el aspecto descriptivo que, como se pretende muchas veces por sus defensores, en el analítico.

3) Proponer un análisis basado en esquemas configuracionales (estructura flexiva de palabra) más que en identificaciones de morfemas concretos.

Ambadiang (1994) aboga por analizar el género nominal en español sirviéndose de la denominada estructura flexiva de palabra. Dicho esquema configuracional sería aplicable a todos los nombres españoles y permite poner en relación la flexión regular e irregular y salvar muchos de los problemas planteados por diversos análisis propuestos para el género por estudiosos tanto tradicionales, como estructuralistas y generativistas.

De este modo, la configuración morfológica, que se refleja en el esquema de estructura flexiva, incluye casillas que corresponden a los rasgos flexivos de género (y número). Según esa interpretación, todos los segmentos vocálicos finales comparten la misma casilla (slot) dentro de la estructura de las palabras en que aparecen; de manera que todas las vocales del español, más que ser marcas de palabra, pueden rellenar la casilla del género (si bien es cierto que solo algunas de ellas, -o/- $a$, marcan regularmente la flexión relativa al género nominal). Las configuraciones morfológicas, fonológicas y prosódicas dan conjuntamente su forma, su esquema configuracional, a los nombres.

En mi opinión, algunas de estas propuestas presentan análisis que son anti-intuitivos y, en cierto modo, incluso ad hoc. Así, que sean coherentemente aplicables a una palabra como chic-o-s (en donde la -o- rellena la casilla de género y la $-s$ la casilla de número) no extiende esa misma coherencia a algunas interpretaciones propuestas, por ejemplo, para las palabras terminadas en consonante: se llega a afirmar que en palabras 
como papel o compás las casillas del género y del número están vacías en singular pero se rellenan en plural, de manera que en papel-E-S y compas$E-S$, la $S$ rellena la casilla de número y la $E$ rellena la casilla de género.

Es cierto, no obstante, que, para evitar este tipo de soluciones, se afinan las descripciones y se añaden así, junto a las estructuras flexivas, una serie de reglas morfosintácticas que permitan dar cuenta de la configuración de los sustantivos tanto regulares como irregulares:

[...] las formas irregulares son de dos tipos en lo que concierne a la flexión de género. Las que acaban en una consonante [del tipo papel] están marcadas para que no se les aplique la regla de adjunción de la marca de género. En lo que concierne a las palabras del tipo tema y mano, la presencia, dentro del lexicón, de una vocal que rellena la casilla relativa al género bloquea la aplicación de la regla [de marca de género] por la que se adjuntaría una de las marcas regulares (Ambadiang 1994: 118).

Aunque con este tipo de análisis se gana en coherencia, no vemos muy bien las ventajas de proponer esquemas configuracionales aparentemente de validez general pero que, a la postre, se enlazan, para la resolución de los problemas analíticos que puedan plantear las palabras, con reglas de aplicación de marcas de género (y de número) que:

a) o se aplican regularmente a veces (en chico y sus variantes),

b) o no se aplican porque quedan bloqueadas debido a que la casilla de género ya estaba llena en el lexicón (tipo tema, mano),

c) o no se aplican porque (caso del tipo papel) se advierte que la E de la terminación ES del plural papeles aparece realmente al adjuntar la marca de número precisamente porque papel no tiene su casilla de género rellenada ni dentro del lexicón (como era el caso de mano o tema) ni por regla (como era el caso de chico). En suma, lo que se dice es que en estos casos la adjunción de la marca de número implica la inserción de la /e/ (junto con la -s típica del plural) cuando la casilla del género de la base está vacía.

Si a aquellas teorías (a las que no nos hemos referido a lo largo del presente artículo) que hablan de morfos cero en la interpretación del género en español se les tacha con frecuencia de injustificadas y ad hoc, el aparato analítico de las explicaciones basadas en esquemas configuracionales puede derivar en ese mismo carácter ad hoc. Pueden ser atractivas e inclu- 
so coherentes con sus propios principios, pero no son tan resolutivas como pretenden presentarse. Es cierto que este tipo de interpretación se aparta del casuismo del que se acusa a las visiones y análisis más tradicionales del género pero, en mi opinión, más que, como pretenden, simplificar la capacidad de explicación de sus análisis, lo que hacen es simplificar los datos reales de la lengua. Si a muchos análisis estructuralistas se les ha acusado, no sin razón, de que su afán de sistematización supone una simplificación excesiva de la gramática que llega a viciar los datos (cfr. Ambadiang 1994: 122), crítica pareja podría hacerse al tipo de propuestas que acabamos de revisar sucintamente. ${ }^{?}$

4) Presentar una caracterización no-discreta del género nominal que vaya desde casos prototípicamente flexivos hasta casos prototípicamente derivativos.

Si se analiza el género en español desde una doble perspectiva, semántica y formal, en ambas facetas se dejan traslucir claramente comportamientos que podríamos denominar no-discretos en los diversos sistemas de oposiciones que subyacen a la organización genérica.

Por un lado, si nos movemos en la denominada semántica del género, está claro que hay que establecer una diferenciación entre el género semántico en los nombres animados y el género semántico en los nombres inanimados basándonos en la mayor o menor regularidad de los criterios de asignación de género en unos y otros tipos de sustantivos. Como bien explica, de nuevo, Ambadiang:

El género semántico difiere entonces en los nombres animados e inanimados por el carácter más o menos absoluto de los criterios que determinan su asignación. La preeminencia de los factores semánticos en los nombres animados cuyos referentes requieren la especificación de sexo explica la sistematicidad de la correlación entre la oposición de género y la diferenciación

9 Desde una perspectiva bien distinta, el viciado de datos y la simplificación excesiva y partidista del análisis de los hechos lingüísticos está también muy presente en el tratamiento de un aspecto del género - muy de moda en la actualidad pero que hemos dejado totalmente de lado en este artículo- como es el de la relación entre sexo (y sexismo) y género. La lista de contribuciones bibliográficas al tema sería interminable, pero una reciente y ajustada presentación de las relaciones entre sexo y género puede verse en Roca $(2005 a$ y $2005 b)$. 
sexual manifiesta en ellos. Por lo contrario, no parece que por sí solas las consideraciones semánticas puedan dar cuenta de todos los nombres inanimados [...] (Ambadiang 1999: 4852).

En suma, la asignación genérica basada en la semántica tiende a la regularidad en los nombres animados (y dentro de ellos, más en los nombres de persona que en los nombres de animales) y tiende a la irregularidad o asistematicidad en los inanimados (aunque es cierto que, por ejemplo, el género de los inanimados de una determinada clase suele coincidir con el genérico de dicha clase: por ejemplo, los días de la semana son masculinos porque día es masculino). ${ }^{10}$ Además, no hay que olvidar que la asignación semántica del género afecta, en todo caso, solo a una parte del léxico español puesto que hay sustantivos que no tienen propiamente hablando género semántico, tanto en los inanimados (por ejemplo, pared, muro...) como, más extrañamente, en los animados (por ejemplo, persona, bebé...). En suma, desde esta perspectiva los representantes prototípicos de la marcación de género semántico serían los sustantivos animados de persona.

Por otro lado, si nos movemos en la denominada asignación formal del género, vemos que también las correlaciones y la sistematicidad varían de unos tipos a otros de nombres, aun sin llegar, en ningún caso, a presentar regularidad total. Así, la motivación semántica del género en los sustantivos inanimados dista de implicar una relación sistemática entre los rasgos genéricos y sus marcas prototípicas en español puesto que no asocia regularmente las terminaciones $-0,-a$ con nombres masculinos $\mathrm{y}$ femeninos respectivamente. Frente a ello, en los animados (otra vez, más en los de persona que en los de animales), la diferenciación masculino/femenino tiende muy mayoritariamente a relacionarse biunívocamente con las marcas $-o,-a$, por lo que de nuevo - igual que ocurría con la perspectiva semántica - parecen ser los representantes prototípicos ahora de la marcación de género con correlato formal estable.

Como se deduce fácilmente de lo que estamos exponiendo, asumimos una caracterización semántica y formal del género, entendido como

10 Esa jerarquización de la marcación genérica parece darse con carácter universal: "A hierarchy determining overt gender marking in languages with semantic gender assignment is: human > animal > other animate > other» (Aikhenvald 2004: 1033). 
categoría, en español. Ello implica que, en nuestra opinión, la superposición de pautas formales y no formales no es, como a veces se defiende, contraria a las preocupaciones hermenéuticas que ha ido adoptando la gramática. Como señalaba Ambadiang, aunque con objetivos bien distintos a los nuestros:

[...] la categoría del género [...] hace oficio de puente entre las características semánticas y formales de los nombres. [...] La categoría del género es inherente a los nombres, a diferencia de lo que ocurre con los adjetivos por ejemplo. Sin embargo, el rasgo concreto de género que recibe cada nombre depende de información de carácter semántico y/o formal (Ambadiang 1999: 4858-4859).

$\mathrm{Al}$ interrelacionar las asignaciones genéricas semánticas y las asignaciones genéricas formales, resulta que, como era intuitivamente ya bien sabido, los sustantivos animados de persona del tipo chic-o/chic-a, hij-o/hij-a o niñ-o/niñ-a son, en español, representantes prototípicos de las oposiciones propias de la categoría género. Se da, por otra parte, el hecho de que las marcas formales de género son precisamente en este tipo de sustantivos en cierta medida redundantes (pues la caracterización semántica dejaría ya evidente el género de esos nombres) y, a la vez, es precisamente ese grupo de nombres el que presenta mayor regularidad en las marcas formales de género (cuando, en principio, podría prescindir de dicha regularidad al ser estas marcas, como acabo de apuntar, redundantes). Es decir: parece que la situación en ese tipo de nombres, en cuanto a la tendencia a una marcada regularidad y sistematicidad semántico-formal, se acerca muy mucho a la que se da, por ejemplo, en otras categorías que, como el número nominal, son claramente flexivas. ${ }^{11}$

11 No obstante, no hay que olvidar que las marcaciones de número y de género en español — que con cierta frecuencia se han tratado casi en un mismo plano de análisis- no parecen guardar tan estrecha relación como se suele suponer. Incluso desde una aproximación experimental psicolingüística las diferencias parecen llamativas: "Cuando las dos raíces en interacción en un error [i. e. en un lapsus línguae] pertenecen a palabras que difieren tanto en género como en número, parece existir una especie de jerarquía en relación con estos sufijos: por ejemplo, en los intercambios de raíces el anclaje afecta siempre al número [por ejemplo, "... un duro de veinte monedas (una moneda de veinte duros)»], algunas veces a ambos sufijos a un tiempo [por ejemplo "como hay médica de huelgos (huelga de médicos)»] y nunca al género solo [no hay ejemplos reales del tipo "médicas de huelgo (huelga de médicos»)]. Ello resulta informativo acerca del orden de adjunción de los sufijos: el género 
No es extraño así que los procesos de flexión de género característicos de este tipo de nombres tiendan a extenderse hacia otros tipos de nombres (podríamos decir que en busca de una regularidad de la que, en principio, carecen). Formaciones atestiguadas dan fe de ello: bebélbebá, bicho/bicha, duquesalduqueso, palabralpalabro, mamarracho/mamarracha... Más que como anécdota creativa del idioma, creo que esas formaciones manifiestan una tendencia hacia una asunción regular de la marcación genérica que, como tal, ya sabemos que no se da en todos los nombres del español. Dicho de otro modo: hay una cierta tendencia a intentar regularizar lo (que parece) irregular, a marcar como clara flexión algo que, en muchos casos, no lo es prototípicamente.

Los estudios sobre el género en diversas variantes dialectales, en el lenguaje infantil y en los aprendientes de español como lengua extranjera no hacen sino subrayar esa tendencia hacia la regularización flexiva prototípica. Es sabido que existe un proceso de sobregeneralización que lleva hacia la búsqueda de una regularidad entre la correlación entre -o y $-a$ finales y los rasgos de género, masculino y femenino respectivamente. Así, no creemos que sea exagerado afirmar que las terminaciones $-0,-a$ tienen en español carácter canónico para la marcación genérica en español y, de ser así, creemos que eso debe ser tenido muy en cuenta a la hora de proponer un determinado análisis del género en los sustantivos españoles por más que ese punto de partida pueda llegar a ser tachado, cosa que evidentemente no compartimos, de rancio. Otra cosa es, y resulta también innegable, que esa marcación (y su respectiva correlación con el género masculino y femenino en español) no permita explicar las innumerables variantes formales y de contenido a las que se liga el género en los nombres. Precisamente para dar cuenta de ellas, propondremos una visión no-discreta del género nominal en español.

En la interpretación morfológica no-discreta que asumimos, creemos que se podría proponer una caracterización prototípica de la flexión de

parece más íntimamente ligado a la raíz y, en consecuencia, tiende a 'moverse' junto con ella en caso de error, en tanto que el número presenta una mayor tendencia a aparecer en su lugar correcto del enunciado, más independiente del movimiento que pueda sufrir la raíz a la que debía adjuntarse» (Del Viso 2002: 378). Para un tratamiento pormenorizado de estas cuestiones, vid. Igoa, García-Albea y Sánchez-Casas (1999). 
género en español, apoyada, por lo menos inicialmente, en cinco criterios delimitativos, en cuya justificación no puedo extenderme todo lo que debiera para aquilatar la propuesta que ahora presento:

1. Desde el punto de vista del contenido, la flexión de género prototípica marca — con más claridad en la flexión de número singular - contraste entre 'sexo masculino' y 'sexo femenino'.

2. Desde el punto de vista formal, la flexión de género prototípica presenta en oposición las marcas flexivas de $-o /-a$.

3. Desde el punto de vista interrelacional, la flexión de género prototípica marca formalmente tanto a masculino como a femenino, con marca flexiva $-o$ el masculino y con marca flexiva $-a$ el femenino.

4. Desde el punto de vista de la orientación genérica, y aunque como fenómeno flexivo no hay estrictamente hablando preexistencia lexicogenética de uno frente a otro, en la flexión de género prototípica el género flexivo masculino es previo — en tanto que no marcado - al femenino. ${ }^{12}$

5. Desde el punto de vista de oposición paradigmática, en la flexión de género prototípica el contraste entre las marcas flexivas de género $-o /-a$ es binario: - $o$ se opone a $-a$ y solo $\mathrm{a}-a, \mathrm{y}-a$ se opone a $-o$ y solo a $-o$.

Partiendo de esta perspectiva, las oposiciones genéricas marcadas en chic-o/chic-a, hij-o/hij-a o niñ-o/niñ-a serían manifestaciones prototípicas de la flexión de género en español; como puede comprobarse fácilmente por su perfecta adecuación a los cinco criterios presentados.

Por el contrario, y desde dicha perspectiva, las oposiciones marcadas en parejas del tipo manzan-a/manzan-o serían manifestaciones del ámbito de la morfología léxica del español, como pone de manifiesto el incumplimiento de los cinco rasgos caracterizadores flexivos antes descritos:

12 En Aliaga García y Lázaro Mora (2003) se defiende una concepción prototípica de la neutralización de la distinción de género, esto es, que aunque prototípicamente el género masculino sea el no marcado, puede ocurrir que no tenga que darse necesariamente así e incluso que, en casos no prototípicos, sea el femenino el que pueda asumir la condición de término no marcado (por ejemplo, odio las palomas). La casuística en las relaciones de marcación entre el género masculino y femenino llega a relaciones tan peculiares como las que se presentan en ejemplos del tipo modista-modisto o azafata-azafato (vid., para estos casos peculiares, Aliaga García y Lázaro Mora 2007). 
1. Desde el punto de vista del contenido, la flexión de género prototípica marca — con más claridad en la flexión de número singular- contraste entre 'sexo masculino' y 'sexo femenino'. Es evidente que en manzan-a/manzan-o no se señala tal oposición: ni se marca sexo ni si quiera el plural masculino (ni el femenino) puede operar como término no marcado de la oposición.

2. Desde el punto de vista formal, la flexión de género prototípica presenta en oposición las marcas flexivas de $-o /-a$. Pues bien, en manzan-a/manzan-o las terminaciones $-o /-a$ no son marcas flexivas en tanto en cuanto son sufijos derivativos. Consideramos que las marcas derivativas - 0 , - $a$ en manzano y manzana son simplemente homónimas a las marcas flexivas de género $-o,-a$ en chico/chica. ${ }^{13}$

3. Desde el punto de vista interrelacional, la flexión de género prototípica marca formalmente tanto a masculino como a femenino, con marca flexiva $-o$ el masculino y con marca flexiva $-a$ el femenino. Como ya queda dicho, en manzan-almanzan-o las terminaciones -o/-a no son marcas flexivas en tanto en cuanto son sufijos derivativos y son simplemente homónimas a las marcas flexivas de género $-0,-a$ que sí aparecen en chico/chica.

4. Desde el punto de vista de la orientación genérica, y aunque como fenómeno flexivo no hay estrictamente hablando preexistencia lexicogenética de uno frente a otro, en la flexión de género prototípica el género flexivo masculino es previo —en tanto que no marcado - al femenino. En manzan-almanzan-o sí hay orientación unidireccional y además esta va del femenino al masculino.

5. Desde el punto de vista de oposición paradigmática, en la flexión de género prototípica el contraste entre las marcas flexivas de género $-o /-a$ es binario: $-o$ se opone a $-a$ y solo a $-a, y-a$ se opone a $-o$ y solo a -o. Repetimos a este respecto que en manzan-a/manzan-o las terminaciones $-o /-a$ no son marcas flexivas. Además, los contrastes paradig-

13 "[...] la -o sería morfema flexivo en niño y morfema derivativo en manzano, como también lo es en saqueo (< saquear). Un hecho que se repite con otros afijos: así, -ía e -i son flexivos en comía, comí, y derivativos en hidalguía, israeli» (García-Page 2008: 160). 
máticos no son binarios ya que, junto a manzan-a/manzan-o tenemos, por ejemplo: per-a/per-al, limón/limon-ero, hig-o/higu-era...

Quizás sea oportuno señalar que, según esta perspectiva, manifestaciones de oposición genérica del tipo padrelmadre o caballolyegua (casos de heteronimia) no atañen, estrictamente hablando, a la morfología del español. Recuérdese a este respecto que ya dijimos al principio que el género es rasgo inherente al sustantivo, y ello independientemente de que tenga manifestación flexiva o no: "el hecho de que el género sea un rasgo inherente e idiosincrásico no implica necesariamente que lo sea también su marca» (Ambadiang 1994: 112). En este sentido, podría ser coherente sostener que en manzan-almanzan-o no hay manifestación flexiva del género sino rasgo inherente de género. ${ }^{14}$

Las relaciones entre las marcaciones de género y los procesos flexivos y/o los procesos derivacionales no son, según lo dicho, biunívocas. Incluso puede darse el caso de que en ciertas formaciones femeninas se presenten, en cierto sentido de modo redundante, marcas tanto flexivas como derivativas que configuren formalmente el género gramatical de esa determinada palabra. Es lo que tal vez sucede en formaciones del tipo ogr-es-a, poet-is-a, gall-in-a...

Por otra parte, y desde una perspectiva general, queda abierto también — sin posibilidad alguna de resolución en este breve trabajo- el debatido problema de la delimitación misma de los conceptos de flexión y

14 Otra posibilidad distinta, en la que habría que profundizar, sería considerar más bien que en los pares del tipo manzanalmanzano los afijos finales -o/-a marcan cumulativamente tanto la relación derivativa como la marca de género (lo que implicaría quizás que el género no es en esos pares inherente).

15 A este respecto, resulta interesante — si bien no exenta de posibles críticas - la postura que García-Page ofrece en relación con estos femeninos a veces denominados irregulares: "Nosotros creemos que, salvo en el sufijo culto $-(t)$ riz $(<$ lat. -tricem), donde se establece un cambio de sufijo único (-(t)or), la marcación del femenino se consigue por la acción conjunta de un afijo derivativo y el morfo flexivo - a prototípico del femenino en español, de modo que el análisis que corresponde a los segmentos -ina, -esa, -isa, es el que discrimina sus dos partes: sufijo (-in, $-e s,-i s)+$ morfema de género $(a)$, y no el que interpreta -ina, -esa, -isa como un sufijo único indescomponible o no segmentable, sin reconocer en la - $a$ ningún valor morfológico ni sintáctico (concordancia)" (García-Page 2008: 98). Frente a esta postura, Ambadiang (1999: $\$$ 74.2.3.6) denomina «morfemas derivativos de sexo femenino" a desinencias como -esa, -isa, -ina, -(tr)iz. 
de derivación y, muy particularmente, la fijación de las, parece, fluctuantes fronteras entre ambos territorios morfológicos. No se trata ya de reconocer que ciertos fenómenos concretos puedan estar a caballo entre las dos parcelas (casos bien conocidos son los de la formación de los diminutivos, los adverbios en -mente o determinadas formaciones sustantivas en -ísimo), sino de replantear que, quizás, flexión y derivación no siempre son lo que parecen. ${ }^{16}$

En resumen, hemos fijado los extremos de la relación de continuum que manifiesta el género en los sustantivos españoles: por una parte las parejas del tipo niño/niña se acomodan perfectamente a la caracterización de la flexión; por otra parte, el contraste manzanalmanzano resulta de la aplicación de procesos derivativos. El contraste de género manifiesta diversos tipos de relaciones entre los sustantivos opuestos o relacionados por él; y solo presenta un proceso flexivo en una parte del sistema y un proceso derivativo en otra parte del sistema.

16 Como ejemplo, un botón, ciertamente alejado de algunos de los postulados que hemos mantenido en este artículo pero que supone una sagaz admonición: «Podría parecer que [la] ausencia de determinismo es propia de la afijación derivativa (que da lugar a categorías léxicas) y no de la flexiva (la que añade categorías funcionales), y que esta es la razón de que el deslinde entre lo enciclopédico y lo gramatical se corresponda [...] con el de las categoría léxicas N, V y A (léxico enciclopédico) frente a las funcionales. Pero no es del todo así. Los nombres castellanos no llevan otras marcas flexivas perceptibles que las de género y número, y ambas, en mayor medida de lo que se suele tener en cuenta, pueden conllevar diferencias semánticas y distribucionales que no se siguen de estas categorías: manzanalmanzano, frutalfruto, bancalbanco, ventanalventano, corrala/corral, ruedalruedo, fosalfoso, pesalpeso [...]. Tampoco, pues, en este sentido es la naturaleza del afijo la que determina por sí misma la condición enciclopédica de una pieza léxica: el afijo flexivo marca cambios de significado perfectamente regulares y deterministas en león/leona/leones/leonas, pero también lo hace el derivativo -miento en muchos de los casos que el diccionario glosa como 'acción y efecto de' (encubrimiento, alargamiento), aunque no lo haga en regimiento. Se mantiene a veces, en una u otra versión, la idea de que la flexión es asunto de la sintaxis, y por tanto accesible a ella, mientras que la derivación corresponde a un módulo independiente encargado de la formación de palabras. En principio, esto excluiría la posibilidad de que la flexión participara decisivamente en la configuración de significados complejos arbitrarios (enciclopédicos), que serían competencia del léxico y del módulo de formación de palabras. Como hemos visto, sin embargo, se aplica una vez más la admonición que ya hizo Karl Verner (1976): "la lingüística no puede [...] excluir del todo lo accidental, pero los accidentes masivos como este [...] ni puede ni debe tolerarlos"» (Piera 2009: 36-37). 
Naturalmente, una vez establecidos los límites prototípicos de la flexión de género en español del modo en que hemos propuesto, la caracterización de las múltiples variaciones e interrelaciones del género semántico y del género formal en español serían descritas a la luz de principios prototípicos no-discretos. Como es obvio, no disponemos en este artículo del espacio necesario para desarrollar esas caracterizaciones no-prototípicas y, en todo caso, también es cierto que previamente habría de desarrollarse una minuciosa tarea analítica de los variados casos de expresión del género en español dadas las múltiples variantes que entran en juego.

Así, y por poner como ejemplo un caso de amplio alcance, quizás debería tenerse en cuenta, también a la hora de proponer aproximaciones no-discretas, la sustancial diferencia que hay, en cuanto a las marcas y a la asignación de género, entre sustantivos derivados y sustantivos simples. En este sentido, quizás habría que considerar que el género es un rasgo inherente no solo a (ciertos) sustantivos sino que también es un rasgo inherente —en el caso de los derivados - a los afijos.

El comportamiento prototípico no-discreto que, en este trabajo, hemos defendido para el género en español no sería, por lo demás, exclusivo de la categoría genérica. Ya defendimos en otro estudio anterior (vid. Serrano-Dolader 2002) el carácter no-discreto de la delimitación de algunas unidades, como anti- y pro-, que fluctúan entre la categoría morfológica de los prefijos y la categoría sintáctica de las preposiciones.

El caso analizado en el presente trabajo es ejemplar — aunque, desde luego, no único- para potenciar el avance de una concepción no-discreta de la lingüística. La prototipicidad y la gradualidad afectan a unidades o a conceptos (palabra, morfema, tipos de morfemas, noción de productividad) básicos y capitales en todo análisis morfológico. En consecuencia, quizás las entidades lingüísticas deben concebirse como multidimensionales y continuas, como nociones complejas y multifactoriales, de modo que habrá ejemplares representantes más típicos o prototípicos pero también ejemplares que se sitúan en una zona de intersección.

En mi opinión, comportamientos como los vistos a lo largo de este estudio vienen a demostrar la vecindad entre entidades, entre unidades o entre ámbitos tradicionalmente enfrentados (en nuestro caso, flexión y derivación), vecindad que habría que explicar partiendo del reconocimiento de la existencia de un cierto continuum organizado de modo gradual. 
Así, por ejemplo, la subdivisión del morfema en subtipos obligaría de nuevo a recurrir a las nociones de prototipicidad y gradualidad. De este modo, los morfemas derivativos están entre los morfemas léxicos y los morfemas flexivos-gramaticales, y comparten de modo gradual propiedades de ambos. ${ }^{17}$

En suma, seguimos estando de acuerdo con Teresa Moure cuando afirma:

Evitando las manifestaciones graduales de un estado de cosas se rinde flaco servicio a la investigación porque se la restringe a meras hipótesis, negándole cualquier desarrollo ulterior. [...] Muchas de las clases establecidas por la teoría lingüística son cortes discretos demasiado abruptos para recoger la naturaleza borrosa de las relaciones y las clases que consideran (Moure 1996: 16-25).

\section{Bibliografía}

Aikhenvald, A. Y. (2004): "Gender and noun class», en G. Booij et alii (eds.), Morphologie/Morphology (Ein internationales Handbuch zur Flexion und Wortbildung / An International Handbook on Inflection and Word-Formation), Berlín/Nueva York, Walter de Gruyter: 1031-1045.

Aliaga García, F., y F. Lázaro Mora (2003): «La "marcación de género" en español», en J. L. Girón Alconchel et alii (eds.), Estudios ofrecidos al profesor José Jesús de Bustos Tovar, Madrid, Editorial Complutense, vol. I: 5-22.

- (2007): «Reflexiones en torno a modisto/modista», en I. Delgados Cobos y A. Puigvert Ocal (eds.), Ex admiratione et amicitia, Homenaje a Ramón Santiago, Madrid, Ediciones del Orto, vol. I: 63-79.

Ambadiang, TH. (1994): La morfología flexiva, Madrid, Taurus.

- (1999): "La flexión nominal. Género y número», en I. Bosque y V. Demonte (dirs.), Gramática Descriptiva de la Lengua Española, Madrid, RAEEspasa, vol. 3, capítulo 74: 4843-4913.

Del Viso, S. (2002): «Los lapsus línguae como fuente de datos en el estudio de la producción del lenguaje: un corpus de errores en castellano", Anuario de Psicología, 33 (3): 355-384.

García, E. C. (1970): "Gender Switch in Spanish Derivation (with Special Reference to $-a \rightarrow-$ ero, $-o \rightarrow-$ era, $-a \rightarrow-n$, -ón)», Romance Philology, XXIV (1): 39-54.

17 Véase una clara explicación de esta perspectiva en Pena (1999: 4322-4324). 
García-Page SÁnchez, M. (2008): Cuestiones de morfología española, Madrid, Editorial Universitaria Ramón Areces, 2. ${ }^{\mathrm{a}}$ ed.

IgOA, J. M., J. E. GarCía-Albea y R. SÁnCheZ-CASAS (1999): «Gender-number dissociations in sentence production in Spanish», Rivista di Linguistica, 11 (1): 163-196.

JeSPERSEN, O. (1975): Filosofía de la gramática, Barcelona, Anagrama.

LliTeras, M. (2008): "Del género derivativo al género flexivo», Gramma-Temas 3: España y Portugal en la tradición gramatical (Colección Contextos, 18), León, Universidad de León: 125-148. Accesible en: <http://www. revistacontextos.es/pdf_vol18/Lliteras1.pdf>.

MASCARÓ, J. (1986): Morfologia, Barcelona, Enciclopèdia Catalana.

Millán Chivite, F. (1994): «Tipología semántica de la oposición de género no sexuado en español», Cauce, 17: 53-75.

Moreno Fernández, F., y H. Ueda (1986): «El género en los sustantivos del español: sobre su naturaleza gramatical», Boletín de la Academia Puertorriqueña de la Lengua Española, 14 (2): 79-109.

MOURE, T. (1996): La alternativa no-discreta en la lingüistica. (Una perspectiva histórica y metodológica), Santiago de Compostela, Servicio de Publicaciones de la Universidad de Santiago de Compostela.

MuRiLlo, J. E. (1999): «La marcación del género en los sustantivos del español: entre la flexión y la derivación", Revista de Filología y Lingüistica de la Universidad de Costa Rica, XXV (1): 181-192.

Pena, J. (1999): «Partes de la morfología. Las unidades del análisis morfológico», en I. Bosque y V. Demonte (dirs.), Gramática Descriptiva de la Lengua Española, Madrid, Espasa-Calpe: 4305-4366.

Piera, C. (2009): "Una idea de la palabra», en E. de Miguel (ed.), Panorama de la lexicología, Barcelona, Ariel: 25-49.

RAE (prepublicación - en prensa): Nueva Gramática de la Lengua Española, Madrid, RAE-Espasa, 2009. [Puede consultarse entero, en prepublicación y como versión no definitiva, el "Capítulo 11. El género», en la dirección: $<$ http://asale.org/ASALE/pdf/folletonvagramatica.pdf $>$ ].

RocA, I. M. (2005a): «La Gramática y la Biología en el género del español (1. a parte)», Revista Española de Lingüistica (RSEL), 35 (1): 17-44.

- (2005b): «La Gramática y la Biología en el género del español (2. a parte)», Revista Española de Lingüistica (RSEL), 35 (2): 397-432.

SerRANO-Dolader, D. (2002): "Hacia una concepción no-discreta de algunas formaciones con anti- en español», Revista Española de Lingüistica (RSEL), 32 (2): $387-411$.

VARela OrTega, S. (2005): Morfología léxica: la formación de palabras, Madrid, Gredos. 
Este libro se terminó de imprimir en los talleres gráficos de Octavio y Félez, de Zaragoza, en septiembre de 2010 $\mathrm{DOOS}$ 


\section{Conocintento Lengaraje}

The Knowledge-Language-Communication series has been established in order to provide a forum for discussion on what we know about language; more concretely, on issues such as how we, human beings, acquire this knowledge, how it is used in verbal communication, and what the grammatical mechanisms underlying this system of knowledge and its usage are.

La serie Conocimiento-Lenguaje-Comunicación ha sido creada para proporcionar un foro en el que debatir acerca del conocimiento del lenguaje, sobre cómo los seres humanos adquirimos este conocimiento, cómo se manifiesta en la actividad verbal y cuáles son los mecanismos gramaticales que constituyen la base de ese sistema de conocimiento y su uso.

Observar sin pensar es tan peligroso como pensar sin observar. La hipótesis es nuestra mejor herramienta intelectual.

SANTIAGO RAMÓN Y CAJAL
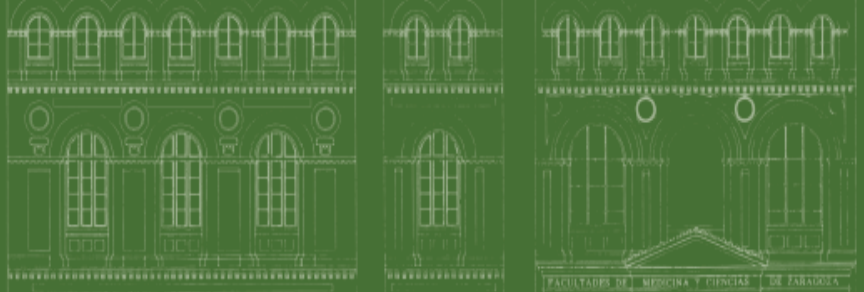